\title{
Modelos Numéricos de Pilares Mistos Curtos de Seções Circulares de Aço Preenchidos com Concreto em Situação de Incêndio
}

Dissertação apresentada ao Departamento de Engenharia de Estruturas da EESC-USP como parte dos requisitos necessários à obtenção do título de Mestre em Engenharia de Estruturas

Área de Concentração: Estruturas Metálicas Orientador: Prof. Dr. Jorge Munaiar Neto 


\section{AUTORIZO A REPRODUÇÃO E DIVULGAÇÃO TOTAL OU PARCIAL DESTE TRABALHO, POR QUALQUER MEIO CONVENCIONAL OU ELETRÔNICO, PARA FINS DE ESTUDO E PESQUISA, DESDE QUE CITADA A FONTE.}

Ficha catalográfica preparada pela Seção de Tratamento da Informação do Serviço de Biblioteca - EESC/USP

$5237 \mathrm{~m}$

Santos, Rodrigo Tadeu dos

Modelos numéricos de pilares mistos curtos de seções circulares de aço preenchidos com concreto em situação de incêndio ; orientador Jorge Munaiar Neto. -- São Carlos, 2009 .

Dissertação (Mestrado-Programa de Pós-Graduação e Área de Concentração em Engenharia de Estruturas) -- Escola de Engenharia de são Carlos da Universidade de São Paulo, 2009 .

1. Estruturas mistas de aço e concreto. 2. Pilares mistos de aço e concreto. 3. Incêndio. 4. Análise térmica. 5. Analise numérica. I. Título. 
FOLHA DE JULGAMENTO

Candidato: Engenheiro RODRIGO TADEU DOS SANTOS

Dissertação defendida e julgada em 05/03/2009 perante a Comissão Julgadora:

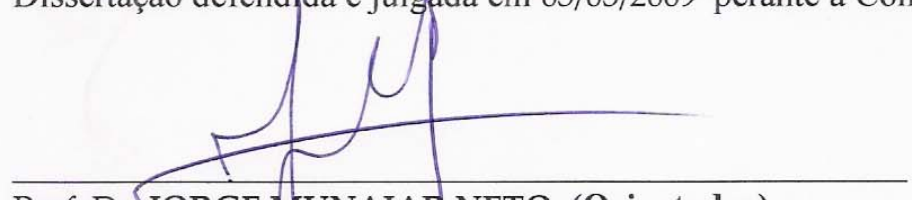

Prof. Dr. CORGE MUNAIAR NETO (Orientador)

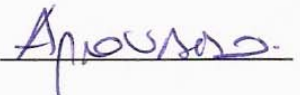

(Escola de Engenharia de São Carlos/USP)

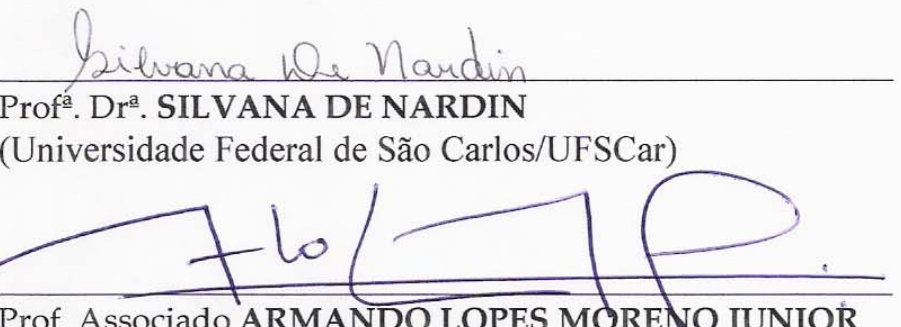

Prof. Associado ARMANDO LOPES MORENO JUNIOR

(Universidade Estadual de Campinas/UNICAMP)
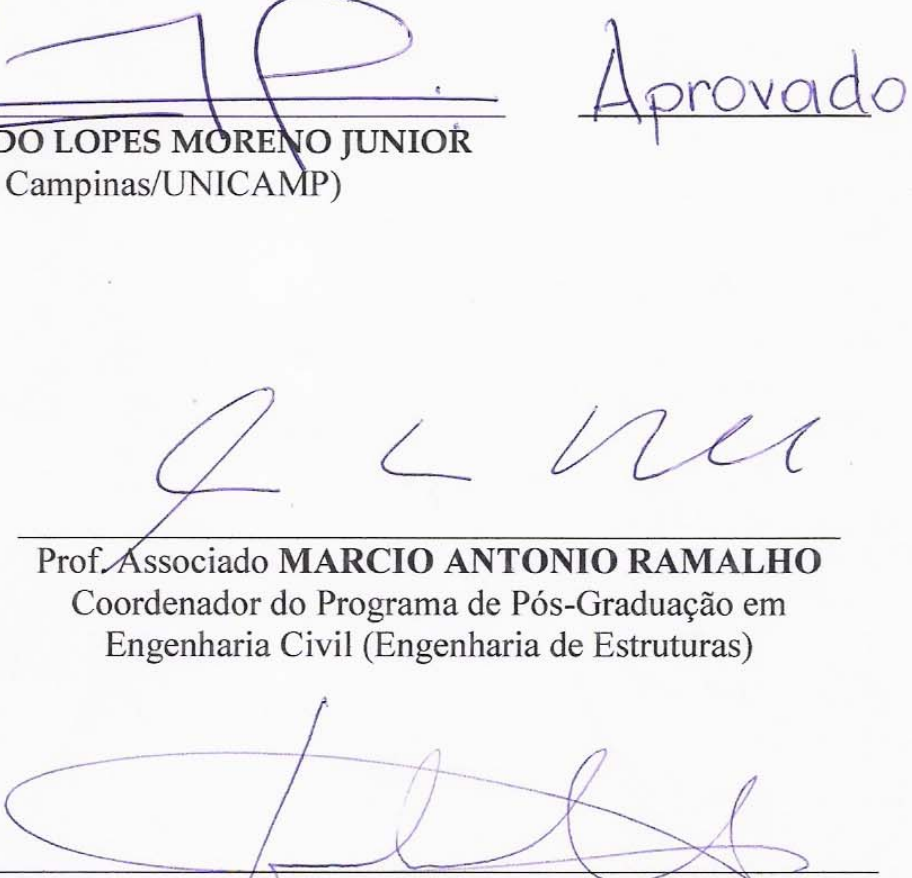

Prof. Associado GERALDO ROBERTO MARTINS DA COSTA

Presidente/da Comissão de Pós-Graduação 

Aos meus pais Gelson e Carmen, meus

irmãos Gabriel e Isabel, e a minha querida namorada Mariana. 



\section{AGRADECIMENTOS}

Primeiramente à Deus.

Ao meu orientador, Prof. Dr. Jorge Munaiar Neto, por toda sua atenção, ensinamentos, amizade e paciência.

Ao CNPQ, pela bolsa de estudos que permitiu o desenvolvimento deste trabalho.

A todos os professores e funcionários do Departamento de Engenharia de Estruturas, os quais proporcionaram boas condições de trabalho.

De todo o meu coração a minha amada família, por minha formação profissional e pessoal.

A minha amada namorada, Mariana por todo o apoio e dedicação.

Ao amigo Ronaldo "Ferrugem", pela amizade, atenção e ajuda desde a graduação e em especial no mestrado durante a realização a análise de todos os modelos com o ANSYS.

A todos os grandes amigos do vôlei CAASO, pelas alegrias e conquistas, por proporcionarem nesses oito anos momentos inesquecíveis e tornarem minha estadia em São Carlos mais prazerosa. Em especial aos amigos Daniel, Fred, Moa, Gú, Julio, Piru, Wesley, Xaxá, Paulino, Ricardo, Vitor, Will, Bird, Neto, Jader, Bruninho, Catalano, Dudão e Markinho.

A os amigos de republica, pelas trocas de informações e experiências: Denis, Gustavo, Filipe, João, Jonatas, Dorival, Jesus e Wesley.

A todos os amigos do Departamento de Engenharia de Estruturas, pela grande troca de experiências, pelo companheirismo e momentos de diversão. Em especial aos amigos Aref, Érica Kimura, Raimundo, Fabio, Vinicius, Rodrigo "Mario", Marcela, Ana, Saulo, Walter e Igor.

Aos amigos da CAT Engenharia.

Aos amigos de Piracaia. 

"E como é fantástica a formação, é mais do que uma etapa, é a constatação do que é viver, se viver for conhecer."

Mariana Paulino Soares 



\section{RESUMO}

SANTOS, R. T. (2009). Modelos Numéricos de Pilares Mistos Curtos de Seções Circulares de Aço Preenchidos com Concreto em Situação de Incêndio. Dissertação (Mestrado) - Escola de Engenharia de São Carlos, Universidade de São Paulo, São Carlos.

Os pilares mistos de aço preenchidos com concreto, quando submetidos a elevadas temperaturas, apresentam comportamento estrutural bastante satisfatório e reduzem no concreto o fenômeno denominado "spalling", devido ao confinamento imposto pelo tubo de aço, mais pronunciado em seções tubulares circulares. Destaca-se ainda a reduzida taxa de aquecimento desse mesmo elemento misto em razão da baixa condutividade térmica do concreto, aspecto de grande interesse para fins de dimensionamento. O presente trabalho tem como principal objetivo modelar numericamente, em campo tridimensional, pilares mistos curtos com seções tubulares circulares de aço, preenchidos com concreto e submetidos ao incêndio-padrão prescrito pela ISO 834:1999. A modelagem se faz com vistas a simular o comportamento estrutural desse elemento em situação de incêndio, buscando avaliar a influência da elevação de temperatura na resistência do elemento e indicar para qual tempo e em que níveis de temperatura o acréscimo de resistência devido ao efeito do confinamento deixa de ser pronunciado. Para a modelagem numérica em campos térmico, estrutural e termo-estrutural, se utiliza o pacote comercial ANSYS ${ }^{\circledR}$ V9.0, elaborado com base no Método dos Elementos Finitos, o qual permite a análise transiente dos efeitos do gradiente térmico nos elementos estruturais. Os resultados das análises térmica, estrutural e acoplada são previamente comparados com valores obtidos com o código computacional TCD 5.5. A análise acoplada foi realizada para três diâmetros de pilares mistos, e as variações do diâmetro e da resistência à compressão do concreto foram consideradas, possibilitando uma análise paramétrica. Por fim, é apresentada uma análise inversa dos modelos, considerando carregamentos crescentes para campos de temperatura fixos.

Palavras-chave: Estruturas mistas de aço e concreto, pilares mistos de aço e concreto, incêndio, análise térmica, análise numérica. 



\section{ABSTRACT}

SANTOS, R. T. (2009) Nonlinear numerical analysis of circular concrete filled steel short columns under fire condition. 2009. Master of Science Dissertation - Escola de Engenharia de São Carlos, Universidade de São Paulo.

Concrete-filled steel columns when subjected to high temperatures present satisfactory structural behavior and the reduction of the spalling phenomenon in the concrete due to confinement action of the steel tube, more notable in circular cross sections. Another advantage is the reduced heating rate of this element due to concrete low thermal conductivity, which is an interesting characteristic in designing procedures. The aim of this work is to develop 3D numerical models of circular concrete-filled steel short columns under fire exposure according to the ISO-834:1999 standard. The numerical models are developed to simulate the structural behavior of those composite short columns under fire condition, in order to evaluate the influence of increasing temperature in the strength of the structural element. This makes possible define the time and the temperature level in which the resistant increment due to the confinement effect is no more appreciable. To perform the numerical model of thermal, structural and thermal-structural fields, a commercial finite element analysis package ANSYS ${ }^{\circledR}$ V9.0 is used, which allows transient analysis of the thermal gradient effects in the structural elements. The results from thermal, structural and coupled analyses are previously compared with the ones obtained with TCD 5.5 package. The coupled analysis is performed for three different columns, changing the diameter and concrete compression strength to be used in a parametric analysis. Finally, it is shown another analysis type, called "reverse analysis", which considers increasing structural loads for fixed temperature fields.

Keywords: Composite structures, composite steel-concrete columns, fire situation, thermal analysis, numerical analysis. 



\section{LISTA DE SÍMBOLOS}

A $\quad$ Área da seção transversal do perfil de aço

$\mathbf{A}_{\mathbf{c}} \quad$ Área da seção transversal de concreto

D Diâmetro do pilar

$\mathbf{E}_{\mathbf{a}}=\mathbf{E}_{\mathbf{s}} \quad$ Módulo de elasticidade tangente inicial do aço em temperatura ambiente

$\mathbf{E}_{\mathbf{c}} \quad$ Módulo de elasticidade secante do concreto em temperatura ambiente

$\mathbf{E}_{\boldsymbol{\theta}} \quad$ Módulo de elasticidade tangente inicial do aço à temperatura elevada

$\mathbf{F}_{\mathbf{c}, \mathbf{t a}} \quad$ Força critica em temperatura ambiente

$\mathbf{F}_{\mathbf{c}, \mathbf{t i}} \quad$ Força crítica em incêndio e

I Momento de inércia da seção transversal do tubo de aço

I $\quad$ Momento de inércia da seção transversal do concreto

K $\quad$ Fator de redução da força resistente do pilar misto

L Comprimento do pilar misto

$\mathbf{N}_{\mathbf{e}} \quad$ Normal de flambagem elástica

$\mathbf{N}_{\text {fi,pl,Rd }} \quad$ Força normal de plastificação de cálculo em situação de incêndio

$\mathbf{N}_{\mathbf{f i}, \mathbf{R d}} \quad$ Força normal resistente de cálculo em situação de incêndio

$\mathbf{N}_{\mathbf{p l}, \mathbf{R d}} \quad$ Força axial resistente de cálculo da seção transversal à plastificação total

$\mathbf{N}_{\text {Rd }} \quad$ Normal resistente de cálculo de pilares mistos

Q Energia calorífica

TRRF Tempo requerido de resistência ao fogo

c Calor específico

$\mathbf{c}_{\mathbf{a}} \quad$ Calor específico do aço

$\mathbf{c}_{\mathbf{c}} \quad$ Calor específico do concreto

$\mathbf{c}_{\mathbf{c n}} \quad$ Calor específico do concreto de densidade normal

$\mathbf{c}_{\mathbf{c b}} \quad$ Calor específico do concreto de baixa densidade

f cesistência de cálculo à compressão do concreto

$\mathbf{f}_{\text {ck }}$ Resistência característica a compressão do concreto

f $\mathbf{y}$ Tensão de escoamento do aço

$\mathbf{f}_{\mathbf{y}, \boldsymbol{\theta}} \quad$ Limite de escoamento do aço em temperatura elevada

$\dot{\mathrm{h}} \quad$ Fluxo de calor por unidade de área 
$\mathbf{k}_{\mathbf{c}, \theta} \quad$ Fator de redução para a resistência característica à compressão do concreto de densidade normal

$\mathbf{k}_{\mathbf{c b}, \theta} \quad$ Fator de redução para a resistência característica à compressão do concreto de baixa densidade

$\mathbf{k}_{\mathbf{E}, \theta} \quad$ Fator de redução do módulo de elasticidade do aço em temperatura elevada relativo à temperatura ambiente

$\mathbf{k}_{\mathbf{y}, \theta} \quad$ Fator de redução do limite de escoamento do aço em temperatura elevada relativo à temperatura ambiente

t Espessura do tubo de aço

t Tempo

$\Delta \boldsymbol{l}_{\mathrm{a}} / \boldsymbol{l}_{\mathrm{a}} \quad$ Alongamento relativo do aço

$\Delta \boldsymbol{l}_{\mathbf{c}} / \boldsymbol{l}_{\mathbf{c}} \quad$ Alongamento específico do concreto

$\Phi$

Fator de configuração

$\alpha \quad$ Coeficiente total de transferência de calor (convecção + radiação)

$\alpha_{c} \quad$ Coeficiente de transferência de calor devido à convecção

$\alpha_{\mathbf{r}} \quad$ Coeficiente de transferência de calor devido à radiação

$\gamma_{\mathbf{c}} \quad$ Coeficiente de minoração da resistência do concreto

$\gamma_{\mathbf{a}} \quad$ Coeficiente de minoração da resistência do aço

$\varepsilon \quad$ Emissividade

$\varepsilon_{\text {res }} \quad$ Emissividade resultante

$\eta_{\mathbf{a}} \quad$ Fator de redução do aço

$\eta_{\mathbf{c}} \quad$ Fator que amplifica a resistência do concreto quando confinado

$\eta_{\mathrm{fi}} \quad$ Nível de carga

$\theta \quad$ Temperatura em graus Celsius

$\theta_{\mathbf{g}} \quad$ Temperatura dos gases do ambiente $\left({ }^{\circ} \mathrm{C}\right)$

$\theta_{0} \quad$ Temperatura dos gases no instante $\mathrm{t}=0$

$\theta_{\mathbf{a}} \quad$ Temperatura do elemento de aço $\left({ }^{\circ} \mathrm{C}\right)$

$\theta_{\mathbf{c}} \quad$ Temperatura do concreto $\left({ }^{\circ} \mathrm{C}\right)$

$\theta_{\text {cr }} \quad$ Temperatura crítica

$\lambda \quad$ Condutividade térmica 


$\begin{array}{ll}\lambda_{\mathbf{a}} & \text { Condutividade térmica do aço } \\ \lambda_{\mathbf{c}} & \text { Condutividade térmica do concreto } \\ \lambda_{\mathbf{c n}} & \text { Condutividade térmica do concreto de densidade normal } \\ \lambda_{\mathbf{c b}} & \text { Condutividade térmica do concreto de baixa densidade } \\ \lambda_{\mathbf{0}} & \text { Índice de esbeltez } \\ \boldsymbol{\rho} & \text { Massa específica } \\ \boldsymbol{\rho}_{\mathbf{a}} & \text { Massa específica do aço } \\ \boldsymbol{\rho}_{\mathbf{c}} & \text { Massa específica do concreto } \\ \boldsymbol{\sigma} & \text { Constante de Stefan-Boltzmann } \\ \chi & \text { Fator de redução associado à resistência à compressão } \\ \varphi & \text { Fluxo de calor } \\ \varphi_{\mathbf{c}} & \text { Fluxo de calor devido à convecção } \\ \varphi_{\mathbf{r}} & \text { Fluxo de calor devido à radiação }\end{array}$





\section{SUMÁRIO}

1 INTRODUÇÃO ...............................................................................................

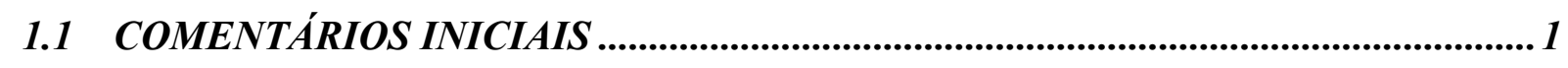

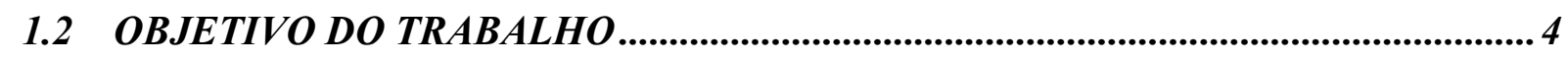

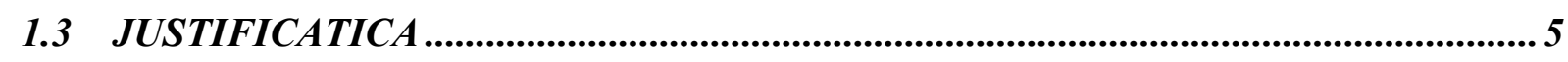

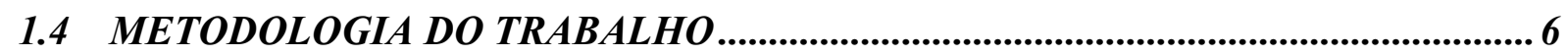

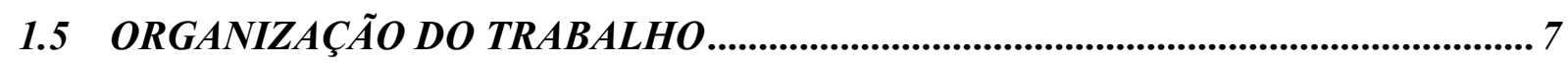

2 SOBRE ESTRUTURAS MISTAS DE AÇO E CONCRETO - Breve abordagem.........9

2.1 ESTRUTURAS MISTAS - Preliminares .............................................................9

2.2 PILARES MISTOS DE AÇO E CONCRETO EM TEMPERATURA AMBIENTE .. 12

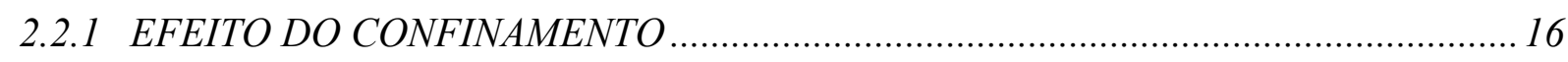

2.2.2 NORMAS REFERENTES AO DIMENSIONAMENTO DE PILARES MISTOS ............ 19

2.2.2.1 Projeto de revisão da NBR 8800:2008 ................................................................................. 21

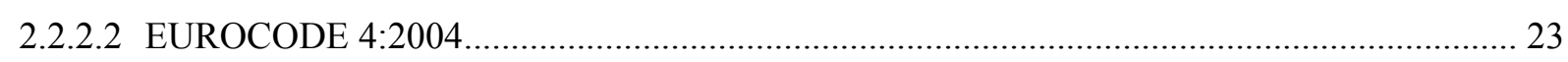

2.3 ESTRUTURAS EM SITUAÇÃO DE INCÊNDIO - Breve histórico........................... 24

2.4 AÇÃO TÉRMICA NAS ESTRUTURAS - Contexto mundial ........................................ 27

2.5 AÇÃO TÉRMICA NAS ESTRUTURAS - Contexto nacional.................................. 29

2.6 PILARES MISTOS DE AÇO PREENCHIDOS COM CONCRETO EM SITUAÇÃO

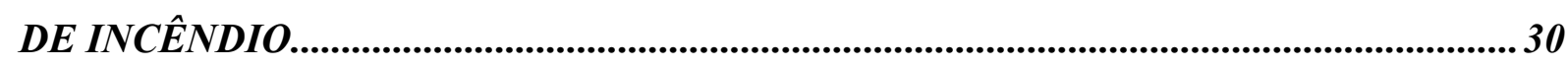

2.7 ASPECTOS DE INTERESSE - Considerações.................................................. 41

3 O INCÊNDIO - ORIGEM, ASPECTOS E EFEITO TÉRMICO NAS ESTRUTURAS ..............................................................................................43

3.1 ORIGEM DO INCÊNDIO - Aspectos de interesse ........................................................ 43

3.2 ESTRUTURAS EM SITUAÇÃO DE INCÊNDIO - Ação térmica ............................... 44

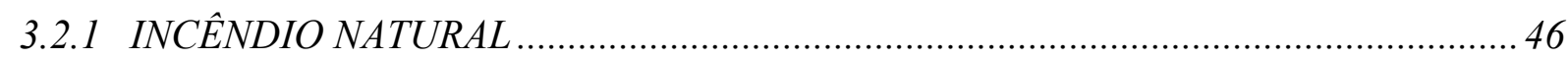

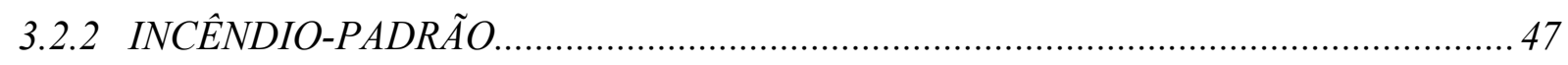

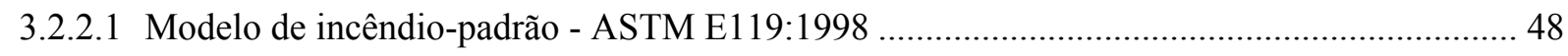

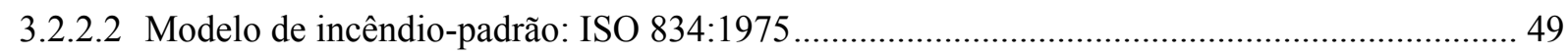

3.3 MECANISMOS DE TRANSFERÊNCIA DE CALOR ........................................50

3.3.1 TRANSFERENCIA DE CALOR POR CONDUÇÃO ….............................................. 51 
3.3.2 TRANSFERENCIA DE CALOR POR CONVECÇÃO................................................. 53

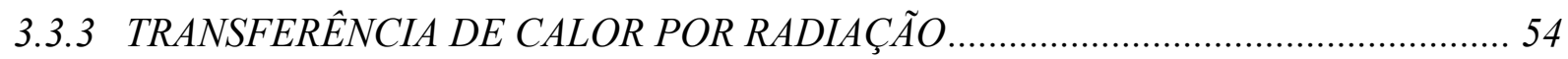

3.4 ELEVAÇÃO DA TEMPERATURA EM ELEMENTOS ESTRUTURAIS................. 55

3.5 PROPRIEDADES DOS MATERIAIS - Sob elevadas temperaturas........................... 58

3.5.1 PROPRIEDADES TÉRMICAS DOS MATERIAIS ................................................... 58

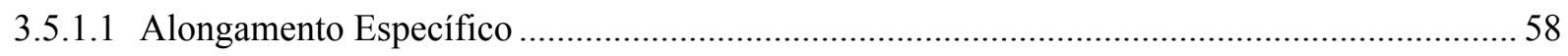

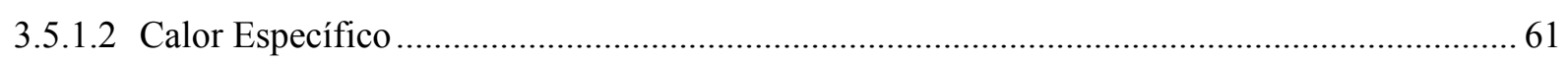

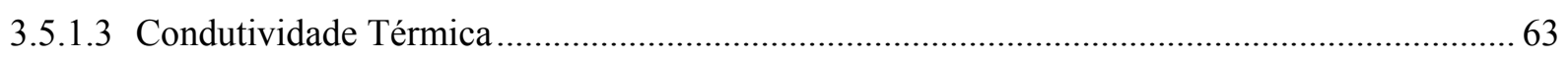

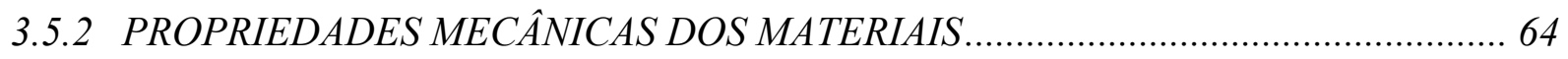

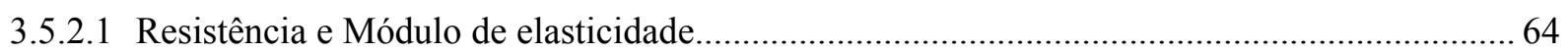

3.6 DIMENSIONAMENTO DOS PILARES MISTOS DE AÇO PREENCHIDOS COM

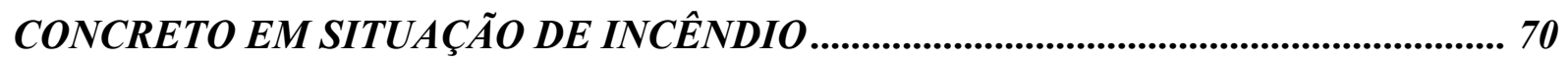

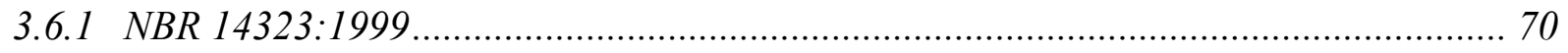

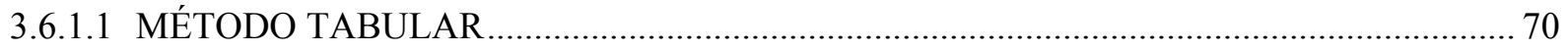

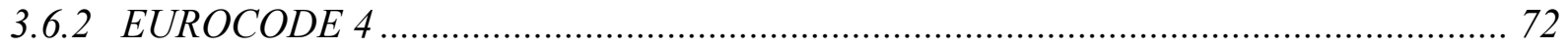

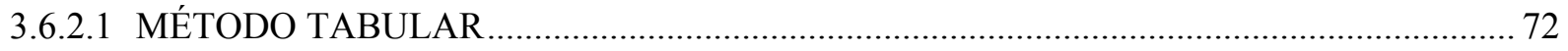

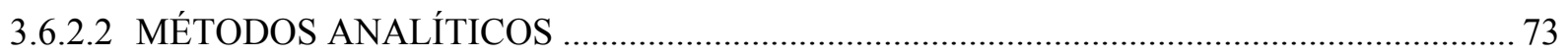

4 ESTRATÉGIAS NUMÉRICAS ADOTADAS: ASPECTOS DE INTERESSE... 77

4.1 ANÁLISES NUMÉRICAS DE INTERESSE - Considerações................................ 77

4.2 ANÁLISE TÉRMICA - Aspectos de interesse.............................................................. 78

4.2.1 ELEMENTOS FINITOS TRIDIMENSIONAIS - Análise térmica ................................. 80

4.2.2 APLICAÇÃO DA AÇÃO TÉRMICA NO MODELO ................................................. 82

4.3 ANÁLISE ESTRUTURAL - Consideraç̃̃es ......................................................... 84

4.4 ANÁLISE TERMO-ESTRUTURAL - Consideraç̃̃es ........................................... 86

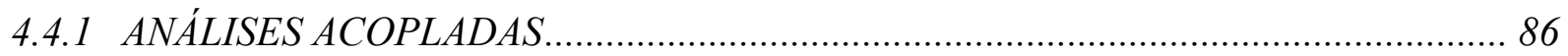

4.4.2 ELEMENTOS FINITOS TRIDIMENSIONAIS - Análise termo-estrutural ................... 86

4.4.3 CONSTRUÇÃO DOS MODELOS NUMÉRICOS - Análise acoplada ......................... 88

5 MODELOS NUMÉRICOS PARA ANÁLISE TÉRMICA - VALIDAÇÃO DA

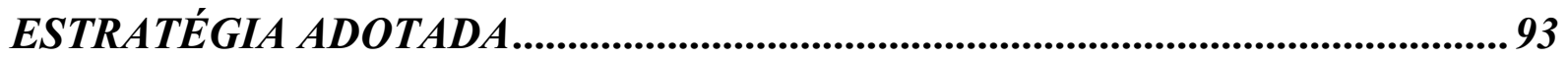

5.1 MODELOS NUMÉRICOS - Validação do campo térmico ......................................... 95

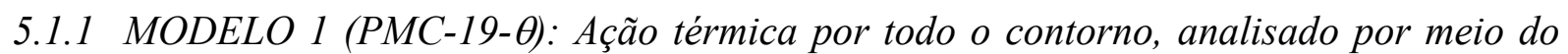
modelo inteiro. 


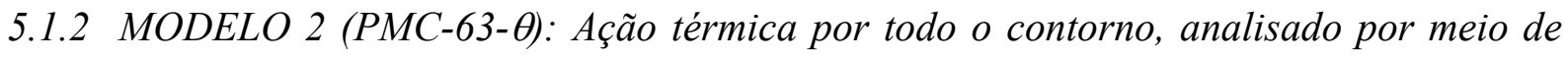
modelo inteiro.

5.1.3 MODELO 3 (PMC-63- $\theta$ ): Ação térmica na metade do contorno, analisado por meio de modelo inteiro.

5.1.4 MODELO 4 (PMC-19-8): Ação térmica por todo o contorno, analisado por meio de modelo simétrico.

6 ANÁLISE DE PILARES MISTOS CURTOS DE AÇO E CONCRETO: TEMPERATURA AMBIENTE E INCÊEDIO ................................................109

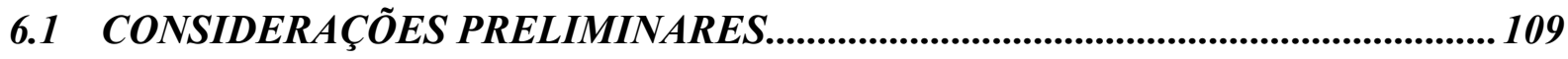

6.2 PILARES MISTOS CURTOS - Análise em temperatura ambiente ............................ 110

6.2.1 MODELO 1 (PMC-19-E) - Análise estrutural em temperatura ambiente.................. 111

6.2.2 MODELO 2 (PMC-26-E) - Análise estrutural em temperatura ambiente.................. 116

6.2.3 MODELO 3 (PMC-46-E) - Análise estrutural em temperatura ambiente.................. 117

6.2.4 MODELOS 1, 2 e 3 (PMC-46-E) - Análises comparativas ...................................... 117

6.3 PILARES MISTOS CURTOS - Análise em situação de incêndio.............................. 119

6.3.1 MODELO 1 (PMC-19-A) - Com carga térmica em todo contorno do pilar .............. 121

6.3.2 MODELO 2 (PMC-26-A) - Com carga térmica em todo contorno do pilar ............... 128

6.3.3 MODELO 3 (PMC- 46) - Com carga térmica em todo contorno do pilar.................. 130

6.3.4 MODELO 4 (PMC-26-A) - Carga térmica apenas em metade do contorno do pilar. 138

6.3.5 ANÁLISE PARAMÉTRICA - diâmetro e resistência à compressão ............................. 140

6.4 PILARES MISTOS CURTOS - Análise complementar em situação de incêndio .... 142

7 CONCLUSÕES E SUGESTÕES PARA TRABALHOS FUTUROS ............... 147

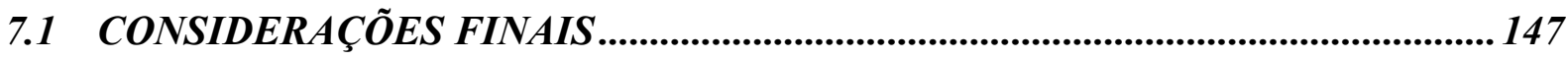

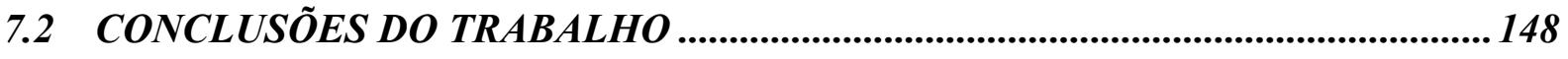

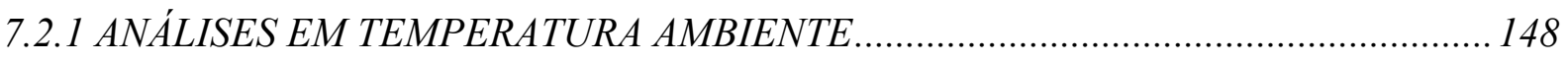

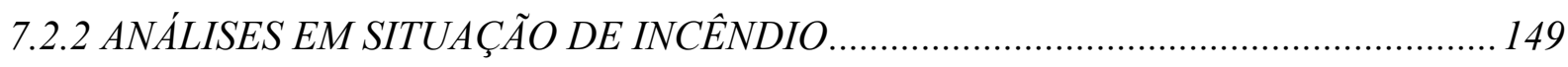

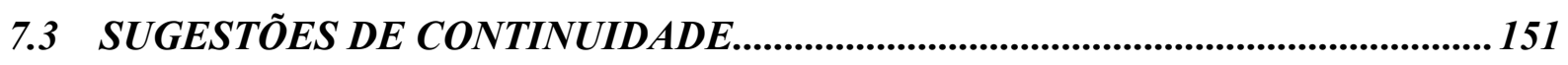

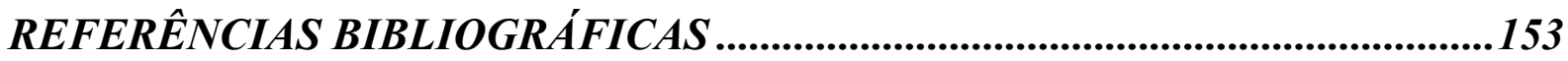





\section{INTRODUÇÃO}

\subsection{COMENTÁRIOS INICIAIS}

Os sistemas estruturais constituídos por elementos mistos, conseqüência do trabalho em conjunto de elementos de aço e de concreto, de madeira e de concreto, e similares, têm sido bastante utilizados nas obras de engenharia civil, na construção de edifícios industriais, comerciais, passarelas, pontes, entre outros. Tal fato está consolidado no contexto mundial e sua utilização vem crescendo consideravelmente no Brasil. No contexto do presente trabalho, atenções serão direcionadas para elementos mistos de aço e de concreto como, por exemplo, as lajes mistas de aço e concreto, os pilares mistos de aço e concreto e as vigas mistas de aço e concreto.

As lajes mistas de aço e concreto, também denominadas "Steel-Deck", constituem elementos estruturais formados por lajes de concreto com fôrma de aço, a qual após o endurecimento do concreto passa a ser incorporada à laje. As vigas mistas de aço e concreto são constituídas por vigas de aço solidarizadas às lajes de concreto armado, cuja associação de ambos os elementos é garantida por dispositivos mecânicos denominados conectores de cisalhamento, situados na interface entre laje e viga. Os pilares mistos de aço e concreto constituem elementos estruturais de aço revestidos (total ou parcialmente) ou preenchidos com concreto (de seções circulares, retangulares ou quadradas).

Os pilares mistos preenchidos com concreto, quando analisados em temperatura ambiente, asseguram uma maior e mais adequada eficiência estrutural para fins de utilização em estruturas correntes. Apresentam como vantagens: ausência de fôrmas, redução ou até mesmo a ausência de armaduras, o núcleo de concreto é responsável por aumentar a rigidez e a resistência do perfil tubular, redução da seção transversal, redução no consumo dos materiais, aumento da área útil no pavimento e uma melhora na ductilidade do pilar. No contexto do presente trabalho, cabe ressaltar que as atenções serão direcionadas aos pilares preenchidos de seção circular. 
Com relação às pesquisas referentes às estruturas em situação de incêndio, estas vêm aumentando de forma significativa no cenário mundial. Tal fato se justifica pela necessidade de avaliar o desempenho das estruturas quando submetidas à ação térmica. $\mathrm{O}$ aumento gradativo de temperatura provoca alterações nas propriedades mecânicas dos materiais, fazendo com que ocorra redução de resistência e rigidez dos elementos estruturais, podendo levar a estrutura ao colapso prematuro.

Os elementos estruturais de concreto possuem um adequado comportamento quando exposto a temperaturas elevadas, em razão da baixa condutividade térmica desse material associada ao fato de esses elementos possuírem seções transversais com dimensões consideráveis, o que permite admitir uma taxa reduzida de aquecimento e, consequentemente, uma redução menos acentuada na resistência e rigidez do material. No entanto, a tendência da expulsão da água existente no concreto (mesmo já endurecido) provoca o fenômeno denominado "spalling" (lascamento da superfície do elemento), ocorrendo uma considerável redução da seção transversal, bem como a exposição das armaduras ao fogo.

Os elementos estruturais constituídos de aço também possuem um adequado comportamento quando exposto a temperaturas elevadas, principalmente quando utilizados com revestimento térmico (argamassa projetada, mantas, etc.). Porém, se comparado ao concreto, o aço possui elevada condutividade térmica e elementos com seções transversais mais esbeltas (ou menos robustas), provocando uma maior taxa de aquecimento e, consequentemente, uma redução mais acentuada na resistência e rigidez do material.

No caso de pilares mistos de aço preenchidos por concreto, quando submetidos a ação térmica, além de apresentarem comportamento estrutural bastante satisfatório, reduz ou mesmo evita o fenômeno denominado "spalling”, presente em elementos de concreto submetidos a elevadas temperaturas, devido o confinamento imposto pelo tubo de aço.

A associação dos materiais aço e concreto na forma de pilares mistos preenchidos de seção circular, garante à estrutura um maior tempo de exposição a altas temperaturas, comparado aos mesmos elementos constituídos desses mesmos materiais utilizados separadamente. Isso se deve ao fato de o concreto absorver calor do aço enquanto este é aquecido, fazendo com que a elevação de temperatura no aço ocorra de forma menos intensa.

Destaca-se ainda o fato de que, quando o tubo de aço começa a perder resistência e rigidez devido ao fato de estar diretamente exposto ao fogo, o carregamento passa a ser transferido para o concreto. Neste caso, se comparado a uma seção de concreto convencional, o concreto preenchido não sofre redução na seção transversal devido ao confinamento. 
O efeito favorável do confinamento, mais presente em pilares preenchidos de seção circular, pode ser reduzido, ou mesmo desconsiderado, dependendo das condições do ambiente em chamas em que o pilar misto se encontra, provocando reduções naquela capacidade resistente do elemento inicialmente prevista em temperatura ambiente. Os fatores que estão associados à redução da capacidade resistente dos pilares mistos em incêndio são basicamente: o tempo de exposição ao fogo, a taxa de temperatura e sua distribuição no elemento estrutural, o diâmetro do pilar, o tipo de concreto, a espessura do tudo de aço e resistência do concreto.

O dimensionamento de pilares mistos de aço e concreto em situação de incêndio é previsto pela norma brasileira NBR 14323:1999, intitulada Dimensionamento de estruturas de aço de edifícios em situação de incêndio - Procedimento, considerando os casos esquematizados na figura 1.1, extraída da norma em questão.

(a)

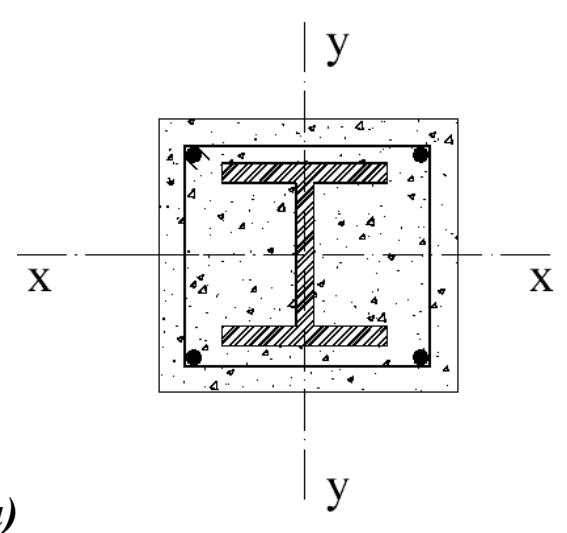

(c)

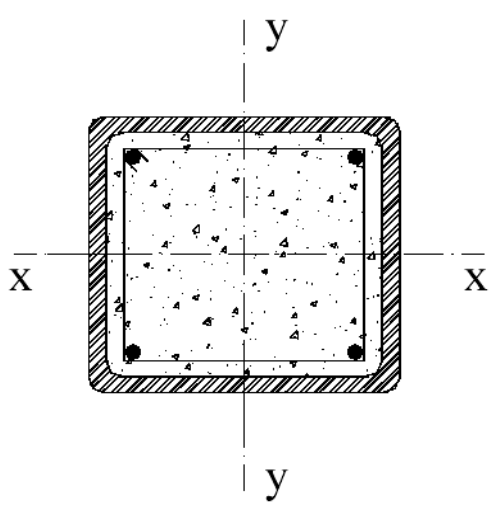

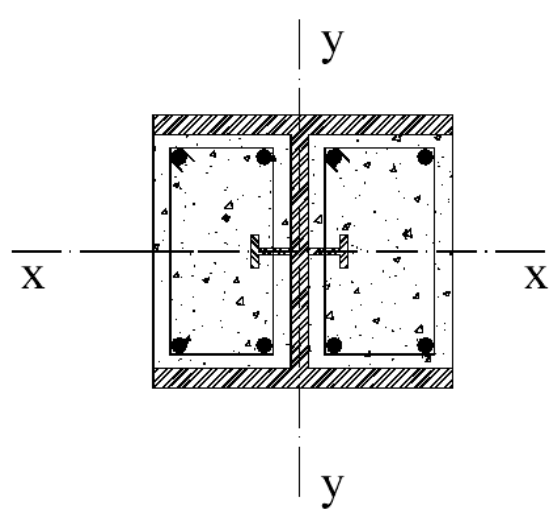

(b)

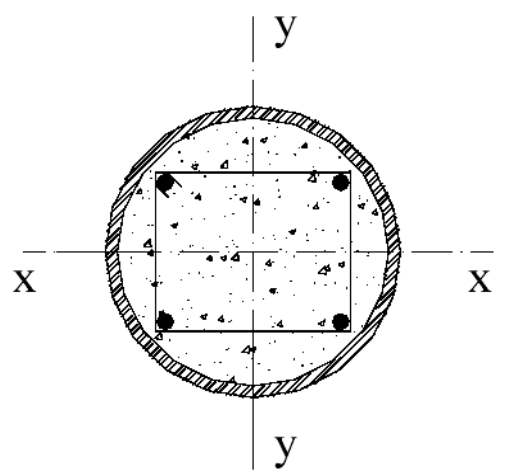

(d)

Figura 1.1 - Tipos de seções transversais de pilares mistos, NBR 14323:1999.

Nos itens que se seguem, são apresentados os objetivos do trabalho, a justificativa para a escolha do tema em questão, a metodologia a ser empregada, bem como breve descrição do conteúdo de cada capítulo que irá compor o trabalho final. 


\subsection{OBJETIVOS DO TRABALHO}

O presente trabalho tem como objetivo principal iniciar pesquisas referentes a pilares mistos em situação de incêndio no Departamento de Engenharia de Estruturas da Escola de Engenharia de São Carlos, realizando uma breve revisão do estado da arte para os pilares mistos em temperatura ambiente, com atenções especiais voltadas para aqueles de seção circular, bem como uma revisão mais detalhada dos mesmos sob elevadas temperaturas.

O estudo aqui se faz com vistas a modelar numericamente, em campo tridimensional, pilares mistos curtos com seções tubulares circulares de aço preenchidas com concreto, submetidos ao incêndio-padrão.

A idéia é determinar, em uma primeira etapa, o tempo (ou temperatura) de colapso, aqui denominado "tempo crítico", referente a uma determinada carga aplicada que será sempre admitida proporcional àquela que provoca o colapso do elemento em temperatura ambiente. Em seguida, considerando as informações da primeira etapa, em uma segunda etapa se faz a análise inversa, em que se considera qual deverá ser a carga de colapso desse mesmo elemento (pilar misto curto) para determinados níveis de temperatura, buscando apenas "sinalizar" para qual nível de temperatura o "efeito do confinamento", presente nesse tipo de elemento, deixa de influenciar no comportamento estrutural do mesmo.

Para a viabilização da porposta, foram construídos modelos numéricos para análises termo-estruturais, porém, com a preocupação de garantir por meio de análises preliminares a eficiência dos mesmos em campo térmico e em campo estrutural em temperatura ambiente. Portanto, foram realizadas previamente:

- Análise do campo térmico em seções de pilares mistos, para avaliação da distribuição de temperatura em função do tempo, considerando análise transiente do gradiente térmico e a comparação com resultados obtidos com pacote computacional específico para análise térmica;

- Modelagem numerica de pilares mistos curtos com seção tubular circular de aço preenchido com concreto, inicialmente em "temperatura ambiente" (considerada igual a $20^{\circ} \mathrm{C}$ ), comparando os resultados numéricos obtidos com resultados experimentais e numéricos encontrados na literatura;

A modelagem aqui proposta se faz com vistas a simular o comportamento estrutural desses pilares mistos curtos e preenchidos, inclusive considerando possíveis efeitos 
localizados, em temperatura ambiente e em situação de incêndio, bem como a influência da elevação de temperatura na resistência e no confinamento desses mesmos elementos.

No entanto, é importante ressaltar que a estratégia aqui adotada se faz com base em algumas hipóteses simplificadoras, tendo em vista ser este trabalho de caráter preliminar e exploratório, cujos resultados servirão de base para trabalhos futuros em que serão analisados pilares mistos de aço e concreto em situação de incêndio, com dimensões a serem adotadas em concordância com aquelas usualmente identificadas na prática da construção. As simplificações adotadas são as seguintes:

- Desconsideração de restrições axiais que aparecem como conseqüência da dilatação térmica em resposta à elevação da temperatura, tendo em vista as reduzidas dimensões do elemento em análise;

- Desconsideração de restrições rotacionais que aparecem como conseqüência da dilatação térmica em resposta à elevação da temperatura do elemento;

- Desconsideração de elementos de transição de carregamento (chapa de topo), tendo em vista a pouca (ou mesmo nenhuma) diferença identificada nos resultados obtidos, a serem apresentados no decorrer deste trabalho;

- Compatibilização de descolamentos entre tubo de aço e núcleo de concreto na extremidade carregada, tendo em vista a desconsideração da chapa de topo;

- Consideração da simetria da seção transversal, utilizando-se apenas metade do pilar misto.

\subsection{JUSTIFICATICA}

Tendo em vista a degradação das propriedades mecânicas dos materiais ao serem submetidos a elevadas temperaturas, à existência de normas referentes a pilares mistos em situação de incêndio, a maior atenção dada atualmente ao tema incêndio nos contextos mundial e brasileiro, acredita-se ser necessário realizar estudos que possam contribuir ou servir de base para futuros trabalhos para revisão futura da atual norma brasileira NBR 14323:1999. Comparando com outros países, embora sejam poucos os pesquisadores que trabalham com o tema Estruturas em Situação de Incêndio, no Brasil, recentemente se tem dado maior atenção ao assunto e, consequentemente, o número de pesquisas vem aumentando.

A NBR 14323:1999 visa à verificação dos elementos estruturais, referindo-se a estabilidade e resistência, em temperaturas elevadas. Os métodos de dimensionamento previstos são: Método Tabular, Método Analítico e Métodos Avançados. O presente trabalho 
se enquadra na NBR 14323:1999 na forma de análise por métodos avançados utilizando-se, para isso, a simulação numérica de modelos tridimensionais de pilares mistos curtos de seção tubular preenchida com concreto.

A escolha da análise de pilares mistos de seção tubular circular se deve ao efeito favorável do confinamento, que se mostra mais evidente neste caso. A determinação adequada dos campos de temperatura associada à análise estrutural é de fundamental importância para a determinação dos valores resistentes desses elementos, principalmente para situação em que o pilar não é exposto ao fogo por todos os lados, como, por exemplo, para pilares de borda ou de canto pertencentes a edificações correntes.

Por se tratar de estudo inicial, optou-se por trabalhar com pilares curtos para simplificar o modelo e estudar apenas a influência da temperatura na resistência a plastificação da seção, não considerando a influência dos efeitos de instabilidade global.

\subsection{METODOLOGIA DO TRABALHO}

Pesquisas bibliográficas foram realizadas sobre o tema de interesse, estabelecendo o atual estado da arte com relação ao tema estruturas mistas, em seguida, particularizando os estudos para os pilares mistos de aço e concreto, em especial, com relação àqueles constituídos de seções preenchidas e pilares mistos em elevadas temperaturas.

Para a modelagem numérica utilizou-se o pacote computacional ANSYS, baseado no Método dos Elementos Finitos para a construção dos modelos matemáticos, o qual permite a análise transiente do gradiente térmico nos elementos estruturais, utilizado em Regobello (2007), dando ênfase ao efeito da elevação térmica em seções transversais de perfis metálicos e mistos de aço e concreto, considerando várias condições de assimetria e o seu efeito na resposta estrutural de vigas sob aquecimento uniforme no sentido longitudinal. O ANSYS permite a análise térmica, estrutural e termo-estrutural.

Os resultados da evolução dos níveis de temperatura ao longo do tempo são comparados com valores obtidos por meio do pacote computacional SuperTempCalc (TCD 5.5) e com outros valores, obtidos numérica e experimentalmente, extraídos de trabalhos desenvolvidos por outros pesquisadores. A curva utilizada para elevação da temperatura dos gases em função do tempo também foi considerada com base na ISO 834 (incêndio padrão), apresentada na norma brasileira NBR 14432:2000. 


\subsection{ORGANIZAÇÃO DO TRABALHO}

No capítulo 1 (presente) faz-se a apresentação do trabalho proposto, incluindo objetivos, justificativa e metodologia.

O capítulo 2 apresenta uma breve revisão do estado da arte para as estruturas mistas dando ênfase aos pilares mistos de seção circular preenchidos com concreto em temperatura ambiente, bem como um breve histórico de acidentes envolvendo incêndio na humanidade. Em seguida, são comentados alguns dos importantes trabalhos realizados no campo experimental e, principalmente, em contexto numérico dos pilares mistos em situação de incêndio. Serão citadas as normas em vigor no Brasil e em outros países.

O capítulo 3 aborda os principais conceitos sobre o incêndio (gases aquecidos), os princípios de transferência de calor (dos gases para os elementos), bem como a influência da elevação de temperatura nas propriedades mecânicas do aço e do concreto.

O capítulo 4 apresenta a proposta de estratégia numérica utilizada na elaboração dos modelos numéricos. São citados e comentados os elementos finitos utilizados, todas as hipóteses consideradas e as etapas de construção.

O capítulo 5 apresenta a distribuição da temperatura em algumas seções de pilares mistos, via ANSYS, cujos resultados são comparados com valores (obtidos por meio do programa SUPERTEMPCALC), gentilmente cedidos pelo professor Valdir Pignatta e Silva, da Escola Politécnica da USP.

O capítulo 6 apresenta os resultados e as análises do modelo numérico estrutural em temperatura ambiente, comparando com resultados numéricos e experimentais, os resultados e as análises dos modelos acoplados dos pilares mistos em situação de incêndio.

No capítulo 7 são apresentadas as conclusões do trabalho, bem como sugestões para trabalhos futuros. 



\section{SOBRE ESTRUTURAS MISTAS DE AÇO E CONCRETO - Breve abordagem}

\subsection{ESTRUTURAS MISTAS - PRELIMINARES}

Os sistemas estruturais mistos têm sido bastante utilizados nas obras de engenharia civil, tanto no contexto mundial quanto no Brasil. No contexto mundial, segundo MALITE (1990), os estudos de sistemas compostos tiveram seu início antes da primeira grande guerra, na Inglaterra, com base em uma série de ensaios para pisos. Entre 1922 e 1939, foram construídos edifícios e pontes que adotavam o sistema de vigas compostas.

A consideração do trabalho em conjunto dos elementos de aço e de concreto para a concepção dos elementos denominados "mistos de aço e concreto", como, por exemplo, as lajes mistas, as vigas mistas e os pilares mistos, surgiram inicialmente com vistas a viabilizar proteção ao fogo e à corrosão dos elementos estruturais de aço, razão pela qual o concreto não possuía qualidade estrutural. Posteriormente, se passou a considerar a contribuição do concreto, enquanto material, na resposta estrutural desses mesmos elementos, garantindo assim uma considerável eficiência estrutural em termos de resistência e de rigidez.

Segundo MALITE (1990), no Brasil, entre 1950 e 1960, a construção em sistemas estruturais mistos limitou-se a alguns edifícios e pequenas pontes. A partir do final da década de 80 crescem as pesquisas sobre o assunto em questão. Atualmente, com o aumento considerável da produção de aço no Brasil e objetivando novas soluções arquitetônicas e estruturais, sua utilização vem crescendo consideravelmente, na construção de edifícios industriais, comerciais, pontes, etc.

As vigas mistas de aço e concreto são elementos estruturais constituídos pela associação de viga de aço solidarizada a lajes de concreto armado, de piso ou de cobertura, pré-fabricadas ou não. A associação de ambos os elementos é garantida por dispositivos mecânicos denominados conectores de cisalhamento, possibilitando o trabalho em conjunto de viga e laje, possibilitando maior eficiência à flexão. 
As vigas mistas se originam de sistemas de piso constituídos por vigas de aço e lajes de concreto, como por exemplo, edifícios de múltiplos andares e pontes. A figura 2.1, extraída de MALITE (1990), ilustra sistemas de vigas mistas de aço e concreto com conectores de cisalhamento do tipo "pino com cabeça". Da união entre ambos os elementos consiste de um sistema estrutural cuja seção transversal resulta em uma laje de concreto situada em uma região predominantemente comprimida, sobre uma viga de aço situada em uma região predominantemente tracionada.

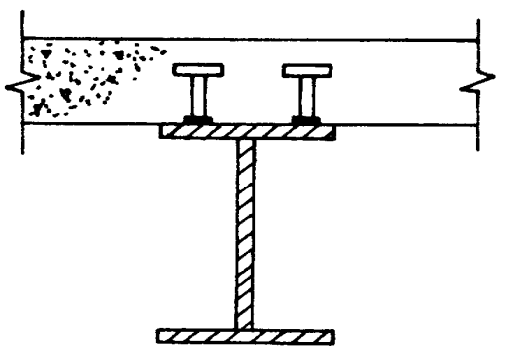

(a)

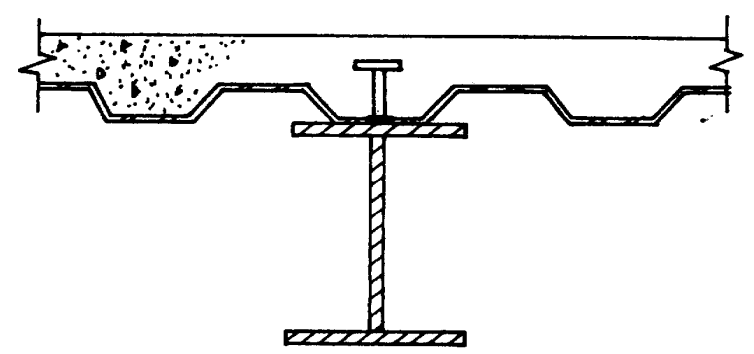

(b)

(c)

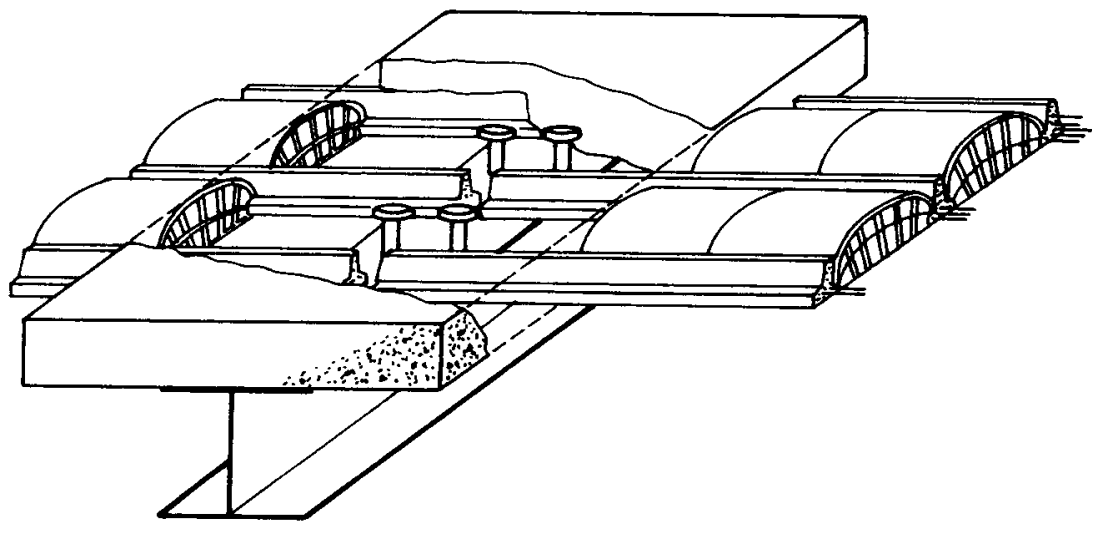

Figura 2.1 - Tipos usuais de vigas mistas de aço e concreto, (a) Laje com face inferior plana,

(b) Laje com forma de aço incorporada e (c) Viga de aço com laje pré-fabricada

A figura 2.2, referente ao Prédio da Engenharia de Produção da EESC/USP, ilustra a situação de viga mista de aço e concreto, na qual foi utilizado perfil U como conector de cisalhamento em substituição ao pino com cabeça.

A figura 2.3 ilustra as lajes mistas de aço e concreto que constituem elementos estruturais formados por lajes de concreto com fôrma de aço incorporada, também denominada "Steel-Deck", e apresentam as mesmas vantagens citadas para as vigas mistas de aço e concreto. Por possuírem fôrmas de aço, podem dispensar o uso de escoramento na fase de endurecimento do concreto. 


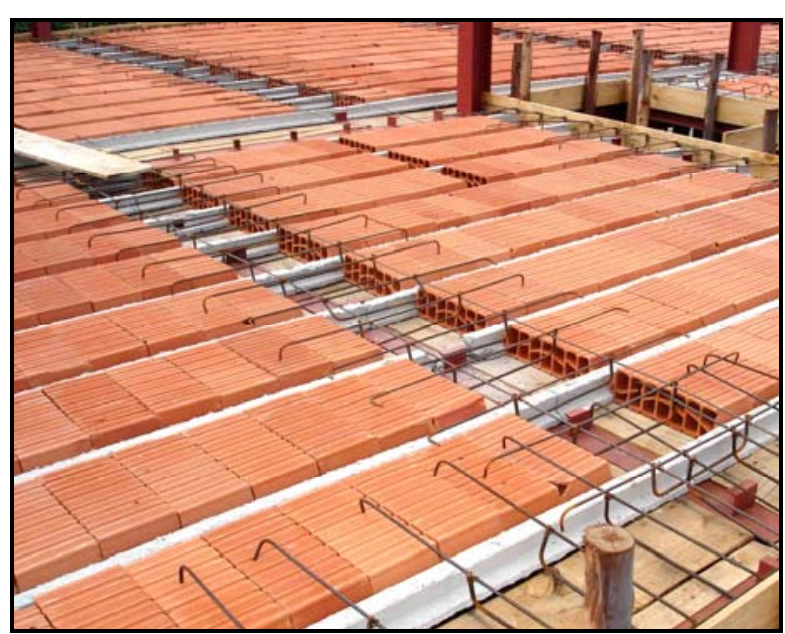

(a)

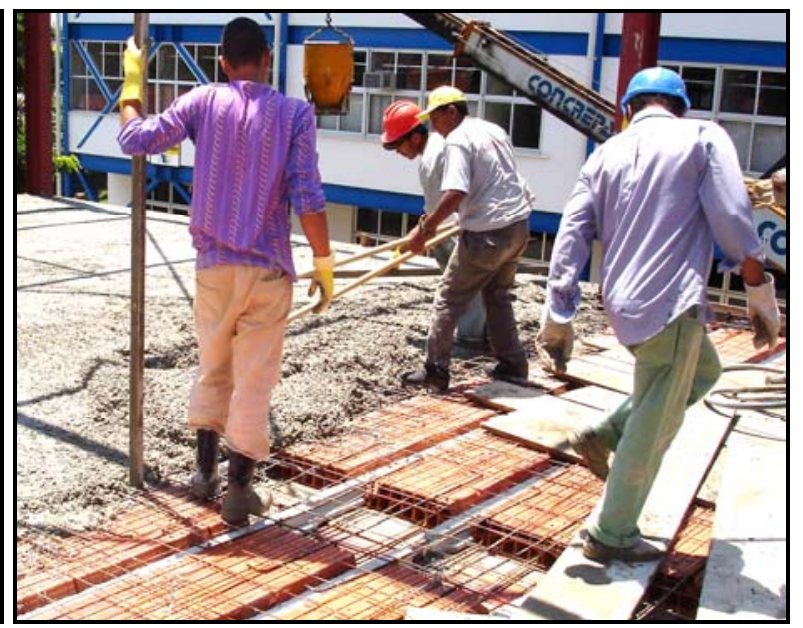

(b)

Figura 2.2 - Vigas mistas de aço e concreto:

(a) Fase de montagem das vigotas e das lajotas e (b) Fase de concretagem.

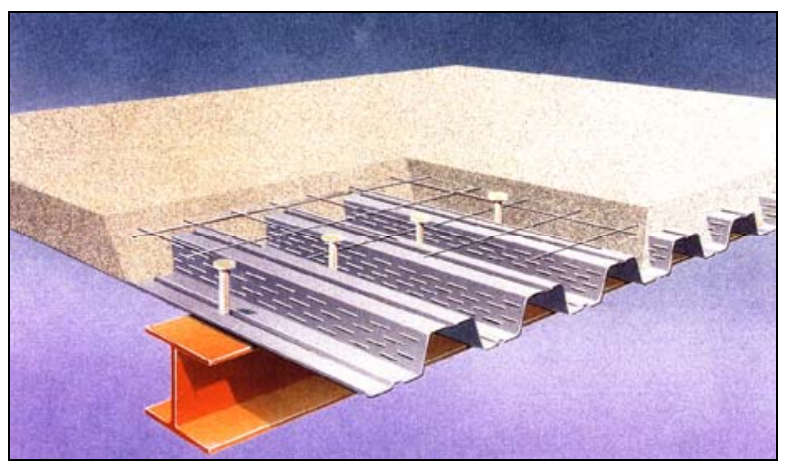

(a)

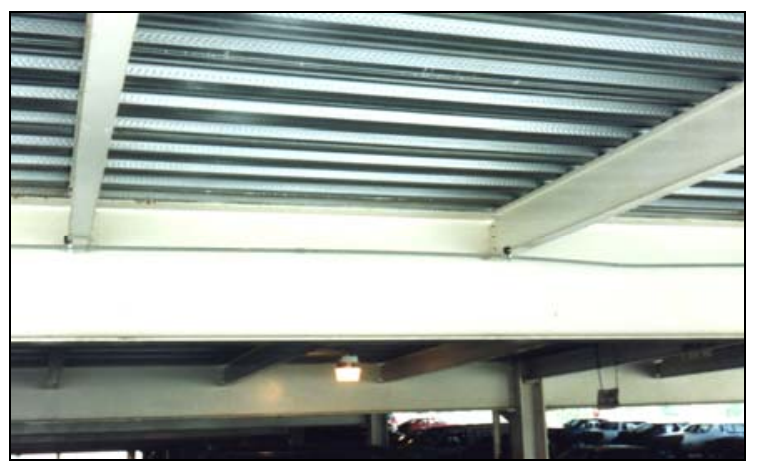

(b)

Figura 2.3 - (a) Detalhe da laje com forma de aço incorporada (laje mista). Fonte: catálogo da CODEME Engenharia e (b) Edifício Garagem, construído nos Estados Unidos.

Os pilares mistos de aço e concreto constituem elementos estruturais de aço revestidos (total ou parcialmente) ou preenchidos com concreto, conforme esquematiza a figura 2.4, extraída de DE NARDIN et al. (2006).

Os pilares mistos preenchidos com concreto (figura 2.4a) são elementos estruturais que surgem em resposta à associação de perfil tubular de seção circular ou quadrada preenchida com concreto de qualidade estrutural. Para esse tipo de pilar misto, em relação ao comportamento estrutural, destaca-se o efeito do "confinamento", que surge em razão da restrição à deformação lateral imposta pelas armaduras ou camisas, ambas de aço.

No caso dos pilares mistos, o concreto utilizado é de resistência à compressão igual ou superior a $20 \mathrm{MPa}$, e pode ser simples ou armado, e os elementos de aço podem ser aplicados na forma de perfis laminados, dobrados ou soldados. 


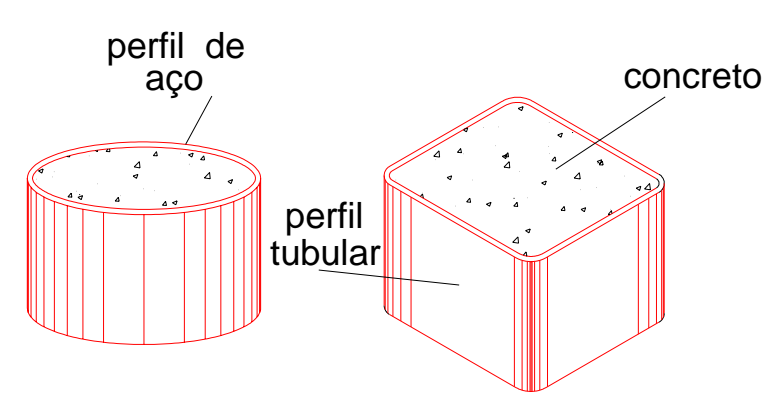

(a)

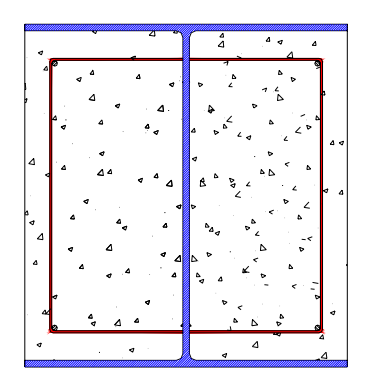

(b)

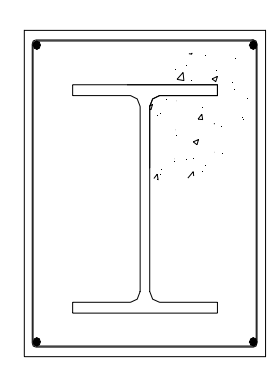

(c)

Figura 2.4 - Pilares mistos de aço e concreto: (a) preenchidos com concreto, (b) revestidos parcialmente com concreto e (c) revestidos totalmente com concreto.

Os materiais aço e concreto são complementares entre si, uma vez que o concreto resulta bem mais eficiente quando submetido a esforços de compressão, enquanto o aço resulta mais eficiência quando solicitado à tração. Outro ponto importante se refere ao fato de o concreto, por ser aplicado como preenchimento ou como revestimento, restringe a possibilidade de flambagens (local ou global) do perfil de aço, enquanto o aço, por sua vez, introduz ductilidade ao concreto.

Dentre as vantagens na utilização de estruturas mistas, são aqui citadas:

- A utilização das estruturas mistas proporciona economia de materiais e maior rapidez na execução da obra;

- Nos aspectos arquitetônicos, vence grandes vãos e os elementos são mais esbeltos, proporcionando um ganho na obtenção de área livre;

- Os elementos mistos funcionam como fôrma permanente e contribuem com a estabilidade da estrutura durante a construção;

- Quando comparado aos métodos construtivos convencionais em concreto ou em aço, as estruturas mistas apresentam maior eficiência, grande capacidade resistente e maior rigidez.

\subsection{PILARES MISTOS DE AÇO E CONCRETO EM TEMPERATURA AMBIENTE}

Segundo DE NARDIN (1999) as vantagens associadas ao uso dos pilares mistos são as responsáveis pelo atual crescimento e divulgação de sua utilização em países como Estados Unidos, Canadá, Japão, Austrália e China. Na última referência foi desenvolvido estudo do comportamento de pilares mistos de aço preenchidos com concreto de alta resistência e 
submetidos à compressão axial, cujos ensaios em modelos físicos se realizaram com controle de deslocamento. As vantagens dos pilares mistos de seção circular preenchidos com concreto são:

- Maior e mais adequada eficiência estrutural;

- Elevada capacidade resistente dos pilares mistos quando comparados com pilares de concreto, resultando em seções transversais de dimensões reduzidas e aumento da área útil do pavimento. Conseqüentemente, redução do peso próprio e alívio das fundações;

- O núcleo de concreto é responsável por aumentar a rigidez e a resistência do perfil tubular, proporcionando maior estabilidade para os perfis de aço e redução de flambagem local;

- Os pilares mistos preenchidos, quando comparados aos pilares de concreto armado, têm como vantagem a ausência de fôrmas e cimbramentos, resultando em economia de material e mão-de-obra, com redução (ou mesmo ausência) de armaduras longitudinais.

- Elevada resistência, rigidez e capacidade de absorver energia (ductilidade) proporcionam aos pilares mistos excelentes propriedades resistentes às ações sísmicas, com possibilidade de atingir deformações plásticas com comportamento dúctil;

- Os pilares mistos quando comparados aos pilares de aço apresentam maior rigidez e resistência ao fogo;

Segundo FURLONG (1967) apud DE NARDIN (1999), o limite inferior de resistência à compressão é dado pela soma de duas forças: a força necessária para causar o escoamento do aço e a força que causaria no concreto a mesma deformação do aço.

Nos pilares mistos preenchidos, o efeito do "confinamento" sobre o concreto proporcionado pelo tubo de aço influi diretamente na capacidade resistente. Devido ao efeito do confinamento, a capacidade resistente do elemento misto não é dada apenas pela soma das resistências do perfil tubular e do concreto preenchido, devendo também ser considerado o acréscimo de resistência do concreto devido ao efeito do confinamento.

As figuras 2.5, 2.6, 2.7 e 2.8 ilustram alguns exemplos de edifícios em que foram utilizados pilares mistos de seção circular preenchidos com concreto em seu sistema estrutural. 

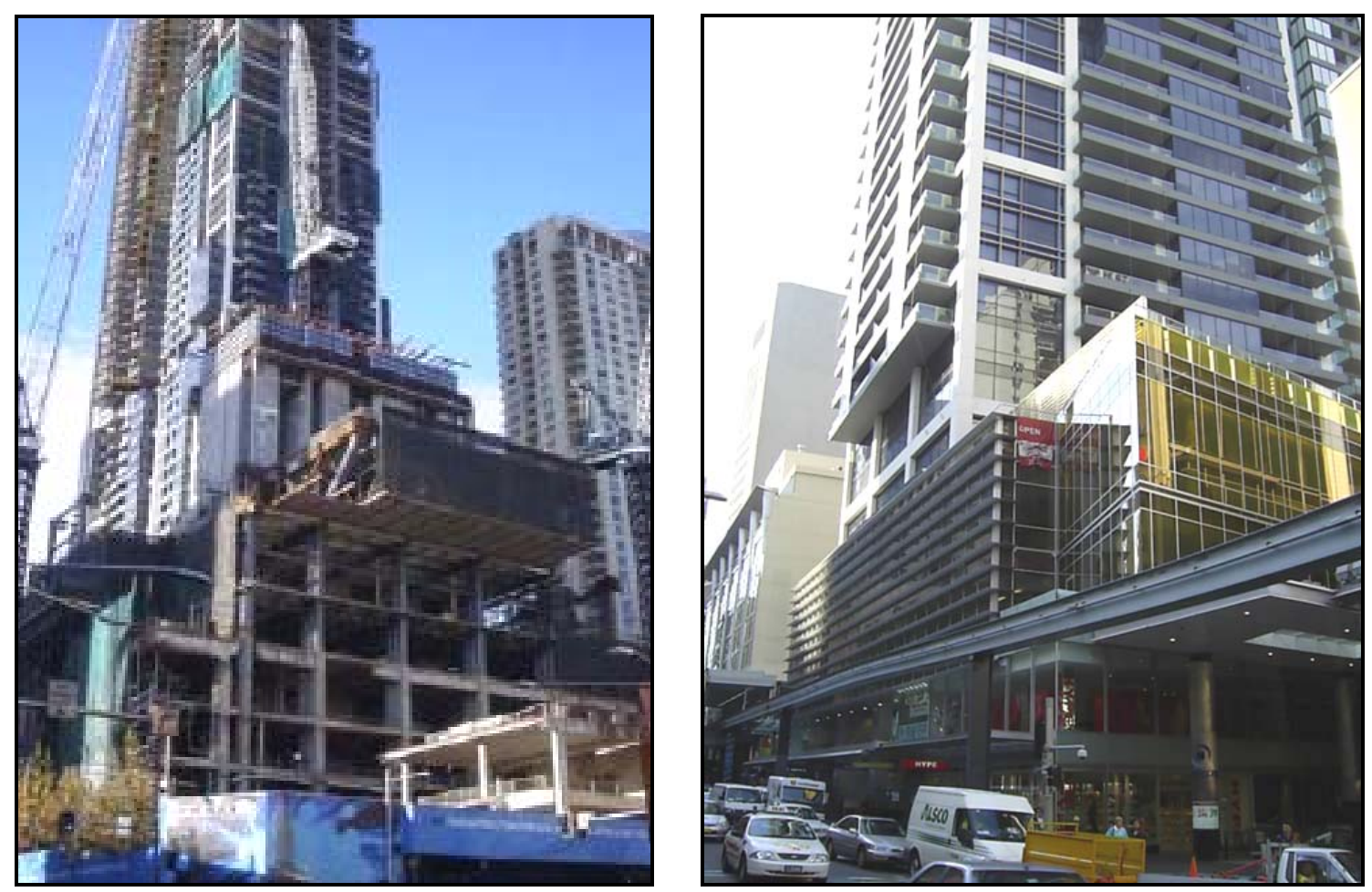

Figura 2.5 - Edifício Latitude Building (Sidnei - Austrália, 1990), com 55 pavimentos. Fonte: http://www.sydneyarchitecture.com/cbd/cbd3-013.htm.
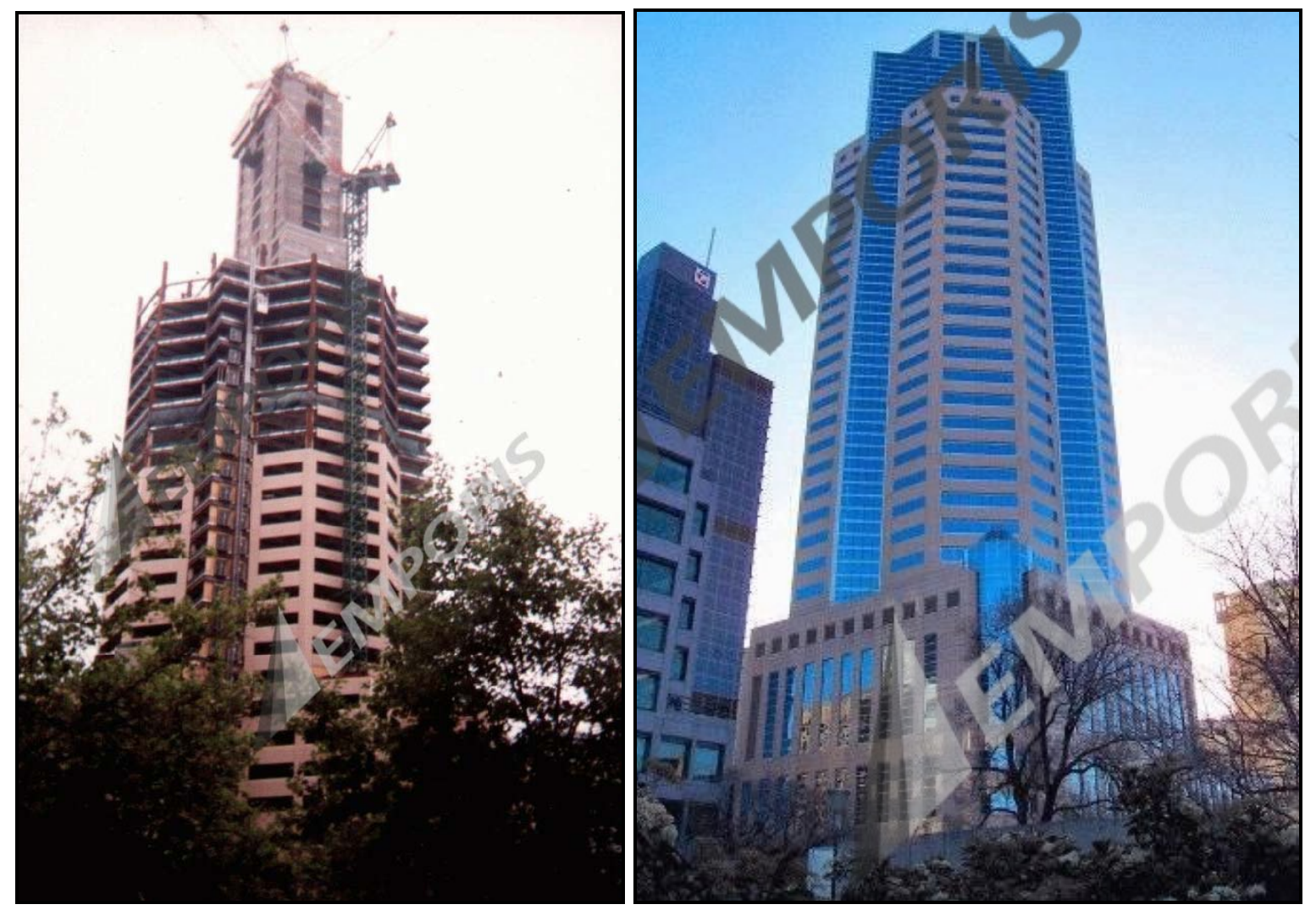

Figura 2.6 - Edifício Casselden Place (Melbourne - Austrália, 1992) com altura total de 166 metros e 43 pavimentos. Fonte: http://www.emporis.com/en/bu/ 

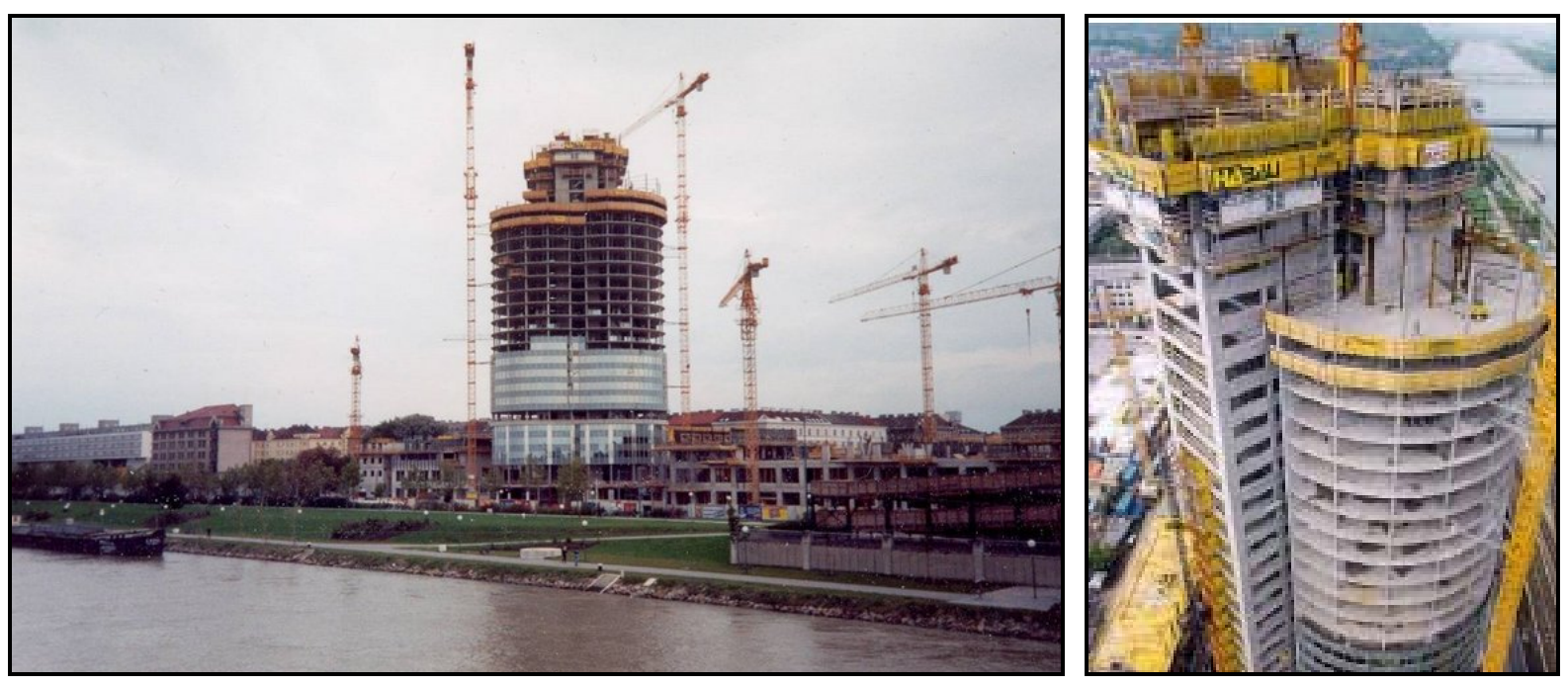

Figura 2.7 - Edifício Millennium Tower (Viena - Áustria, 1999) com altura total de 202 metros e 51 pavimentos. Fonte: http://www.emporis.com/en/bu/
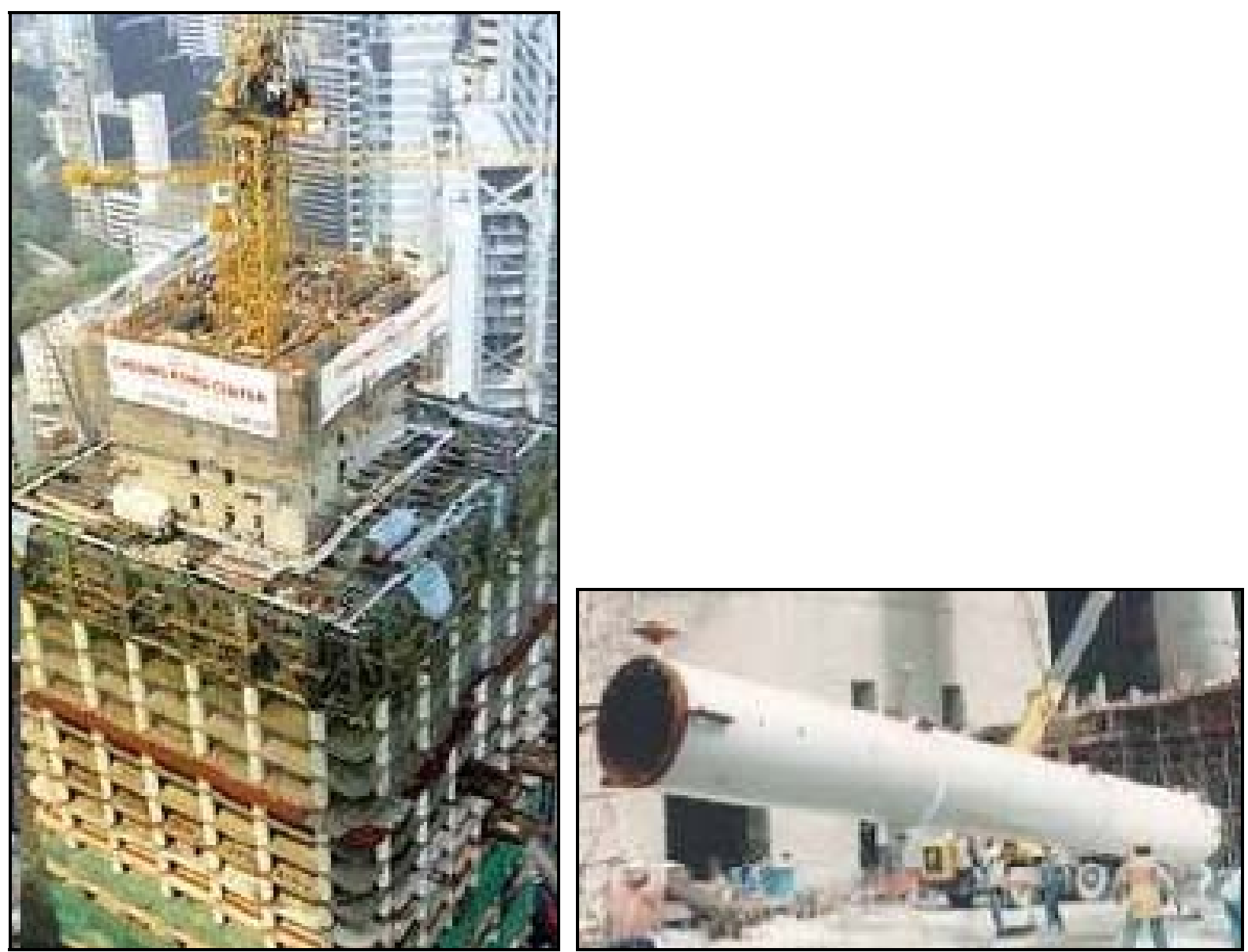

Figura 2.8 - Edifício Cheung Kong Center (Hong Kong, 1999) com altura total de 289 metros e 63 pavimentos. Fonte: http://www.emporis.com/en/bu/ 


\subsubsection{EFEITO DO CONFINAMENTO}

Segundo aspectos descritos em DE NARDIN et al. (2006), nos primeiros estágios de carregamento, o coeficiente de Poisson do concreto é menor quando comparado ao do aço, razão pela qual o perfil não exerce efeito de confinamento sobre o núcleo de concreto. Com o aumento das deformações longitudinais do pilar, a expansão lateral do concreto não confinado torna-se, gradualmente, superior àquela observada no aço, desenvolvendo "pressões radiais" de expansão na interface entre o aço e o concreto.

O núcleo de concreto, ao tentar se expandir é impedido pelo perfil tubular que responde com pressões laterais de confinamento, responsáveis pelo acréscimo na resistência à compressão uniaxial do concreto. A figura 2.9, extraída de DE NARDIN et al. (2006), esquematiza os níveis de confinamento, na forma de tensões, para seções tubulares de diferentes formas, preenchidas com concreto.

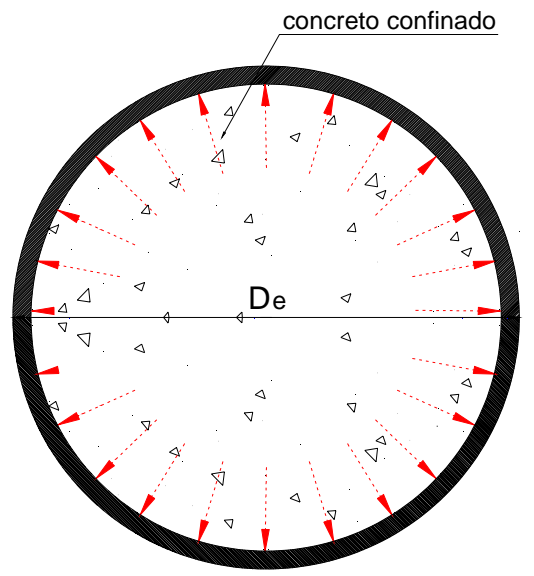

(a)

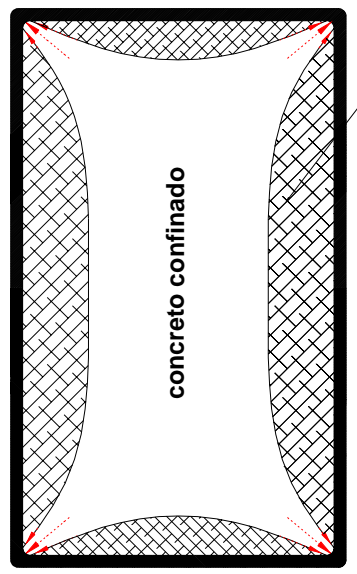

(b) concreto não-confinado

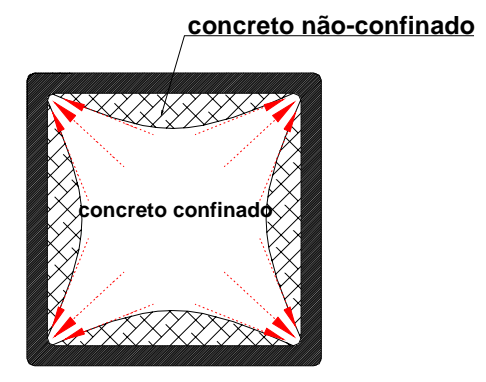

(c)

Figura 2.9 - Confinamento em seções: (a) circulares, (b) retangulares e (c) quadradas.

Segundo a última referência, a espessura do perfil tubular, o índice de esbeltez do pilar misto, a excentricidade da força, a resistência dos materiais e a forma da seção transversal são fatores importantes para a determinação do grau de confinamento do concreto. A forma da seção transversal é de fundamental importância, como mostra a figura 2.9, uma vez que para seções circulares o concreto de preenchimento está sujeito a um mesmo grau de confinamento em todos os pontos da seção transversal.

Para seções retangulares e quadradas, figuras $2.9 \mathrm{~b}$ e $2.9 \mathrm{c}$, as parcelas de concreto localizadas no centro e nos cantos do núcleo estão sujeitas a um grau de confinamento maior quando comparadas àquelas regiões situadas nos lados, aspecto que pode ser atribuído à ocorrência de convergência das tensões de confinamento, do centro da seção para os cantos, 
com distribuição das tensões em forma de arco. Vale destacar que para as seções retangulares, a variação no grau de confinamento do concreto é ainda maior quando comparada àquela verificada nas seções quadradas.

O confinamento é característica importante quando se trata de pilares preenchidos e, embora nem sempre aumente a capacidade resistente da seção mista, o mesmo confere ductilidade ao concreto. Ressalta-se, no entanto, que as características anteriormente citadas são referentes às análises em temperatura ambiente, e podem, eventualmente, não ser verificadas quando consideradas em temperaturas elevadas, conforme esquematiza a figura 2.10, extraída de WANG (2002), em que a instabilidade local da chapa de aço interfere no efeito do confinamento e, conseqüentemente, na resistência do pilar misto.

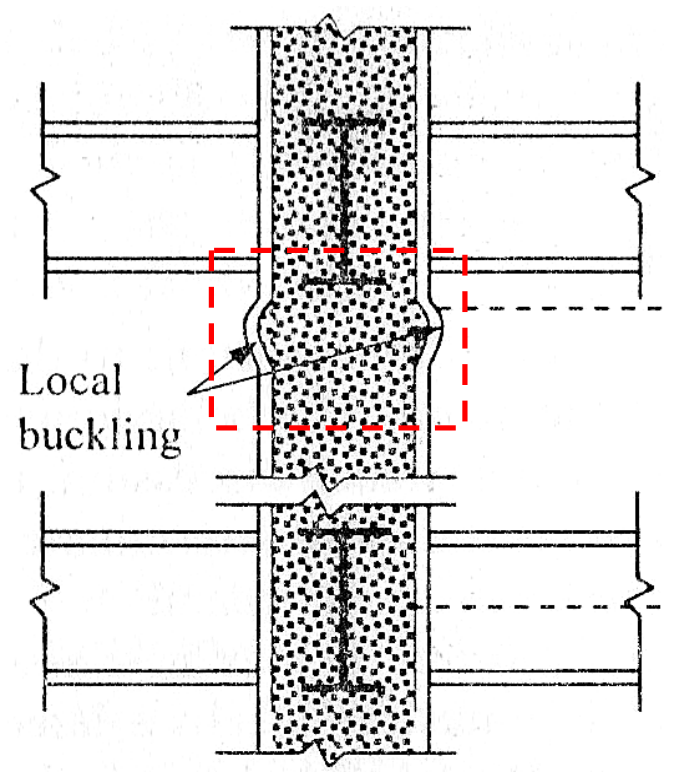

Figura 2.10 - Influência da instabilidade local de chapa no efeito do confinamento.

Em JOHANSSON (2002) é avaliado o comportamento do pilar misto preenchido submetido à compressão, criando um modelo numérico a partir de análises experimentais. Segundo a última referência, a análise numérica não implica na exclusão dos ensaios, apenas na redução do número deles, pois os ensaios são necessários para verificar se as análises numéricas representam o comportamento real. Ambas as análises possibilitam obter um melhor entendimento do comportamento mecânico dos pilares.

Ainda segundo JOHANSSON (2002), o comportamento mecânico de um pilar CFT (Concrete Filled Tube) carregado axialmente em toda a seção é significativamente afetado pela diferença de dilatação entre o núcleo de concreto e o tubo de aço devido ao efeito Poisson. 
Na primeira parte do carregamento (Fase 1), a expansão lateral do concreto é menor se comparada àquela ocorrida no tubo de aço e, por essa razão, o tubo se deforma (expande) mais rapidamente na direção radial do que o núcleo de concreto. Portanto, o aço não restringe o núcleo de concreto, conforme esquematizam as figuras $2.11 \mathrm{a}$ e $2.11 \mathrm{~b}$.

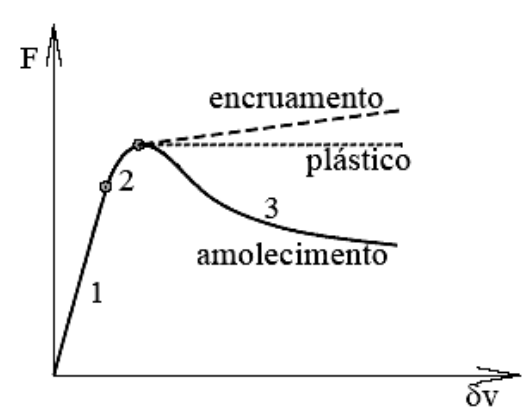

a) força $\times$ deformação

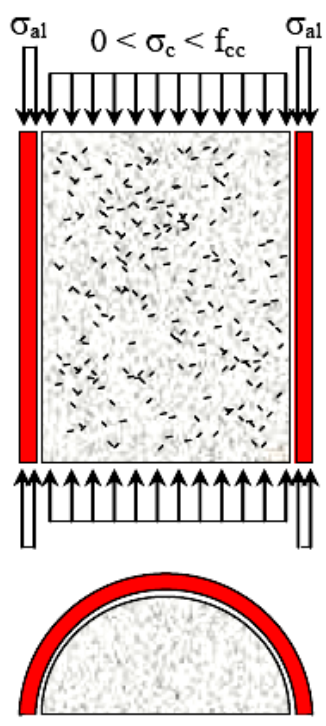

b) Fase 1

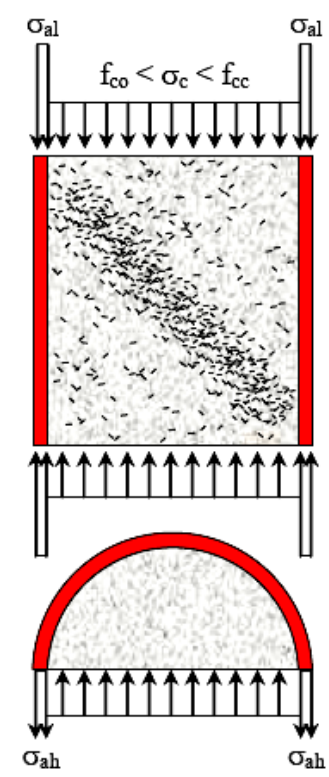

c) Fase 2

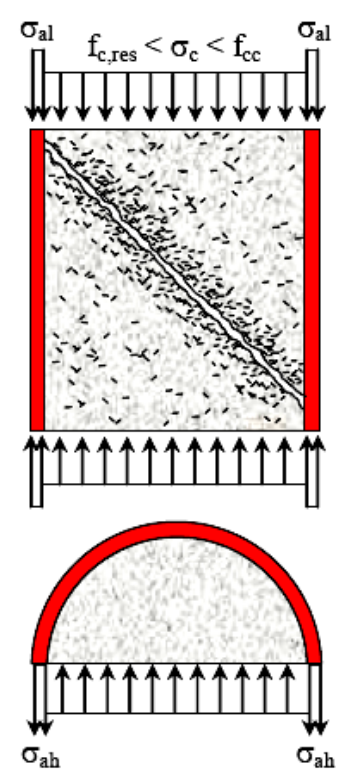

d) Fase 3

Figura 2.11 - Comportamento esquemático força x deformação para um pilar preenchido carregado axialmente em toda a seção, fonte JOHANSSON (2002).

Durante a primeira fase do carregamento, a microfissuração do núcleo de concreto é bem distribuída. No entanto, com o aumento do carregamento, as tensões no núcleo de concreto se aproximam da resistência à compressão do concreto "não confinado", dando início à propagação e aumento no tamanho das microfissuras. Quando o carregamento está próximo da resistência uniaxial do concreto, as deformações laterais do núcleo de concreto começam a aumentar até que se tornam próximas ou mesmo coincidentes com aquelas observadas no tubo de aço, quando então ocorre o contato entre aço e concreto.

Aumentando o carregamento (Fase 2), Figura 2.11c, o tubo de aço passa a limitar a expansão do núcleo de concreto $\left(\sigma_{\mathrm{ah}}>0\right)$ e, consequentemente, o núcleo de concreto e perfil de aço são submetidos a estados triaxial e biaxial de tensões, respectivamente.

Portanto, antes de a resistência do concreto não confinado $\left(\mathrm{f}_{\mathrm{co}}\right)$ ser atingida, o tubo de aço não tinha quase nenhum efeito restritivo sobre o núcleo de concreto. Antes dessa fase não há qualquer efeito de confinamento, e a resistência do pilar preenchido corresponde à soma das resistências uniaxial do núcleo de concreto e do tubo de aço. 
Com os crescentes danos sofridos pelo concreto, a resistência mecânica na zona de cisalhamento (ver figura 2.11c) diminui, aspecto que possibilita neutralizar o efeito positivo do aumento do confinamento no núcleo de concreto. Num determinado momento, os danos são tão extensos que a pressão de confinamento não é suficiente para evitar a fissuração instável e a máxima resistência à compressão do concreto $\left(\mathrm{f}_{\mathrm{cc}}\right)$ é atingida.

Em seguida, vem um ramo descendente (Fase 3) que tende para um valor residual ou resistência residual $\left(\mathrm{f}_{\mathrm{c}, \text { res }}\right)$, correspondendo à formação completa do plano de cisalhamento, figura $2.11 \mathrm{~d}$. A resistência residual do pilar pode ser mantida para grandes deformações e representa a capacidade resistente absorvida pelo tubo de aço devido ao cisalhamento no núcleo de concreto.

É importante destacar novamente que o efeito do confinamento depende de alguns fatores, tais como a forma da seção transversal, esbeltez do pilar misto, espessura do perfil tubular, relação (D/t) diâmetro espessura, excentricidade do carregamento axial, resistência característica a compressão do concreto e resistência ao escoamento do aço.

Por exemplo, o efeito do confinamento perde intensidade com o aumento da esbeltez dos pilares mistos, bem como com o aumento na relação $\mathrm{D} / \mathrm{t}$ e com o aumento da excentricidade do carregamento. Consequentemente, a pressão de confinamento resultante promovida pelo tubo de aço será sempre maior para tubos mais espessos.

\subsubsection{NORMAS REFERENTES AO DIMENSIONAMENTO DE PILARES MISTOS}

Em OLIVEIRA (2008) são apresentados os procedimentos de cálculo adotados por algumas das principais normas para o dimensionamento, em temperatura ambiente, de pilares mistos de aço e concreto, como, por exemplo a norma brasileira ABNT-NBR 8800:2008, da norma européia EUROCODE 4:2004, da norma americana ANSI/AISC e da norma canadense CAN/CSA:2001.

Serão apresentadas, no decorrer do presente texto, apenas as prescrições existente para as duas primeiras normas citadas no parágrafo anterior, referentes à determinação da capacidade resistente de pilares mistos preenchidos e de seção circular, submetidos à compressão simples.

A tabela 2.1 apresenta os limites de aplicabilidade das normas em função da resistência dos materiais. Na tabela 2.2 são apresentadas equações para a determinação do módulo de elasticidade do concreto em função do $f_{c k}$. 
Tabela 2.1- Limites de aplicabilidade

\begin{tabular}{|c|c|c|}
\hline Norma & Concreto (MPa) & Aço (MPa) \\
\hline NBR 8800:2008 & $20 \leq \mathrm{f}_{\mathrm{ck}} \leq 50$ & $250 \leq \mathrm{f}_{\mathrm{y}} \leq 450$ \\
\hline EUROCODE 4:2004 & $20 \leq \mathrm{f}_{\mathrm{ck}} \leq 60$ & $235 \leq \mathrm{f}_{\mathrm{y}} \leq 460$ \\
\hline
\end{tabular}

Tabela 2.2 - Cálculo do módulo de elasticidade secante do concreto

\begin{tabular}{|c|c|c|}
\hline Norma & Recomendação & Observações \\
\cline { 1 - 2 } NBR 8800:2008 & $\mathrm{E}_{\mathrm{c}}=4760 \cdot \sqrt{\mathrm{f}_{\mathrm{ck}}}$ & \multirow{2}{*}{$\mathrm{f}_{\mathrm{ck}} \mathrm{em} \mathrm{MPa}$} \\
\cline { 1 - 2 } EUROCODE 4:2004 & $\mathrm{E}_{\mathrm{cm}}=22000 \cdot\left(\frac{\mathrm{f}_{\mathrm{ck}}}{10}\right)^{0,3}$ & \\
\hline
\end{tabular}

Para garantir que as resistências à compressão do concreto e ao escoamento do aço sejam atingidas sem que ocorra a flambagem local da seção transversal do tubo de aço, devem ser utilizados valores de espessura $(\mathrm{t})$ do tubo segundo equações apresentadas na tabela 2.3, em que D é o diâmetro externo do tubo de aço e $\mathrm{E}_{\mathrm{a}} \mathrm{o}$ módulo de elasticidade do aço.

Tabela 2.3 - Cálculo da espessura mínima (t) do tubo de aço

\begin{tabular}{|c|c|}
\hline Norma & Recomendação \\
\hline NBR $8800: 2008$ & $\mathrm{t} \geq \frac{\mathrm{D} \cdot \mathrm{f}_{\mathrm{y}}}{0,15 \cdot \mathrm{E}_{\mathrm{a}}}$ \\
\hline EUROCODE $4: 2004$ & $\mathrm{t} \geq \frac{\mathrm{D} \cdot \mathrm{f}_{\mathrm{y}}}{90 \cdot 235 \mathrm{MPa}}$ \\
\hline
\end{tabular}

Com relação à esbeltez global do elemento, os limites de aplicabilidade das normas estão apresentados na tabela 2.4 .

Tabela 2.4 - Limites de esbeltez global

\begin{tabular}{|c|c|}
\hline Norma & Recomendação \\
\hline NBR 8800:2008 & $\lambda_{0} \leq 2$ \\
\hline EUROCODE 4:2004 & $\bar{\lambda} \leq 2$ \\
\hline
\end{tabular}




\subsubsection{NBR 8800:2008}

A ABNT-NBR 8800:2008 apresenta apenas equações associada a um método denominado "Método simplificado", e os pré-requisitos para a sua utilização são:

a-) Os pilares mistos devem ter dupla simetria e seção transversal constante ao longo do comprimento;

b-) O fator de contribuição do aço ( $\delta$ ) do perfil deve estar entre 20 e $90 \%$, sendo calculado pela equação 2.1 .

$$
\delta=\frac{\mathrm{f}_{\mathrm{y}} \cdot \mathrm{A}_{\mathrm{a}}}{\mathrm{N}_{\mathrm{Rd}, \mathrm{pl}}}
$$

$\mathrm{Na}$ equação 2.1, $\mathrm{f}_{\mathrm{y}}$ é a resistência ao escoamento do aço, $\mathrm{A}_{\mathrm{a}}$ é a área da seção transversal do perfil de aço e $\mathrm{N}_{\mathrm{Rd}, \mathrm{pl}}$ é a força axial de compressão resistente de cálculo da seção transversal mista associada à plastificação total, calculada de acordo com a equação 2.5.

c-) O concreto utilizado deve possuir densidade normal;

d-) As seções transversais preenchidas com concreto podem ser fabricadas sem qualquer armadura, exceto para condições em situação de incêndio (usar a ABNT-NBR 14323:1999). A máxima porcentagem de armadura na seção de concreto é de $4 \%$ desta;

A força axial resistente de cálculo de pilares mistos axialmente comprimidos sujeitos à instabilidade por flexão, é dada pela equação 2.2 apresentada a seguir.

$$
\mathrm{N}_{\mathrm{Rd}}=\chi \cdot \mathrm{N}_{\mathrm{Rd}, \mathrm{pl}}
$$

Com relação à equação $2.2, \mathrm{~N}_{\mathrm{Rd}, p l}$ é a força axial de compressão resistente de cálculo da seção transversal à plastificação total (calculada de acordo com a equação. 2.5), $\chi$ é o fator de redução associado à resistência à compressão, o qual depende da curva de dimensionamento à compressão (única) e pode ser calculado pela equação 2.3 . 


$$
\begin{aligned}
& \chi=0,658^{\lambda_{0}^{2}}, \text { se } \lambda_{0} \leq 1,5 \\
& \chi=\frac{0,877}{\lambda_{0}^{2}}, \text { se } \quad \lambda_{0} \geq 1,5
\end{aligned}
$$

$\mathrm{Na}$ equação $2.3, \lambda_{0}$ o índice de esbeltez reduzido por conta do efeito da flambagem local pode ser calculado com a equação 2.4.

$$
\lambda_{0}=\sqrt{\frac{\mathrm{N}_{\mathrm{R}, \mathrm{pl}}}{\mathrm{N}_{\mathrm{e}}}}
$$

$\mathrm{Na}$ equação 2.4, $\mathrm{N}_{\mathrm{R}, \mathrm{pl}}$ é o valor de $\mathrm{N}_{\mathrm{Rd}, \mathrm{pl}}$ tomando-se respectivamente $\mathrm{f}_{\mathrm{y}}, \mathrm{f}_{\mathrm{ck}}$ e $\mathrm{f}_{\mathrm{ys}}$ no lugar de $f_{y d}, f_{c d}$ e $f_{\text {sd }}$, ou seja, tomando os coeficientes de segurança iguais a 1 na Eq. 2.5, $\mathrm{N}_{\mathrm{e}}$ é a força normal de flambagem elástica, dada pela Eq. 2.6. Como neste trabalho não foram adotadas barras de armadura adicionais colocadas dentro dos pilares, as parcelas referentes a esta contribuição foram suprimidas das expressões.

$$
\begin{aligned}
& \mathrm{N}_{\mathrm{Rd}, \mathrm{pl}}=\frac{\mathrm{f}_{\mathrm{y}} \cdot \mathrm{A}_{\mathrm{a}}}{\gamma_{\mathrm{a}}}+\alpha \cdot \frac{\mathrm{f}_{\mathrm{ck}} \cdot \mathrm{A}_{\mathrm{c}}}{\gamma_{\mathrm{c}}} \\
& \mathrm{N}_{\mathrm{e}}=\frac{\pi^{2} \cdot(\mathrm{EI})_{\mathrm{e}}}{(\mathrm{KL})^{2}}
\end{aligned}
$$

Nas equações 2.5 e 2.6, $\mathrm{A}_{\mathrm{c}}$ a área da seção transversal do concreto, $\mathrm{f}_{\mathrm{ck}}$ é a resistência característica do concreto à compressão, $\gamma_{c}$ é o coeficiente de minoração da resistência do concreto, $f_{y}$ é a resistência ao escoamento do aço, $\gamma_{\mathrm{a}}$ é o coeficiente de minoração da resistência do aço, $\alpha$ é 0,95 para seção circular e leva em conta, ainda que de forma simplista, o efeito do confinamento nas seções circulares preenchidas, KL é o comprimento de flambagem do pilar e $(\mathrm{EI})_{\mathrm{e}}$ é a rigidez efetiva à flexão da seção mista, que pode ser calculada por meio da equação 2.7 , na qual $\mathrm{I}_{\mathrm{a}}$ é o momento de inércia da seção transversal do tubo de aço e $I_{c}$ é o momento de inércia da seção transversal do concreto.

$$
(\mathrm{EI})_{\mathrm{e}}=\mathrm{E}_{\mathrm{a}} \cdot \mathrm{I}_{\mathrm{a}}+0,6 \cdot \mathrm{E}_{\mathrm{c}} \cdot \mathrm{I}_{\mathrm{c}}
$$




\subsubsection{EUROCODE 4:2004}

A formulação proposta pelo EUROCODE 4 (BS EN 1994-1-1:2004) abrange o dimensionamento de pilares mistos submetidos à compressão axial e a esforços combinados de flexão e compressão. Ressalta-se, no entanto, que no presente trabalho será apresentado apenas o dimensionamento de pilares mistos submetidos à compressão axial.

O coeficiente de redução 0,85 pode ser omitido para pilares mistos preenchidos. No caso de seções circulares preenchidos por concreto, com esbeltez relativa $(\bar{\lambda})$ igual ou inferior a 0,5 e excentricidade da carga inferior a $10 \%$ do diâmetro do tubo, pode-se levar em conta o efeito do confinamento do concreto, calculando-se a máxima normal de plastificação de cálculo com a Eq. 2.8.

$\mathrm{N}_{\mathrm{pl}, \text { Rd }}=\eta_{\mathrm{a}} \cdot \frac{\mathrm{f}_{\mathrm{y}} \cdot \mathrm{A}_{\mathrm{a}}}{\gamma_{\mathrm{a}}}+\frac{\mathrm{f}_{\mathrm{ck}} \cdot \mathrm{A}_{\mathrm{c}}}{\gamma_{\mathrm{c}}} \cdot\left[1+\eta_{\mathrm{c}} \cdot\left(\frac{\mathrm{t}}{\mathrm{D}}\right) \cdot \frac{\mathrm{f}_{\mathrm{y}}}{\mathrm{f}_{\mathrm{ck}}}\right]$

$\mathrm{Na}$ equação 2.8, $\eta_{\mathrm{c}}$ é o fator que amplifica a resistência do concreto quando confinado, definido pela equação 2.9 , e $\eta_{\mathrm{a}}$ é o fator de redução do aço, definido pela equação 2.10. No presente trabalho se considera que não há excentricidade na aplicação do carregamento. A esbeltez relativa $\bar{\lambda}$ é calculada por meio da equação 2.11 .

$$
\begin{aligned}
& \eta_{\mathrm{c}}=4,9-18,5 \cdot \bar{\lambda}+17 \cdot \bar{\lambda}^{2} \geq 0 \\
& \eta_{\mathrm{a}}=0,25 \cdot(3+2 \cdot \bar{\lambda}) \leq 1 \\
& \bar{\lambda}=\sqrt{\frac{\mathrm{N}_{\mathrm{pl}, \mathrm{Rk}}}{\mathrm{N}_{\mathrm{cr}}}}
\end{aligned}
$$

$\mathrm{Na}$ equação 2.11, $\mathrm{N}_{\mathrm{pl}, \mathrm{Rk}}$ é calculado pela equação 2.8 considerando os coeficientes parciais de segurança iguais a 1 , e $\mathrm{N}_{\text {cr }}$ é a força normal de flambagem elástica calculado segundo a equação 2.6. A capacidade resistente do pilar é calculada com a equação 2.12.

$\mathrm{N}_{\mathrm{Rd}}=\chi \cdot \mathrm{N}_{\mathrm{pl}, \mathrm{Rd}}$ 
O fator de redução associado à resistência a compressão $(\chi)$, depende da curva de dimensionamento à compressão ( $\mathrm{a}, \mathrm{b}, \mathrm{c}$ ou $\mathrm{d}$ ), determinada em função do tipo de seção transversal, do modo de instabilidade e do eixo em relação ao qual a instabilidade ocorre. Esse fator pode ser calculado com a equação 2.13 .

$$
\chi=\frac{1}{\Phi+\sqrt{\Phi^{2}-\bar{\lambda}^{2}}} \leq 1
$$

Na equação 2.13, $\Phi$ é o efeito de flambagem local, calculado por meio da equação 2.14, e $\alpha$ é um coeficiente relacionado à curva de dimensionamento à compressão que leva em conta as imperfeições iniciais. Para pilares mistos preenchidos, $\alpha=0,21$.

$$
\Phi=0,5 \cdot\left[1+\alpha \cdot(\bar{\lambda}-0,2)+\bar{\lambda}^{2}\right]
$$

\subsection{ESTRUTURAS EM SITUAÇÃO DE INCÊNDIO - breve histórico}

A ocorrência de um grande incêndio na cidade de Londres, figura 2.12, datado de 1666, foi uma das maiores catástrofes da capital inglesa, destruindo 13.200 casas, 87 igrejas, a Catedral de Saint Paul e a maior parte das construções das autoridades da cidade. Este acontecimento foi o passo inicial para se impor as primeiras exigências de proteção contra incêndio.

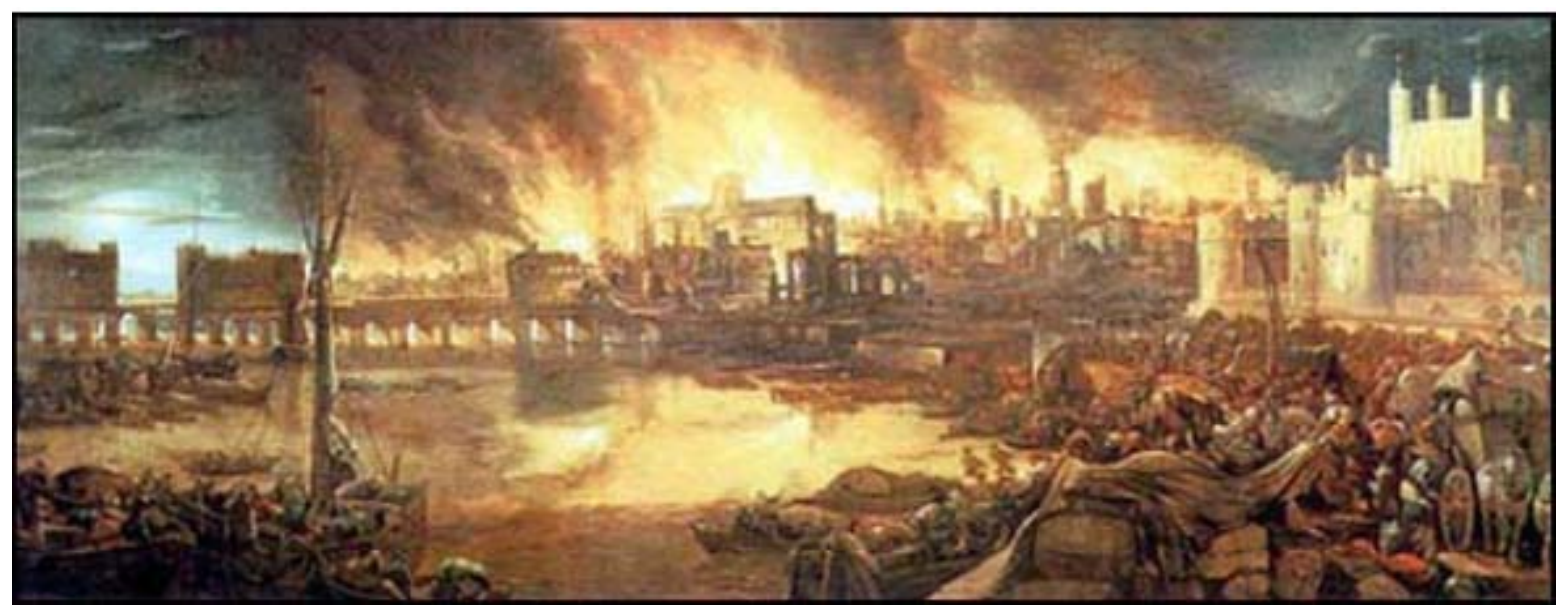

Figura 2.12 - O grande incêndio de Londres, 1966.

Fonte - http://www.luminarium.org/encyclopedia/greatfire.htm 
No ano de 1755, a cidade de Lisboa foi abalada por um terremoto, que resultou na destruição quase completa da cidade. O sismo foi seguido de um maremoto e de vários focos de incêndio, deixando quase dez mil vítimas fatais.

Os maiores desastres no Brasil fazem parte de uma história mais recente. No ano de 1972, um grande incêndio ocorreu no Edifício ANDRAUS, ilustrado na figura 2.13a, com 31 andares, que reunia escritórios empresariais no centro da cidade de São Paulo. Acredita-se que a causa mais provável do acidente foi uma sobrecarga no sistema elétrico, destacando-se, porém, que o edifício não possuía sistemas de segurança, como chuveiros de incêndio, sinalização de saídas de emergência e alarme de detecção automática.

Dois anos depois, outro grande incêndio destruiu 14 dos 25 pavimentos, além de 6 pavimentos de subsolo do Edificio JOELMA, ilustrado na figura 2.13b, também em São Paulo. Assim como no caso anteriormente citado, a causa desse incêndio foi uma sobrecarga elétrica. Uma das características desse edifício era a escada em forma triangular situada no centro dos pavimentos, fato este que dificultou sua desocupação. O telhado de placas de cimento amianto impossibilitou o pouso de helicópteros de resgate. Internamente, havia muitas divisões de madeira e cortinas, facilitando a propagação do fogo para outros ambientes.

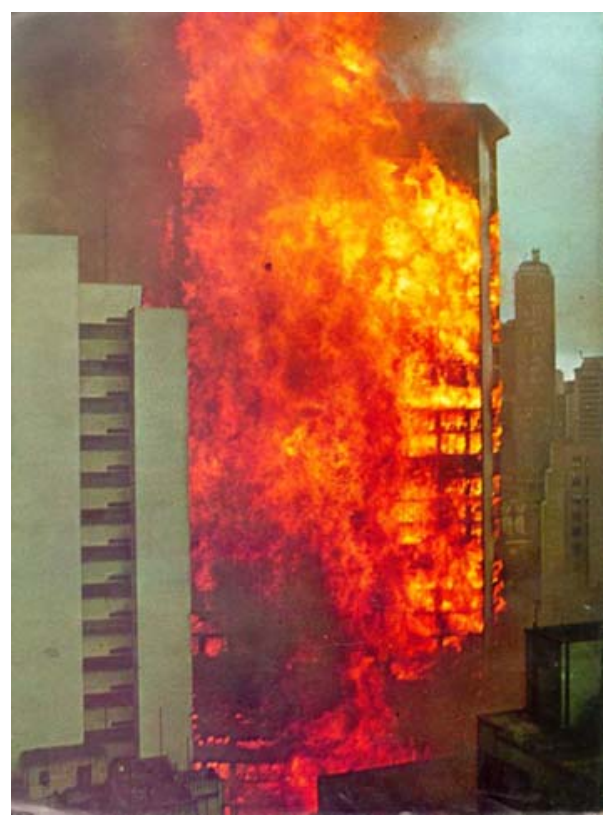

(a)

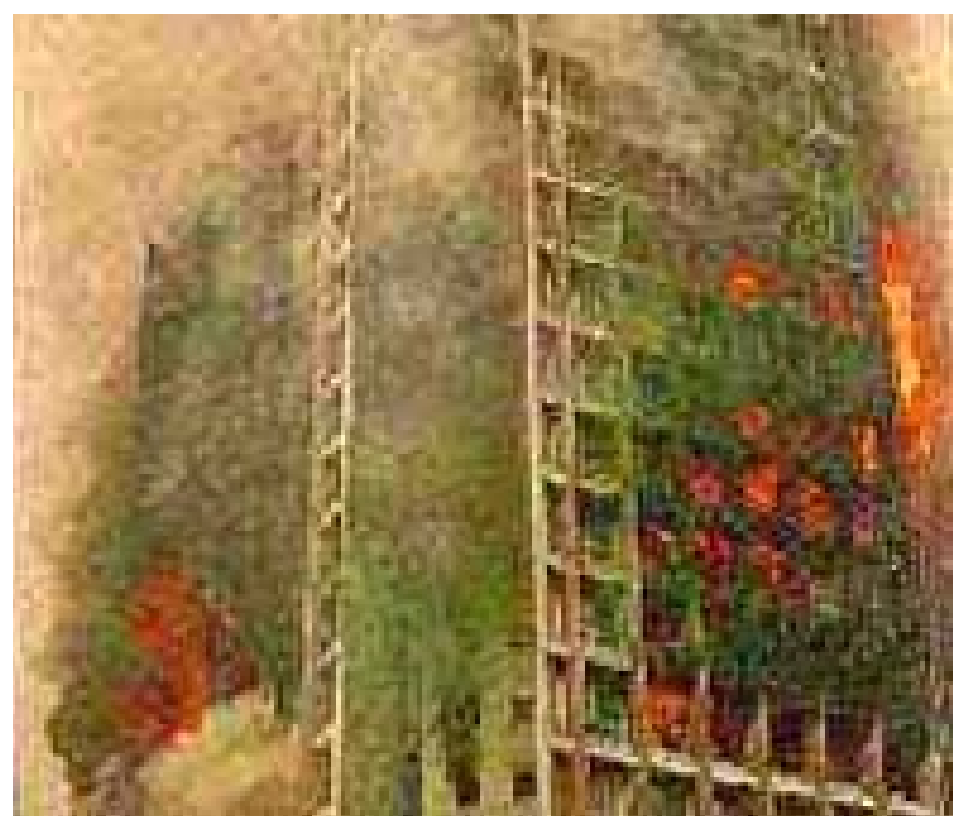

(b)

Figura 2.13 - Fotos dos incêndios ocorridos nos edifícios: (a) Andraus e (b) Joelma

Fonte - http://www.lmc.ep.usp.br/people/valdir/?page id=16 http://www.bombeirosemergencia.com.br/Incêndio\%20Edifício\%20Joelma/base1.html. 
Neste mesmo ano, o edifício da Caixa Econômica Federal, no Rio de Janeiro teve perdas materiais significativas em decorrência do incêndio que destruiu 19 dos 31 andares de escritórios, porém, não houve vítimas fatais. Embora tenha havido chuveiros automáticos em parte dos andares, os forros e acabamentos eram combustíveis. A figura 2.14 ilustra alguns dos notáveis casos de incêndio da história recente.

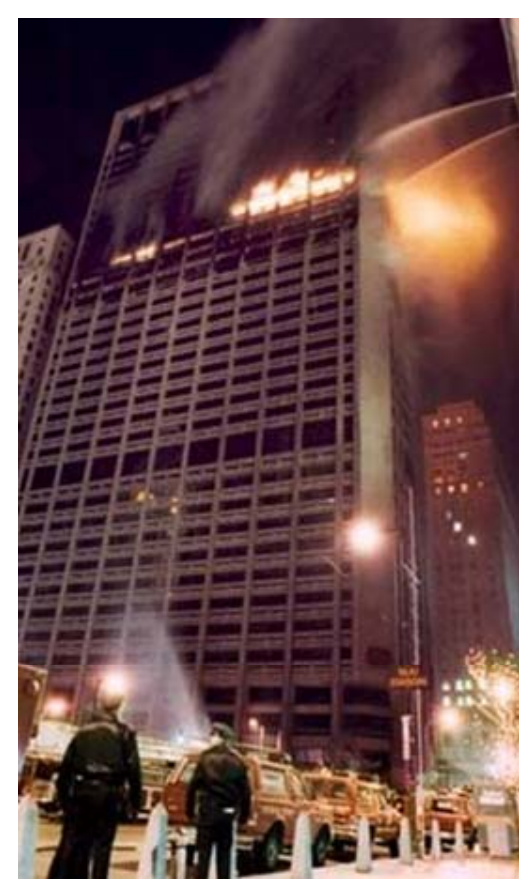

(a)

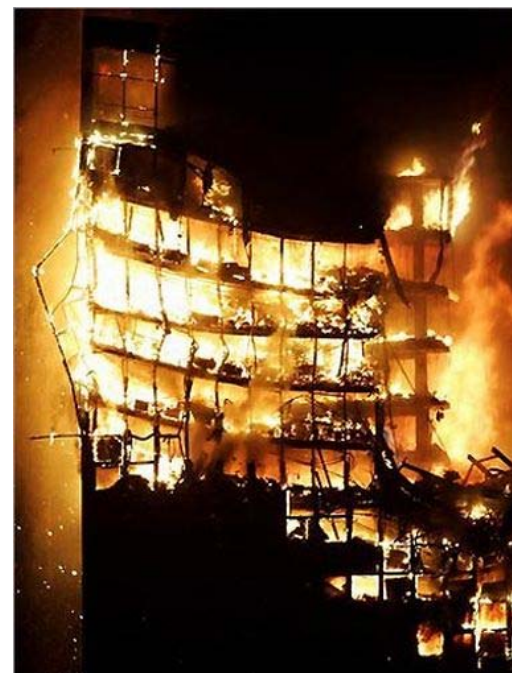

(d)

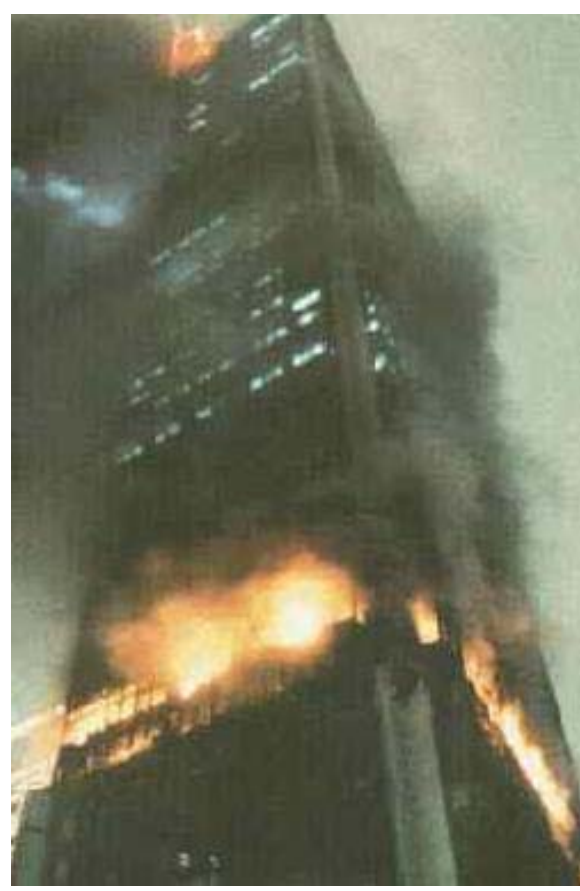

(b)

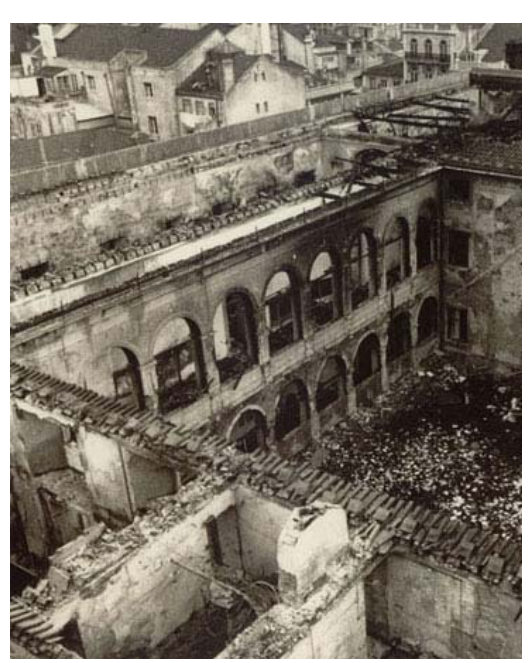

(e)

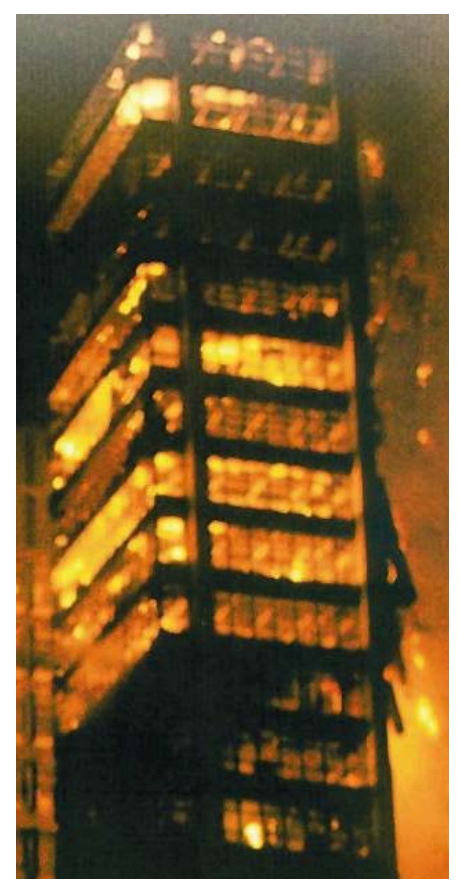

(c)

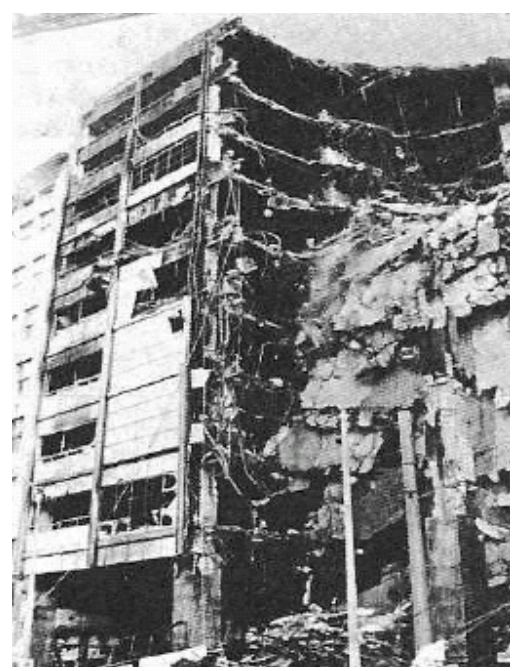

(f)

Figura 2.14 - (a) Meridian Plaza na Filadélfia - EUA, em 1991, (b) Edifício do Firts Interstate Bank em 1988; (c) Edifício da CESP, em São Paulo - 1987; (d) Torre Windsor, Madrid, 2005, (e) Museu Colonial de Lisboa; (f) Edifício Katrantzos Sport, em Atenas, na Grécia 1987; fontes (a) http://911 research.wtc7.net/talks/b7/history.html, (b) http://911research.wtc7.net/cache/wtc/analysis/compare/lafire firstinterstate.htm, (c) e (d) http://www.lmc.ep.usp.br/people/valdir/?page id=16, (e) http://www.triplov.com/politecnica/fotos_museu bocage/pages/a incendio.htm e (f) http://www.fpemag.com/archives/article.asp?issue $\mathrm{id}=27 \& \mathrm{i}=153$. 
Diante desses fatos, e de outros não citados no presente texto, vêm se desenvolvendo pesquisas relacionadas ao tema estruturas em situação de incêndio e estes estudos permitem uma compreensão mais cuidadosa do assunto para a aplicação dos resultados na engenharia.

\subsection{ACÃO TÉRMICA NAS ESTRUTURAS - Contexto mundial}

No contexto mundial, as primeiras exigências de proteção contra incêndio surgiram por volta de 1666, com a ocorrência de um grande incêndio na cidade de Londres, já apresentado no item 2.3. Porém, este tema só começou a ser realmente estudado em meados do século 19 e início do século 20.

Conforme mencionado em CLARET (2000), o estabelecimento das primeiras normas para testes de resistência ao fogo deve-se à ASTM - American Society for Testing and Materials que, em 1911, estabeleceu a norma "Standard tests for fireproof constructions". Em 1932, a British Standard Institution publicou a norma BS 476, intitulada "Fire tests on buildings materials and structures", a qual, com as devidas revisões e ampliações, ainda hoje é bastante utilizada.

Nos últimos anos, atenções têm sido direcionadas para o desenvolvimento de procedimentos mais racionais de dimensionamento, com base em ensaios mais realísticos com vistas à investigação do comportamento de estruturas de edifícios durante as condições de incêndio. Um dos mais recentes estudos desenvolvidos com esse propósito foi realizado entre os anos de 1995 e 1996, pela British Steel, hoje conhecida como CORUS, que executou quatro ensaios com ênfase em incêndio, em uma estrutura construída em escala real (com 8 pavimentos) localizada na cidade de Cardington, Reino Unido.

A figura 2.15 ilustra, respectivamente, o Laboratório de Cardington, situado na Inglaterra (utilizado para a execução dos ensaios em estruturas em escala real submetidas a temperaturas elevadas) e o sistema estrutural, o qual foi citado anteriormente, submetido ao incêndio. A figura 2.16 ilustra a configuração deformada dos elementos estruturais do edifício da figura 2.15, após a ocorrência do incêndio.

A BHP, um dos maiores fabricantes de aço da Austrália vem, ao longo dos anos, pesquisando soluções em engenharia de incêndio para as construções em aço. Ensaios de resistência ao fogo, em escala real, têm sido executados no Laboratório de Melbourne. A figura 2.17 ilustra um dos testes de resistência ao fogo executado em escala real. 

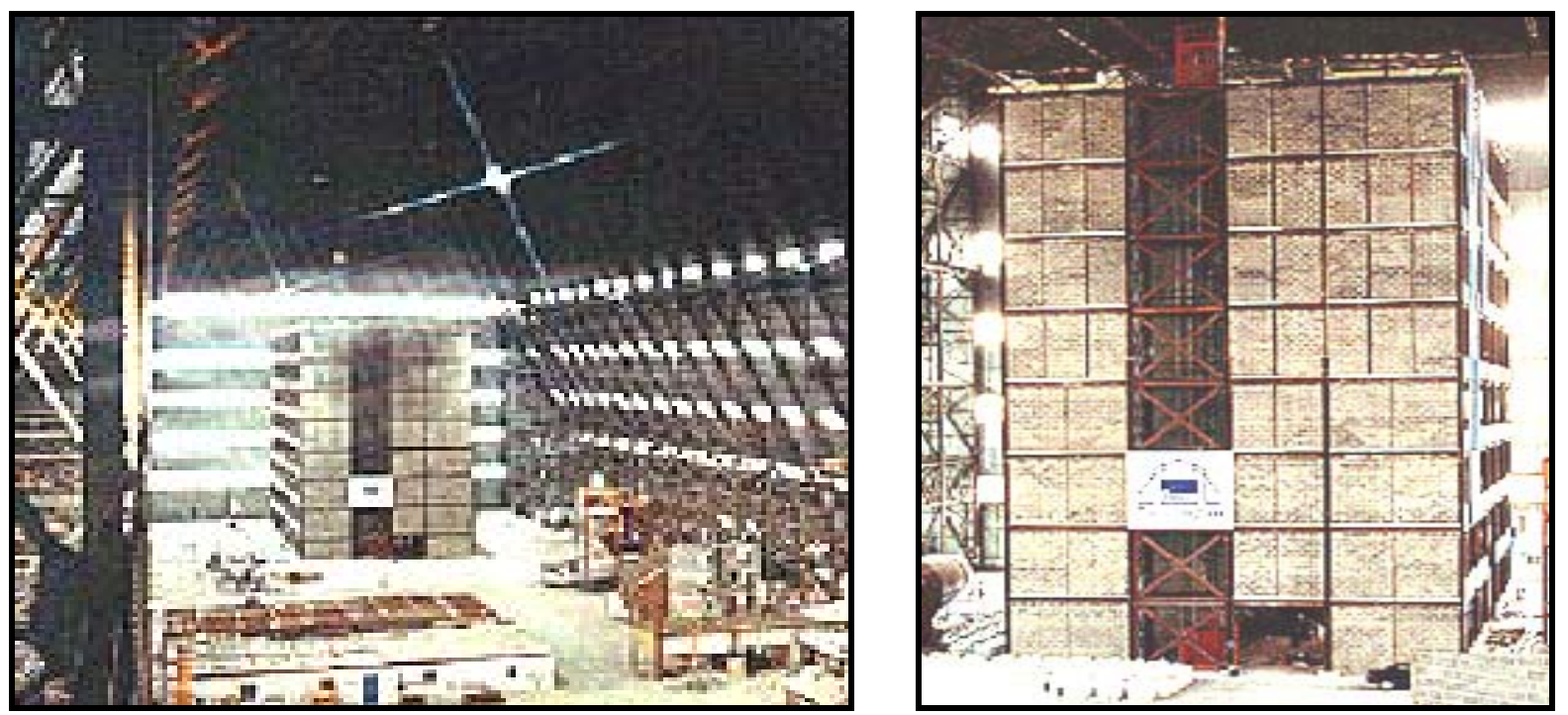

Figura 2.15 - Laboratório Cardington, Inglaterra: Estrutura de 8 (oito) pavimentos em escala real. Fontes: http://fire.nist.gov/bfrlpubs/fire02/art081.html

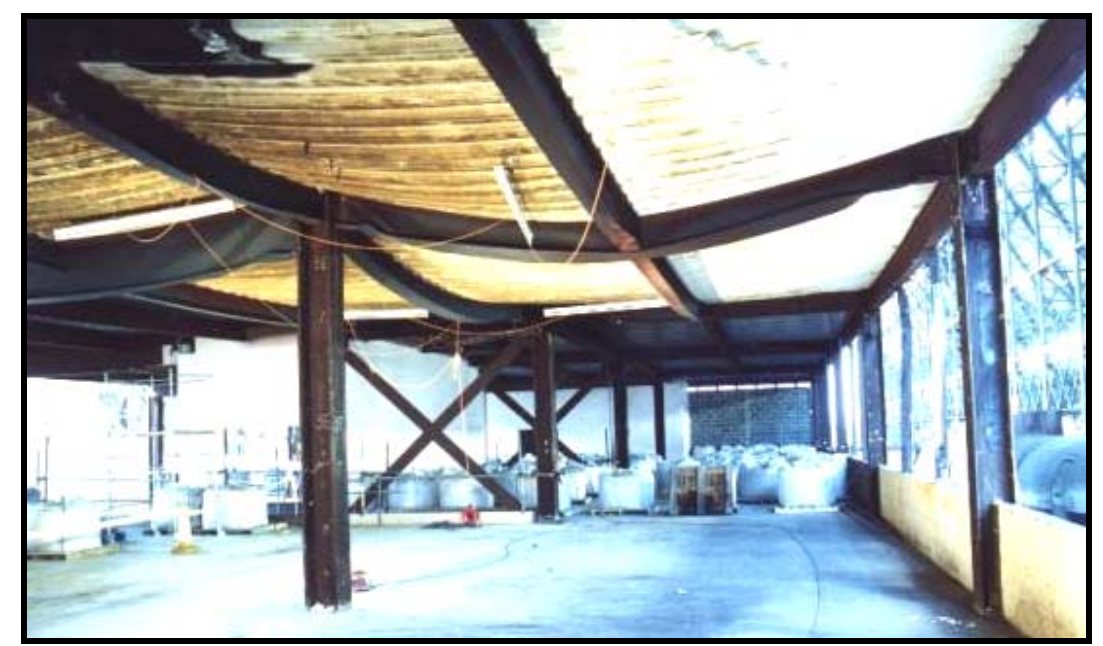

Figura 2.16 - Vista geral de um dos pavimentos e configuração deformada dos elementos estruturais após o incêndio. Fonte: LAMONT (2001).

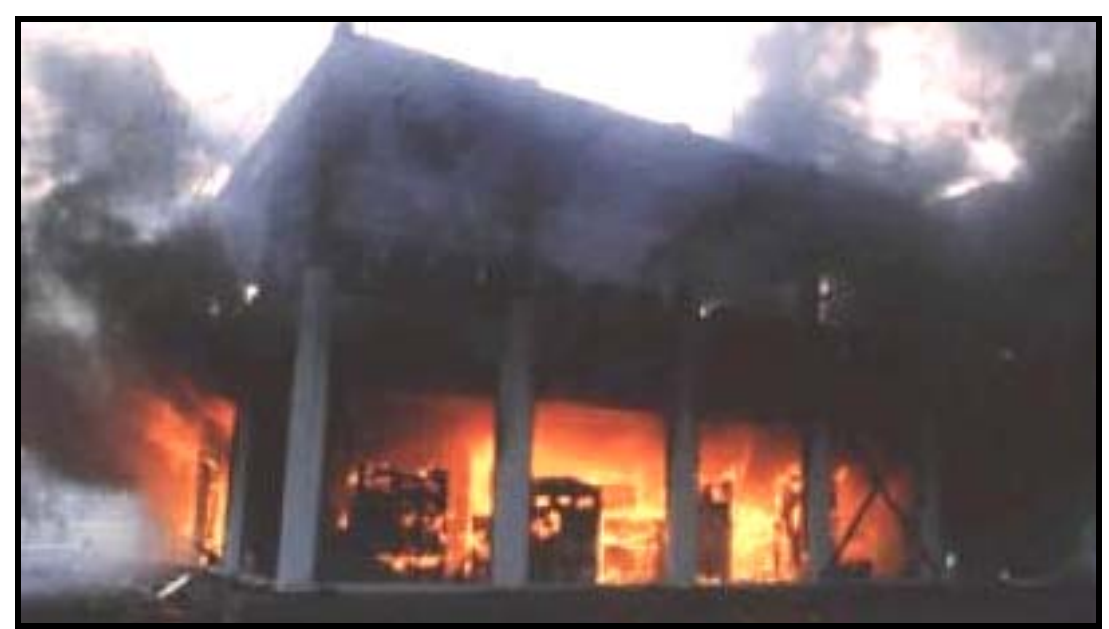

Figura 2.17 - Teste de resistência ao fogo executado pela BHP na Austrália. Fonte: http://members.fortunecity.com/911/fire/SCI.htm 


\subsection{ACÃO TÉRMICA NAS ESTRUTURAS - Contexto nacional}

Após os incêndios ocorridos nos Edifícios Andraus (1972), da Caixa Econômica do Rio de Janeiro (1974) e Joelma (1974), conforme apresentado no item 2.3, atenções foram direcionadas a este assunto, tendo em vista que no Brasil, até 1970, todos os regulamentos utilizados como, por exemplo, os Códigos do Corpo de Bombeiros e de Obras Civis, haviam sido adaptados de seguradoras americanas, e as exigências para instalações de segurança não eram muito rigorosas.

Com relação às Estruturas de Concreto, em 1980 foi publicada a ABNT NBR 5627 "Exigências particulares das obras de concreto armado e protendido em relação à resistência ao fogo”, Em 1993 foi criado o decreto 38069 no Estado de São Paulo, que estabelecia especificações para proteção contra incêndio. Em 1994, o Corpo de Bombeiros publicou a Instrução Técnica IT-CB-0233/94, que determinava o tempo de resistência ao fogo para vários tipos de estruturas de aço.

A norma ABNT NBR 5627:1980 foi cancelada em 2001 por apresentar valores de cobrimentos e dimensões mínimas, que inviabilizavam economicamente a execução das obras de concreto, e foi substituída pelo Anexo B do texto de revisão da NBR 6118, versão de 2001. Esse anexo foi suprimido na versão final da NBR 6118:2003 "Projeto de estruturas de concreto - Procedimento", e se tornou texto-base para a atual norma brasileira ABNT NBR 15200:2004, atualmente em vigor e intitulada "Projeto de estruturas de concreto em situação de incêndio".

Com relação às estruturas de aço e mistas de aço e concreto, conforme descrito em REGOBELLO (2007), em 1995 representantes do meio universitário e do corpo técnico, contando com a participação do Corpo de Bombeiros/SP, dos fabricantes de estruturas metálicas e de materiais de revestimento contra fogo, de representantes das siderúrgicas, de representante do IPT, etc., elaboraram as normas brasileiras ABNT-NBR 14323:1999 intitulada "Dimensionamento de estruturas de aço de edificios em situação de incêndio" e ABNT-NBR 14432:2000, intitulada "Exigências de resistência ao fogo de elementos construtivos das edificações”, em que são apresentados critérios para dimensionamento de elementos isolados e determinação do tempo que as estruturas devem resistir antes do colapso (tempo requerido de resistência ao fogo - TRRF), respectivamente.

Vale destacar que no Capítulo 3 serão apresentados maiores detalhes com relação às prescrições apresentadas na norma ABNT NBR 14323 com vistas ao dimensionamento de elementos de aço e mistos de aço e concreto. 
Nos últimos anos, diversos trabalhos têm sido desenvolvidos com relação às estruturas de aço e de concreto em situação de incêndio, com o objetivo de se desenvolver métodos mais racionais de dimensionamento com base em modelos mais realísticos de incêndio e com critérios de segurança mais adequados para o cotidiano brasileiro. Tendo em vista que no Brasil ainda não existem fornos de grandes dimensões para a realização de estudos experimentais de sistemas estruturais em escala real, pesquisas no contexto de estruturas em situação de incêndio são desenvolvidas predominantemente no campo de análises numéricas.

\subsection{PILARES MISTOS DE AÇO PREENCHIDOS COM CONCRETO EM SITUAÇÃO DE INCÊNDIO}

Em resposta aos aspectos apresentados nos itens anteriores, bem como com relação àqueles que serão também comentados no capítulo 3 , se conclui que ao se conceber o projeto de uma dada estrutura de interesse se faz necessária uma verificação da mesma em situação de incêndio, para fins de dimensionamento, se podendo considerar ainda a utilização ou não de elementos de proteção ao fogo, com a intenção de reduzir os danos a custos aceitáveis.

Tendo em vista a importância de os elementos estruturais resistirem aos efeitos do fogo por um período de tempo suficiente para garantir a desocupação, com segurança estrutural, do ambiente em chamas e, consequentemente da edificação, estudos voltados para esse tema tem sido realizados por pesquisadores em várias instituições para as estruturas em situação de incêndio, inclusive com foco direcionado particularmente aos pilares mistos de aço preenchidos com concreto, conforme descrito nos parágrafos que se seguem.

\section{- KODUR (1998)}

De acordo com a referência, o comportamento do pilar misto preenchido, quando exposto ao fogo, depende do nível de temperatura e da duração do incêndio, conforme demonstrado na figura 2.18 para um típico pilar misto preenchido (usado em edifícios) exposto ao fogo, em um forno especialmente confeccionado para ensaios sob condições de incêndio, conforme figura 2.19 .

Conforme descrito na referência em questão, durante os estágios iniciais de exposição ao fogo, o aço resiste a maior parcela da carga aplicada, tendo em vista o fato de seção de aço se expandir mais rapidamente que a do núcleo de concreto. Com o aumento da temperatura, a seção de aço começa a se deformar mais por conta da diminuição da resistência 
ao escoamento e do módulo de elasticidade longitudinal, quando então o pilar subitamente se contrai após 20 a 30minutos de exposição. Essa contração é freqüentemente acompanhada por flambagem local da seção de aço.

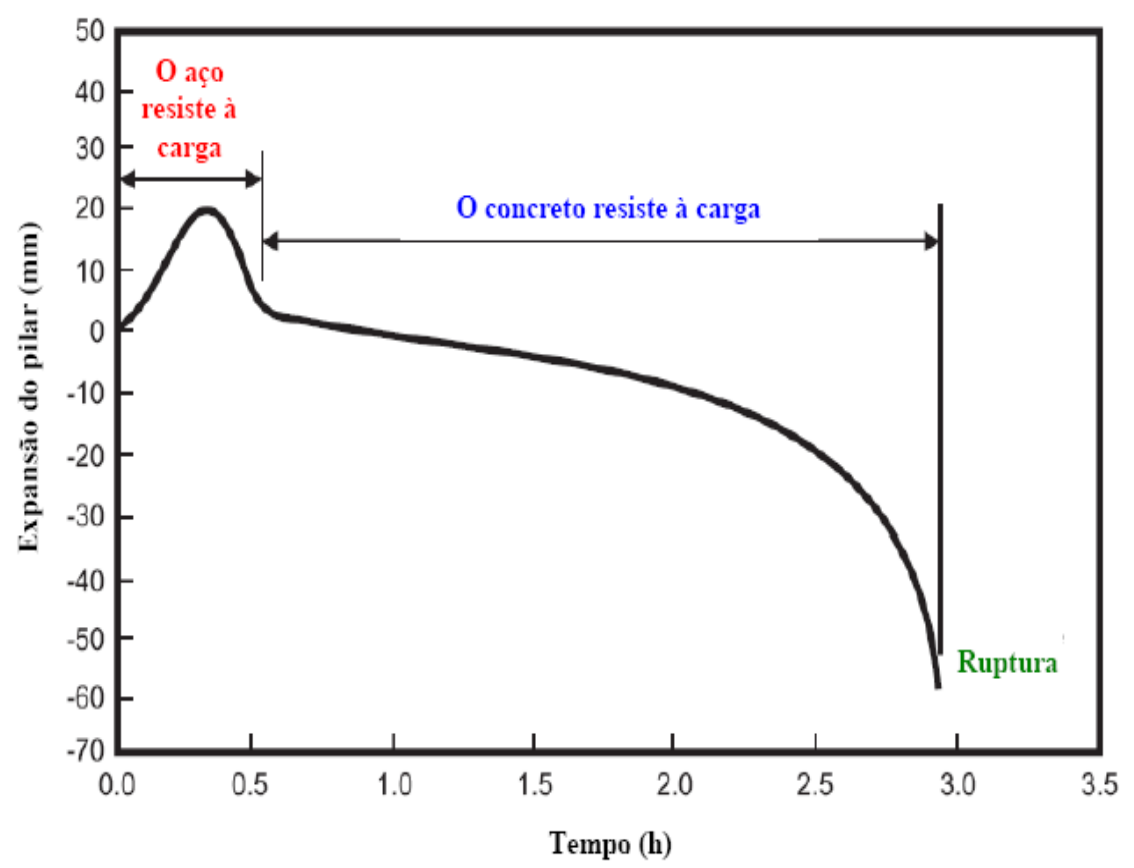

Figura 2.18 - Expansão do pilar misto preenchido durante a exposição ao fogo.

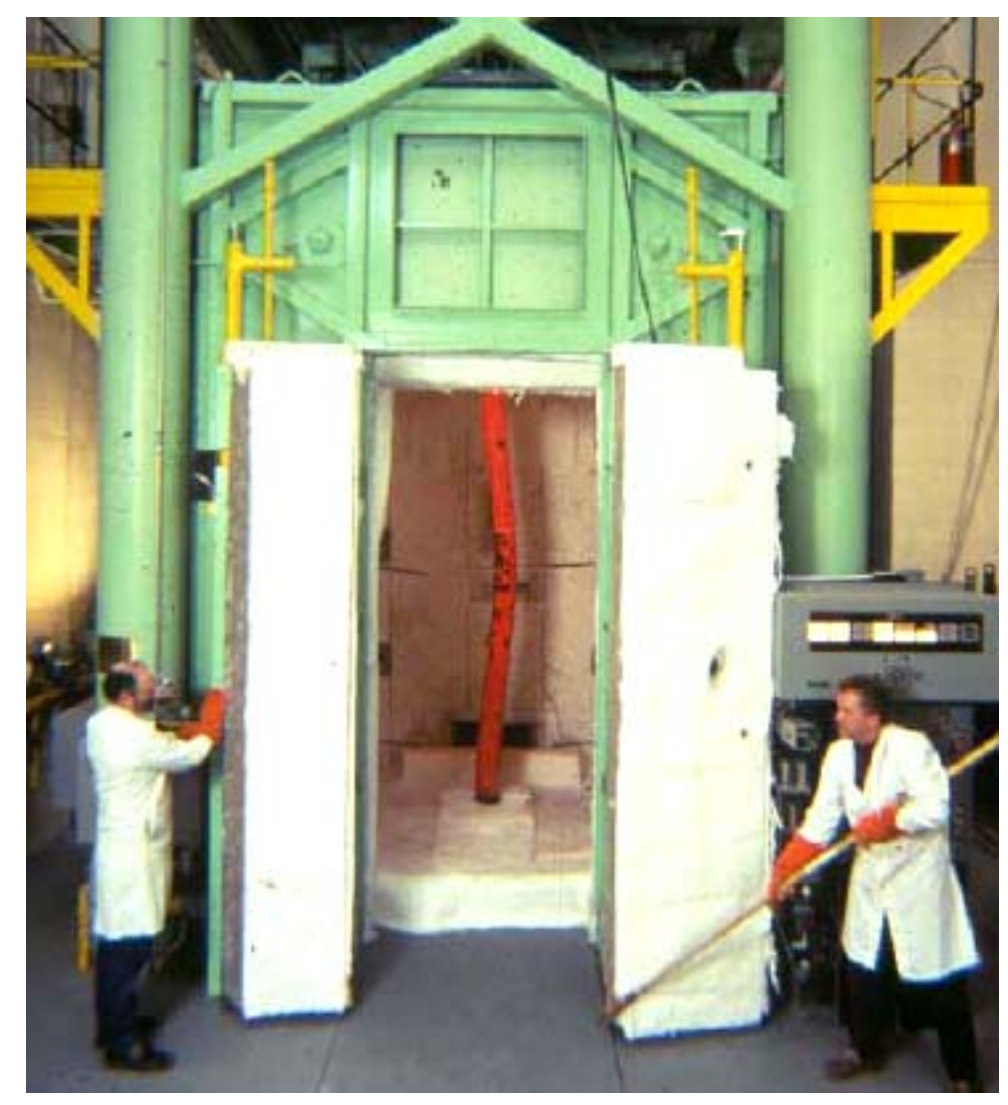

Figura 2.19 - Deformação no pilar misto preenchido logo após o ensaio em um forno. 
A partir desse estágio, o concreto passa a receber cada vez mais carga, devido ao aumento da temperatura, tendo em vista que a contribuição do tubo de aço na resistência do pilar misto vai diminuindo em resposta à elevação da temperatura. $\mathrm{O}$ concreto, devido à sua baixa condutividade térmica e alto calor específico, perde resistência mais lentamente que o aço e, praticamente, assume a responsabilidade de resistência ao fogo do pilar para esse estágio do ensaio.

A resistência do concreto também diminui com o tempo e, num certo estágio, quando o núcleo de concreto não pode mais resistir à carga, a ruptura acontece tanto por flambagem global quanto por compressão. O tempo que o concreto é capaz de resistir, sob essas condições (curva padrão tempo vs. temperatura), é mostrado na figura 2.18.

\section{- HAN (2001)}

Esse trabalho apresenta um estudo sobre o desempenho dos pilares do tipo CFST em situação de incêndio com a aplicação do MEF (Método dos Elementos Finitos) para o cálculo do campo térmico, bem como um modelo teórico para o cálculo das deformações e resistência ao fogo. Analisa também a influência de diversos parâmetros, tais como: diferentes valores de resistência dos materiais, variação nas dimensões da seção transversal e da excentricidade do carregamento.

O modelo teórico desse trabalho foi utilizado para fornecer dados sobre as medidas necessárias de proteção contra incêndio para os pilares mistos no edifício SEG Plaza, em Shen Zhen-City, Sul da China, com pilares de até $1600 \mathrm{~mm}$ de diâmetro, $28 \mathrm{~mm}$ de espessura e $4800 \mathrm{~mm}$ de altura, conforme ilustra a figura 2.20 extraída da mesma referência.
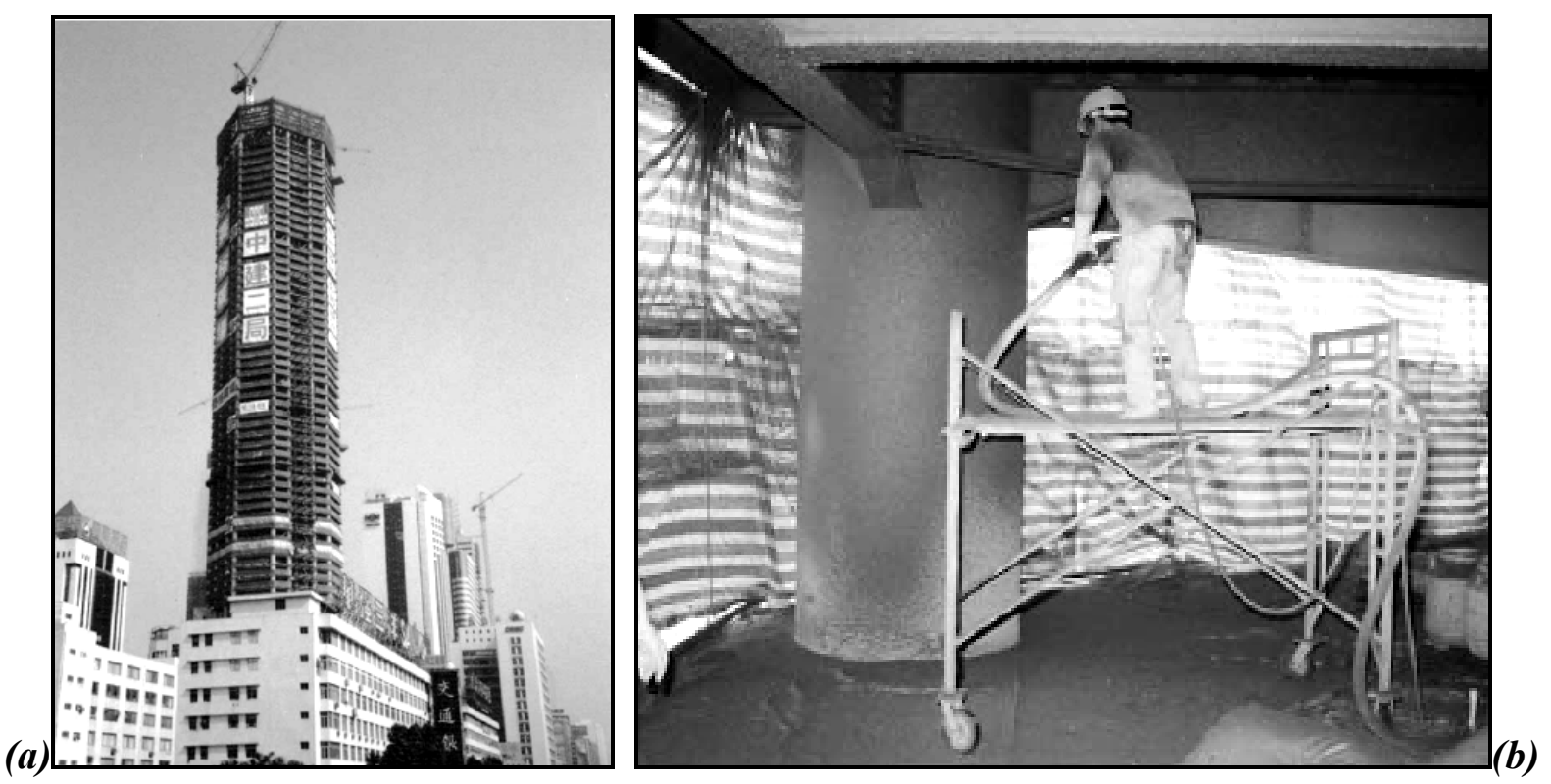

Figura 2.20 - (a) Edifício SEG Plaza e (b) Detalhe do pilar. 
O modelo foi utilizado para estimar a resistência ao fogo de CFST de edifícios reais, e possibilitou concluir que as dimensões e esbeltez dos pilares mistos preenchidos influenciam na resistência ao fogo, sugerindo que o método analítico é capaz de predizer a resistência ao fogo de pilares mistos preenchidos.

\section{- ZHA (2003)}

Nessa referência é apresentada a aplicação do Método dos Elementos Finitos (MEF) para determinar a resistência ao fogo dos pilares mistos preenchidos, submetidos ao incêndio por todos os lados, tendo em vista que com o desenvolvimento do MEF é possível prever com maior precisão o colapso dos pilares em altas temperaturas.

A distribuição da temperatura foi determinada pelo código computacional FIRES-T, o qual depende basicamente das propriedades térmicas dos materiais como dados de entrada. O cálculo da resistência ao fogo para os pilares mistos envolveu a determinação da distribuição da temperatura, a deformação dos elementos (expansão e compressão) e a redução na resistência em resposta à elevação da temperatura.

Para fins de análise termo-estrutural, foi utilizado o código computacional DYNA $3 D$, para análise em campo tridimensional por meio de elementos finitos não-lineares. Foi considerada a análise transiente, bem como utilizado $1 / 4$ de simetria do modelo completo com excentricidade na geometria. Os comportamentos do aço e do concreto, enquanto material, foram assumidos como isotrópicos.

A análise dos resultados indica proximidade desses com aqueles calculados por meio do EUROCODE 4 (via Método Tabular), sendo o colapso causado principalmente pela instabilidade global. A variação do diâmetro do pilar indicou que, quanto maior a seção, maior é a resistência ao incêndio. Em contrapartida, o aumento da espessura do tubo resulta na diminuição da sua resistência ao incêndio. Também se conclui que o colapso é causado pela combinação da redução da resistência dos materiais devido à elevação da temperatura, da perda da capacidade resistente na região exposta ao incêndio e da instabilidade do elemento.

\section{- HAN et al (2003)}

O referido trabalho apresenta estudos experimentais com pilares mistos preenchidos com concreto submetidos a elevadas temperaturas, os quais foram ensaiados com e sem revestimento contra o fogo, bem como submetidos a carregamentos axiais ou excêntricos.

De acordo com o relato da série de ensaios experimentais realizados nos pilares mistos, o objetivo foi avaliar a influência de parâmetros como o diâmetro, o tipo de 
carregamento, a espessura dos revestimentos e a resistência dos materiais aço e concreto, com vistas ao desenvolvimento de um modelo matemático a ser utilizado para determinar a resistência ao fogo. Os autores destacam os benefícios dos pilares mistos em relação aos sistemas tradicionais em aço ou em concreto armado, o aumento da resistência mecânica e ao fogo, o menor risco da ocorrência do "spalling", a ausência de fôrmas, entre outros aspectos.

O programa experimental foi composto pelo ensaio de 13 pilares mistos, oito deles sem revestimento contra fogo e cinco com a aplicação de revestimento contra fogo com várias espessuras. Os pilares possuíam altura total de $3810 \mathrm{~mm}$ e seções transversais com até 478 mm de diâmetro, incluindo chapas nas duas extremidades (para garantir que o carregamento fosse aplicado uniformemente no conjunto aço-concreto), dois furos semi-circulares de 20 mm de diâmetro em cada extremidade para garantir a saída do vapor como conseqüência do aquecimento da água, existente na matriz do concreto, durante a elevação de temperatura

Para fins comparativos, é apresentada na mesma referência uma relação dos edifícios chineses que utilizam pilares mistos preenchidos, conforme tabela 2.5.

Tabela 2.5 - Edifícios chineses constituídos de pilares mistos preenchidos.

\begin{tabular}{|c|c|c|c|c|c|c|}
\hline Edifício & Cidade & $\begin{array}{c}\mathrm{n}^{\circ} \\
\text { pavimentos }\end{array}$ & $\begin{array}{c}\text { Altura } \\
\text { (m) }\end{array}$ & $\begin{array}{l}\text { Seção } \\
(\mathrm{mm})\end{array}$ & Ano & $\begin{array}{l}\text { Tipo de } \\
\text { seção }\end{array}$ \\
\hline Communication Center & Quanzhou & 16 & 63.5 & 800 & 1990 & Circular \\
\hline Lu Hai & Shanghai & 25 & 84.7 & 300 & 1999 & Circular \\
\hline Fu Kang & Xiamen & 27 & 86.5 & 1000 & 1994 & Circular \\
\hline Jin Yuan & Xiamen & 30 & 96 & 900 & 1995 & Circular \\
\hline Post Office & Nanan & 30 & 99 & 720 & 1997 & Circular \\
\hline World Square & Chongqin & 33 & 110.6 & 800 & 1998 & Circular \\
\hline World Center & Guangzhou & 36 & 116.3 & 1200 & 1995 & Circular \\
\hline Economic Building & Beijing & 36 & 120 & 1400 & 1998 & Circular \\
\hline Jin Wan Bo & Tianjin & 40 & 137 & 1020 & 1995 & Circular \\
\hline Post Center & Shenzhen & 48 & 180 & 1200 & 2000 & Circular \\
\hline New China Center & Guangzhou & 56 & 201.8 & 1400 & 2000 & Circular \\
\hline Jin Guang Square & Guangzhou & 60 & 220 & 1600 & 2000 & Circular \\
\hline Seg Plaza & Shenzhen & 76 & 291.6 & 1600 & 1999 & Circular \\
\hline Queen's Road Central & Hong Kong & 69 & 292 & $800 \times 800$ & 1997 & Quadrada \\
\hline Di Wang & Shenzhen & 68 & 384 & $1000 \times 1000$ & 1996 & Quadrada \\
\hline
\end{tabular}


O aquecimento do forno seguiu a curva padrão proposta pela ISO 834, e o nível de carregamento adotado em situação de incêndio foi de 0,77 da normal resistente de cálculo em temperatura ambiente, calculada pela norma chinesa.

Conforme descrito, o tubo de aço começa a expandir axialmente no início da fase de aquecimento, passando a absorver a maior parte da carga aplicada, fazendo com que a tensão de compressão no núcleo de concreto diminua. Posteriormente, com o aumento da temperatura, o aço passa a se deformar localmente (flambagem local) e a carga é gradualmente transferida para o concreto. Em um estágio final de carregamento o perfil de aço não consegue mais confinar o concreto e a amostra rompe geralmente de forma brusca.

Os resultados experimentais mostram que, dentre os parâmetros analisados, o diâmetro da seção transversal e a esbeltez tem grande influência na resistência ao fogo, ou seja, a resistência aumenta com o aumento do diâmetro e diminui com o aumento da esbeltez, conforme esquematiza a figura 2.21, em que $S I$ é o índice de resistência associado ao pilar.

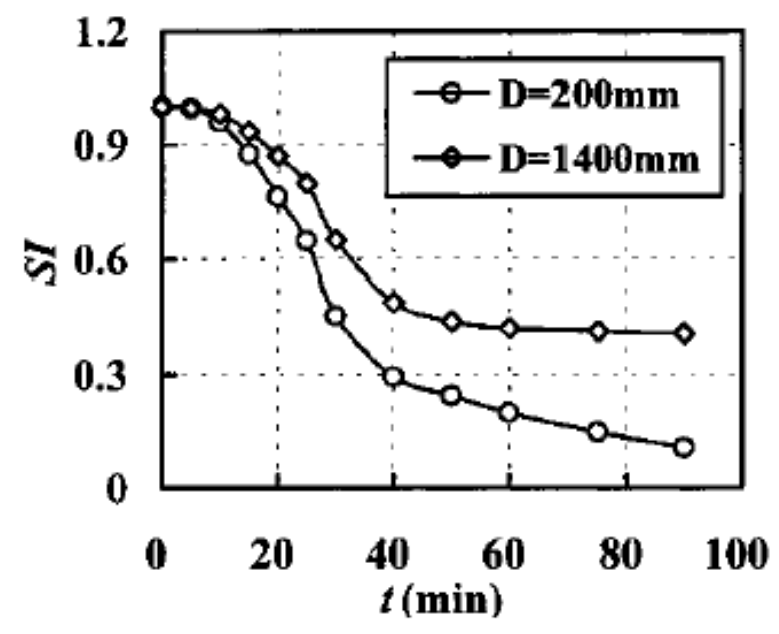

(a)

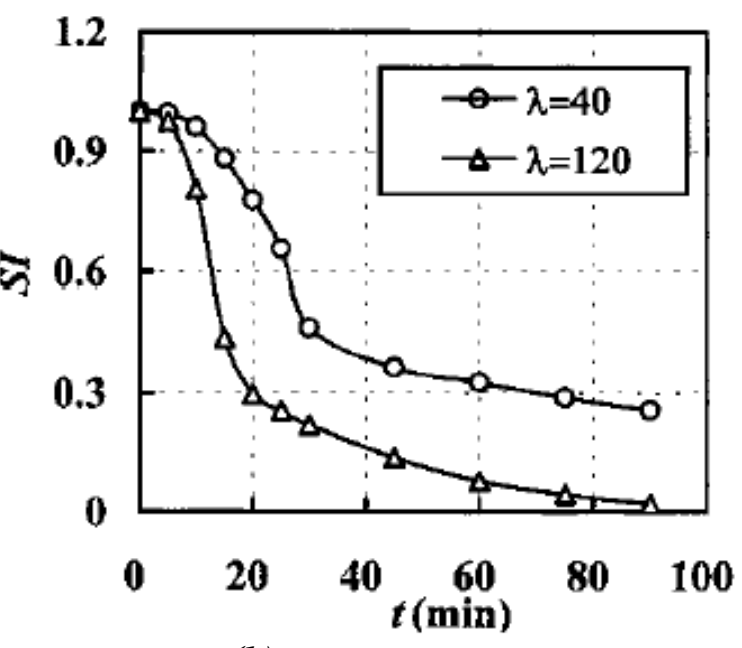

(b)

Figura 2.21 - Resistência relativa em relação: (a) ao diâmetro e (b) à esbeltez.

As variações na espessura, excentricidade, resistência dos materiais aço e concreto, têm influência moderada sobre a resistência ao fogo da amostra. Os aumentos da espessura do tubo de aço e da excentricidade de carga resultam numa pequena diminuição da resistência ao fogo da amostra, enquanto que o aumento na resistência dos materiais aço e concreto provocam um pequeno aumento desta.

O modelo analítico apresenta bons resultados, mostrando-se adequado para o cálculo da resistência ao fogo dos pilares mistos preenchidos com concreto e para a determinação da espessura da camada de proteção, e a principal vantagem é quando se trata de pilares mistos com grandes dimensões. 
Os limites para a utilização do modelo matemático são: tempo ( $\mathrm{t} \leq 180 \mathrm{~min}$ ), diâmetro $(\mathrm{D}=150 \mathrm{~mm}$ a $2000 \mathrm{~mm})$, índice de esbeltez $(\lambda=15$ a 80$)$, resistência ao escoamento do aço $(f y=200$ a $500 \mathrm{MPa})$, resistência à compressão do concreto $\left(f_{\text {ck }}=20\right.$ a 60 $\mathrm{MPa})$ e excentricidade ( $\alpha=0,04$ a 0,2$)$. A mesma referência destaca o fato de que durante os ensaios o comportamento dúctil dos pilares favoreceu o controle dos ensaios.

\section{- HAN et al (2005)}

Nesse trabalho descreve-se a realização de ensaios de compressão e flexão em pilares mistos curtos de seções circulares e seções quadradas preenchidas por concreto, realizados com a exposição das amostras à curva de incêndio padrão (ISO 834) por 90 minutos e, em seguida, resfriados naturalmente com a finalidade de se obter a resistência residual.

Ao final, são comparados os resultados obtidos experimentalmente com os resultados de resistência calculados em temperatura ambiente, sendo que para o cálculo da resistência em temperatura ambiente foram utilizadas várias normas, dentre elas o AISC e o EC4. Foram verificados os seguintes aspectos: o modo de falha resulta idêntico àquele observado em temperatura ambiente, a ruptura ocorreu de forma dúctil, um aumento da resistência e ductilidade do núcleo de concreto e uma redução da flexão local do tubo de aço.

\section{- YIN et al. (2006)}

No referido trabalho foram apresentados estudos analíticos do comportamento de pilares mistos preenchidos com concreto, com seções dos tipos quadrada e circular, carregados axialmente e expostos a elevadas temperaturas.

O cálculo da resistência ao incêndio e a comparação dos resultados sugerem (ou mesmo indicam) que pilares mistos de seção circular apresentam resistência ao incêndio ligeiramente superior quando comparados àqueles de seção quadrada, ainda que para seções de mesma área, provavelmente pelo fato de o pilar com seção quadrada possui maior perímetro $(\cong 1,13$ vezes) se comparado com o circular, bem como pelo fato de que quando suas quatro faces são expostas ao fogo, essas absorvem mais calor e seu campo de temperatura resulta superior em intensidade com relação ao pilar com seção circular.

As investigações sobre o desempenho de pilares do tipo CFST (concrete filled steel tube) submetidos a elevadas temperaturas e a correspondente resistência ao fogo só começou no início dos anos 1990. A referência apresenta um modelo de análise não-linear para predizer 
a resistência ao fogo de pilares do tipo CFST. O modelo desenvolvido tem por base as curvas de tensão-deformação para temperaturas elevadas.

Como a análise estrutural em incêndio resulta, em gera,l bastante complexa, pois envolve muitas variáveis (aumento da temperatura, duração do incêndio, distribuição da temperatura nos elementos estruturais, mudança nas propriedades dos materiais e a influência do carregamento nos sistemas estruturais), o processo foi dividido em três etapas: exposição

\section{ao fogo, transferência de calor dos gases para a estrutura e a resposta estrutural.}

$\mathrm{Na}$ mesma referência também se sugere que a capacidade resistente do pilar misto exposto ao fogo depende da espessura do tubo de aço. Neste caso, quanto menor a espessura do tubo mais lenta será a transferência de calor para o núcleo de concreto e, conseqüentemente, a perda de capacidade resistente do pilar também será mais lenta. Para um pilar circular com raio igual a $250 \mathrm{~mm}$ e espessura do tubo igual a $10 \mathrm{~mm}$, a capacidade resistente é reduzida em $68 \%$ se exposto ao fogo por duas horas, enquanto que, para um pilar de mesmo diâmetro com espessura do tubo igual a $30 \mathrm{~mm}$, a capacidade será reduzida em $86 \%$ após as mesmas duas horas de exposição.

\section{- DING E WANG (2008)}

Nessa referência são apresentados resultados de modelagem numérica em contexto térmico e também termo-estrutural de pilares mistos de seção transversal quadrada preenchida com concreto, em situação de incêndio com base na curva de incêndio-padrão e sem proteção ao fogo, utilizando o pacote computacional ANSYS. A figura 2.22, extraída da mesma referência, apresenta malhas de elementos finitos utilizadas na modelagem citada.

Segundo a mesma referência, a maioria dos pesquisadores assume como hipótese simplificadora, durante a exposição ao fogo, o contato perfeito na interface entre o aço e o concreto nos pilares mistos preenchidos. No entanto, também se ressalta o fato de a dilatação do aço ser maior que a do concreto no início do aquecimento, impondo um descolamento no contato dando origem à existência de uma "folga" (Gap de ar) entre ambos, fenômeno que deve ser levado em conta em análises experimental e numérica.

No entanto, a mesma referência destaca que tal consideração deve ser melhor estudada em trabalhos futuros, tendo em vista que ocorrem casos em que o tempo de resistência ao fogo cresce devido à folga, mostrando que as análises de modelos convencionais (sem Gap) estão a favor da segurança. Por outro lado, para os casos em que o contrário se verifica, a diferença se mostra pouco expressiva. 


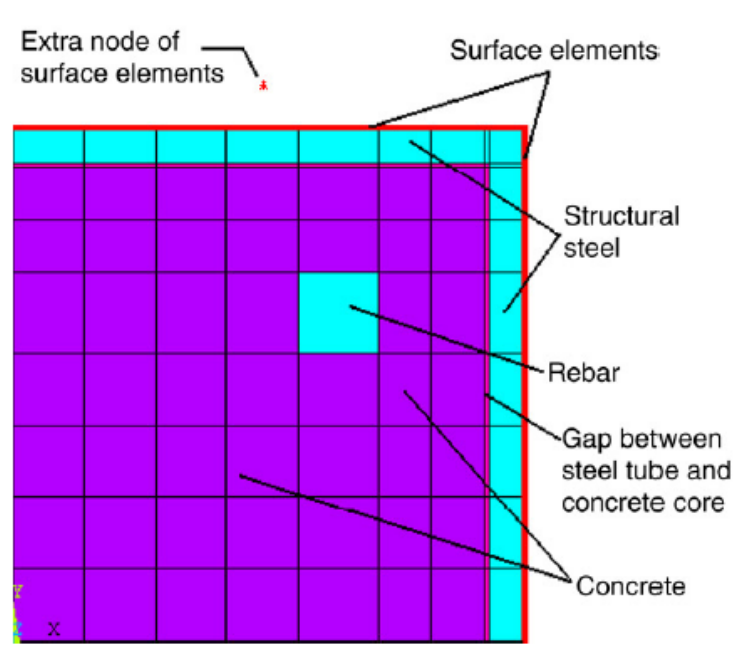

(a) Rectangular cross-section.

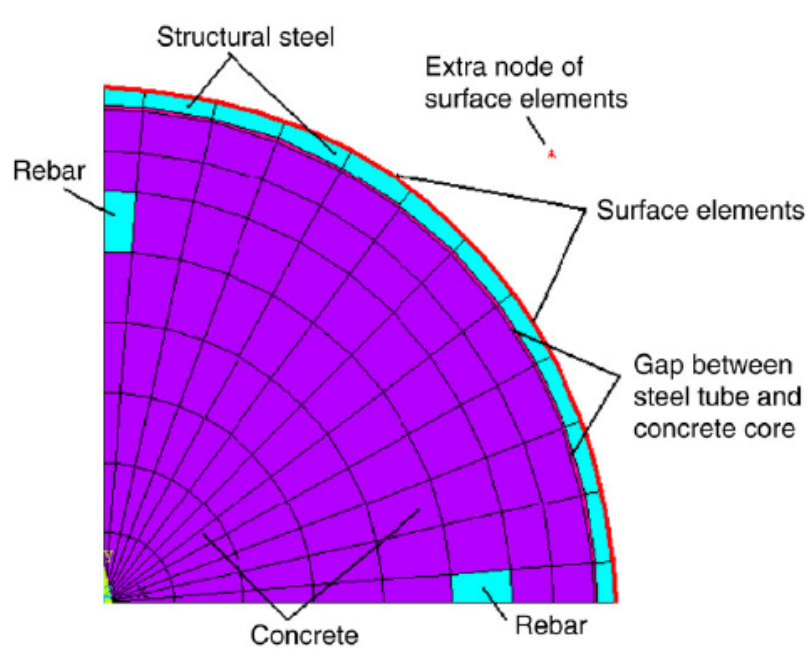

(b) Circular cross-section.

Figura 2.22 - Malha de elementos finitos: quarto da seção transversal dos Pilares Mistos.

$\mathrm{Na}$ mesma referência também se realizou um estudo de refinamento (eficiência) da malha, em que se comparam resultados de deslocamento em função do tempo de exposição ao fogo dos modelos numéricos (mesh) com experimental (measured), verificando que os resultados obtidos no estudo da malha não diferem entre si, apresentando comportamentos muito próximos ao experimental como pode ser visualizado na figura 2.23.

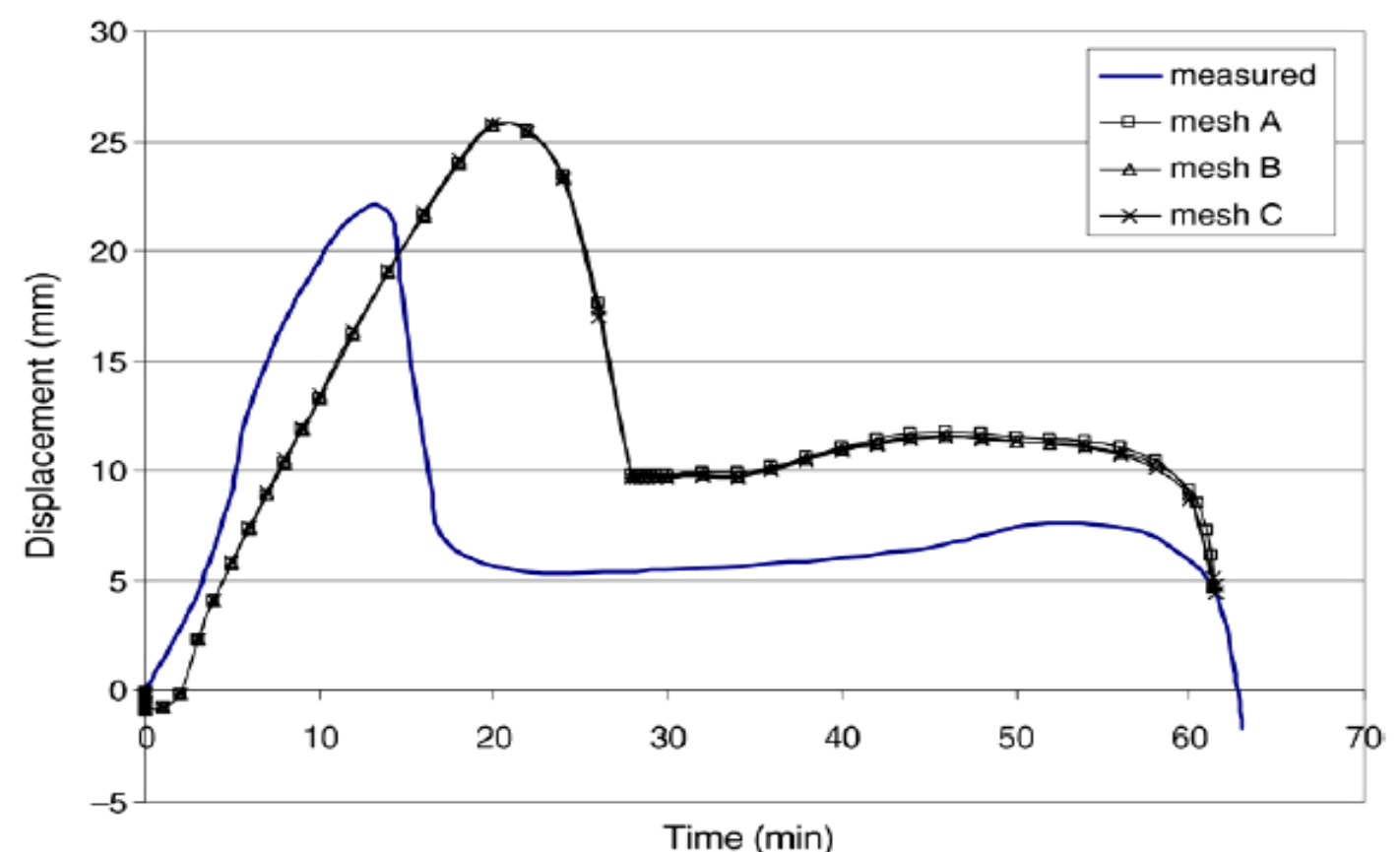

Figura 2.23 - Deslocamento vertical no topo do pilar. 
Foram construídos dois modelos numéricos, cujos resultados foram comparados com resultados experimentais, conforme figura 2.24, em que pode ser observado que o tempo de ruptura é praticamente o mesmo, mas os comportamentos dos modelos numéricos apresentam diferenças no trecho inicial (primeiro terço) do gráfico, em resposta à consideração ou não de escorregamento relativo entre tubo de aço e núcleo de concreto.

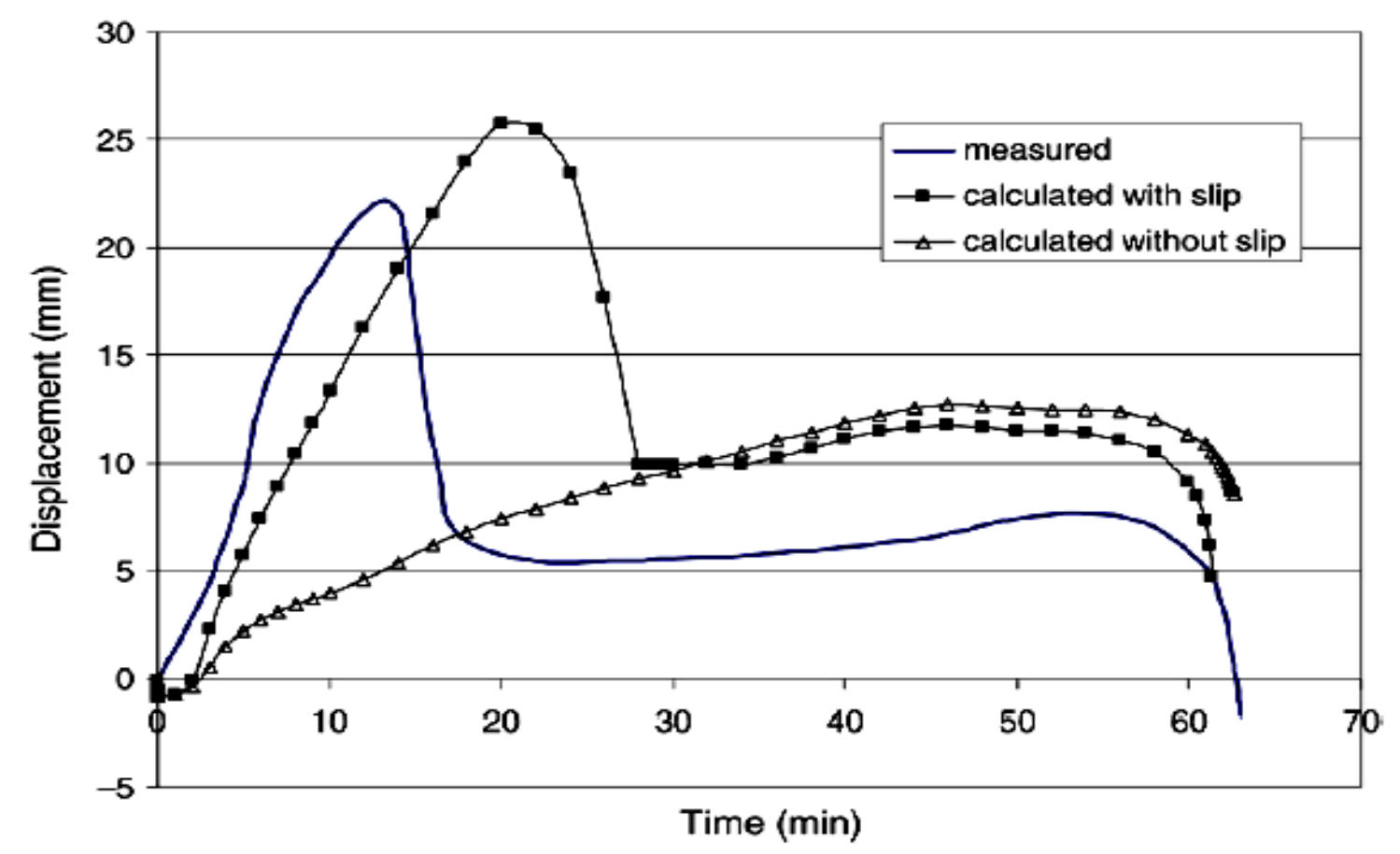

Figura 2.24 - Deslocamento vertical no topo do pilar misto

Enquanto no modelo com escorregamento ("with slip") o comportamento se aproxima mais do experimental, no modelo sem escorregamento ("without slip") o comportamento é diferente, porém, apenas nos trechos inicial e intermediário. No entanto, de acordo com a referência, o principal fator de interesse nesse caso é o tempo de ruptura, de modo que os resultados obtidos com ambos os modelos numéricos (com e sem escorregamento) podem ser considerados representativos.

Na figura 2.25 se pode verificar a configuração deformada do pilar misto exposto ao fogo por todos os lados, para um tempo de 28 min, verificando a separação dos materiais aço e concreto após o colapso. Os autores concluem que diante dos resultados apresentados, o modelo apresenta boa capacidade para a simulação de pilares mistos preenchidos em situação de incêndio. 

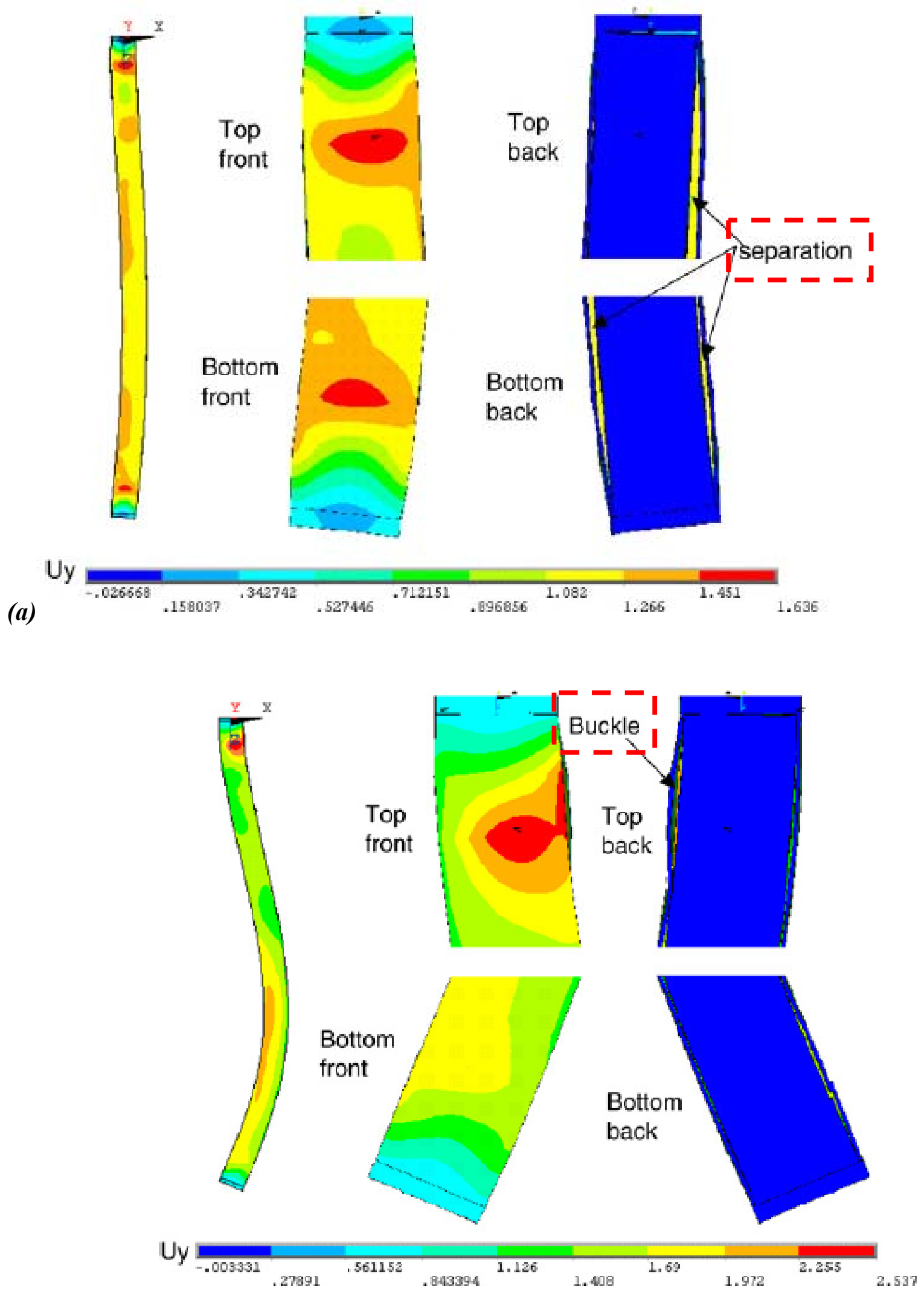

Figura 2.25 - Deformação do pilar misto considerando o escorregamento relativo:

(a) para 28 minutos de exposição ao fogo e (b) no instante do colapso. 


\subsection{ASPECTOS DE INTERESSE - Consideraç̃̃es}

Buscando selecionar algumas considerações com relação aos aspectos citados ao longo do presente capítulo, em particular com relação ao item 2.6, são aqui destacados os principais aspectos que influenciam no fator de resistência dos pilares mistos (relação resistência dos pilares mistos em situação de incêndio com a resistência dos pilares mistos em temperatura ambiente) de seção circular preenchidos com concreto. Dentre eles, são citados o diâmetro, a esbeltez, a espessura do tubo, a excentricidade do carregamento e a resistência dos materiais.

Como primeiro indicativo, o diâmetro e a esbeltez são os parâmetros que exercem maior influência no fator de resistência dos pilares mistos, sendo que o aumento no diâmetro proporciona um aumento no valor do fator de resistência, enquanto que o aumento na esbeltez provoca uma redução no valor do fator de resistência.

Como segundo indicativo, a espessura do tubo de aço, a excentricidade do carregamento aplicado e a resistência dos materiais influenciam muito pouco no fator de resistência. $\mathrm{O}$ aumento na espessura do tubo, na resistência do aço e excentricidade da carga provocam uma pequena diminuição no valor do fator de resistência. Já o aumento na resistência do concreto, por sua vez, provoca um pequeno aumento no valor do fator de resistência

No Capítulo 3 será conceituado o incêndio, em que se apresentam alguns comentários sobre os conceitos necessários para descrever a ação térmica nas estruturas (mecanismos de transferência de calor) e as propriedades térmicas e estruturais dos materiais aço e concreto. Tendo em vista esse aspecto, optou-se por disponibilizar ao leitor os procedimentos normativos para o dimensionamento dos pilares mistos em situação de incêndio no final do mesmo Capítulo 3. 



\section{O INCENNDIO - ORIGEM, ASPECTOS E EFEITO TÉRMICO NAS ESTRUTURAS}

\subsection{ORIGEM DO INCÊNDIO - Aspectos de interesse}

O incêndio se caracteriza pela ocorrência do fogo, sem controle, o qual só existirá se houver a reunião de três elementos, fonte de calor, combustível e oxigênio, conhecidos como "triângulo do fogo" e ilustrado na figura 3.1, adaptada de FERNANDES (2006). O trabalho em conjunto desses três elementos origina uma reação química que libera grande intensidade de calor (exotérmica), envolvendo a oxidação da matéria orgânica e a liberação de vapor d'água e dióxido de carbono. A falta, ou extinção, de um desses elementos num determinado ambiente impossibilitará a existência do fogo e o incêndio não ocorrerá ou se extinguirá.

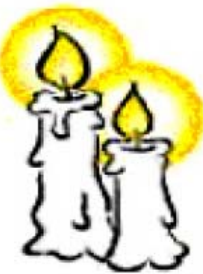

Fonte de calor

(igniza o material combustivel)
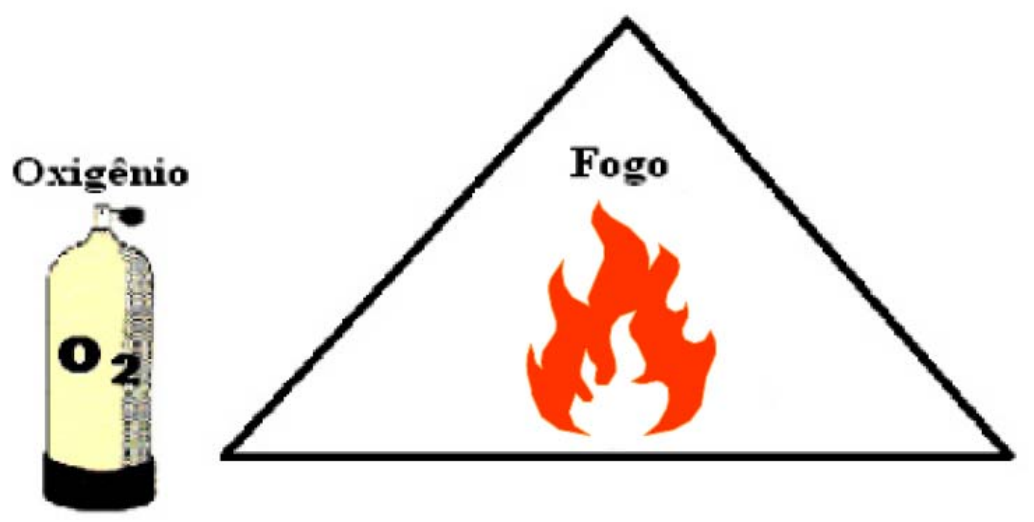

Combustivel

Figura 3.1 - Esquematização do Triângulo do fogo.

A combustão se dá por meio de reações químicas entre o material combustível e um comburente (nesse caso, o oxigênio), com liberação de luz, calor, fumaça e gases. A combustão de qualquer material requer a disponibilidade de oxigênio, para que a oxidação possa ocorrer. 
Portanto, o processo de queima de um combustível requer a presença de uma fonte de calor externa para aumentar sua temperatura até atingir o ponto de ignição. Em seguida as chamas crescem até que a sua intensidade se torne estável. A partir desse momento, as chamas se tornam grandes o suficiente para manter a reação de combustão sem a necessidade de qualquer fonte de calor externa.

As fontes de calor comumente encontradas nas edificações são: as fontes de chamas tais como fósforos, velas, aquecedores a gás e lareiras, fontes fumegantes, tais como cigarros, fontes elétricas, a citar as falhas nos circuitos elétricos, e as fontes radiantes, as superfícies quentes, fricção, relâmpagos e outras.

A quantidade de calor e temperatura requeridas para causar a ignição dependem das características do material combustível (do tamanho, da forma e das propriedades térmicas) e do tempo de exposição ao calor, e o tempo necessário para ocorrer à ignição do material depende da sua inércia térmica, definida como o produto entre a condutividade térmica, densidade e calor específico do material. Quando exposto a uma mesma fonte de calor, a superfície do material com menor inércia térmica aquecerá mais rapidamente se comparada aos materiais com maior inércia térmica, conduzindo a uma ignição mais rápida.

A intensidade e a duração do incêndio estão associadas aos seguintes fatores:

- Quantidade, tipo e posicionamento da carga de incêndio (que pode ser entendido como o material combustível que constitui o mobiliário, equipamentos e o acabamento);

- As características físicas do edifício, as quais definem a compartimentação dos ambientes;

- A ventilação, determinada pela quantidade, tamanho e a posição das janelas (aberturas), compartimentos com maior ventilação propiciam incêndios mais intensos e, por conseqüência, de menor duração;

- As propriedades térmicas e a espessura dos materiais que constituem a estrutura.

\subsection{ESTRUTURAS EM SITUAÇÃO DE INCÊNDIO - Ação térmica}

O incêndio provoca o aumento da temperatura nos elementos estruturais, que sofrem alterações em suas propriedades, tais como redução da rigidez, da resistência e, por conseqüência, grandes deformações. $\mathrm{O}$ aumento da temperatura nos elementos, imposto pelo incêndio, ocorre devido à ação térmica descrita por meio do fluxo de calor (Q), como conseqüência dos fenômenos de radiação $\left(\mathrm{Q}_{\mathrm{r}}\right)$ e convecção $\left(\mathrm{Q}_{\mathrm{c}}\right)$, estabelecendo uma diferença de temperatura entre os gases do ambiente em chamas e os elementos estruturais. 
No que concerne ao estudo da segurança das estruturas, o incêndio, enquanto modelo, pode ser caracterizado por uma curva que fornece a temperatura dos gases em função do tempo, e serve como ponto de partida para o dimensionamento de elementos estruturais sob a ação térmica. Dentre as várias maneiras de se descrever (modelar) o incêndio, enquanto curva "Temperatura $(\theta)$ x Tempo (t)", se destaca aquela descrita na figura 3.2 , denominada curva de Incêndio Real, e tornará possível determinar a máxima temperatura atingida pelos elementos. Essa curva pode ser dividida em três fases distintas e de interesse: Ignição, aquecimento (com temperatura máxima) e resfriamento.

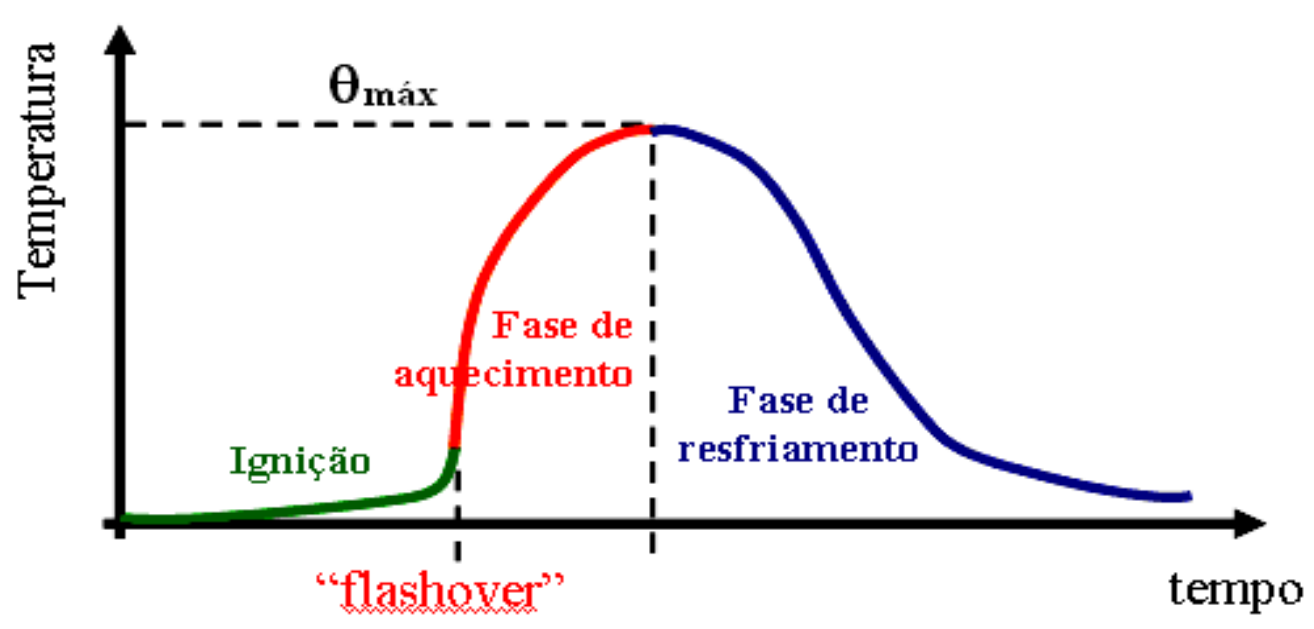

Figura 3.2 - Curva temperatura x tempo de um incêndio real. Fonte: REGOBELLO (2007)

Durante a fase de ignição, as temperaturas são baixas e o incêndio é considerado de pequenas proporções. $\mathrm{O}$ aquecimento ocorre de forma relativamente lenta e não oferece riscos a vida humana (o fogo permanece localizado), embora uma quantidade significativa de fumaça comece a ser produzida, podendo ser facilmente controlado.

Considerando a possibilidade da não ocorrência do controle do incêndio na fase de ignição, começa a ser estabelecida uma segunda fase do incêndio, denominado período préflashover, em que as medidas de proteção contra incêndio (detectores de calor e de fumaça, chuveiros automáticos e brigada de incêndio) deverão ser suficientes no combate às chamas.

Entre a fase inicial do incêndio (ignição) e a fase de aquecimento, no caso de as medidas de proteção não serem suficientes para extinguir o fogo, ocorrerá um aumento brusco de temperatura, fase essa denominada "flashover" ou instante de inflamação generalizada, instante esse em que praticamente toda carga combustível entra em ignição.

Durante essa fase, a temperatura dos gases aumenta rapidamente até atingir sua intensidade máxima, instante em que toda carga de incêndio se extingue. Vale destacar que o 
flashover pode ser eventualmente identificado, pois nesse instante o incêndio cresce rapidamente, podendo ocorrer explosões e quebra de janelas, após a ocorrência do flashover todo o ambiente estará envolvido pelas chamas e o controle do incêndio torna-se mais difícil. A partir de então, começa a fase de resfriamento, com a redução gradativa da temperatura.

Para verificação da segurança da estrutura é necessário avaliar o efeito térmico nos elementos estruturais. Por isso, se modela o incêndio tendo por base ensaios (modelos matemáticos aferidos por ensaios) que buscam simular uma possível situação de incêndio real, em que se considera a variação da quantidade de material combustivel (denominada carga de incêndio) e o grau de ventilação do compartimento em chamas.

No entanto, é geralmente de difícil determinação uma curva de um incêndio real de interesse, uma vez que está relacionada a parâmetros como disposição das aberturas, quantidade de cargas combustíveis, fator de ventilação, que são de grande variabilidade e específicas para cada tipo de edificação. Em resposta a essas dificuldades, são propostos outros modelos para o comportamento da curva temperatura $\mathrm{x}$ tempo de um incêndio, com algumas simplificações, porém, suficientemente representativos para aplicação em casos práticos. Dentre os modelos, serão citados o modelo de incêndio natural e aqueles desenvolvidos pelos principais órgãos normativos em vigor no contexto mundial.

\subsubsection{INCENNDIO NATURAL}

Segundo SILVA (2001) o incêndio natural admite que a temperatura dos gases respeite as curvas temperatura-tempo construídas a partir de ensaios experimentais de incêndio, ou de modelos matemáticos aferidos desses ensaios, que simulem o mais próximo possível a real situação de um compartimento em chamas. Os ensaios são realizados em compartimentos com aberturas (janelas), nos quais o incêndio ocorre sem a possibilidade de propagação para fora dos mesmos em função de características como isolamento térmico, estanqueidade e resistência dos elementos de vedação.

O modelo de incêndio natural, conforme figura 3.3, corresponde a uma simplificação das condições de incêndio real, em que se desconsidera a fase de ignição, por se entender que as temperaturas não atingem níveis que possam afetar a capacidade portante da estrutura, bem como se faz um ajuste na fase de resfriamento por meio de uma reta. Portanto, a curva temperatura $\mathrm{x}$ tempo de um incêndio natural aborda tanto a fase de aquecimento após o flashover (de interesse) como a fase de resfriamento dos gases, e utiliza o conceito de tempo efetivo para obter os mesmos efeitos de um incêndio real. 


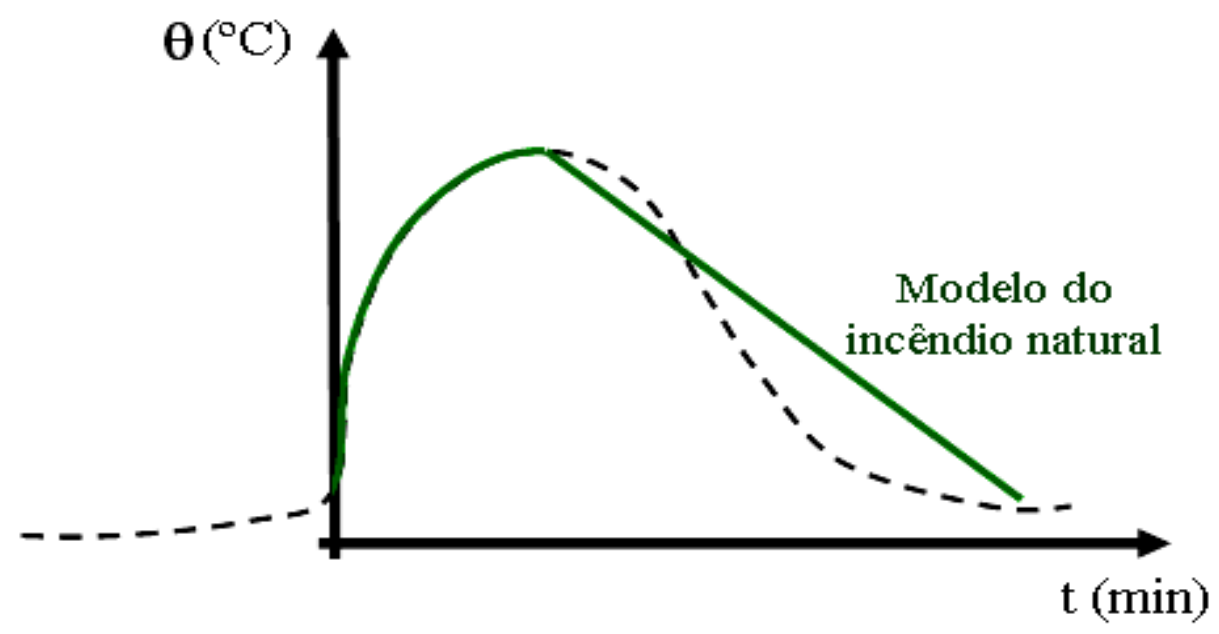

Figura 3.3 - Modelo do incêndio natural. Fonte: REGOBELLO (2007)

Apesar das simplificações inseridas quando comparado ao modelo de incêndio real, o modelo de incêndio natural ainda depende da determinação do grau de ventilação que depende da condição das aberturas no compartimento, da distribuição e da quantidade de carga de incêndio, dos materiais que a mesma é constituída, das características da compartimentação, espessura e o material das paredes. Em consideração a esses fatores, se convencionou adotar um outro modelo de incêndio, denominado incêndio-padrão, cuja origem se dá a partir de análises experimentais de estruturas, elementos estruturais, materiais e elementos de proteção térmica, o qual será descrito no item que segue.

\subsubsection{INCÊNDIO-PADR ÃO}

O modelo do incêndio-padrão tem como principal característica possuir apenas um ramo ascendente, como pode ser visualizado na figura 3.4. Admite-se, nesse caso, que a temperatura seja sempre crescente com o tempo, sem a dependência das características do ambiente (tamanho do compartimento e condições de ventilação) e da carga de incêndio.

É importante ressaltar que esse modelo de curva não representa um incêndio real. Deve-se atentar, ao analisar resultados de ensaios obtidos com a utilização da curva de incêndio-padrão, que os resultados não representam o comportamento real do incêndio, das estruturas ou elementos estruturais submetidos ao incêndio.

A NBR 14432: 2000 prescreve um modelo de incêndio-padrão, cuja elevação da temperatura dos gases se dá em resposta a intervalos de tempo, obtidos por meio do parâmetro TRRF, denominado Tempo Requerido de Resistência ao Fogo. 


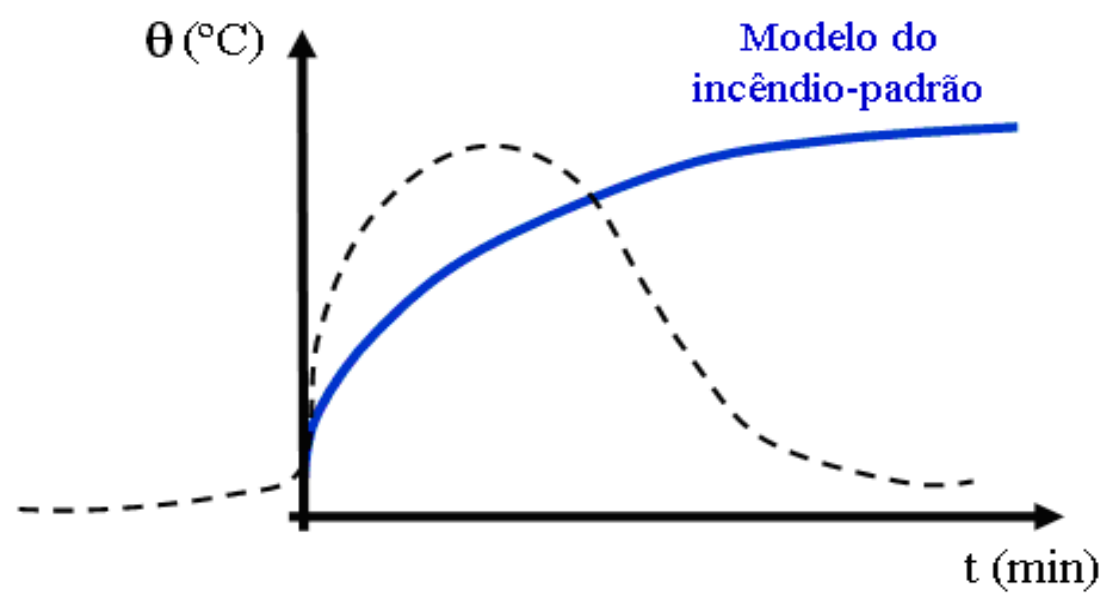

Figura 3.4 - Modelo do incêndio-padrão. Fonte: REGOBELLO (2007)

O TRRF representa o tempo mínimo de resistência de um elemento submetido ao modelo do incêndio-padrão, e não corresponde ao tempo real de ocorrência do incêndio, ou seja, trata-se de um tempo fictício que busca obter na curva de incêndio-padrão aquela mesma temperatura máxima que seria obtida para uma situação de incêndio natural. As curvas padronizadas mais utilizadas serão apresentadas nos itens que se seguem.

\subsubsection{Modelo de incêndio-padrão - ASTM E119:1998}

Segundo SILVA (2001), a American Specification of Testing and Materials, por meio da ASTM E119 (1988) - "Standard test methods for fire tests of building construction and materials", recomenda o uso de uma curva temperatura-tempo respeitando os valores apresentados na tabela 3.1 .

Tabela 3.1- Temperatura dos gases em função do tempo, ASTM E119 Fonte: SILVA (2001)

\begin{tabular}{|c|c|c|c|}
\hline Tempo (min.) & Temperatura $\left({ }^{\circ} \mathbf{C}\right)$ & Tempo $(\mathbf{m i n})$. & Temperatura $\left({ }^{\circ} \mathbf{C}\right)$ \\
\hline 0 & 20 & 55 & 916 \\
\hline 5 & 538 & 60 & 927 \\
\hline 10 & 704 & 65 & 937 \\
\hline 15 & 760 & 70 & 946 \\
\hline 20 & 795 & 75 & 955 \\
\hline 25 & 821 & 80 & 963 \\
\hline 30 & 843 & 85 & 971 \\
\hline 35 & 862 & 90 & 978 \\
\hline 40 & 878 & 120 & 1010 \\
\hline 45 & 892 & 240 & 1093 \\
\hline 50 & 905 & 480 & 1260 \\
\hline
\end{tabular}


Dentre as várias equações desenvolvidas para descrever essa curva, a equação 3.1 é aquela que melhor representa os valores da tabela.

$\theta_{\mathrm{g}}=750 \cdot\left\lfloor 1-\mathrm{e}^{-3,79553 \cdot \sqrt{\mathrm{t}_{\mathrm{h}}}}\right\rfloor+170,41 \cdot \sqrt{\mathrm{t}_{\mathrm{h}}}+\theta_{0}$

Com relação à equação $3.1, \theta_{0}$ é a temperatura dos gases no instante $\mathrm{t}_{0}$ (temperatura ambiente, em $\left.{ }^{\circ} \mathrm{C}\right), \theta_{\mathrm{g}}$ é a temperatura dos gases do ambiente em chamas (em $\left.{ }^{\circ} \mathrm{C}\right)$ e $\mathrm{t}_{\mathrm{h}}$ é o tempo decorrido em horas $(\mathrm{h})$.

\subsubsection{Modelo de incêndio-padrão: ISO 834:1975}

Segundo SILVA (2001), a International Organization for Standardization, por meio da norma ISO 834:1975 "Fire-resistence tests - Elements of building construction", recomenda a curva temperatura-tempo dos gases descrita pela equação 3.2. Esse é o modelo adotado pela norma brasileira ABNT-NBR 14323:1999, que estabelece prescrições para o dimensionamento de elementos de aço e mistos de aço e concreto em situação de incêndio.

$\theta_{\mathrm{g}}=\theta_{0}+345 \cdot \log _{10} \cdot(8 \cdot \mathrm{t}+1)$

Com relação à equação $3.2, \theta_{\mathrm{g}}$ é a temperatura dos gases $\left(\mathrm{em}{ }^{\circ} \mathrm{C}\right), \theta_{0}$ é a temperatura dos gases no instante $\mathrm{t}_{0}$ (temperatura ambiente, em ${ }^{\circ} \mathrm{C}$ ) e t é o tempo decorrido (em minutos). A figura 3.5 compara as curvas obtidas pelos dois modelos apresentados.

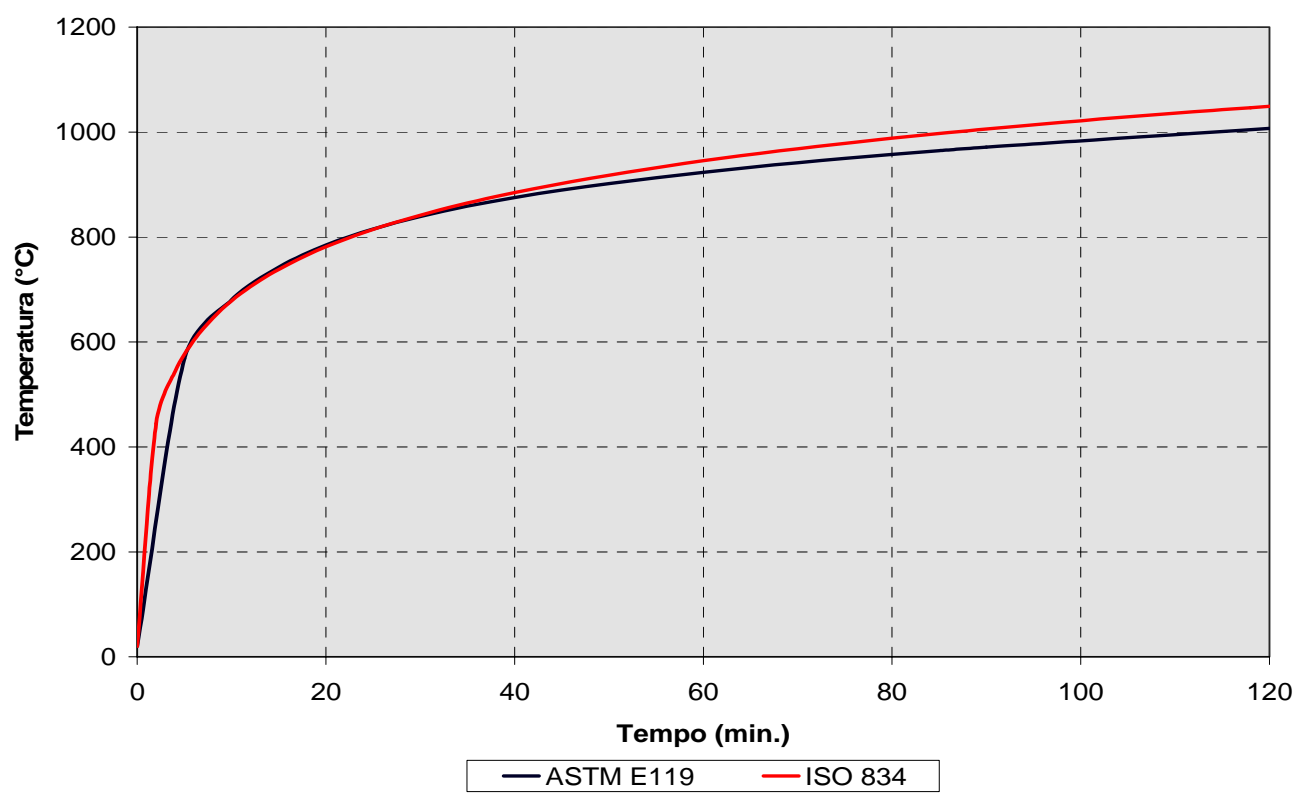

Figura 3.5 - Curvas-padrão temperatura-tempo: ISO 834 x ASTM E199. 
Conforme já comentado anteriormente, é importante lembrar que a ação térmica na estrutura é descrita pelo fluxo de calor provocado pela diferença de temperatura entre os gases quentes do ambiente e os componentes da estrutura. $\mathrm{O}$ aumento da temperatura nos elementos estruturais, em conseqüência da ação térmica, causa redução da resistência, da rigidez e o aparecimento dos esforços solicitantes adicionais nas estruturas hiperestáticas.

No próximo item deste capítulo serão brevemente apresentados alguns comentários sobre os conceitos necessários para descrever a ação térmica nas estruturas.

\subsection{MECANISMOS DE TRANSFERÊNCIA DE CALOR}

Quando sistemas com diferentes temperaturas entram em contato, ocorre transferência de energia térmica, também conhecida como transferência de calor, a qual pode ocorrer por três modos distintos, conhecidos por condução, convecção e radiação, conforme indicados na figura 3.6.

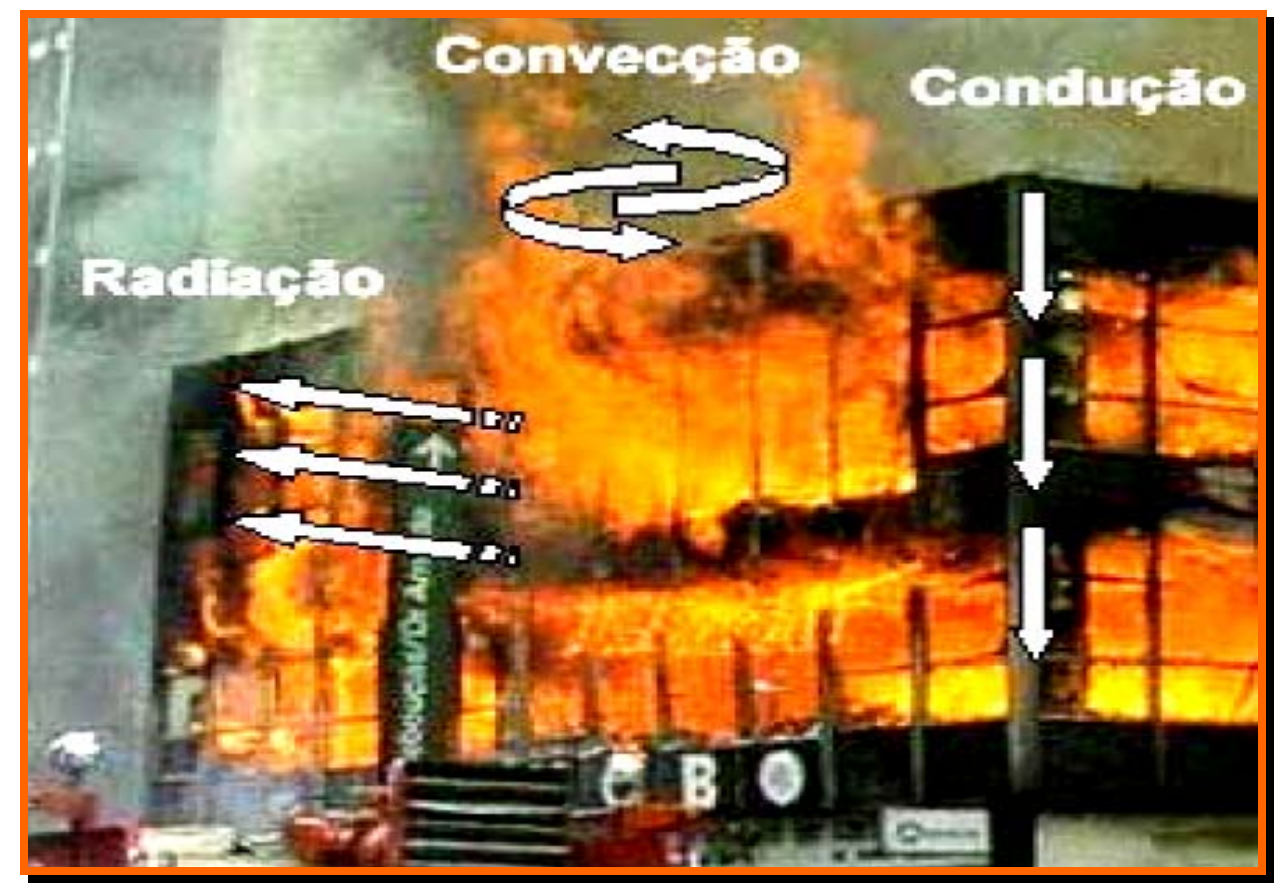

Figura 3.6 - Mecanismos de transferência de calor. Fonte: AZEVEDO (2006)

No que segue, são descritos os três mecanismos de transferência de calor de modo bastante resumido, destacando-se que, em REGOBELLO (2007), são apresentadas informações mais detalhadas a respeito dos conceitos de transferência térmica aplicados ao estudo do incêndio nas estruturas. 


\subsubsection{TRANSFERENNCIA DE CALOR POR CONDUÇÃO}

Condução é o processo de transferência de calor que ocorre entre as moléculas que constituem o elemento, cujo fluxo ocorre da região de maior temperatura para a de menor temperatura. Esse processo pode ocorrer nas moléculas dos elementos em estados líquido, gasoso ou sólido, sendo mais expressivo no estado sólido. A condução de calor é um importante fator na ignição das superfícies sólidas e na resistência à ação térmica das estruturas.

Para o cálculo da transferência de calor por condução é necessário conhecer algumas propriedades dos materiais de interesse. São elas: densidade, calor especifico e condutividade térmica do material. A densidade, $\rho$ é definida como sendo a massa do material por unidade de volume; o calor específico, $c$ é o calor requerido para aquecer uma unidade de massa de um material em uma unidade de temperatura e; a condutividade térmica, $\lambda$ representa a taxa de calor transferido através de uma unidade de espessura por uma variação unitária de temperatura. Há ainda outras propriedades derivadas que também são necessárias: a difusividade térmica, dada pela equação 3.3, e a inércia térmica, representada por $\lambda$. .p.c.

$$
\alpha=\frac{\lambda}{\rho \cdot c_{p}}
$$

Os materiais com baixa inércia térmica quando são expostos ao calor sofrem um rápido aumento de temperatura em sua superfície, sendo, mais propensos à ignição. Para uma dada carga de incêndio, ambientes forrados com materiais de baixa inércia térmica terão temperaturas mais altas que ambientes com materiais de inércia térmica mais elevada. Numa condição estacionária, a transferência de calor por condução é diretamente proporcional ao gradiente de temperatura entre dois pontos, ponderado por uma constante de proporcionalidade conhecida como condutividade térmica.

\section{- Condução no estado estático em campo unidimensional}

Em campo unidimensional, a equação de calor segue a Lei de Fourier de condução de calor, e é expressa conforme apresentada na equação 3.4. O sinal (-) na referida equação indica que o calor flui do ponto de temperatura mais alta para o de temperatura mais baixa.

$$
\dot{\mathrm{h}}=-\lambda \cdot \frac{\mathrm{d} \theta}{\mathrm{dx}}
$$


$\mathrm{Na}$ equação $3.4, \dot{\mathrm{h}}$ é o fluxo de calor por unidade de área (em $\left.\mathrm{W} / \mathrm{m}^{2}\right), \lambda$ é a condutividade térmica do material (em W/mK), $\theta$ é a temperatura (em $\mathrm{K}$ ou ${ }^{\circ} \mathrm{C}$ ) e $\mathrm{x}$ é a distância na direção do fluxo de calor (em m).

- Condução no estado estacionário em campo unidimensional de materiais compósitos

Em compósitos, assume-se que a condutividade térmica de cada material independe da temperatura. De acordo com o princípio da conservação de energia (fluxo de calor através de cada camada permanece constante), usando a equação 3.5 e conhecendo a temperatura nas duas faces externas do compósito, é possível obter o fluxo de calor.

$\theta_{1}-\theta_{\mathrm{n}, \mathrm{n}+1}=\dot{\mathrm{h}} \cdot \sum_{\mathrm{i}=1}^{\mathrm{n}} \mathrm{R}_{\mathrm{i}, \mathrm{i}+1}$

Na última equação, $\theta_{1}$ e $\theta_{\mathrm{n}, \mathrm{n}+1}$ são as temperaturas nas faces externas do compósito, $\dot{\mathrm{h}}$ é o fluxo de calor através do compósito, $\lambda_{\mathrm{i}, \mathrm{i}+1}$ é a condutividade térmica da camada, $\Delta \mathrm{x}_{\mathrm{i}, \mathrm{i}+1}$ é a espessura da camada e $\mathrm{R}_{\mathrm{i}, \mathrm{i}+1}=\frac{\Delta \mathrm{x}_{\mathrm{i}, \mathrm{i}+1}}{\lambda_{\mathrm{i}, \mathrm{i}+1}}$ é a resistência térmica de cada material componente do compósito. Com o valor de $\dot{\mathrm{h}}$, as temperaturas nas faces de cada camada são obtidas por meio da equação 3.6.

$$
\theta_{\mathrm{i}}-\theta_{\mathrm{i}+1}=\dot{\mathrm{h}} \cdot \frac{\Delta \mathrm{x}_{\mathrm{i}, \mathrm{i}+1}}{\lambda_{\mathrm{i}, \mathrm{i}+1}}
$$

Para o fluxo transiente de calor, a quantidade de calor dissipada na mudança de temperatura do meio (material) deve ser incluída. Para o campo unidimensional, a transferência de calor por condução em um material sem calor interno liberado, é governada pela equação 3.7, em que t é o tempo [s] e $\alpha$ é a difusividade térmica $\left[\mathrm{m}^{2} / \mathrm{s}\right.$ ]

$$
\frac{\partial^{2} \theta}{\partial \mathrm{x}^{2}}=\frac{1}{\alpha} \cdot \frac{\delta \theta}{\delta \mathrm{t}}
$$




\subsubsection{TRANSFERENCIA DE CALOR POR CONVECÇÃO}

O mecanismo de conveç̧ão é o processo de transferência de calor que ocorre na interface formada entre duas superfícies de estados físicos diferentes, devido aos fluidos em movimento, sejam eles gases ou líquidos. A convecção é um importante fator de espalhamento das chamas, no transporte ascendente de fumaça e gases quentes até o teto ou para o exterior do compartimento em chamas. A equação que relaciona o fluxo de calor convectivo com a temperatura dos gases foi proposta por Isaac Newton em 1701.

Segundo LIENHARD IV e LIENHARD V (2005) apud REGOBELLO (2007), em 1701, Isaac Newton já considerava o processo de convecção e sugeriu que o "resfriamento" de um corpo, como apresentado na figura 3.7, fosse descrito pela equação 3.8.

$\frac{\mathrm{dT}_{\text {corpo }}}{\mathrm{dt}} \cong \mathrm{T}_{\text {corpo }}-\mathrm{T}_{\infty}$

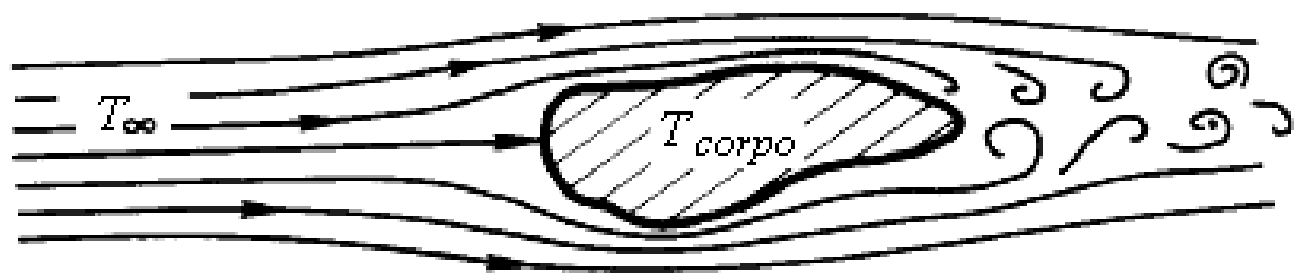

Figura 3.7 - Resfriamento convectivo de um corpo aquecido. Fonte: REGOBELLO (2007)

$\mathrm{Na}$ equação $3.8, \mathrm{~T}_{\text {corpo }}$ é a temperatura do corpo e $\mathrm{T}_{\infty}$ é a temperatura do fluído em movimento nas adjacências do corpo, ambas em graus Kelvin (K). Segundo a equação 3.8, o calor é transferido do corpo aquecido para o fluido. Se for assumida a hipótese de que a temperatura do corpo é mantida constante, como que se houvesse geração de calor interno, $\frac{\mathrm{dT}_{\text {corpo }}}{\mathrm{dt}}$ pode ser interpretado como taxa de transferência de calor $(\dot{\mathrm{Q}})$ entre o corpo e o fluido.

Reescrevendo a equação 3.8 em termos de fluxo de calor, $\varphi=\dot{Q} / \mathrm{A}$, sendo A a área em $\mathrm{m}^{2}$ da superfície do corpo em contato com o fluido, resulta a equação 3.9 , denominada $l e i$ de Newton do resfriamento.

$\varphi_{\mathrm{c}}=\alpha_{\mathrm{c}}\left(\mathrm{T}_{\text {corpo }}-\mathrm{T}_{\infty}\right)$ 
$\mathrm{Na}$ equação 3.9, $\alpha_{\mathrm{c}}$ é o coeficiente de transferência de calor por convecção (em $\left.\mathrm{W} / \mathrm{m}^{2} \mathrm{~K}\right)$ e $\left(T_{\text {corpo }}-T_{\infty}\right)$ é a diferença de temperatura entre a superfície sólida e o fluido (em $\mathrm{K}$ ou $\left.{ }^{\circ} \mathrm{C}\right)$. $\mathrm{O}$ valor do coeficiente de transferência de calor por convecção $\alpha_{c}$ pode variar dependendo de fatores como geometria e rugosidade da superfície, além da natureza do fluxo. O valor adotado pelo EUROCODE 3 part 1-2 é $\alpha_{c}=25 \mathrm{~W} / \mathrm{m}^{2} \mathrm{~K}$.

\subsubsection{TRANSFERÊNCIA DE CALOR POR RADIAÇÃO}

Radiação é o processo de transferência de calor que ocorre por propagação de ondas eletromagnéticas, da região de maior temperatura para a de menor temperatura, na velocidade da luz. Quando a energia térmica radiante passa por um meio, qualquer objeto dentro desse caminho pode absorver, refletir ou transmitir a radiação térmica incidente, esse comportamento é ilustrado na figura 3.8.

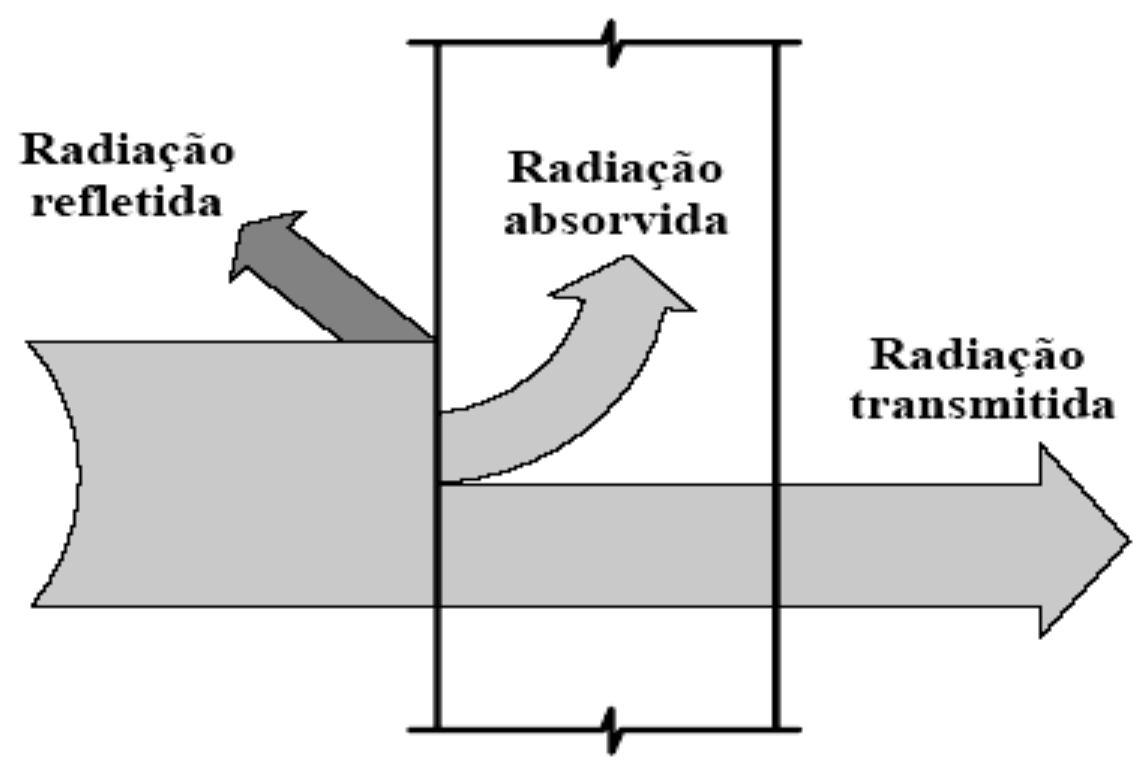

Figura 3.8 - Distribuição da radiação incidente. Fonte: AZEVEDO (2006)

Os parâmetros denominados absortividade $(\alpha)$, refletividade $(\rho)$ e transmitância $(\tau)$ permitem representar frações de radiação térmica (incidente) que um dado corpo absorve, reflete ou transmite, respectivamente, conforme descrito pela equação 3.10.

$\alpha+\rho+\tau=1$ 
Segundo BUCHANAN (2001), A radiação é muito importante nos incêndios porque é o principal mecanismo de transferência de calor das chamas para a superfície do combustível. A transferência de calor radiante em um ponto da superfície radiante é dada pela equação 3.11 .

$$
\dot{\mathrm{Q}}_{\mathrm{r}}=\phi \cdot \varepsilon_{\mathrm{e}} \cdot \sigma \cdot \mathrm{A} \cdot\left(\theta_{\mathrm{e}}+273,15\right)^{4}
$$

Na equação $3.11, \dot{\mathrm{Q}}_{\mathrm{r}}$ é o fluxo de calor por radiação $(\mathrm{W}), \phi$ é o fator de configuração, $\varepsilon_{\mathrm{e}}$ é a emissividade da superfície radiante, $\sigma$ é a constante de Stefan-Boltzmann $\left(5,67 \times 10^{-8} \mathrm{~W} / \mathrm{m}^{2}\right.$ ${ }^{\circ} \mathrm{C}^{4}$ ), A é a área da seção atravessada pelo calor $\left(\mathrm{m}^{2}\right)$ e $\theta_{\mathrm{e}}$ é a temperatura da superfície emissora $\left({ }^{\circ} \mathrm{C}\right)$. A transferência de calor da superfície radiante para a superfície receptora é dada pela equação 3.12 , em que $\theta_{\mathrm{r}}$ é a temperatura da superfície receptora $\left({ }^{\circ} \mathrm{C}\right)$ e $\varepsilon_{\mathrm{r}}$ é a emissividade da superfície receptora. Na mesma equação, $\varepsilon$ é a emissividade resultante das duas superfícies, dada pela equação 3.13 .

$$
\begin{aligned}
& \dot{\mathrm{Q}}_{\mathrm{r}}=\phi \cdot \varepsilon \cdot \sigma \cdot \mathrm{A} \cdot\left[\left(\theta_{\mathrm{e}}+273,15\right)^{4}-\left(\theta_{\mathrm{r}}+273,15\right)^{4}\right] \\
& \varepsilon=\frac{1}{\frac{1}{\varepsilon_{\mathrm{e}}}+\frac{1}{\varepsilon_{\mathrm{r}}}-1}
\end{aligned}
$$

\subsection{ELEVAÇÃO DA TEMPERATURA EM ELEMENTOS ESTRUTURAIS}

O aumento na temperatura dos elementos estruturais em situação de incêndio normalmente ocorre por meio dos mecanismos de radiação e de convecção, já apresentados anteriormente. Para os casos comuns de elementos de aço em situação de incêndio, com e sem revestimento, a elevação de temperatura $\Delta \theta_{\mathrm{a}}$ no elemento estrutural pode ser determinada, segundo a norma ABNT NBR 14323:1999 ou por meio dos EUROCODE 3 e 4.

Vale aqui mencionar que tais procedimentos serão aqui apresentados de forma bastante sucinta, destacando-se que maiores informações sobre esse assunto poderão ser obtidas em REGOBELLO (2007). 
- Elevação da temperatura em elemento de aço sem revestimento

Usando uma aproximação passo a passo, e assumindo um incremento de tempo compatível $(\Delta \mathrm{t} \leq 5 \mathrm{~s})$, o incremento da temperatura do aço durante o intervalo $\Delta \mathrm{t}$ pode ser calculado por meio da equação 3.14 .

$$
\Delta \theta_{\mathrm{a}, \mathrm{t}}=\mathrm{k}_{\mathrm{sh}} \cdot \frac{\mathrm{A} / \mathrm{V}}{\mathrm{c}_{\mathrm{a}} \cdot \rho_{\mathrm{a}}} \cdot \varphi \cdot \Delta \mathrm{t}
$$

$\mathrm{Na}$ equação 3.14 o numerador $\mathrm{A} / \mathrm{V}$ apresentado é denominado fator de massividade ou fator de forma do elemento de aço e $\mathrm{k}_{\mathrm{sh}}$ é um fator de correção para o efeito sombra. A equação 3.14 é adotada pelos EUROCODE 3 (2005) Part 1-2 e EUROCODE 4 (2005) Part 12 e, de forma similar, pela NBR 14323:1999. A NBR 14323:1999 apresenta esta mesma equação, porém, reescrita na forma da equação (3.15).

$$
\Delta \theta_{\mathrm{a}, \mathrm{t}}=\frac{(\mathrm{u} / \mathrm{A})}{\mathrm{c}_{\mathrm{a}} \cdot \rho_{\mathrm{a}}} \cdot \varphi \cdot \Delta \mathrm{t}
$$

$\mathrm{Na}$ equação (3.15), $\Delta \theta_{\mathrm{a}, \mathrm{t}}$ representa a variação da temperatura $\left({ }^{\circ} \mathrm{C}\right)$ no elemento estrutural de aço durante um intervalo de tempo $\Delta \mathrm{t}(\mathrm{s})$, e $\mathrm{u} / \mathrm{A}$ é o fator de massividade para elementos estruturais de aço sem revestimento contra incêndio, com unidade $\mathrm{em} \mathrm{m}^{-1}$, sendo que u é o perímetro do elemento estrutural de aço exposto ao incêndio (m), A é a área da seção transversal do elemento estrutural $\left(\mathrm{m}^{2}\right), \mathrm{c}_{\mathrm{a}}$ é o calor específico do aço $\left(\mathrm{J} / \mathrm{kg}^{\circ} \mathrm{C}\right), \rho_{\mathrm{a}}$ é a massa específica do aço $\left(\mathrm{kg} / \mathrm{m}^{3}\right)$ e $\varphi$ é o fluxo de calor por unidade de área $\left(\mathrm{W} / \mathrm{m}^{2}\right)$, descrito pela equação 3.16 .

$\varphi=\varphi_{\mathrm{c}}+\varphi_{\mathrm{r}}$

Das parcelas que constituem a equação $3.16, \varphi_{c}$ é o componente do fluxo de calor devido à convecção $\left(\mathrm{W} / \mathrm{m}^{2}\right)$ e $\varphi_{\mathrm{r}}$ é o componente do fluxo de calor devido à radiação $\left(\mathrm{W} / \mathrm{m}^{2}\right)$, representados pelas equações 3.17 e 3.18 , respectivamente.

$$
\varphi_{\mathrm{c}}=\alpha_{\mathrm{c}}\left(\theta_{\mathrm{g}}-\theta_{\mathrm{a}}\right)
$$


$\varphi_{\mathrm{r}}=5,67 \times 10^{-8} \varepsilon_{\text {res }}\left\lfloor\left(\theta_{\mathrm{g}}+273\right)^{4}-\left(\theta_{\mathrm{a}}+273\right)^{4}\right\rfloor$

Nas equações 3.17 e 3.18, $\alpha_{c}$ é o coeficiente de transferência de calor por convecção (podendo ser tomado, para os casos práticos, igual a $25 \mathrm{~W} / \mathrm{m}^{2 \circ} \mathrm{C}$ ), $\theta_{\mathrm{g}}$ é a temperatura dos gases $\left({ }^{\circ} \mathrm{C}\right), \theta_{\mathrm{a}}$ é a temperatura na superfície do aço $\left({ }^{\circ} \mathrm{C}\right)$ e $\varepsilon_{\text {res }}$ é a emissividade resultante, podendo ser tomada para os casos práticos igual a 0,5 .

Para o caso de pilares mistos preenchidos, as normas NBR 14323:1999 e o EUROCODE 4 não apresentam equacionamento direto para a determinação da temperatura na seção transversal, sendo esta bastante complexa, tendo em vista a troca de calor entre o núcleo de concreto e o perfil de aço, devido ao gradiente térmico entre os dois materiais e a influência da umidade do concreto, que modifica o fluxo de calor. A inexistência de um equacionamento direto sugere a utilização de métodos numéricos ou de programas computacionais para a determinação do campo térmico na seção transversal dos pilares mistos.

Apenas em caráter informativo, menciona-se aqui o método para a determinação da elevação de temperatura na seção transversal dos pilares mistos, apresentado em LIE \& WHITE (1992) apud RIGAZZO et al (2006), o qual consiste na divisão da seção mista de aço e concreto em camadas para a determinação de uma temperatura média para cada camada, como ilustrado na figura 3.9. O objetivo de apresentar a última referência se deve ao fato de essa mesma possuir similaridade com a estratégia a ser adotada no presente trabalho.

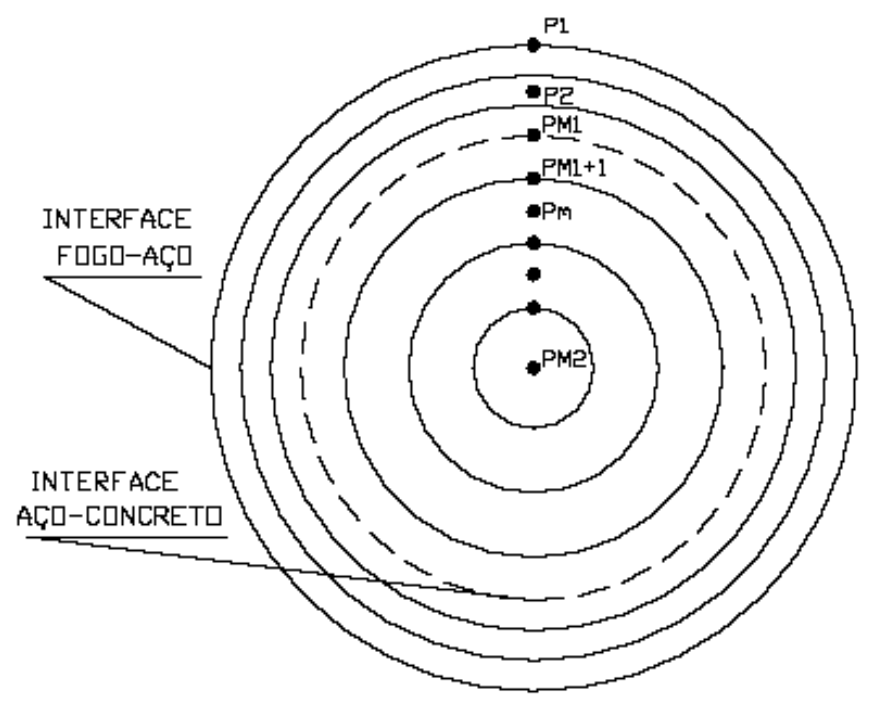

Figura 3.9 - Divisão da seção transversal em camadas. Fonte: RIGAZZO et al (2006) 


\subsection{PROPRIEDADES DOS MATERIAIS - Sob elevadas temperaturas}

Os materiais de forma geral quando submetidos a elevadas temperaturas sofrem alterações em suas propriedades físicas, tais como redução na sua resistência e em sua rigidez, bem como provoca o surgimento de esforços solicitantes adicionais, tornando-se de fundamental importância o estudos das propriedades térmicas e mecânicas dos materiais.

Na ABNT-NBR 14323:1999 são apresentadas as propriedades mecânicas e térmicas dos materiais aço e concreto, diretamente de interesse para os objetivos do presente trabalho. Ainda sugere que aços estruturais com propriedades diferentes das apresentadas em seu texto, ou que tenha suas propriedades alteradas em virtude dos trabalhos realizados para a conformação ou revestimento dos perfis ou composição da estrutura, tenham seus valores determinados e utilizados.

Entretanto, tais valores devem ser obtidos por meio de especificação estrangeira ou ensaios realizados em laboratório nacional ou estrangeiro, de acordo com norma nacional ou estrangeira. As propriedades térmicas dos materiais apresentadas pela NBR 14323:1999 têm como base o EUROCODE 3 Part 1-2.

Tendo em vista que atualmente a ABNT-NBR 14323:1999 encontra-se em processo de revisão e, portanto, seu texto base ainda não é definitivo, considerou-se adequado tomar como base os métodos de cálculo propostos pelo EUROCODE 3 part 1-2 para o aço e o EUROCODE 2 part 1-2 para o concreto.

\subsubsection{PROPRIEDADES TÉRMICAS DOS MATERIAIS}

Neste item serão apresentadas as propriedades térmicas dos materiais aço e concreto quando submetidos a elevadas temperaturas: condutividade térmica, alongamento específico e calor específico.

\subsubsection{Alongamento Específico}

\section{- Aço}

$\mathrm{O}$ alongamento específico do aço $\left(\Delta \ell_{a} / \ell_{a}\right)$ é dado em função da temperatura no elemento de aço $\left(\theta_{a}\right)$. As equações para o cálculo do alongamento específico estão apresentadas nas equações 3.19 . 


$$
\begin{array}{ll}
\Delta \ell_{\mathrm{a}} / \ell_{\mathrm{a}}=1,2 \cdot 10^{-5} \theta_{\mathrm{a}}+0,4 \cdot 10^{-8} \theta_{\mathrm{a}}^{2}-2,416 \cdot 10^{-4} & 20{ }^{\circ} \mathrm{C} \leq \theta_{a}<750{ }^{\circ} \mathrm{C} \\
\Delta \ell_{\mathrm{a}} / \ell_{\mathrm{a}}=1,1 \cdot 10^{-2} & 750{ }^{\circ} \mathrm{C} \leq \theta_{a}<860{ }^{\circ} \mathrm{C} \\
\Delta \ell_{a} / \ell_{a}=2 \cdot 10^{-5} \cdot \theta_{a}-6,2 \cdot 10^{-3} & 860^{\circ} \mathrm{C}<\theta_{a}<1200{ }^{\circ} \mathrm{C}
\end{array}
$$

A NBR 14323:1999 especifica que, caso se empregue o método simplificado de cálculo, a variação do alongamento relativo do aço com a temperatura pode ser considerada constante, conforme linha tracejada da figura 3.10. Neste caso, pode ser adotado o alongamento relativo simplificado, descrito pela equação 3.20.

$$
\frac{\Delta \ell_{\mathrm{a}}}{\ell_{\mathrm{a}}}=1,4 \cdot 10^{-6} \cdot\left(\theta_{\mathrm{a}}-20\right)
$$

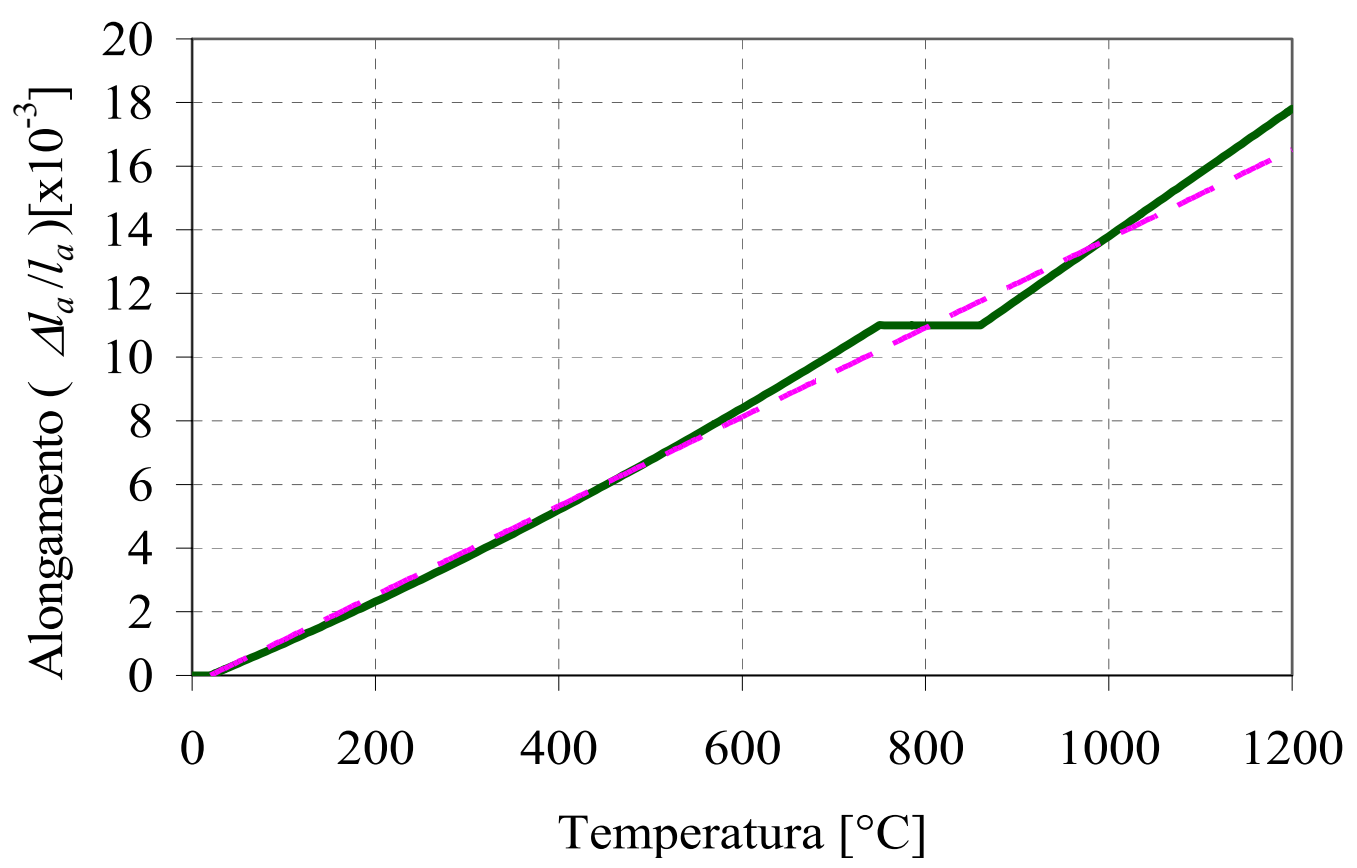

Figura 3.10 - Alongamento específico do aço em função da temperatura.

\section{- Concreto com agregados silicosos}

Segundo o EUROCODE 2 (2002) Part 1-2, o alongamento específico do concreto $\left(\Delta \ell_{\mathrm{c}} / \ell_{\mathrm{c}}\right)$, constituído por agregados silicosos, é dado em função da temperatura no concreto $\left(\theta_{c}\right)$. As equações para o cálculo do alongamento específico estão apresentadas nas Eq. 3.21.

$$
\begin{array}{ll}
\Delta \ell_{c} / \ell_{c}=-1,8 \cdot 10^{-4}+9 \cdot 10^{-6} \cdot \theta_{c}+2,3 \cdot 10^{-11} \cdot \theta_{c}^{3} & 20^{\circ} \mathrm{C} \leq \theta_{c}<700{ }^{\circ} \mathrm{C} \\
\Delta \ell_{c} / \ell_{c}=-1,4 \cdot 10^{-2} & 700^{\circ} \mathrm{C} \leq \theta_{c}<1200^{\circ} \mathrm{C}
\end{array}
$$




\section{- Concreto com agregados calcários}

Segundo o EUROCODE 2 (2002) Part 1-2, o alongamento específico do concreto $\left(\Delta \ell_{c} / \ell_{c}\right)$, constituído por agregados calcários, é dado em função da temperatura no concreto $\left(\theta_{c}\right)$. As equações para o cálculo do alongamento específico estão apresentadas nas equações 3.22 .

$$
\begin{array}{ll}
\Delta \ell_{c} / \ell_{c}=-1,2 \cdot 10^{-4}+6 \cdot 10^{-6} \cdot \theta_{c}+1,4 \cdot 10^{-11} \cdot \theta_{c}^{3} & 20^{\circ} \mathrm{C} \leq \theta_{c}<700^{\circ} \mathrm{C} \\
\Delta \ell_{c} / \ell_{c}=-1,2 \cdot 10^{-2} & 700^{\circ} \mathrm{C} \leq \theta_{c}<1200^{\circ} \mathrm{C}
\end{array}
$$

A NBR 14323:1999 permite que o alongamento específico do concreto de densidade normal em função da temperatura seja considerado constante, conforme linha tracejada da figura 3.11. Neste caso, pode ser adotado o alongamento relativo simplificado, descrito pela equação 3.23 .

$$
\frac{\Delta \ell_{c}}{\ell_{c}}=1,8 \cdot 10^{-6} \cdot\left(\theta_{c}-20\right)
$$

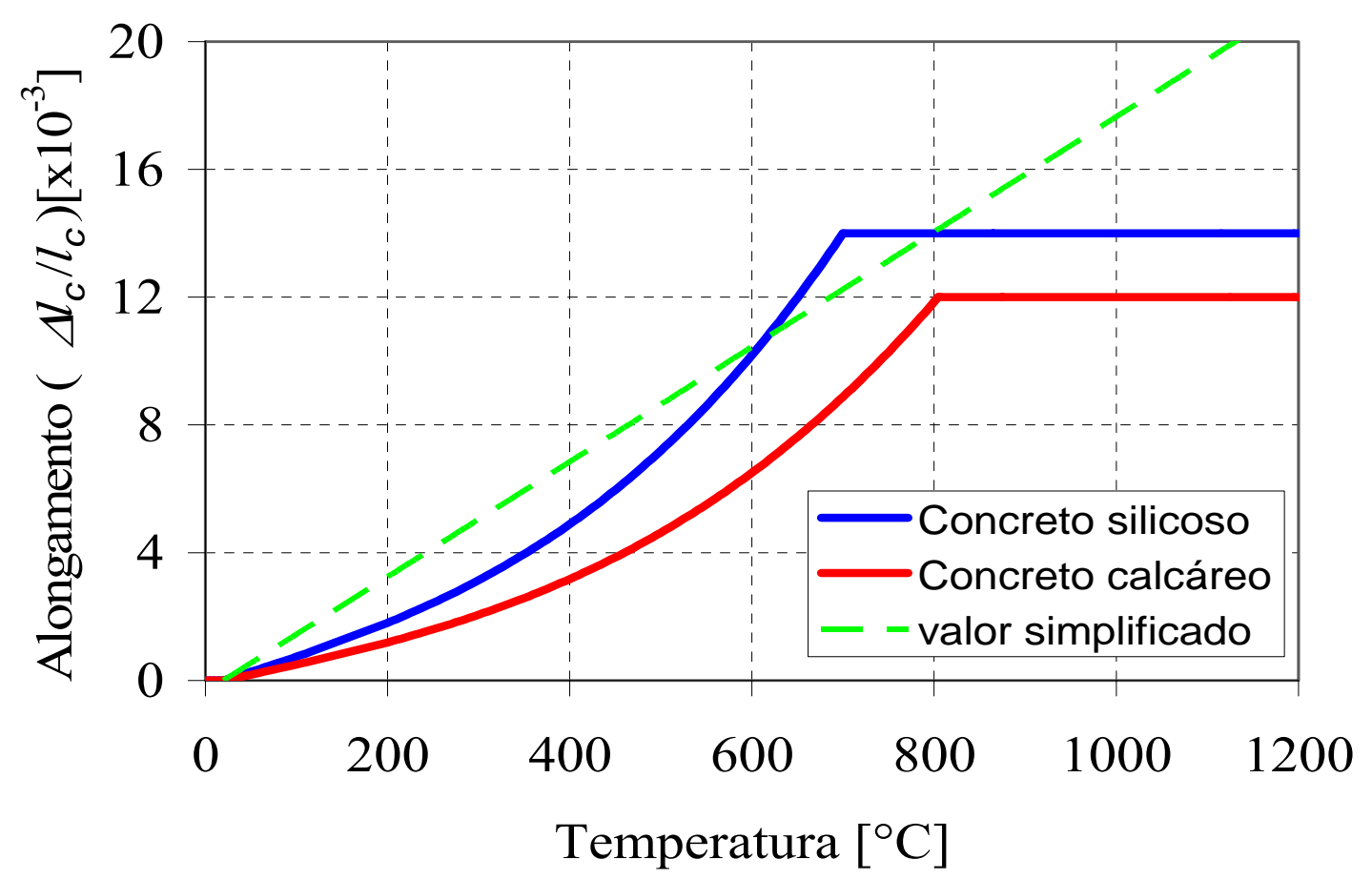

Figura 3.11 - Alongamento específico do concreto em função da temperatura. 


\subsubsection{Calor Específico}

- Aço

O calor específico do aço $\left(c_{a}\right)$, em Joule por quilograma e por grau Celsius $\left(\mathrm{J} / \mathrm{kg}^{\circ} \mathrm{C}\right)$, é dado em função da temperatura no elemento de aço $\left(\theta_{a}\right)$, com a temperatura do aço $\left(\mathrm{em}^{\circ} \mathrm{C}\right)$, o calor específico é dado pelas equações 3.24, conforme esquematização na figura 3.12.

$$
\begin{array}{ll}
c_{a}=1,2 \cdot 10^{-5} \cdot \theta_{a}+0,4 \cdot 10^{-8} \cdot \theta_{a}^{2}-2,416 \cdot 10^{-4} & 20{ }^{\circ} \mathrm{C} \leq \theta_{a}<600{ }^{\circ} \mathrm{C} \\
c_{a}=666+\frac{13002}{738-\theta_{a}} & 600{ }^{\circ} \mathrm{C} \leq \theta_{a}<735{ }^{\circ} \mathrm{C} \\
c_{a}=545+\frac{17820}{\theta_{a}-731} & 735^{\circ} \mathrm{C}<\theta_{a}<900{ }^{\circ} \mathrm{C} \\
c_{a}=650 & 900{ }^{\circ} \mathrm{C}<\theta_{a}<1200{ }^{\circ} \mathrm{C}
\end{array}
$$

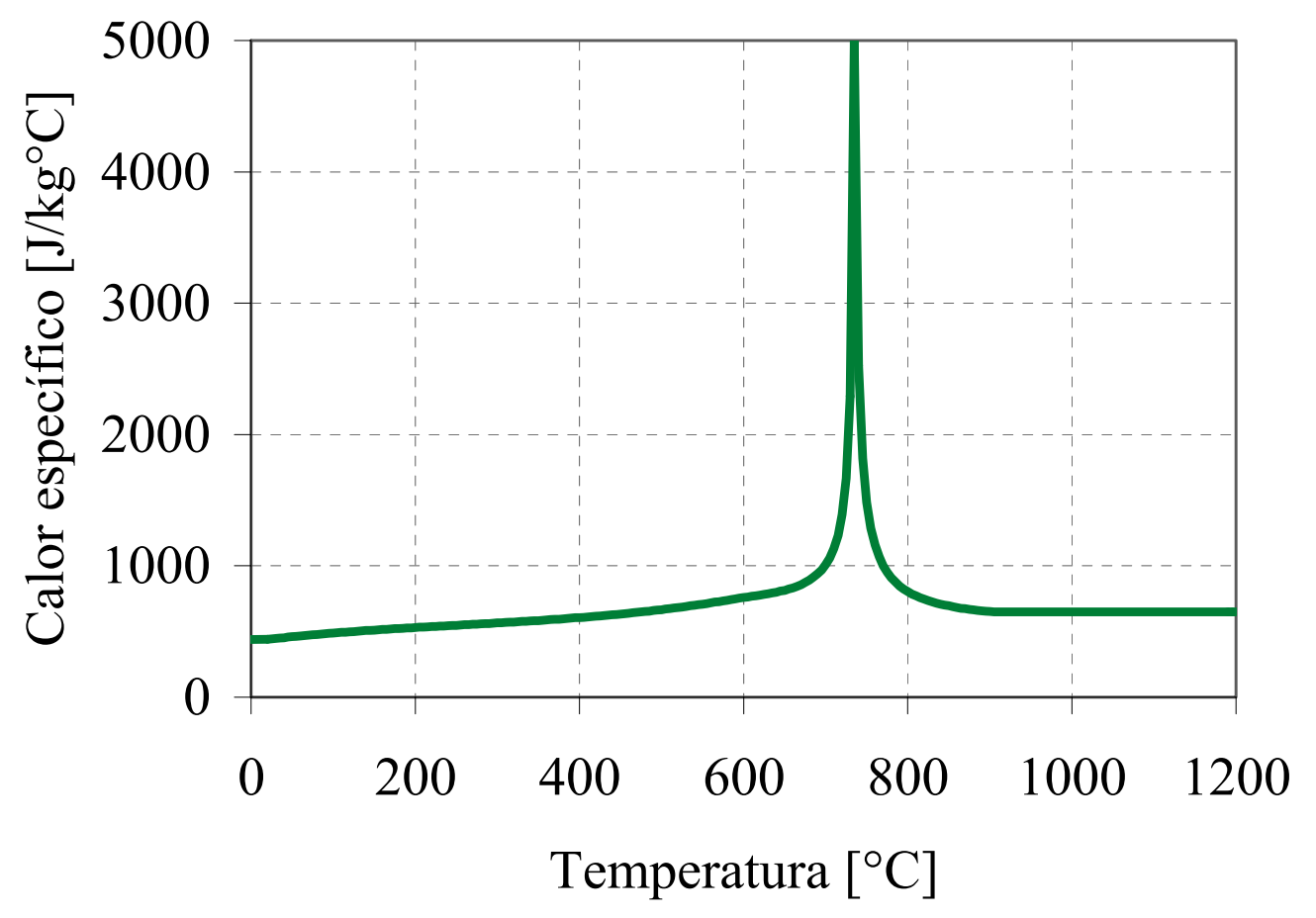

Figura 3.12 - Calor específico do aço em função da temperatura.

\section{- Concreto}

Segundo o EUROCODE 2 (2002) Part 1-2, o calor específico do concreto $\left(c_{c}\right)$, independe do tipo de agregado que o compõe, em Joule por quilograma e por grau Celsius 
$\left(\mathrm{J} / \mathrm{kg}^{\circ} \mathrm{C}\right)$, é dado em função da temperatura no concreto $\left(\theta_{\mathrm{c}}\right)$, com a temperatura do aço (em ${ }^{\circ} \mathrm{C}$ ), o calor específico é dado pelas equações 3.25.

$$
\begin{array}{ll}
c_{c}=900 & 20{ }^{\circ} \mathrm{C} \leq \theta_{c}<100{ }^{\circ} \mathrm{C} \\
c_{c}=900+(\theta c-100) & 100{ }^{\circ} \mathrm{C} \leq \theta_{c}<200{ }^{\circ} \mathrm{C} \\
c_{c}=1000+\frac{(\theta c-200)}{2} & 200{ }^{\circ} \mathrm{C}<\theta_{c}<400{ }^{\circ} \mathrm{C} \\
c_{c}=1100 & 400{ }^{\circ} \mathrm{C}<\theta_{a}<1200^{\circ} \mathrm{C}
\end{array}
$$

É importante ressaltar que a umidade presente no concreto pode alterar o valor do calor específico, que atinge um pico entre as temperaturas de $100{ }^{\circ} \mathrm{C}$ e $115^{\circ} \mathrm{C}$, decrescendo linearmente até a temperatura de $200{ }^{\circ} \mathrm{C}$. Os valores para o pico no calor específico em função da umidade do concreto estão apresentados na tabela 3.2. O gráfico da figura 3.13 apresenta a variação do calor específico para o concreto, em função da temperatura, também para diferentes umidades do concreto.

Tabela 3.2- Calor específico de pico em função da umidade

\begin{tabular}{|c|c|c|c|}
\hline Umidade & $\mathbf{0 , 0} \%$ & $\mathbf{1 , 5 \%}$ & $\mathbf{3 , 0} \%$ \\
\hline $\mathrm{c}_{\mathrm{c}, \text { pico }}$ & $900 \mathrm{~J} / \mathrm{kg}^{\mathrm{o}} \mathrm{C}$ & $1470 \mathrm{~J} / \mathrm{kg}^{\mathrm{o}} \mathrm{C}$ & $2020 \mathrm{~J} / \mathrm{kg}^{\mathrm{o}} \mathrm{C}$ \\
\hline
\end{tabular}

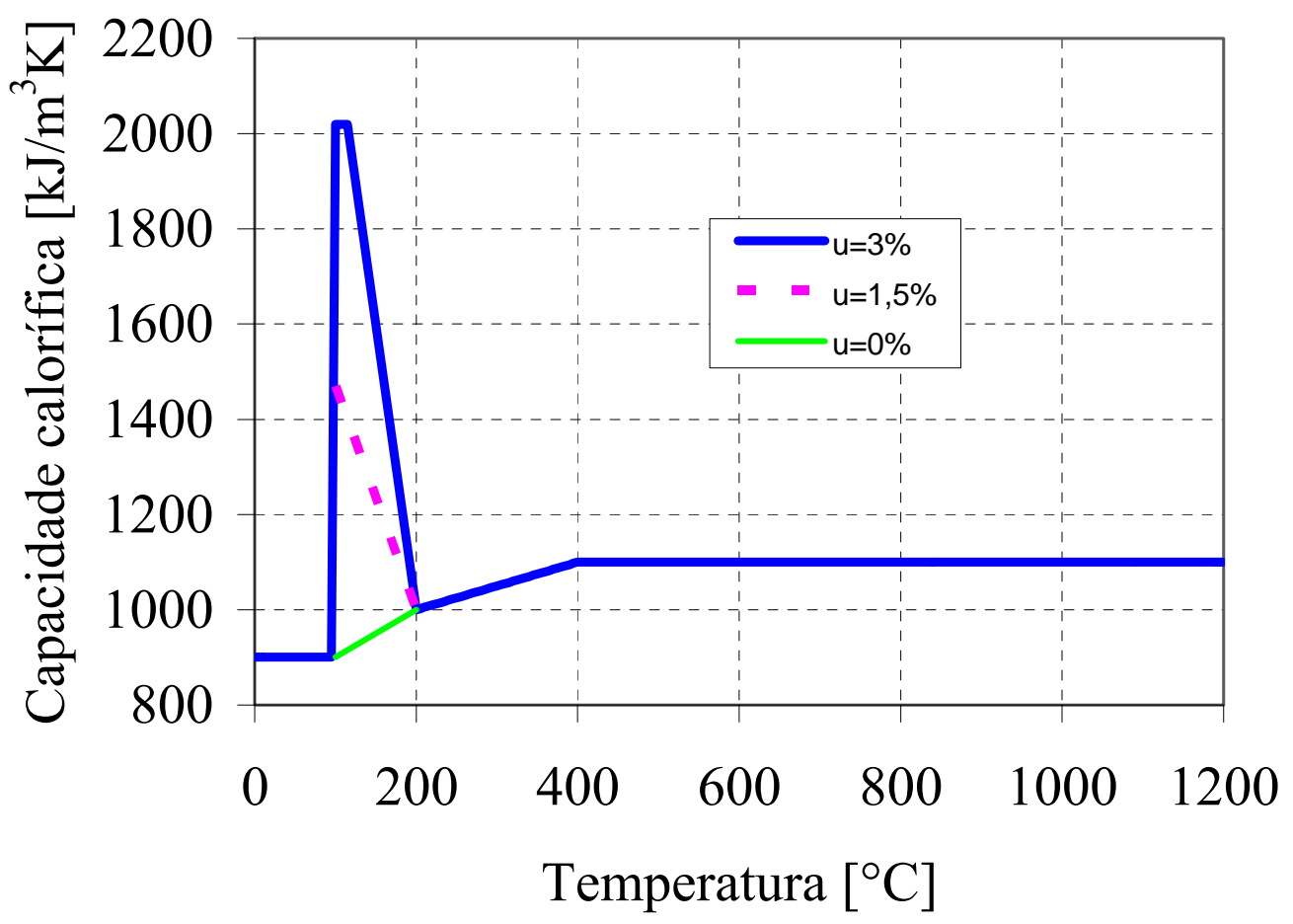

Figura 3.13 - Calor específico do concreto em função da temperatura. 


\subsubsection{Condutividade Térmica}

- Aço

A condutividade térmica do aço, $\lambda_{\mathrm{a}}$, em Watt por metro e por grau Celsius $\left(\mathrm{W} / \mathrm{m}^{\circ} \mathrm{C}\right)$, é dada em função da temperatura no elemento de aço $\left(\theta_{\mathrm{a}}\right.$, em $\left.{ }^{\circ} \mathrm{C}\right)$, conforme descrito pela equação 3.26 .

$$
\begin{array}{ll}
\lambda_{a}=54-3,33 \cdot 10^{-2} \cdot \theta_{a} & 20{ }^{\circ} \mathrm{C} \leq \theta_{a}<800{ }^{\circ} \mathrm{C} \\
\lambda_{a}=27,3 & 800{ }^{\circ} \mathrm{C} \leq \theta_{a}<1200{ }^{\circ} \mathrm{C}
\end{array}
$$

O gráfico da figura 3.14 apresenta a variação da condutividade térmica do aço em função da temperatura.

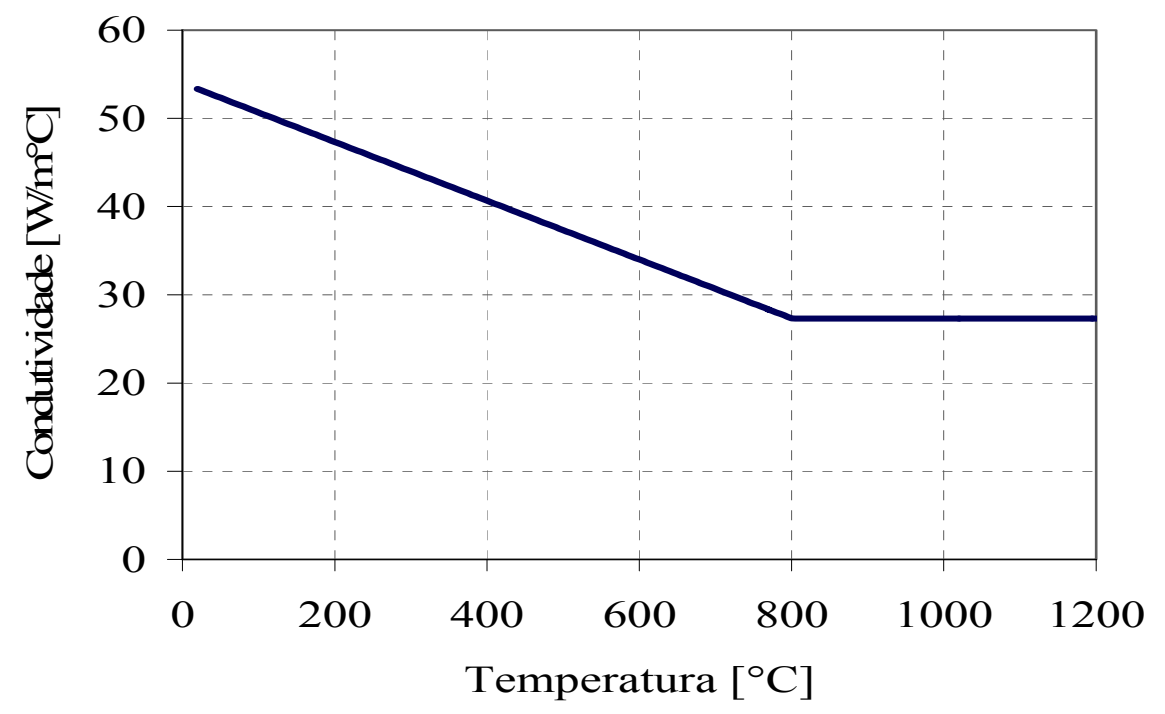

Figura 3.14 - Condutividade térmica do aço em função da temperatura.

\section{- Concreto}

Segundo o EUROCODE 2 (2002) Part 1-2, condutividade térmica do concreto $\left(\lambda_{\mathrm{c}}\right)$ independe do tipo de agregado que o compõe, com unidade em $\mathrm{W} / \mathrm{m}^{\circ} \mathrm{C}$, em função da temperatura no concreto $\left(\theta_{\mathrm{c}}\right)$ A condutividade térmica do concreto está contida num intervalo entre dois limites superior e inferior, expresso pelas equações (3.27) e (3.28), respectivamente.

$$
\lambda_{\mathrm{c}}=2-0,2452 \cdot\left(\frac{\theta}{100}\right)+0,0107 \cdot\left(\frac{\theta}{100}\right)^{2} \quad 20{ }^{\circ} \mathrm{C} \leq \theta_{c} \leq 1200{ }^{\circ} \mathrm{C}
$$




$$
\lambda_{\mathrm{c}}=1,36-0,136 \cdot\left(\frac{\theta}{100}\right)+0,0057 \cdot\left(\frac{\theta}{100}\right)^{2} \quad 20^{\circ} \mathrm{C} \leq \theta_{c} \leq 1200{ }^{\circ} \mathrm{C}
$$

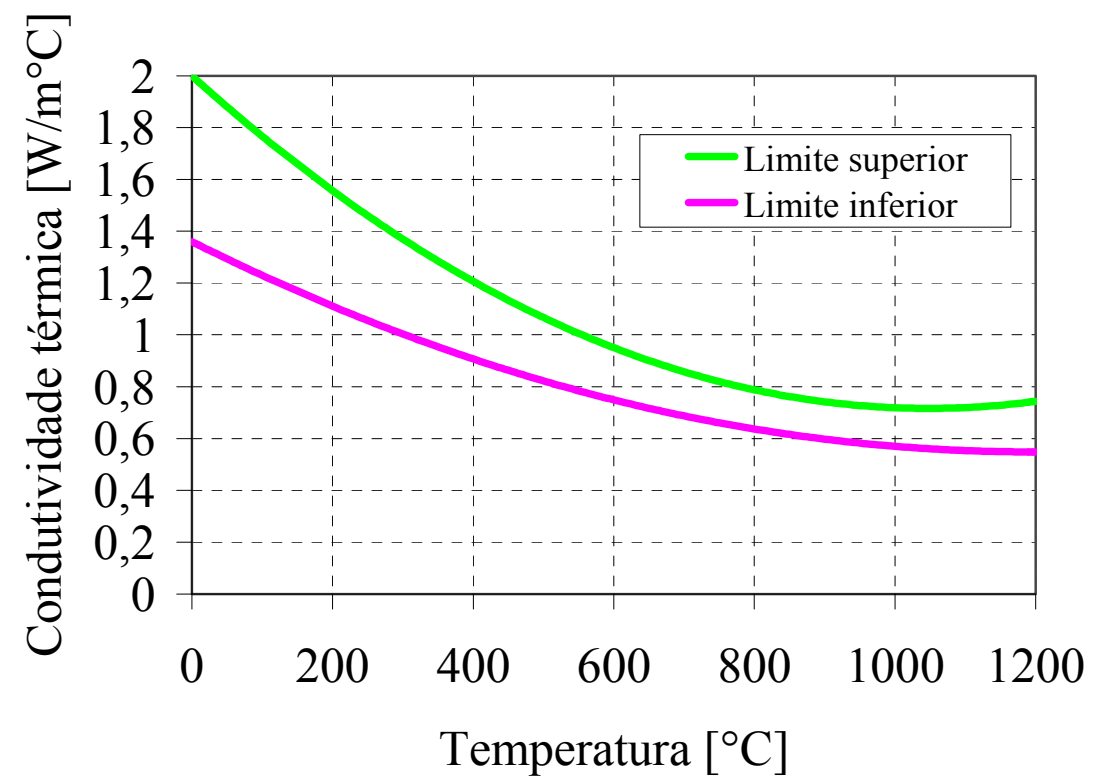

Figura 3.15 - Condutividade térmica do concreto em função da temperatura.

\subsubsection{PROPRIEDADES MECÂNICAS DOS MATERIAIS}

Neste item serão apresentadas as propriedades mecânicas dos materiais aço e concreto, quando submetidos a elevadas temperaturas, no referente à resistência e ao módulo de elasticidade.

\subsubsection{Resistência e Módulo de elasticidade}

- Aço

A relação constitutiva do aço em temperaturas elevadas, proposta pelo EUROCODE 3 Part 1.2, é determinada por meio de ensaio térmico transiente, com taxa de aquecimento de $10^{\circ} \mathrm{C} / \mathrm{min}$, como ocorre na maioria dos casos reais de estruturas metálicas expostas ao fogo. A figura 3.16 ilustra o gráfico da relação constitutiva do aço adotada na última referência.

$\mathrm{Na}$ última figura, pode-se observar um primeiro estágio que consiste de resposta elástica- linear para o nível de tensão aplicado, cuja resposta se mantém até que o elemento atinja a tensão de proporcionalidade. Posteriormente, a relação constitutiva segue o comportamento elasto-plástico com encruamento. 


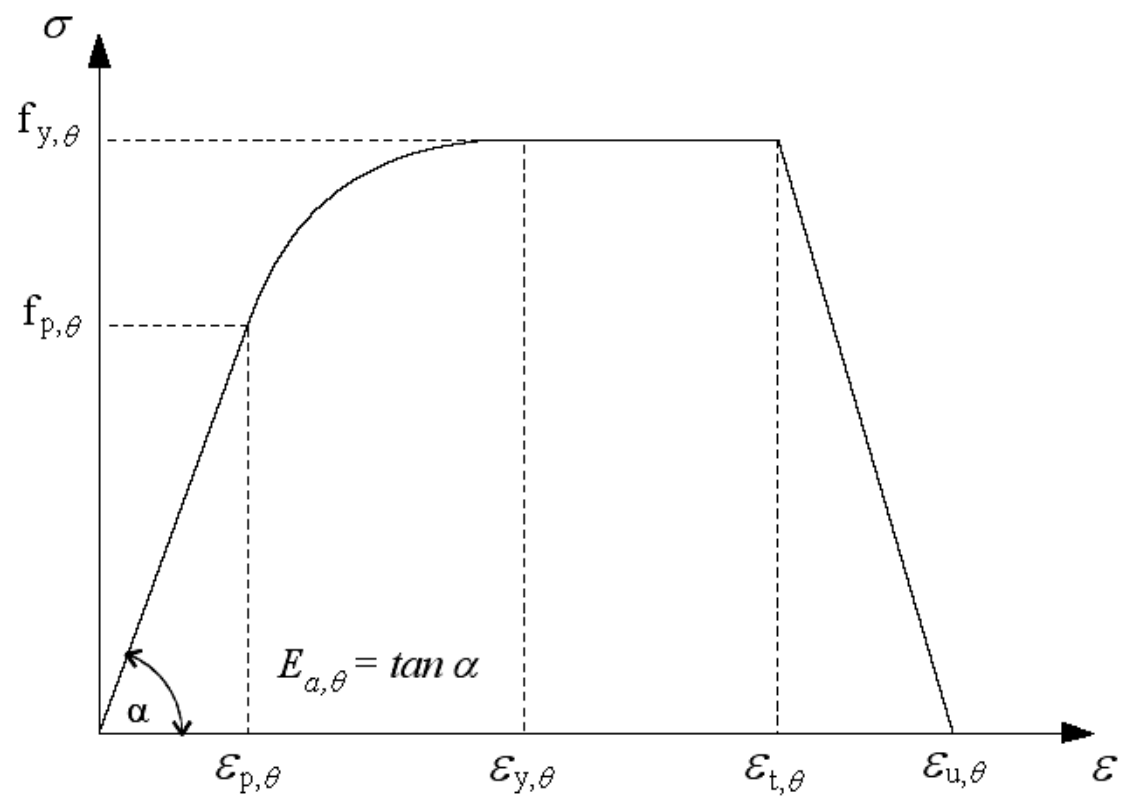

Figura 3.16 - Relação constitutiva do aço carbono para uma temperatura $\theta$.

Tabela 3.3 - Equações para relação constitutiva a uma determinada temperatura $\theta$.

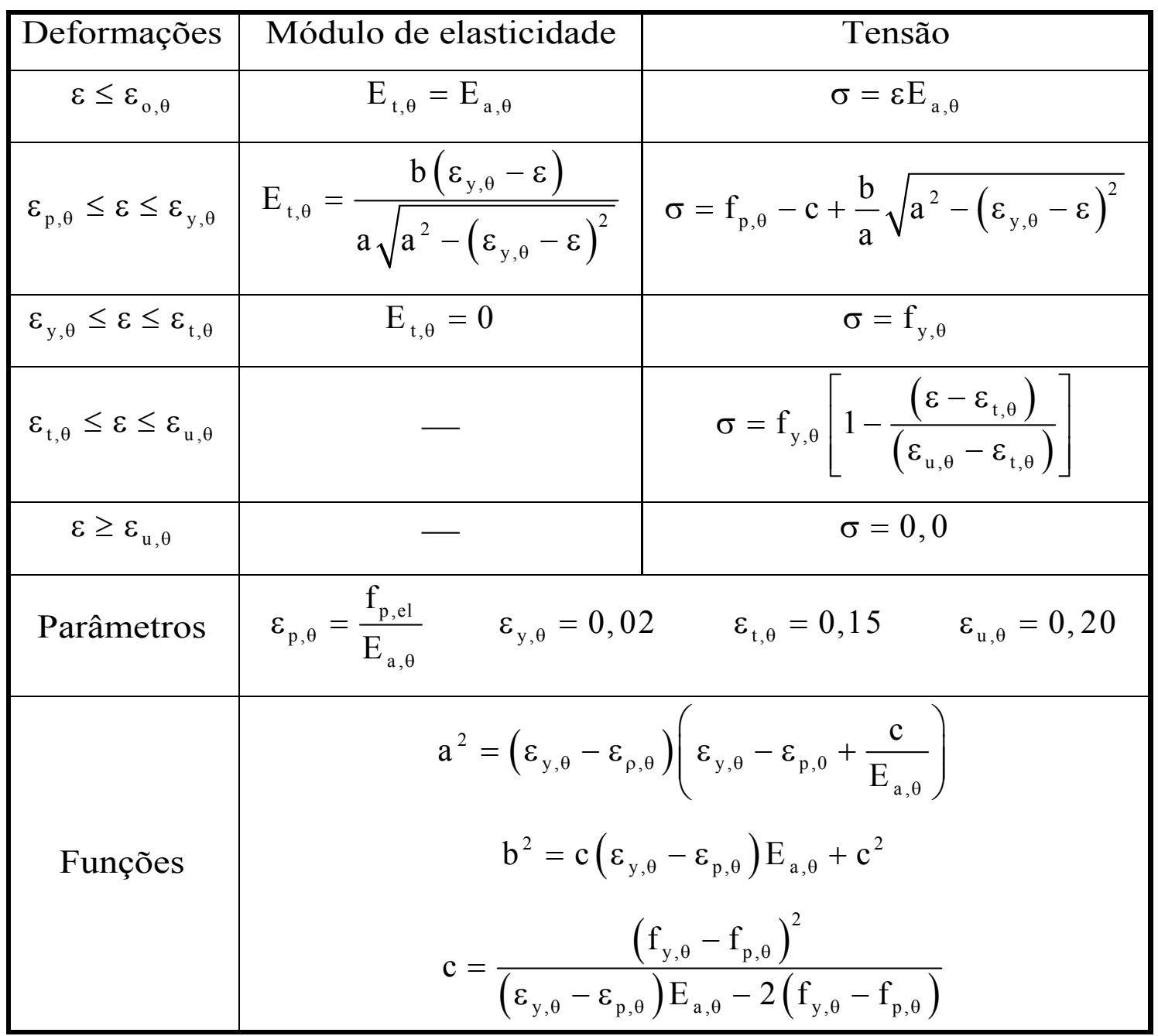


O estágio seguinte representa o escoamento da barra, com acréscimo de deformação sem variação do nível de tensão. A última parte da curva é caracterizada pelo decrescimento linear da tensão até que, na deformação última, a tensão seja zero.

$\mathrm{Na}$ figura 3.16, $\mathrm{f}_{\mathrm{y}, \theta} \theta$ é a resistência efetiva de escoamento, $\mathrm{f}_{\mathrm{p}, \theta}$ é o limite de proporcionalidade, $\mathrm{E}_{\mathrm{a}, \theta}$ é o modulo de elasticidade na fase elástica, $\varepsilon_{\mathrm{p}, \theta}$ é o limite de proporcionalidade na deformação, $\varepsilon_{\mathrm{y}, \theta}$ é a deformação de escoamento, $\varepsilon_{\mathrm{t}, \theta}$ é o limite de deformação para a resistência ao escoamento e $\varepsilon_{\mathrm{u}, \theta}$ é a deformação de ruptura. Na tabela 3.3 são apresentadas equações para a determinação da relação constitutiva em função da temperatura, conforme figura 3.16.

$\mathrm{Na}$ tabela 3.4 são apresentados os coeficientes de redução para a resistência ao escoamento e módulo de elasticidade do aço, em função da temperatura, sendo utilizado o EUROCODE 3 part. 1-2 como referência. Esses mesmos valores estão apresentados em forma de gráfico nas figuras 3.17 e 3.18 .

Tabela 3.4 - Fatores de redução para o aço.

\begin{tabular}{|c|c|c|c|}
\hline $\begin{array}{c}\text { Temperatura do Aço } \\
\theta_{a}\end{array}$ & $\begin{array}{c}\text { Fator de redução } \\
\text { para a resistência ao } \\
\text { escoamento dos aços } \\
\text { laminados }\end{array}$ & $\begin{array}{c}\text { Fator de redução } \\
\text { para o limite de } \\
\text { proporcionalidade }\end{array}$ & $\begin{array}{c}\text { Fator de redução } \\
\text { para o módulo de } \\
\text { elasticidade dos aços } \\
\text { laminados }\end{array}$ \\
\hline$\left({ }^{\circ} \mathbf{C}\right)$ & $\mathbf{k}_{\mathbf{y}, \theta}=\mathbf{f}_{\mathbf{y}, \theta} / \mathbf{f}_{\mathbf{y}}$ & $\mathbf{k}_{\mathbf{p}, \theta}=\mathbf{f}_{\mathbf{p}, \theta} / \mathbf{f}_{\mathbf{y}}$ & $\mathbf{k}_{\mathbf{E}, \theta}=\mathbf{E}_{\mathbf{a}, \theta} / \mathbf{E}_{\mathbf{a}}$ \\
\hline 20 & 1,000 & 1,000 & 1,000 \\
\hline 100 & 1,000 & 1,000 & 1,000 \\
\hline 200 & 1,000 & 0,807 & 0,900 \\
\hline 300 & 1,000 & 0,613 & 0,800 \\
\hline 400 & 1,000 & 0,420 & 0,700 \\
\hline 500 & 0,780 & 0,360 & 0,600 \\
\hline 600 & 0,470 & 0,180 & 0,310 \\
\hline 700 & 0,230 & 0,075 & 0,130 \\
\hline 800 & 0,110 & 0,050 & 0,090 \\
\hline 900 & 0,060 & 0,0375 & 0,0675 \\
\hline 1000 & 0,040 & 0,0250 & 0,045 \\
\hline 1100 & 0,020 & 0,0125 & 0,0225 \\
\hline 1200 & 0,000 & 0,0000 & 0,0000 \\
\hline
\end{tabular}




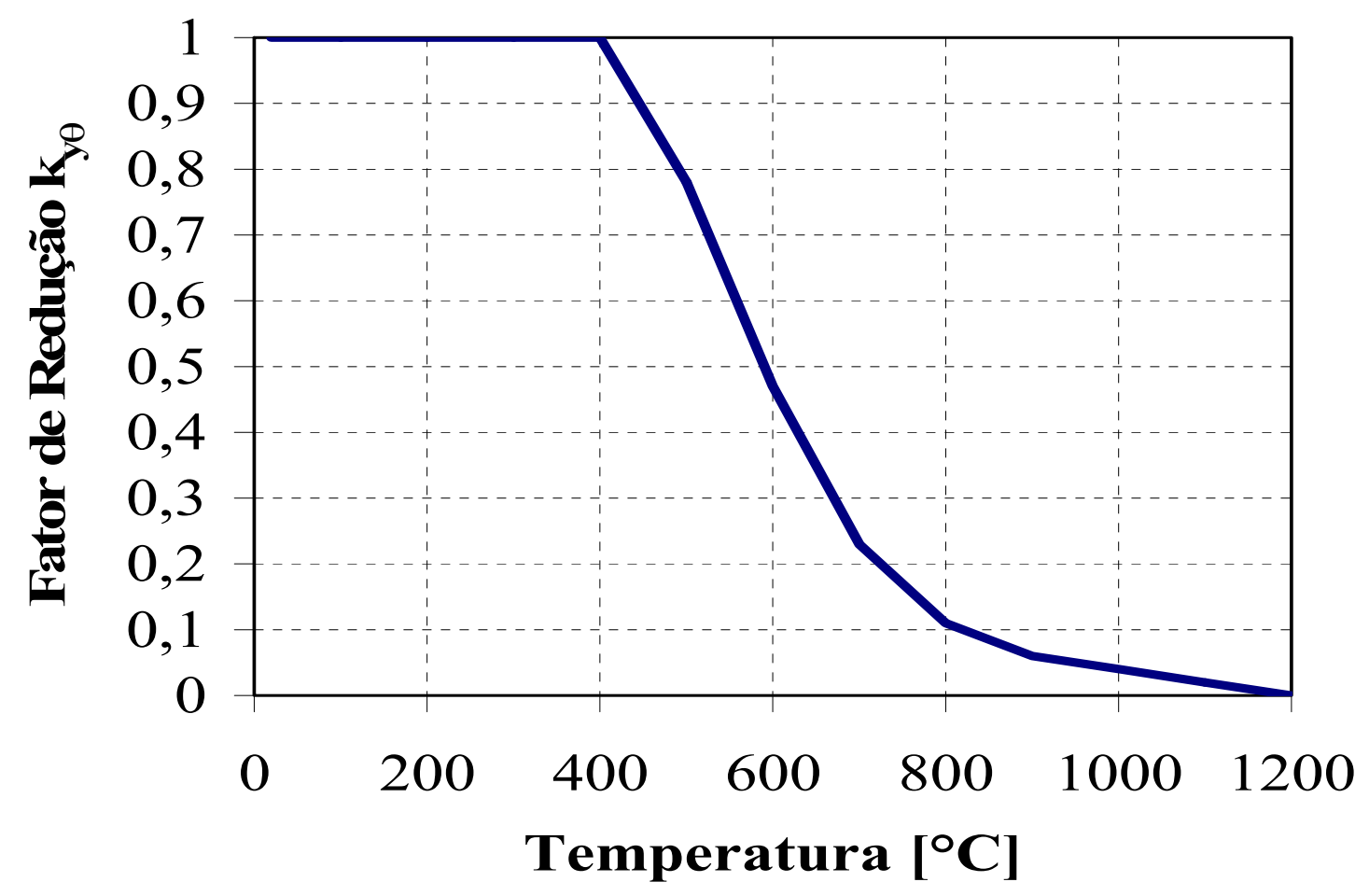

Figura 3.17 - Redução da resistência ao escoamento do aço x temperatura.

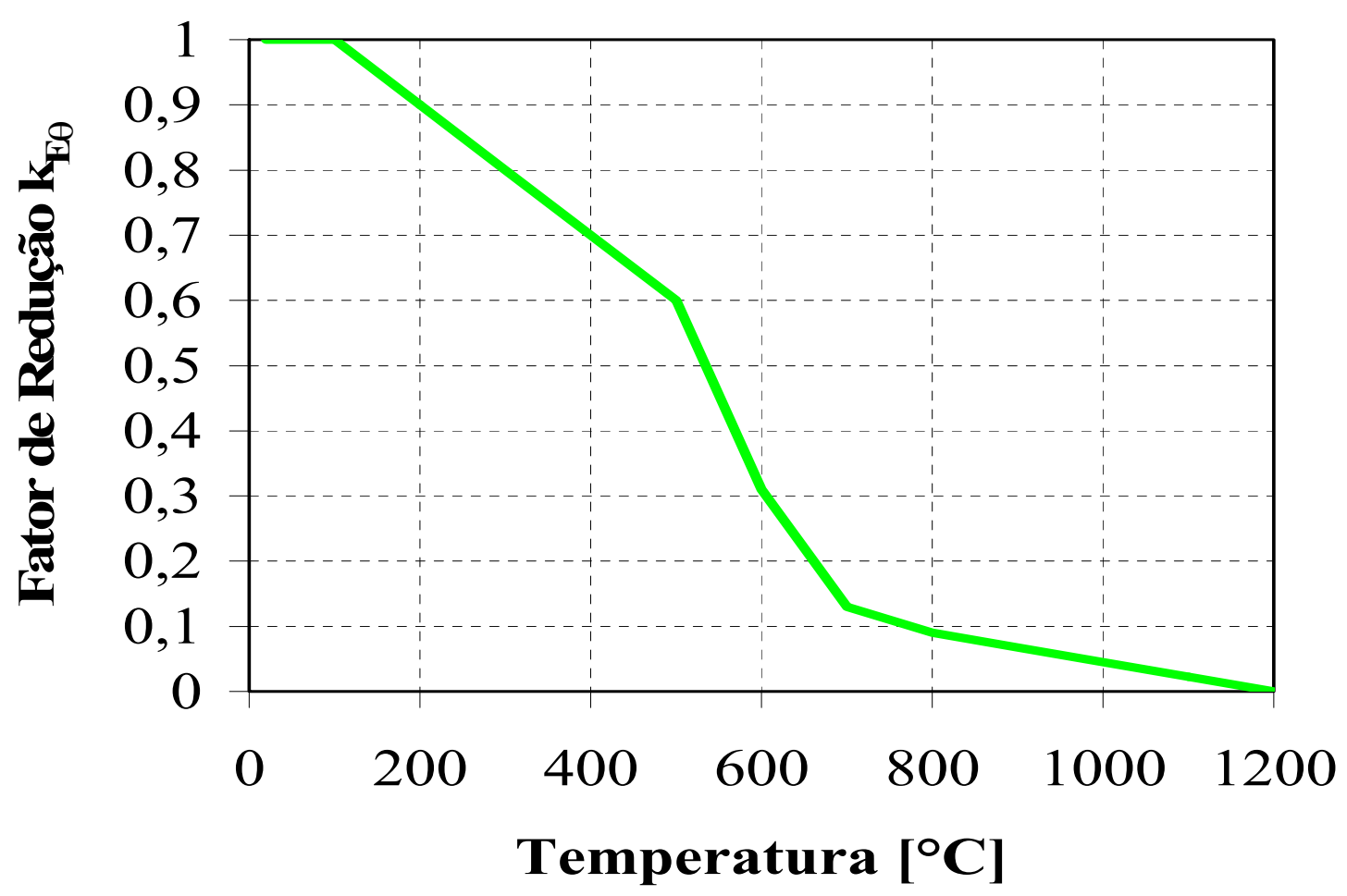

Figura 3.18 - Redução do módulo de elasticidade do aço x temperatura. 


\section{- Concreto}

O concreto quando submetido a elevadas temperaturas perde suas propriedades mecânicas, e esse fator pode ainda ser agravado pelo "spalling" que implica na redução da seção transversal do elemento.

Segundo WANG (2002), o concreto é um material higroscópico que contém água e, devido à migração da água no interior de sua matriz, o processo de transferência de calor é afetado. Para avaliar de forma precisa a temperatura nesse tipo de material deve ser realizada uma análise combinada de transferência de temperatura e massa. Porém, essa análise é complexa e muito custosa computacionalmente.

As propriedades físicas de resistência e deformação do concreto, quando submetido a elevadas temperaturas, são apresentadas no EUROCODE 2 Part 1-2 para os concretos de densidade normal, possibilitando a obtenção da relação constitutiva, para uma temperatura $\theta$ qualquer, descrita pela equação 3.29.

$$
\sigma(\theta)=\frac{3 \cdot \varepsilon \cdot \mathrm{f}_{\mathrm{c}, \theta}}{\varepsilon_{\mathrm{cl}, \theta} \cdot\left(2+\left(\frac{\varepsilon}{\varepsilon_{\mathrm{c} 1, \theta}}\right)^{3}\right)} \quad \quad \text { para } \varepsilon \leq \varepsilon_{\mathrm{c} 1, \theta}
$$

$\mathrm{Na}$ equação $3.29, \sigma(\theta)$ é a tensão aplicada no concreto, $\varepsilon$ é a deformação correspondente à tensão $\sigma, \varepsilon_{\mathrm{cu}, \theta}$ é a deformação última à compressão, $\varepsilon_{\mathrm{c} 1, \theta} \theta$ é a deformação à compressão correspondente a $\mathrm{f}_{\mathrm{c}, \theta}$ e $\mathrm{f}_{\mathrm{c}, \theta}$ é a resistência à compressão do concreto. Para $\varepsilon_{\mathrm{c} 1, \theta} \leq \varepsilon$ $\leq \varepsilon_{\mathrm{cu}, \theta}$, pode ser adotado um ramo descendente linear ou não-linear. A equação 3.29 é representada graficamente na figura 3.19 .

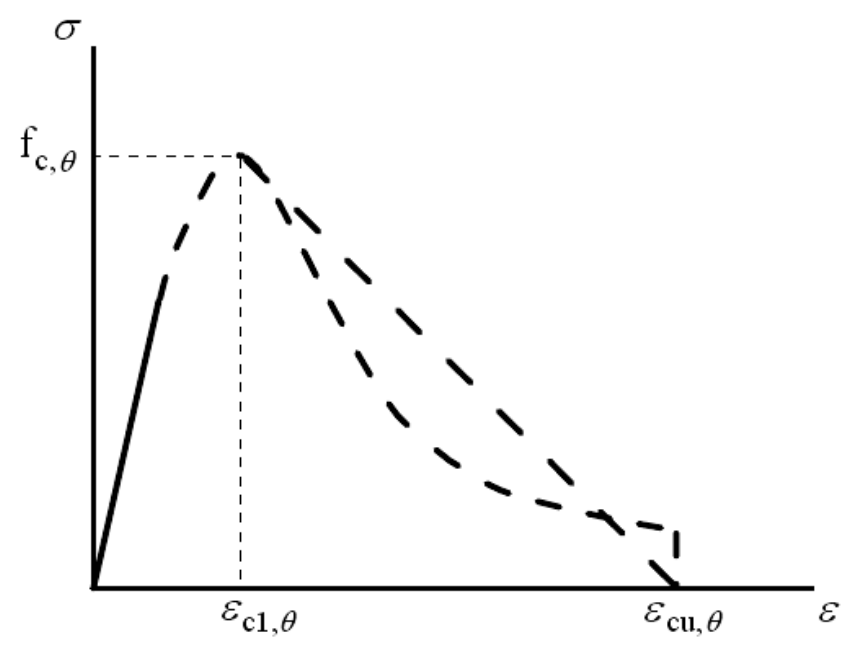

Figura 3.19 - Relação constitutiva do concreto de densidade normal. 
A tabela 3.5 apresenta os fatores de redução das propriedades mecânicas do concreto apresentadas pelo EUROCODE 2, para o concreto composto por agregado silicoso e agregado calcáreo. Esses mesmos valores estão apresentados no gráfico da figura 3.20.

Tabela 3.5 - Fatores de redução para o concreto.

\begin{tabular}{|c|c|c|c|c|c|c|}
\hline \multirow{2}{*}{$\begin{array}{c}\text { Temperatura } \\
\left({ }^{\circ} \mathrm{C}\right) \\
\end{array}$} & \multicolumn{3}{|c|}{ Concreto com agregado silicoso } & \multicolumn{3}{|c|}{ Concreto com agregado calcáreo } \\
\hline & $\mathrm{f}_{\mathrm{c} \theta} / \mathrm{f}_{\mathrm{ck}}$ & $\varepsilon_{\mathrm{cl} \theta} \theta$ & $\varepsilon_{\mathrm{cul} \theta}$ & $\mathrm{f}_{\mathrm{c}, \theta} / \mathrm{f}_{\mathrm{ck}}$ & $\varepsilon_{\mathrm{cl} \theta}$ & $\varepsilon_{\mathrm{cul} \theta}$ \\
\hline 20 & 1,00 & 0,0025 & 0,0200 & 1,00 & 0,0025 & 0,0200 \\
\hline 100 & 1,00 & 0,0040 & 0,0225 & 1,00 & 0,0040 & 0,0225 \\
\hline 200 & 0,95 & 0,0055 & 0,0250 & 0,97 & 0,0055 & 0,0250 \\
\hline 300 & 0,85 & 0,0070 & 0,0275 & 0,91 & 0,0070 & 0,0275 \\
\hline 400 & 0,75 & 0,0100 & 0,0300 & 0,85 & 0,0100 & 0,0300 \\
\hline 500 & 0,60 & 0,0150 & 0,0325 & 0,74 & 0,0150 & 0,0325 \\
\hline 600 & 0,45 & 0,0250 & 0,0350 & 0,60 & 0,0250 & 0,0350 \\
\hline 700 & 0,30 & 0,0250 & 0,0375 & 0,43 & 0,0250 & 0,0375 \\
\hline 800 & 0,15 & 0,0250 & 0,0400 & 0,27 & 0,0250 & 0,0400 \\
\hline 900 & 0,08 & 0,0250 & 0,0425 & 0,15 & 0,0250 & 0,0425 \\
\hline 1000 & 0,04 & 0,0250 & 0,4500 & 0,06 & 0,0250 & 0,4500 \\
\hline 1100 & 0,01 & 0,0250 & 0,0475 & 0,02 & 0,0250 & 0,0475 \\
\hline 1200 & 0,00 & - & - & 0,00 & - & - \\
\hline
\end{tabular}

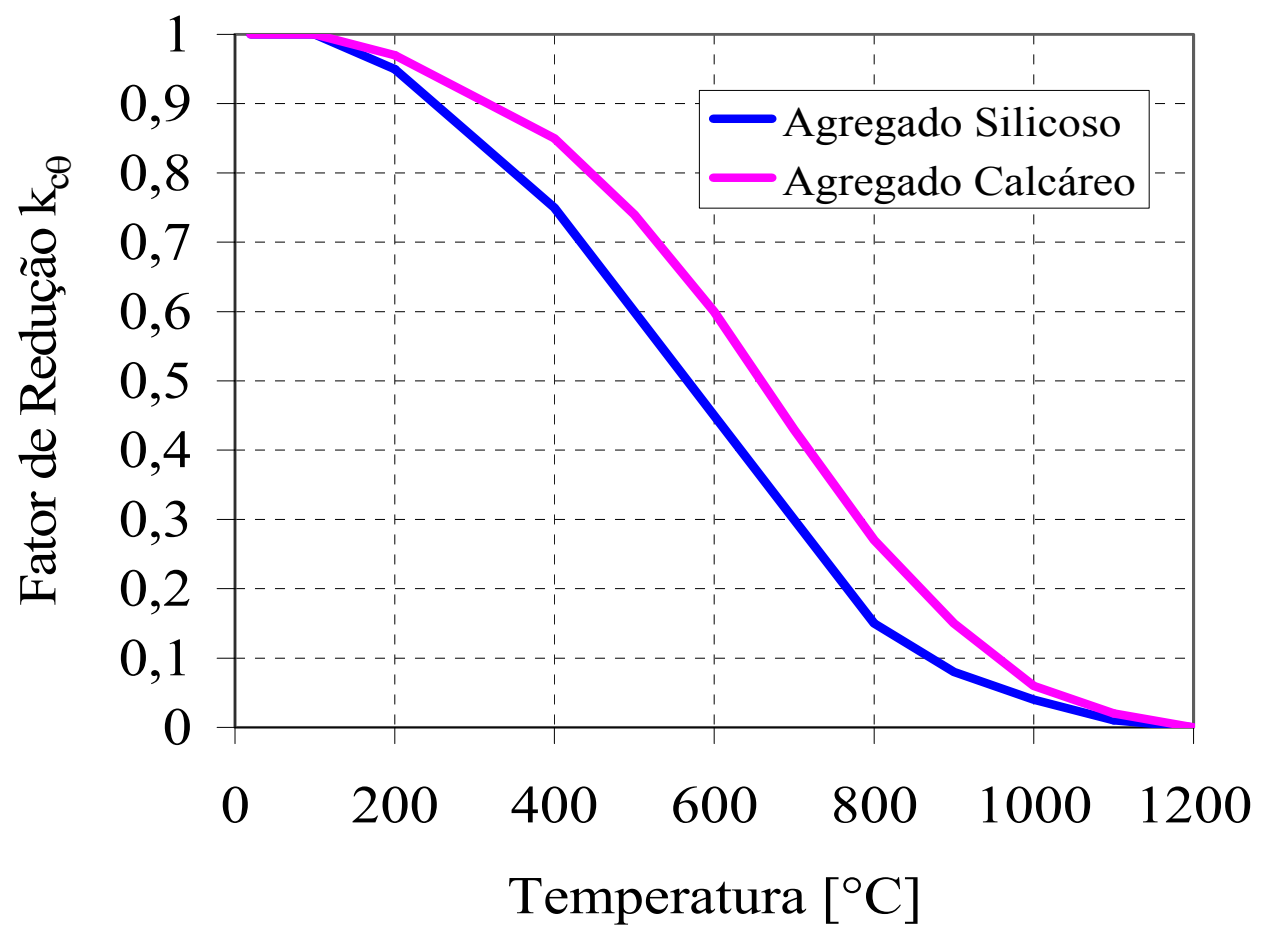

Figura 3.20 - Redução da resistência característica à compressão do concreto x temperatura. 
Para a obtenção do fator de redução do módulo de elasticidade do concreto, representado pelo parâmetro $\mathrm{k}_{\mathrm{Ec}, \theta}$, se utiliza a equação 3.30 .

$$
\mathrm{k}_{\mathrm{Ec}, \theta}=\frac{\mathrm{k}_{\mathrm{c}, \theta} \cdot \mathrm{f}_{\mathrm{ck}}}{\varepsilon_{\mathrm{cl}, \theta} \cdot \mathrm{E}_{\mathrm{c} 0}}
$$

sendo:

$\mathrm{k}_{\mathrm{Ec}, \theta}$ : fator de redução do módulo de elasticidade do concreto;

$\mathrm{k}_{\mathrm{c}, \theta}$ : fator de redução da resistência característica do concreto a compressão, dado na Tab. 3.5;

$\mathrm{f}_{\mathrm{ck}}$ : resistência característica do concreto a compressão;

\subsection{DIMENSIONAMENTO DOS PILARES MISTOS DE AÇO PREENCHIDOS COM CONCRETO EM SITUAÇÃO DE INCÊNDIO}

Neste item serão apresentados os métodos de dimensionamento de pilares mistos preenchidos com concreto em situação de incêndio apresentados pela norma brasileira ABNT NBR 14323:1999 e pelo EUROCODE 4.

\subsubsection{NBR 14323:1999}

\subsubsection{MÉTODO TABULAR}

A ABNT NBR 14323:1999 trata, em seu ANEXO B, do dimensionamento dos pilares mistos em temperatura elevada. Os pilares mistos devem estar expostos ao fogo ao longo de todo o seu comprimento e é utilizado o método tabular. Os limites de aplicabilidade são:

- O incêndio é limitado a somente um pavimento;

- As barras estão submetidas à temperatura uniforme ao longo do comprimento;

- As condições de contorno das barras em temperatura ambiente são invariantes com a temperatura;

- Os esforços nos apoios e extremidades das barras em temperatura ambiente são invariantes com a temperatura.

As tabelas apresentadas pelas normas foram elaboradas considerando os efeitos de deformações térmicas resultantes de gradientes de temperatura. 
O método tabular consiste na verificação das dimensões mínimas da seção transversal, das taxas mínimas de armadura e distâncias mínimas entre os eixos das barras da armadura à face do perfil, sendo que estas dimensões mínimas são determinadas em função do tempo requerido de resistência a incêndio (TRRF) e do nível de carga, $\eta_{\text {fi }}$ dado pela equação 3.31. A tabela 3.6 apresenta o método tabular adotado pela NBR 14323:1999.

$$
\eta_{\mathrm{fi}}=\frac{\mathrm{R}_{\mathrm{fi}, \mathrm{d}}}{\mathrm{R}_{\mathrm{d}}}
$$

Tabela 3.6 - Método Tabular proposto pela NBR:14323:1999.

\begin{tabular}{|c|c|c|c|c|c|}
\hline & 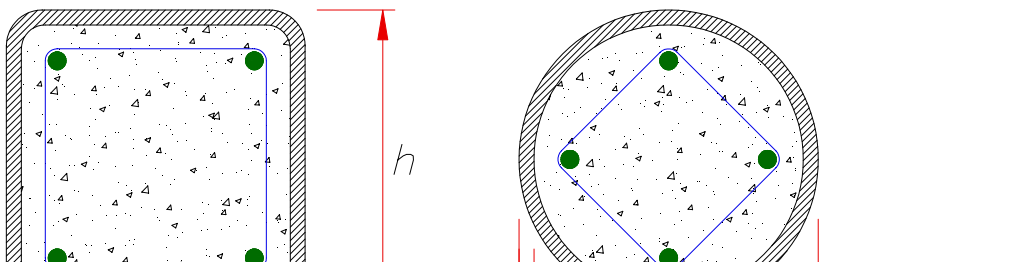 & \multicolumn{4}{|c|}{ TRRF (min) } \\
\hline \multicolumn{2}{|r|}{ Seção de aço: $(\mathrm{b} / \mathrm{e}) \geq 25 \mathrm{ou}(\mathrm{d} / \mathrm{e}) \geq 25$} & 30 & 60 & 90 & 120 \\
\hline$\overline{1}$ & $\begin{array}{l}\text { Dimensões mínimas da seção transversal para o nível de carga } \\
\eta_{\mathrm{fi}} \leq 0,3\end{array}$ & \multirow{4}{*}{$\begin{array}{c}160 \\
0 \\
-\end{array}$} & \multirow{4}{*}{$\begin{array}{c}260 \\
1,5 \\
30\end{array}$} & \multirow{4}{*}{$\begin{array}{l}300 \\
3,0 \\
40\end{array}$} & \multirow{4}{*}{$\begin{array}{c}300 \\
6,0 \\
50\end{array}$} \\
\hline 1.1 & Dimensões mínimas de $\mathrm{h}$ e b ou diâmetro mínimo d (mm) & & & & \\
\hline 1.2 & Taxa mínima de armadura $A_{s} /\left(A_{c}+A_{s}\right)$ em $\%$ & & & & \\
\hline 1.3 & Distância mínima da face ao eixo das barras da armadura $u_{\mathrm{s}}(\mathrm{mm})$ & & & & \\
\hline 2 & $\begin{array}{l}\text { Dimensões mínimas da seção transversal para o nível de carga } \\
\eta_{\mathrm{fi}} \leq 0,5\end{array}$ & \multirow{4}{*}{$\begin{array}{c}260 \\
0\end{array}$} & \multirow{4}{*}{$\begin{array}{c}260 \\
3,0 \\
30\end{array}$} & \multirow{4}{*}{$\begin{array}{c}400 \\
6,0 \\
40\end{array}$} & \multirow{4}{*}{$\begin{array}{r}450 \\
6,0 \\
50\end{array}$} \\
\hline 2.1 & Dimensões mínimas de $\mathrm{h}$ e b ou diâmetro mínimo d (mm) & & & & \\
\hline 2.2 & Taxa mínima de armadura $A_{s} /\left(A_{c}+A_{s}\right)$ em $\%$ & & & & \\
\hline 2.3 & Distância mínima da face ao eixo das barras da armadura $u_{\mathrm{s}}(\mathrm{mm})$ & & & & \\
\hline 3 & $\begin{array}{l}\text { Dimensões mínimas da seção transversal para o nível de carga } \\
\eta_{\mathrm{fi}} \leq 0,7\end{array}$ & \multirow[b]{2}{*}{260} & \multirow[b]{2}{*}{450} & \multirow[b]{2}{*}{550} & \\
\hline 3.1 & Dimensões mínimas de h e b ou diâmetro mínimo d (mm) & & & & - \\
\hline 3.2 & Taxa mínima de armadura $A_{s} /\left(A_{c}+A_{s}\right)$ em $\%$ & 3,0 & 6,0 & 6,0 & - \\
\hline 3.3 & Distância mínima da face ao eixo das barras da armadura $u_{\mathrm{s}}(\mathrm{mm})$ & 25 & 30 & 40 & - \\
\hline
\end{tabular}


$\mathrm{Na}$ equação $3.31, \mathrm{R}_{\mathrm{fi}, \mathrm{d}}$ é a resistência de cálculo em situação de incêndio e $\mathrm{R}_{\mathrm{d}} \mathrm{a}$ resistência de cálculo em temperatura ambiente; $\mathrm{Na}$ determinação de $\mathrm{R}_{\mathrm{d}}$ e de $\mathrm{R}_{\mathrm{fi}, \mathrm{d}}=\eta_{\mathrm{fi}} \cdot \mathrm{R}_{\mathrm{d}}$, em combinação com a tabela 3.6, aplicam-se as seguintes regras:

- Independente do valor da resistência ao escoamento do aço dos perfis tubulares, o máximo valor adotado poderá ser de $250 \mathrm{MPa}$;

- A espessura " $t$ " da parede do perfil tubular não pode exceder 1/25 da menor dimensão da seção retangular " $b$ " ou do diâmetro da seção circular " $d$ ";

- As taxas de armadura $A_{s} /\left(A_{c}+A_{s}\right)$ maiores que 3\% não podem ser consideradas;

- A resistência do concreto é tomada igual à resistência de projeto em temperatura ambiente.

\subsubsection{EUROCODE 4}

O EUROCODE 4 Part 1-2 apresenta um método tabular e dois métodos analíticos para a verificação dos pilares mistos preenchidos com concreto, em situação de incêndio.

\subsubsection{MÉTODO TABULAR}

O método tabular apresentado pelo EUROCODE 4, assim como o da ABNT NBR 14323:1999, consiste na verificação das dimensões mínimas da seção transversal, das taxas mínimas de armadura e distâncias mínimas entre os eixos das barras da armadura à face do perfil, sendo estas dimensões mínimas determinadas em função do tempo requerido de resistência a incêndio (TRRF) e do nível de carga, $\eta_{\text {fi,t }}$ dado pela equação 3.32. A tabela 3.7 apresenta o método tabular adotado pelo EUROCODE 4.

$$
\eta_{\mathrm{fi}, \mathrm{t}}=\frac{\mathrm{R}_{\mathrm{fi}, \mathrm{d}, \mathrm{t}}}{\mathrm{R}_{\mathrm{d}}}
$$

$\mathrm{Na}$ equação $3.32, \mathrm{R}_{\mathrm{fi}, \mathrm{d}, \mathrm{t}}$ é a normal solicitante de cálculo em situação de incêndio e $\mathrm{R}_{\mathrm{d}} \mathrm{a}$ normal resistência de cálculo em temperatura ambiente. Na determinação de $\mathrm{R}_{\mathrm{d}} \mathrm{e}$ de $\mathrm{R}_{\mathrm{fi}, \mathrm{d}, \mathrm{t}}=$ $\eta_{\mathrm{fi}, \mathrm{t}}$. $\mathrm{R}_{\mathrm{d}}$, em combinação com a tabela 3.7 aplicam-se as seguintes regras:

- Independente do valor da resistência ao escoamento do aço dos perfis tubulares, o máximo valor adotado poderá ser de $235 \mathrm{MPa}$;

- A espessura "t" da parede do perfil tubular não pode exceder 1/25 da menor dimensão da seção retangular "b" ou do diâmetro da seção circular "d";

- As taxas de armadura $\mathrm{A}_{\mathrm{s}} /\left(\mathrm{A}_{\mathrm{c}}+\mathrm{A}_{\mathrm{s}}\right)$ maiores que 3\% não podem ser consideradas;

- A resistência do concreto é tomada igual à resistência de projeto em temperatura ambiente. 
Tabela 3.7 - Método Tabular proposto pelo EUROCODE 4 Part 1-2.

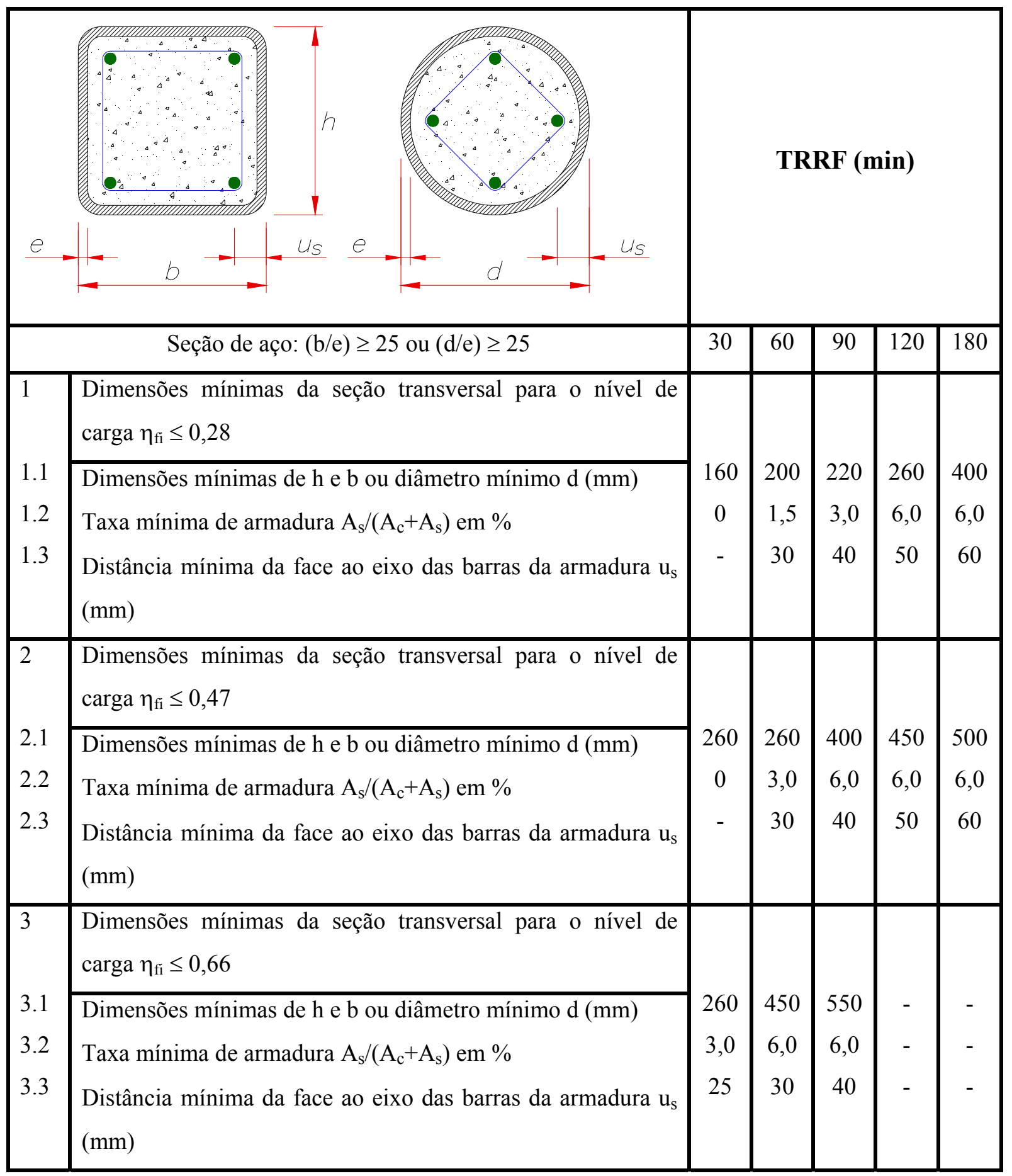

\subsubsection{MÉTODOS ANALÍTICOS}

O EUROCODE 4 apresenta dois métodos analíticos para a verificação da normal resistente para os pilares mistos preenchidos com concreto em situação de incêndio. Para a 
utilização do primeiro método analítico, são apresentados na tabela 3.8 valores para os limites de aplicabilidade deste método, para os pilares mistos preenchidos sem revestimento.

Tabela 3.8 - Limites de aplicabilidade do Método Analítico proposto pelo EUROCODE 4.

\begin{tabular}{|l|c|c|}
\hline \multicolumn{1}{|c|}{ Variáveis } & $\begin{array}{c}\text { Limite } \\
\text { Mínimo }\end{array}$ & $\begin{array}{c}\text { Limite } \\
\text { Máximo }\end{array}$ \\
\hline Comprimento efetivo de flambagem & - & $4,50 \mathrm{~m}$ \\
\hline Menor dimensão da seção retangular ou diâmetro da seção circular & $140 \mathrm{~mm}$ & $400 \mathrm{~mm}$ \\
\hline Resistência do concreto de preenchimento & $20 \mathrm{MPa}$ & $50 \mathrm{MPa}$ \\
\hline Taxa de armadura & $1 \%$ & $5 \%$ \\
\hline TRRF & - & $120 \mathrm{~min}$ \\
\hline
\end{tabular}

Aplicando-se o primeiro método, a normal resistente de cálculo para os pilares mistos preenchidos, em situação de incêndio, submetidos à compressão axial pode ser calculada pela equação 3.33 .

$$
\mathrm{N}_{\mathrm{fi}, \mathrm{Rd}}=\chi_{\mathrm{fi}} \cdot \mathrm{N}_{\mathrm{fi}, \mathrm{pl}, \mathrm{Rd}}
$$

$\mathrm{Na}$ equação 3.33, $\mathrm{N}_{\mathrm{fi}, \mathrm{Rd}}$ é a força normal resistente de cálculo; $\chi_{\mathrm{fi}} \mathrm{o}$ fator de redução associado à curva de dimensionamento "c" do EUROCODE 4 Part 1-2, em função do índice de esbeltez reduzido, $\bar{\lambda}_{\theta}$, e $\mathrm{N}_{\text {fi,pl,Rd }}$ a força normal de plastificação de cálculo em situação de incêndio. A força normal de plastificação de cálculo em situação de incêndio pode ser calculada pela equação 3.34, e o índice de esbeltez reduzido em situação de incêndio pela equação 3.35 .

$$
\mathrm{N}_{\mathrm{fi}, \mathrm{pl}, \mathrm{Rd}}=\sum_{\mathrm{j}}\left(\mathrm{A}_{\mathrm{a}, \theta} \cdot \mathrm{f}_{\mathrm{a} \max , \theta}\right)+\sum_{\mathrm{k}}\left(\mathrm{A}_{\mathrm{s}, \theta} \cdot \mathrm{f}_{\mathrm{s} \max , \theta}\right)+\sum_{\mathrm{m}}\left(\mathrm{A}_{\mathrm{c}, \theta} \cdot \mathrm{f}_{\mathrm{c} \max , \theta}\right)
$$

Na equação 3.34, valem:

$\sum_{\mathrm{j}}\left(\mathrm{A}_{\mathrm{a}, \theta} \cdot \mathrm{f}_{\mathrm{a} \text { max }, \theta}\right)$ : somatório dos produtos da área dos elementos componentes do perfil de aço pelo limite de escoamento do aço do mesmo;

$\sum_{\mathrm{k}}\left(\mathrm{A}_{\mathrm{s}, \theta} \cdot \mathrm{f}_{\mathrm{smax}, \theta}\right)$ : somatório dos produtos da área das barras da armadura pelo limite de escoamento do aço das mesmas; 
$\sum_{\mathrm{m}}\left(\mathrm{A}_{\mathrm{c}, \theta} \cdot \mathrm{f}_{\mathrm{cmax}, \theta}\right)$ : somatório dos produtos da área dos elementos de concreto pela resistência características à compressão das mesmas.

$\bar{\lambda}_{\theta}=\sqrt{\frac{\mathrm{N}_{\mathrm{fi}, \mathrm{pl}, \mathrm{Rd}}}{\mathrm{N}_{\mathrm{fi}, \mathrm{cr}}}}$

sendo $\mathrm{N}_{\text {fi,cr }}$ a carga crítica de EULER ou carga elástica crítica, em situação de incêndio, dada pela equação 3.36 .

$\mathrm{N}_{\mathrm{fi}, \mathrm{cr}}=\frac{\pi^{2} \cdot(\mathrm{EI})_{\mathrm{fi}, \mathrm{eff}}}{\mathrm{L}_{\theta}^{2}}$

sendo:

$(\mathrm{EI})_{\mathrm{fi}, \mathrm{eff}}$ : rigidez efetiva do pilar misto à flexão, dada pela equação 3.37;

$\mathrm{L}_{\theta}$ : comprimento efetivo de flambagem do pilar em situação de incêndio, tomado igual ao comprimento de flambagem em temperatura ambiente.

$(\mathrm{EI})_{\mathrm{fi}, \mathrm{eff}}=\sum_{\mathrm{j}}\left(\varphi_{\mathrm{a}, \theta} \cdot \overline{\mathrm{E}}_{\mathrm{a}, \theta} \cdot \mathrm{I}_{\mathrm{a}, \theta}\right)+\sum_{\mathrm{k}}\left(\varphi_{\mathrm{s}, \theta} \cdot \overline{\mathrm{E}}_{\mathrm{s}, \theta} \cdot \mathrm{I}_{\mathrm{s}, \theta}\right)+\sum_{\mathrm{m}}\left(\varphi_{\mathrm{c}, \theta} \cdot \overline{\mathrm{E}}_{\mathrm{c}, \mathrm{sec}, \theta} \cdot \mathrm{I}_{\mathrm{c}, \theta}\right)$

sendo:

$\overline{\mathrm{E}}_{\mathrm{a}, \theta}, \overline{\mathrm{E}}_{\mathrm{s}, \theta}$ : módulo de deformação longitudinal do aço do perfil e do aço das barras da armadura, respectivamente, a temperatura $\theta$;

$\overline{\mathrm{E}}_{\mathrm{c}, \mathrm{sec}, \theta}$ : módulo de elasticidade secante do concreto à temperatura $\theta$, na tensão de compressão $\mathrm{f}_{\mathrm{c}, \theta}$, dado por $\mathrm{f}_{\mathrm{c}, \theta}$ dividido por $\varepsilon_{\mathrm{cu}, \theta}$;

$\mathrm{I}_{\mathrm{a}, \theta}, \mathrm{I}_{\mathrm{s}, \theta}, \mathrm{I}_{\mathrm{c}, \theta}$ : momento de inércia da seção do perfil de aço, das barras da armadura e do concreto, respectivamente;

$\varphi_{\mathrm{a}, \theta}, \varphi_{\mathrm{s}, \theta}, \varphi_{\mathrm{c}, \theta}$ : coeficiente de redução que depende dos efeitos das tensões térmicas no perfil de aço, nas barras da armadura e no concreto, respectivamente, apresentados na tabela 3.9, em função do TRRF e do material. 
Os coeficientes de redução que dependem dos efeitos das tensões térmicas para os pilares mistos de aço preenchidos com concreto são apresentados na tabela 3.9.

Tabela 3.9 - Coeficientes de redução $\varphi_{\mathrm{i}, \theta}$.

\begin{tabular}{|c|c|c|c|}
\hline TRRF (minutos) & Perfil de aço $\left(\varphi_{\mathbf{a}, \theta}\right)$ & Armadura $\left(\varphi_{\mathbf{s}, \theta}\right)$ & Concreto $\left(\varphi_{\mathbf{c}, \theta}\right)$ \\
\hline 30 & 1,0 & 1,0 & 0,8 \\
\hline 60 & 0,9 & 0,9 & 0,8 \\
\hline 90 & 0,8 & 0,8 & 0,8 \\
\hline 120 & 1,0 & 1,0 & 0,8 \\
\hline
\end{tabular}

O segundo método analítico proposto pelo EUROCODE 4, apresentado em seu Anexo F, é um método iterativo e incremental que leva em consideração a tensão a que está submetido o pilar misto preenchido em determinada temperatura. $\mathrm{O}$ processo, em resumo, tem os seguintes passos:

1-) Primeiramente, se deve determinar os campos térmicos na seção transversal do pilar misto para um determinado tempo;

2-) Supõe-se uma tensão solicitante para a seção e a distribui de maneira adequada para cada membro da seção mista, correlacionando-a com as deformações correspondentes de cada membro;

3-) Obter os módulos de elasticidade em função da tensão imposta;

4-) Verificar a normal crítica em função da tensão, logo após, a normal de plastificação de cálculo, se as duas não tomarem valores iguais, continua-se o processo iterativo e incremental; 5-) Incrementa-se a tensão solicitante;

6-) O processo estará terminado quando a normal crítica for igual à normal de plastificação de cálculo em situação de incêndio, sendo este valor tomado igual à normal resistente em situação de incêndio.

Neste mesmo anexo, o EUROCODE 4 contempla, com um método gráfico, os casos em que o carregamento aplicado ao pilar misto preenchido é excêntrico, limitando-se esta excentricidade a metade da menor dimensão da seção retangular ou metade do diâmetro da seção circular. 


\section{ESTRATÉGIAS NUMÉRICAS ADOTADAS: ASPECTOS DE INTERESSE}

\subsection{ANÁLISES NUMÉRICAS DE INTERESSE - CONSIDERAÇÕES}

A análise numérica de pilares mistos curtos de seção circular preenchidos com concreto é aqui realizada por meio do pacote computacional ANSYS ${ }^{\circledR}$ V9.0, com modelos numéricos construídos em campo tridimensional. O trabalho foi dividido em três etapas: análise estrutural, análise térmica e análise termo-estrutural (ou análise acoplada).

Em uma primeira etapa, os modelos numéricos aqui propostos são construídos com vistas a simular o comportamento estrutural global dos pilares mistos curtos preenchidos, inicialmente em temperatura ambiente, submetidos à compressão centrada, buscando analisar a coerência de seus resultados quando comparados a resultados obtidos de ensaios experimentais realizados por outros pesquisadores. A idéia é buscar a coerência da resposta do modelo em seu contexto de referência (ponto de partida), ou seja, submetidos a $20^{\circ} \mathrm{C}$.

Em uma segunda etapa, se faz a análise térmica para a obtenção do gradiente térmico nas seções transversais dos elementos estruturais, considerando o mesmo procedimento descrito em REGOBELLO (2007), e aqui aplicado à análise dos pilares mistos curtos agora submetidos ao incêndio-padrão. Portanto, se busca a coerência da resposta do modelo em contexto de temperaturas elevadas (ou incêndio).

Em uma terceira e última etapa, se faz análises termo-estruturais dos modelos numéricos, com vistas a simular o comportamento estrutural global (com eventuais efeitos localizados), bem como a influência da elevação de temperatura na resistência desses mesmos elementos em situação de incêndio. São consideradas:

- Fase I: Análise estática considerando a aplicação de um dado nível (ou intensidade) de carregamento concentrado e centrado, em temperatura ambiente;

- Fase II: Análise termo-estrutural, considerando a aplicação do campo térmico no elemento estrutural já carregado (fase I), em que é levada em conta a influência da temperatura nas propriedades mecânicas dos materiais. 


\subsection{ANÁLISE TÉRMICA - Aspectos de interesse}

A análise térmica aqui apresentada tem por objetivo determinar a distribuição de temperatura e de outras variáveis de interesse nos pilares mistos de aço preenchidos por concreto. As variáveis térmicas de interesse são: $O$ campo e a evolução de temperaturas, $a$ quantidade de calor (absorvido ou perdido), os gradientes térmicos e os fluxos térmicos.

Atualmente, na engenharia de estruturas, é de grande interesse a análise de edifícios em situação de incêndio para que se possa garantir a segurança do edifício quanto ao colapso prematuro, prejudicando a desocupação do mesmo em tempo hábil. Nesta situação, análises térmicas são de fundamental importância para que possam ser levados em conta os efeitos da elevação de temperatura no contexto da análise estrutural.

Esse tipo de análise geralmente tem caráter transiente, tendo em vista o fato de a temperatura de um ambiente em situação de incêndio variar com o tempo. Notadamente, para os materiais aço e concreto, por exemplo, estas análises também possuem um caráter nãolinear, uma vez que as propriedades térmicas e mecânicas desses materiais também variam de acordo com a temperatura, conforme o exposto no Capítulo 3.

A análise térmica pode ser executada de duas formas distintas, conforme informações disponibilizadas no ANSYS, por meio das ferramentas do item "Thermal analysis guide - Types of Thermal Analysis”. São as seguintes:

- Análise estacionária: determina a distribuição da temperatura e outras grandezas térmicas sob condição de cargas estacionárias, ou seja, a variação das grandezas térmicas dentro de um período de tempo pode ser ignorada. Esta análise ainda pode ser do tipo linear, com propriedades dos materiais constantes, ou do tipo não-linear com propriedades dos materiais dependentes da temperatura;

- Análise transiente: determina temperatura e outras grandezas térmicas em função do tempo. Na engenharia, são comumente usadas temperaturas calculadas por meio da análise térmica transiente, as quais servirão como dados de entrada em análises estruturais para avaliação das tensões induzidas pelas deformações térmicas. Muitas aplicações em transferência de calor, tais como problemas de tratamento térmico, sistemas de tubulação, vasos de pressão, estruturas em situação de incêndio, etc., envolvem análise térmica transiente.

Vale destacar que a análise térmica transiente segue basicamente os mesmos procedimentos de uma análise térmica estacionária. A principal diferença é que a maioria das forças aplicadas em uma análise transiente é considerada em função do tempo. 
A base para a análise térmica no ANSYS é a equação de equilíbrio térmico, obtida do princípio de conservação de energia. A solução por elementos finitos calcula a temperatura nodal, que será utilizada para obter outros parâmetros térmicos. O código ANSYS considera os três modos primários de transferência de calor, ou seja, condução, convecção e radiação, considerando:

- Condução: Como citado em REGOBELLO (2007), o problema da condução de calor ocorre entre os elementos sólidos, o qual envolve as temperaturas nodais, como carregamento nos nós, e o fluxo de calor entre esses elementos. A origem da condução de calor pode ser os processos de convecção ou radiação. Para a resolução do problema térmico de condução, devem ser fornecidas ao ANSYS duas propriedades físicas: condutividade térmica (nas direções $x, y$ e z) e densidade. (ANSYS guide - How ANSYS Treats Thermal Modeling);

- Convecção: A convecção é especificada como um carregamento de superfície, ou elemento finito sólido ou casca de condução de calor. A transferência de calor por este mecanismo ocorre por meio da aplicação de um filme de convecção, com coeficiente de transferência de calor por convecção $\alpha_{c}$, e da maior parte da temperatura do fluido incidente na superfície do elemento. Se o coeficiente do filme é uma função da temperatura, deve ser especificada uma tabela de temperatura com o correspondente valor do coeficiente do filme de convecção.

- Radiação: O ANSYS permite resolver os problemas de radiação, que são não-lineares, por quatro formas distintas (de acordo com Ansys thermal guide - Radiation):

a-) Pelo uso do elemento linear de radiação (LINK31): para problemas simples envolvendo dois pontos ou vários pares de pontos. O LINK31 é um elemento não linear de dois nós, que calcula o fluxo de calor causado pela radiação entre dois pontos. Devem ser fornecidos os seguintes dados: Área efetiva da superficie radiante; Fator de forma; Emissividade; Constante de Stefan-Boltzmann. O uso do elemento LINK 31 é limitado a casos simples onde é possível calcular manualmente os fatores de forma da radiação.

b-) Pelo uso do elemento de superficie de contato com a opção radiação (SURF151 em modelos 2-D ou SURF 152 em modelos 3-D): para introduzir o efeito da radiação entre uma superfície e um ponto, utilizam-se elementos de efeito de superfície modelados sobre os elementos sólidos, capazes de emitir ou receber radiação. Este será o método utilizado nas análises termo-estruturais apresentadas no decorrer do presente trabalho.

c-) Pela geração de uma matriz de radiação e usando esta matriz como um superelemento em uma análise térmica: esse método é aplicável a problemas de radiação 
generalizada envolvendo várias superfícies de radiação. A matriz é constituída pelos fatores de visada entre as superfícies radiantes. Também podem ser incluídas superfícies ocultas ou parcialmente ocultas, assim como um nó espacial que pode absorver energia radiante.

d-) Pelo uso do método solução da radioatividade: este método também trabalha com problemas generalizados de radiação, envolvendo duas ou mais superfícies receptoras ou emissoras de radiação. O método pode ser adotado por todos os elementos 3-D e 2-D tendo a temperatura como grau de liberdade. Ele consiste de cinco passos: definir as superfícies de radiação; definir as opções de solução; definir as opções do fator de visada; calcular e verificar o fator de visada; definir as opções de carregamento;

No item que se segue, serão apresentados os elementos utilizados na construção dos modelos numéricos aplicados à análise térmica. Esses elementos apresentam características em comum, no caso, a temperatura nodal como único grau de liberdade, aplicáveis tanto na análise transiente como na análise térmico-estacionária. Por fim, são apresentados os elementos adotados para construção de modelos térmicos possuem elementos finitos estruturais equivalentes, para os casos em que se realizam análise termo-estrutural.

\subsubsection{ELEMENTOS FINITOS TRIDIMENSIONAIS - Análise térmica}

$\mathrm{Na}$ elaboração dos modelos numéricos para a análise térmica se seguiu a mesma estratégia adotada em REGOBELLO (2007), em que foram utilizados dois tipos de elementos finitos: o SOLID70, para modelar o pilar misto de aço preenchido por concreto, e o SURF152, para aplicar ao modelo as condições de contorno respectivas à carga térmica (referente à convecção e à radiação).

O SOLID70, esquematizado na figura 4.1a, é um elemento finito sólido que possui oito nós, com um grau de liberdade em cada nó, no caso, a temperatura. O SURF152, esquematizado na figura $4.1 \mathrm{~b}$, possui de quatro a nove nós, além de um nó extra para simular efeitos térmicos, todos com apenas um grau de liberdade, no caso, também a temperatura.

Na figura 4.2 são apresentadas a geometrias e a discretização da malha de elementos finitos referente ao pilar misto de aço preenchido com concreto, o perfil metálico composto pelo elemento finito SOLID70 e o núcleo de concreto, também constituído pelo elemento finito SOLID70. 


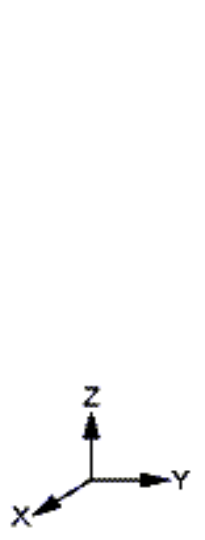

(a)
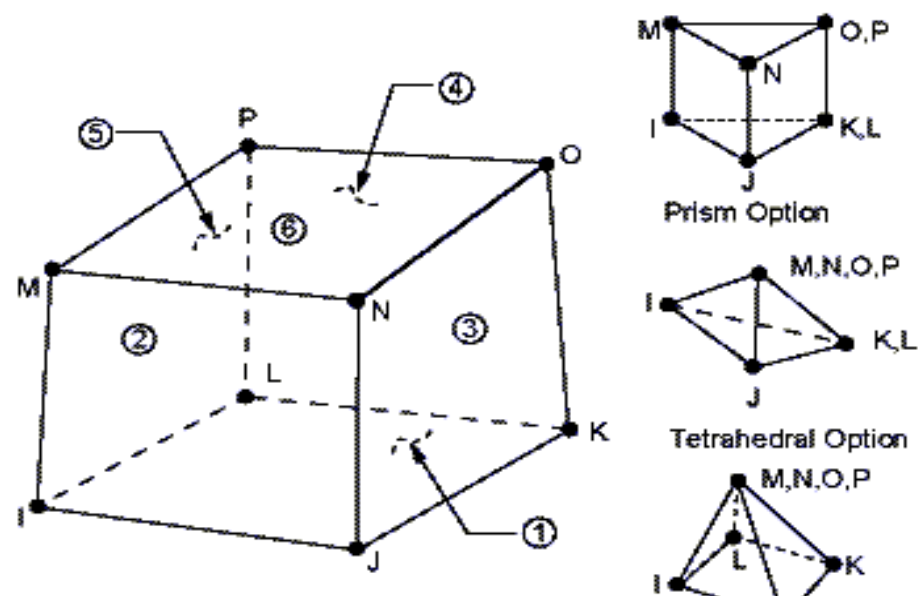

Tetrahedral Option

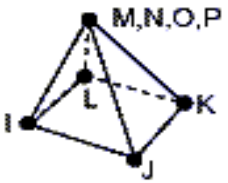

Pyramid Option
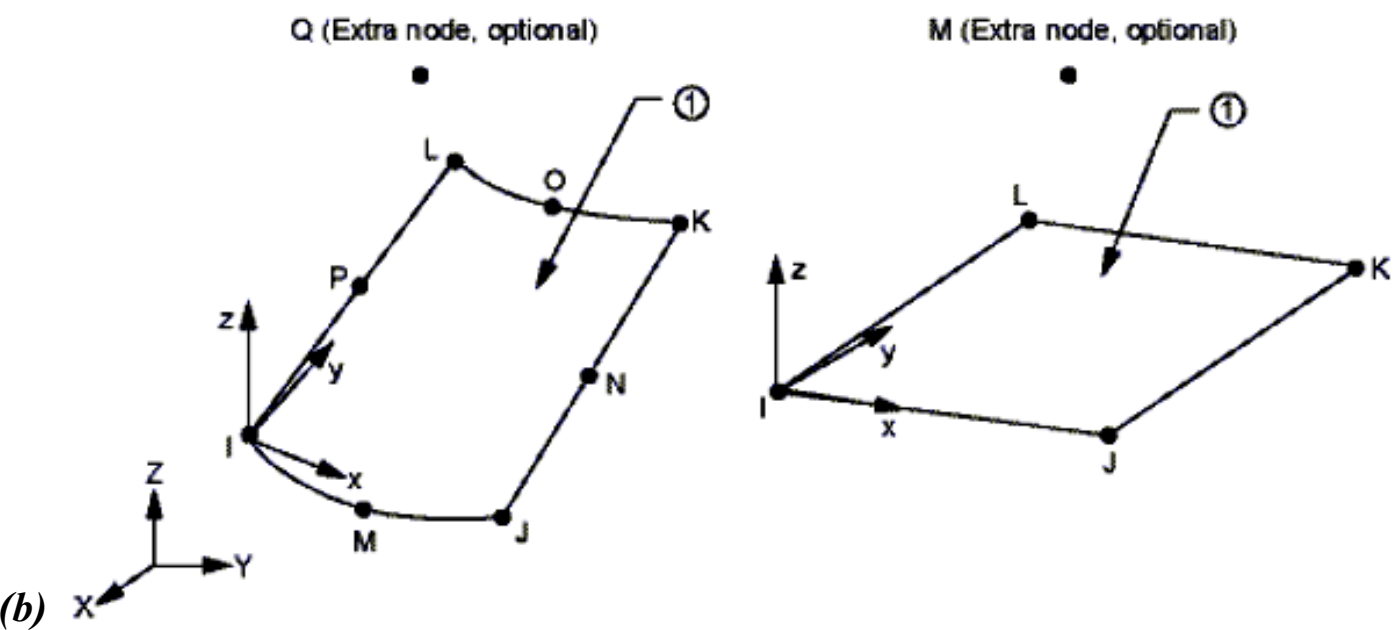

Figura 4.1 - Elementos finitos utilizados: (a) SOLID70 e (b) SURF152.

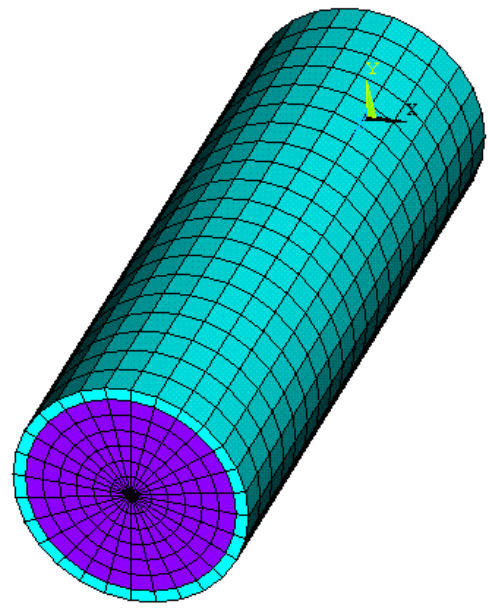

(a)

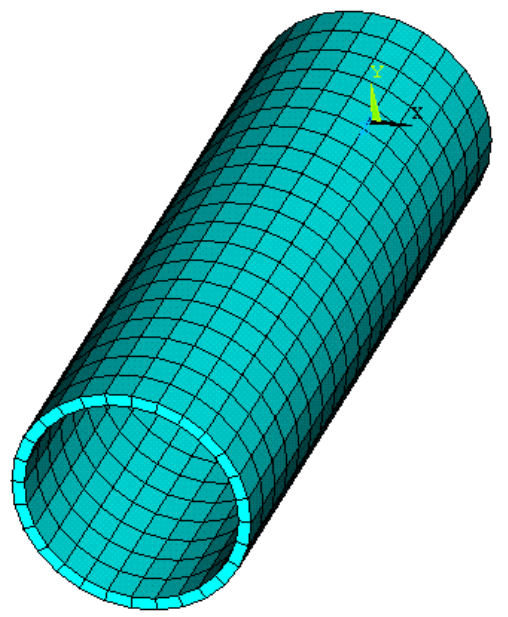

(c)

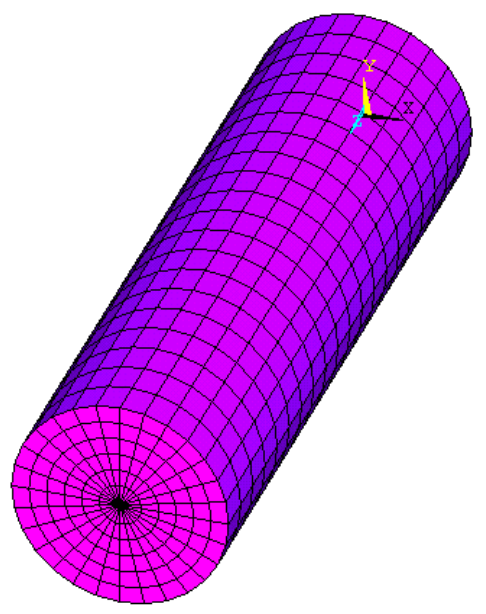

(b)

Figura 4.2 - Geometria e malha dos elementos SOLID70: (a) Pilar misto curto preenchido, (b) Perfil de aço isolado e (c) Núcleo de concreto isolado. 


\subsubsection{APLICAÇÃO DA AÇÃO TÉRMICA NO MODELO}

A aplicação da ação térmica no modelo é feita diretamente sobre o contorno do volume de interesse, ou com o auxílio do elemento finito de superfície SURF152. O elemento SURF152 pode ser usado para vários carregamentos e efeitos de superfície em análises térmicas tridimensionais. Ele pode ser sobreposto à face de vários elementos, permitindo que vários carregamentos e efeitos de superfície possam ser aplicados simultaneamente.

Esse elemento possui um nó, denominado "extra" que, quando usado, possibilita a aplicação de efeitos de radiação ou convecção. Vale ressaltar que a convecção ou fluxos de calor podem ser aplicados diretamente ao elemento.

Em todos os modelos térmicos a serem desenvolvidos neste trabalho, utilizar-se-á a opção do elemento $\boldsymbol{S U R F 1 5 2}$ com o nó extra, de modo que a aplicação de temperatura com relação ao nó extra é interpretada como uma temperatura ambiente externa ao modelo, conforme esquematiza a figura 4.3. Desta forma, é possível simular com este elemento finito os efeitos da elevação da temperatura dos gases do ambiente.

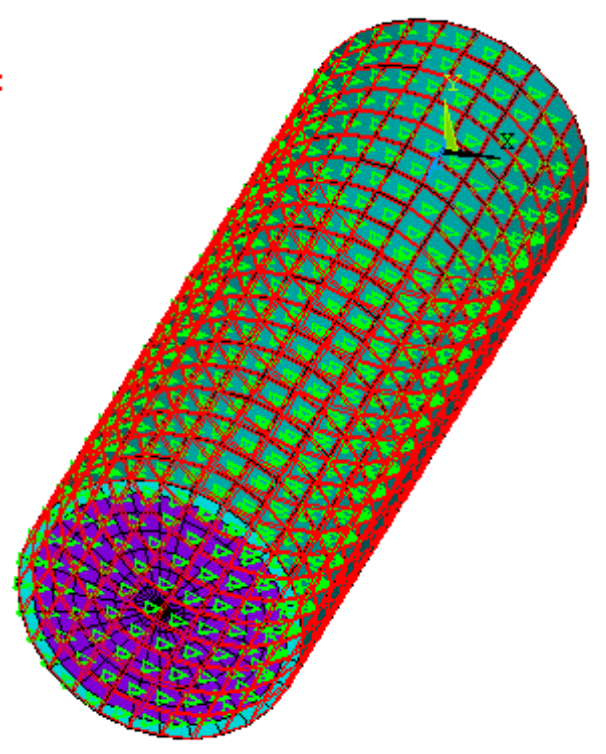

"nó extra"

Figura 4.3 - Ponto emissão de calor por meio do "nó extra".

Para simular os efeitos da convecção em função da temperatura, a elevação de temperatura será fornecida ao nó extra. O cálculo da "matriz de condutividade superficial" devido à convecção emprega o coeficiente de transferência de calor por convecção, o qual deve ser fornecido ao ANSYS na forma de dado de entrada. O fluxo de calor devido à convecção é, então, calculado com base na diferença de temperatura da superfície do modelo e da suposta temperatura dos gases do ambiente. 
Da mesma forma que para a convecção, os efeitos da radiação podem ser obtidos também com o uso de mais uma camada de elementos SURF152 aplicados à superfície do modelo, conforme esquematizam as figuras $4.4 \mathrm{a}$ e $4.4 \mathrm{~b}$, em que estão apresentadas as geometrias dos elementos de superfície de convecção e radiação, respectivamente.

Para o cálculo da matriz de condutividade superficial devido à radiação é necessário fornecer a emissividade resultante, o fator de configuração, e a constante de Stefan-

\section{Boltzmann.}

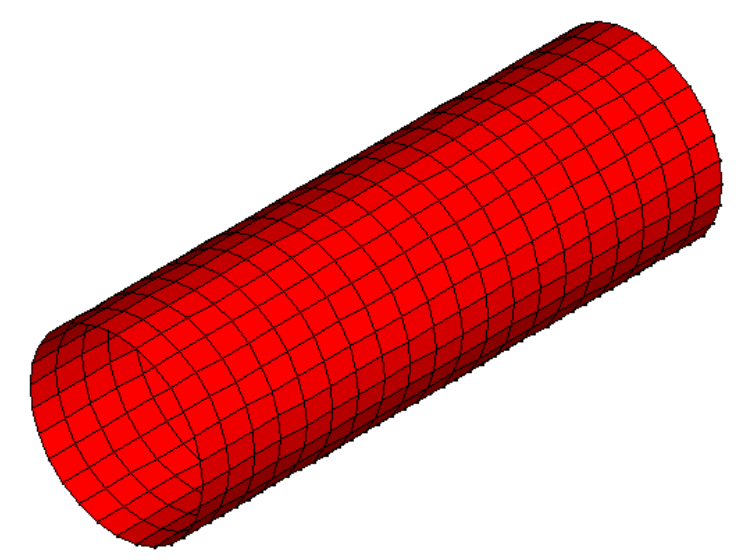

(a)

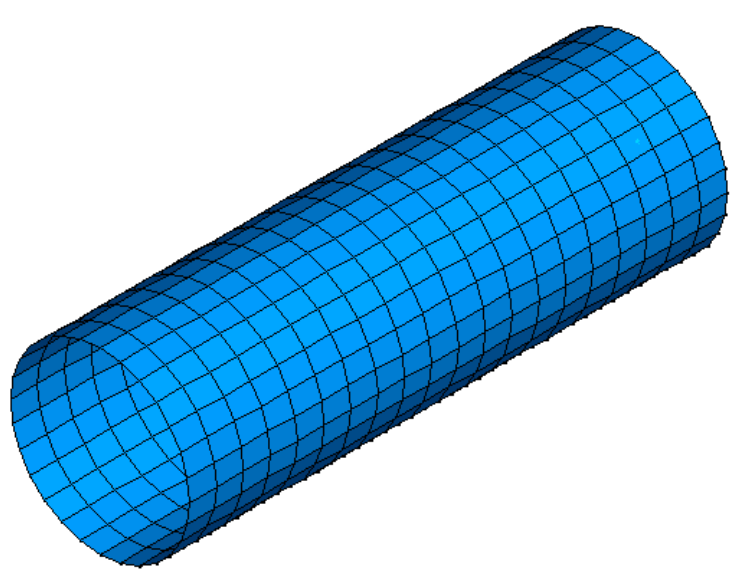

(b)

Figura 4.4 - Esquematização da geometria e malha dos elementos SURF152:

(a) Superfície de convecção e (b) Superfície de radiação.

Como nos problemas de estruturas em situação de incêndio se adota a hipótese da troca de calor entre duas superfícies paralelas e infinitas, conforme descrito em REGOBELLO (2007), o fator de configuração é aqui tomado igual 1,0. O fluxo de calor devido à radiação é então calculado com base na temperatura da superfície do modelo e da suposta temperatura dos gases do ambiente aplicada ao nó extra.

A propagação da temperatura da face externa do tubo de aço para o seu interior ocorre por condução, de modo que a temperatura do aço se transfere para o núcleo de concreto pelo acoplamento dos nós do aço e do concreto que estão em contato, na interface entre tubo de aço e núcleo de concreto.

Nesse caso, a mesma temperatura identificada no nó do elemento de aço é imposta ao nó do elemento de concreto, cujo acoplamento pode ser visualizado na figura 4.5, destacado pelas setas verdes, ressaltando que a propagação da temperatura da face externa do núcleo de concreto para o seu interior também ocorre por condução. 


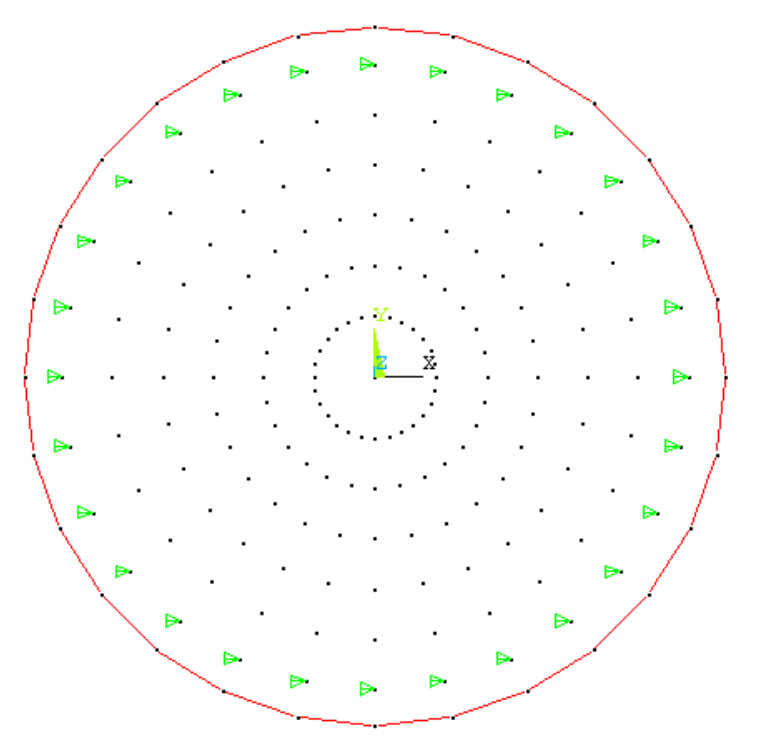

Figura 4.5 - Esquematização do acoplamento, enquanto valores de temperatura, entre os nós de contato do aço e do concreto.

\subsection{ANÁLISE ESTRUTURAL - Considerações}

A análise estrutural aqui apresentada tem por objetivo determinar as deformações sofridas pelos pilares mistos curtos de aço preenchidos por concreto, para cada incremento de carga aplicado, com vistas a determinar sua carga de colapso.

A estratégia numérica adotada inicialmente seguiu, os passos adotados em CUNHA (2006), em que foi proposta estratégia numérica capaz de representar os ensaios experimentais de pilares mistos curtos de aço e concreto, em temperatura ambiente, sob carregamento axial aplicado na seção inteira (aço e concreto), para diferentes resistências de concreto à compressão $(25,44,51$ e $73 \mathrm{MPa})$, no qual também foi utilizado o ANSYS V9.0. A diferença da estratégia adotada no presente trabalho quando comparado àquela adotada na última referência consiste na escolha dos elementos finitos, na discretização da malha de elementos finitos, na utilização de elementos de contato entre os materiais aço e concreto, bem como na forma de carregamento aqui realizada em que se considerou incremento de força em vez de incrementos de deslocamento.

A utilização de elementos finitos diferentes se deve ao fato de estar construindo um modelo estrutural que também possa ser adotado na análise termo-estrutural. A diferença na discretização da malha de elementos finitos teve por objetivo manter a simetria em sua malha, a utilização dos elementos de contato (para evitar a penetração entre os materiais). 
Como os elementos finitos adotados na análise estrutural são os mesmos adotados nos modelos acoplados, optou-se por descrevê-los no item que trata dos modelos acoplados, em itens seguintes. A malha adota em CUNHA (2006) é esquematizada na figura 4.6a em que foram utilizados como elementos finitos o SOLID45 para o aço e o SOLID65 para o concreto, enquanto que a malha adotada no presente trabalho pode ser visualizada na figura 4.6b.

(a)

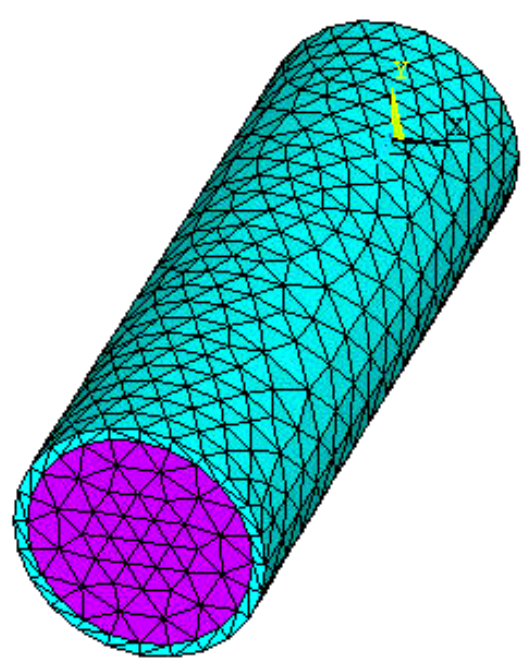

(b)

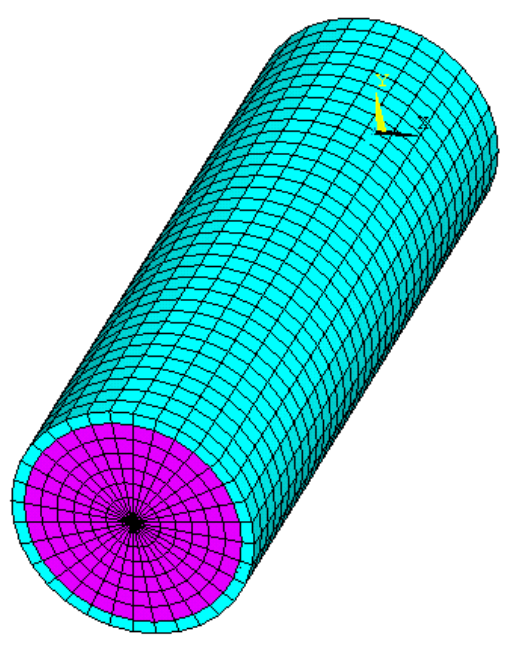

Figura 4.6 - Geometria e malha de elementos finitos: (a) triangular e (b) quadrada.

Para os estudos iniciais foram adotadas a mesma geometria e o mesmo tipo de acoplamento na direção longitudinal dos nós dos materiais aço e concreto na face superior do pilar misto, conforme esquematiza a figura 4.7, de modo a possibilitar atribuir um nó de referência, chamado nó mestre, onde o carregamento é aplicado, de modo que todos os demais nós da mesma seção apresentem o mesmo deslocamento axial.

(a)

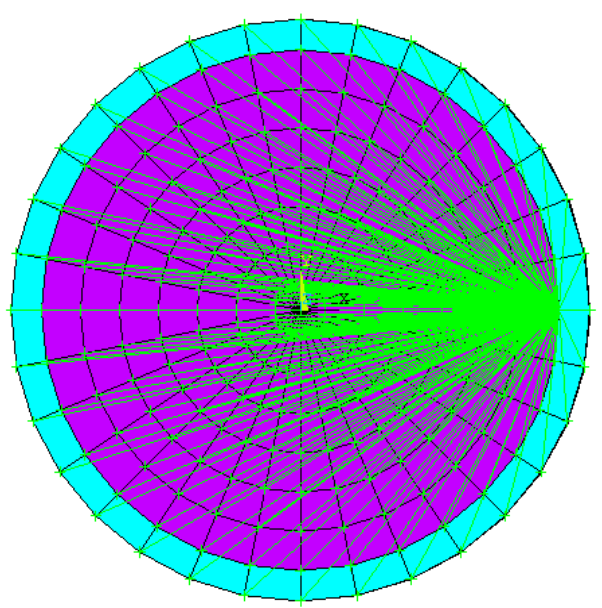

Figura 4.7 - Acoplamento da face superior: (a) vista superior e (b) vista em perfil. 
As condições de contorno impostas consideram que, na base, foram impedidos os deslocamentos dos nós nas direções $X, Y$ e $Z$ simulando um engaste, enquanto que no topo (em que é aplicado o carregamento) foram impedidos os deslocamentos dos nós nas direções $X$ e $Y$ (plano da seção), liberando o deslocamento em $Z$ (direção do carregamento).

Vale ressaltar que os elementos finitos utilizados nos modelos estruturais anteriormente apresentados nas figuras $4.6 \mathrm{~b}$ e 4.7 , serão os mesmos utilizados na análise termo-estrutural, conforme descrito no item que se segue.

\subsection{ANÁLISE TERMO-ESTRUTURAL - Considerações}

\subsubsection{ANÁLISES ACOPLADAS}

O ANSYS possibilita a realização de análises acopladas, em que é levada em conta a interação (acoplamento) entre duas ou mais áreas da engenharia. Uma análise piezelétrica, por exemplo, lida com a interação entre as áreas elétrica e estrutural: ela determina uma distribuição de voltagem para deslocamentos aplicados, ou vice-versa. Como outros exemplos de análises acopladas, podem ser também citados: a análise termo-estrutural, a análise termoelétrica, e a análise fluido-estrutural.

No contexto do presente trabalho, a análise denominada acoplada levará em conta a interação entre os efeitos de um carregamento estático, concentrado e centrado, inicialmente em contexto de temperatura ambiente $\left(20^{\circ} \mathrm{C}\right)$, com posterior consideração de um campo térmico, cujos níveis de temperatura são variáveis com o tempo.

\subsubsection{ELEMENTOS FINITOS TRIDIMENSIONAIS - Análise termo-estrutural}

$\mathrm{Na}$ elaboração dos modelos numéricos para a análise termo-estrutural também se segue a mesma estratégia adotada em REGOBELLO (2007), em que foi utilizado apenas o SOLID45 para representação do perfil metálico, porém, para o presente trabalho foram utilizados quatro tipos de elementos finitos: o SOLID45 para modelar o tubo de aço, o SOLID185 para modelar o concreto, e os elementos de contato TARGE170 e CONTA174, para representar o contato entre os materiais aço e concreto.

Para a análise térmica, é importante lembrar que, se considera os mesmos elementos finitos descritos no item 4.2 , apresentados anteriormente. 
O SOLID45, apresentado na figura 4.8a, possui oito nós, com três graus de liberdade, em cada nó, referentes às translações nas direções $\mathrm{X}, \mathrm{Y}$ e $\mathrm{Z}$ (coordenadas globais). $\mathrm{O}$ SOLID185, apresentado na figura 4.8b, possui oito nós, com três graus de liberdade, em cada nó, referentes às translações nas direções X, Y e Z (coordenadas globais), diferenciando-se do SOLID45 apenas por permitir simular materiais com características hipoelásticas e hiperelásticas, aspectos que não serão aqui levados em conta por extrapolarem os interesses do presente trabalho.

(a)

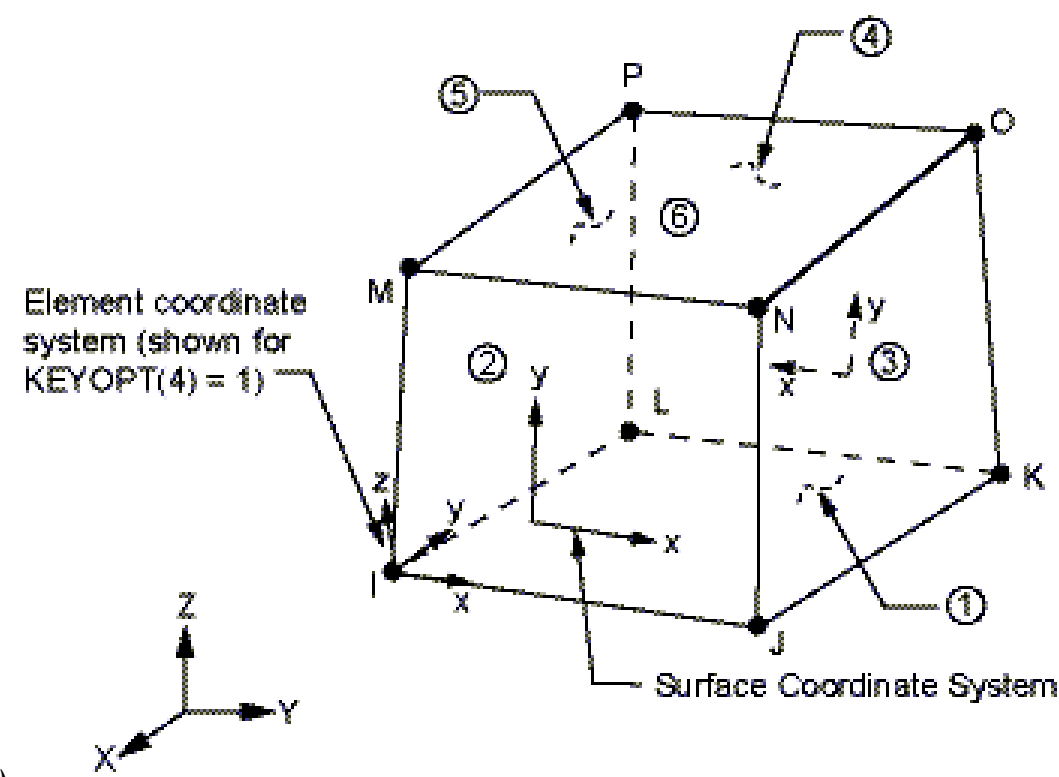

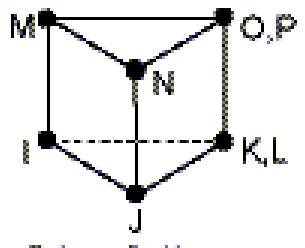

Prism Option

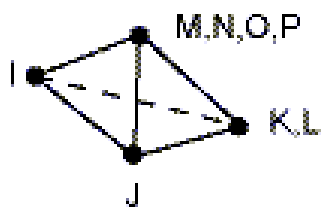

Tetrahedral Option not recommended

(b)

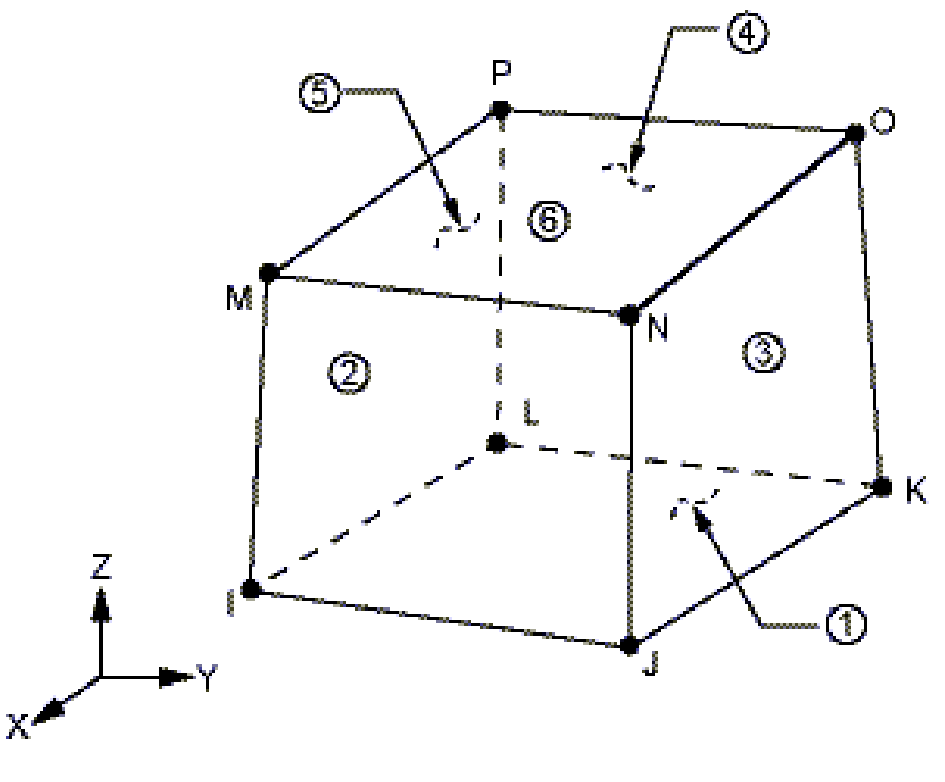

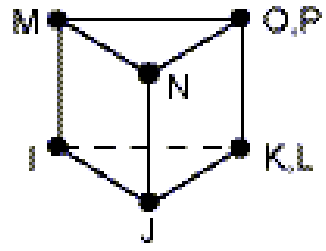

Prism Option

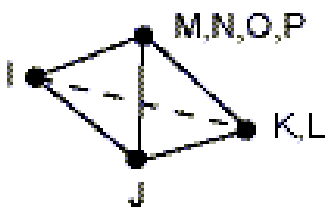

Tetrahedral Option not recommended

Figura 4.8 - Elementos finitos utilizados: (a) SOLID45 e (b) SOLID185. 
O elemento finito TARGE170, ilustrado na figura 4.9a, é um elemento finito tridimensional utilizado em conjunto com o elemento de contato CONTA174, ilustrado na figura 4.9b. Ambos apresentam as mesmas características possuem oito nós, com três graus de liberdade por nó, referentes às translações nas direções $\mathrm{X}, \mathrm{Y}$ e Z (coordenadas globais). A figura 4.9 é aqui apresentada apenas para fins de ilustração.

(a)

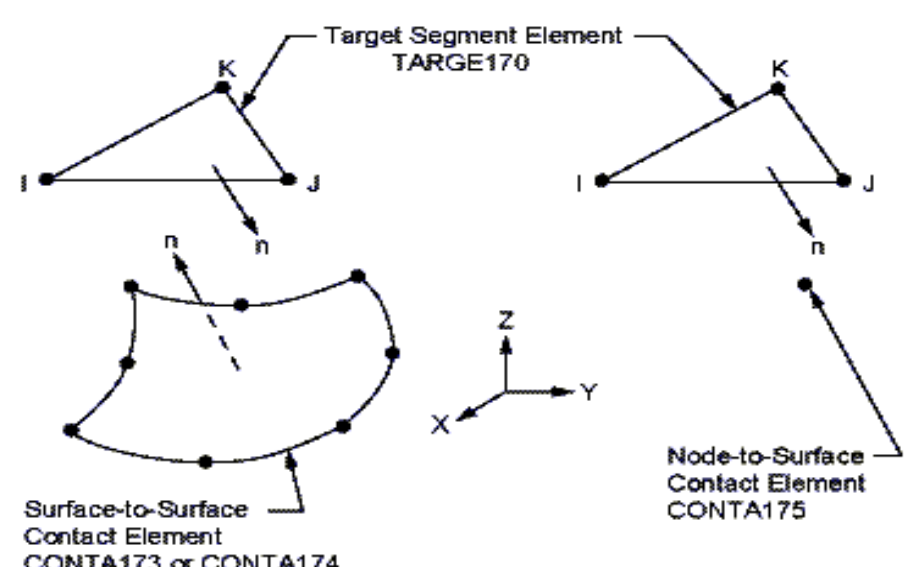

CONTA173 or CONTA174

Contact Element

ONTA175

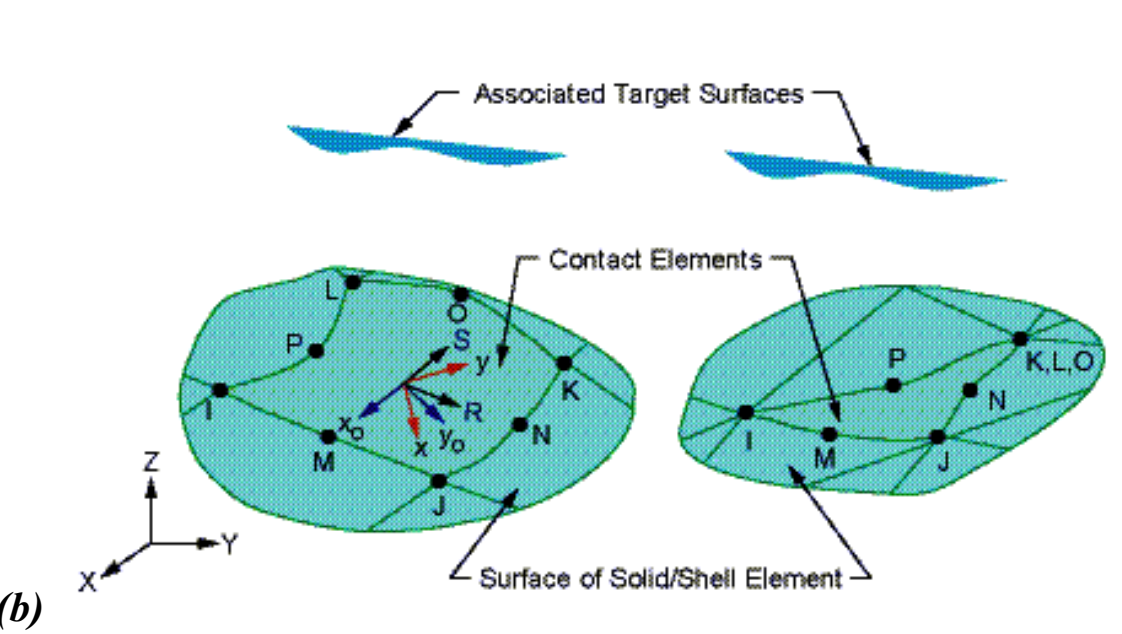

Figura 4.9 - Elementos finitos utilizados: (a) TARGE170 e (b) CONTA174.

Fonte: Manual eletrônico do ANSYS V9.0

\subsubsection{CONSTRUÇÃO DOS MODELOS NUMÉRICOS - Análise acoplada}

Conforme já mencionado em capítulos anteriores, o objetivo principal do presente trabalho se refere à análise numérica do comportamento de pilares mistos curtos de aço e concreto sob elevadas temperaturas.

Para tanto, é importante ressaltar que alguns aspectos devem ser levados em conta, tais como a ocorrência de uma expansão mais pronunciada do tubo de aço, se comparada ao 
núcleo de concreto, no início do aumento da temperatura, situação em que apenas o tubo de aço resiste ao carregamento e, somente após o escoamento do tubo de aço, o concreto passa a resistir aos esforços solicitantes, ocorrendo um deslizamento na interface aço-concreto devido a uma expansão diferencial entre os materiais.

No entanto é importante destacar que o fenômeno descrito no último parágrafo, apesar de ser comprovado experimentalmente por meio de trabalhos apresentados por outros pesquisadores (e comentado com maiores detalhes no capítulo 5), aparentemente não exerce influência significativa quando da análise de pilares mistos curtos, aqui objeto de estudo. Porém, para se recuperar numericamente tal comportamento, se faz necessária a utilização de uma chapa de topo na face superior do pilar misto curto, a qual permitirá a expansão axial diferenciada entre o tubo de aço e o núcleo de concreto e, ao mesmo tempo, permitir que o carregamento ocorra de forma compatível com aquela verificada experimentalmente.

A geometria e a malha de elementos finitos para o modelo constituído pelo pilar misto composto pela chapa de topo podem ser visualizadas na figura 4.10 , em que são apresentadas duas vistas: a base do pilar e o topo do mesmo.

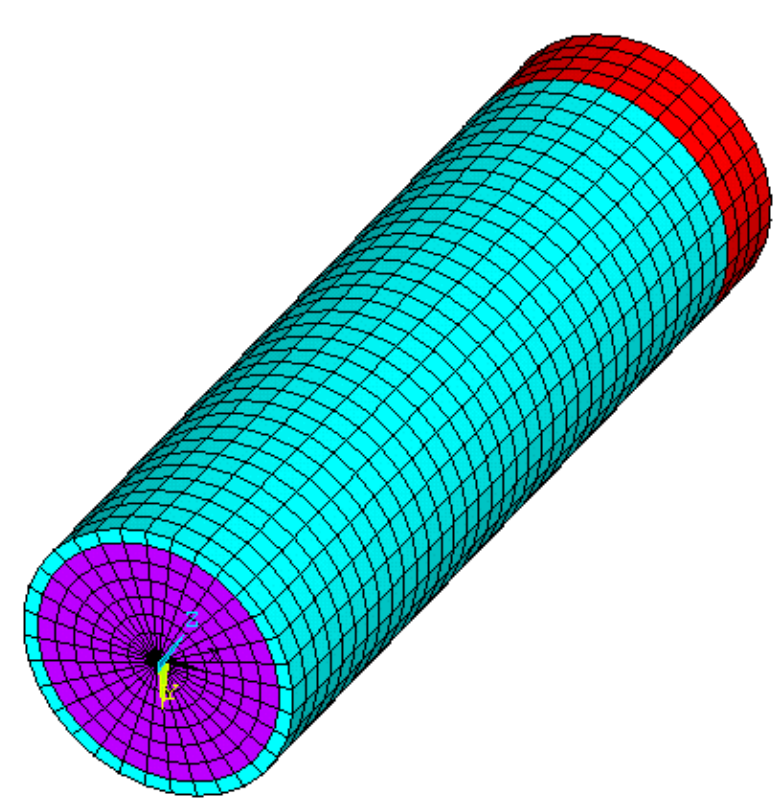

(a)

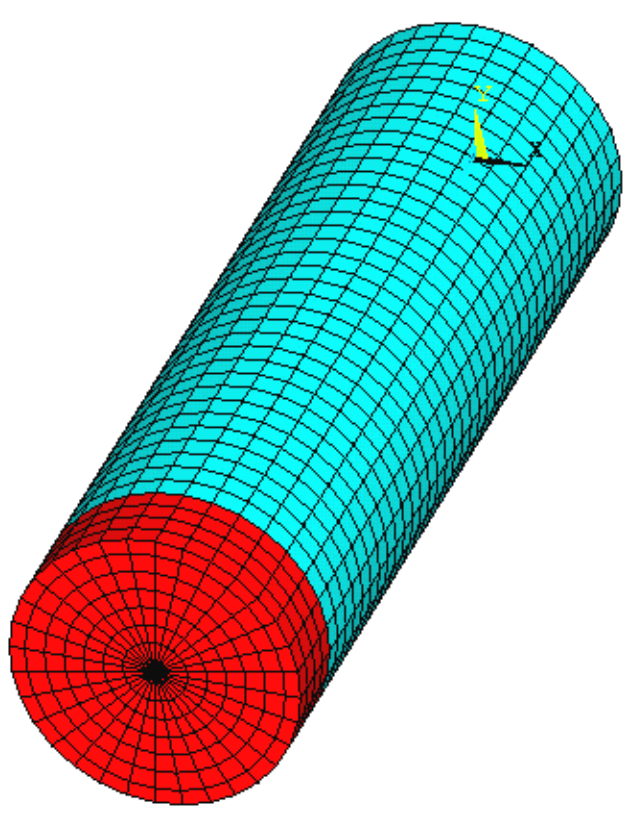

(b)

Figura 4.10 - Geometria e malha de elementos finitos: (a) vista da base e (b) vista do topo.

Na elaboração do modelo com chapa de topo, foram utilizados elementos de contato na interface aço-concreto, na lateral e entre a chapa de topo e concreto. A geometria dos elementos de contato pode ser visualizada na figura 4.11a, lembrando que na interface tubo de aço e chapa de topo os nós foram acoplados, conforme figura $4.11 \mathrm{~b}$. 


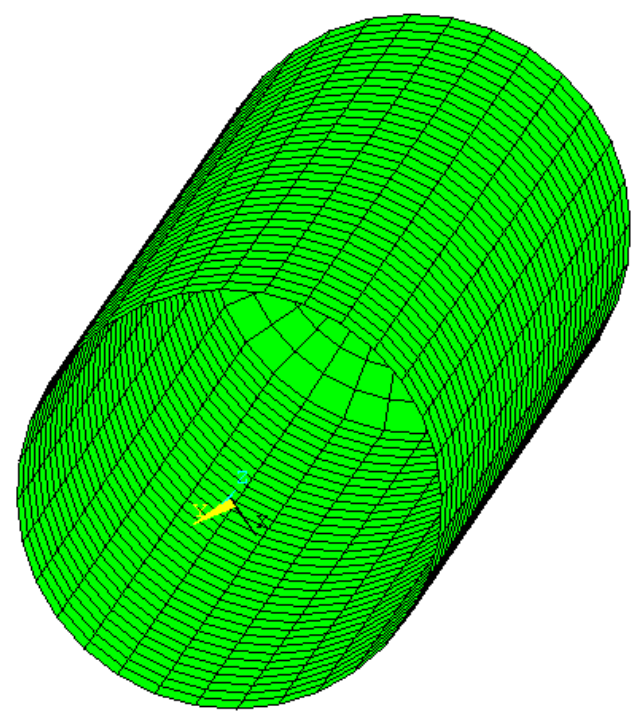

(a)

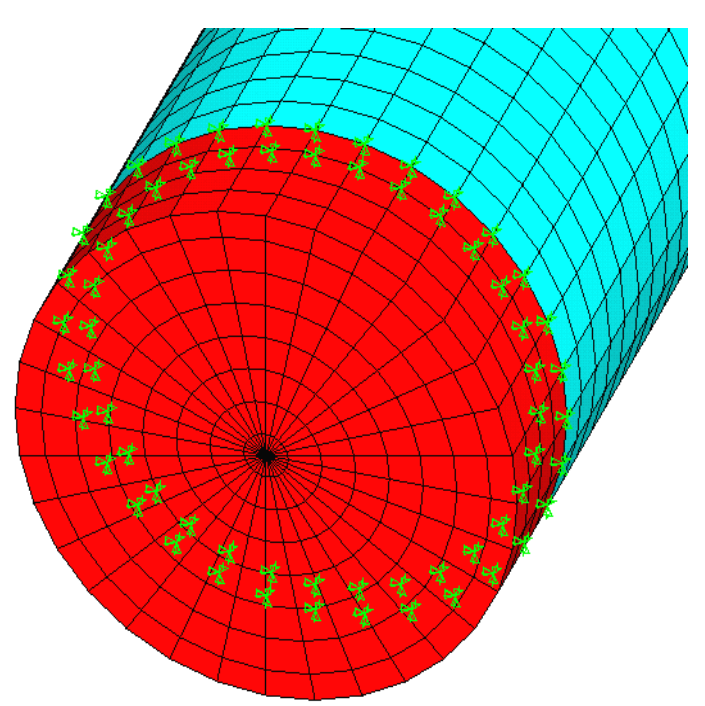

(b)

Figura 4.11 - (a) elemento de contato e (b) acoplamento dos nós na interface entre chapa de topo e extremidade do pilar misto.

Como condição de contorno se destaca que para os nós da base foram impedidos os deslocamentos nas direções $X, Y$ e $Z$, simulando um engaste na base do pilar, enquanto que a aplicação do carregamento axial ocorre na chapa de topo e de forma centrada.

No entanto, um procedimento comumente adotado para diminuir o tempo de processamento (ou esforço computacional) se refere à consideração de condição de simetria, que consiste da construção de apenas metade da seção transversal do modelo de pilar misto, conforme figura 4.12 .

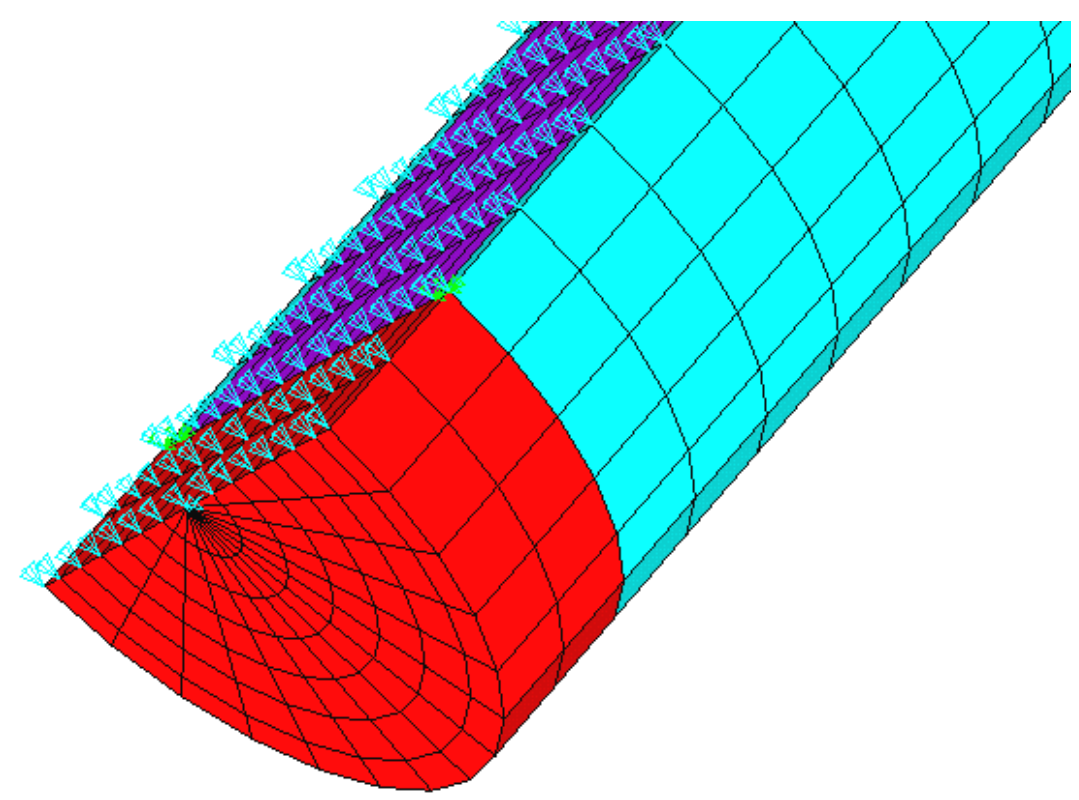

Figura 4.12 - Modelo de pilar misto curto: considerando $1 / 2$ simetria da seção circular. 
O procedimento de consideração de $1 / 2$ simetria, dependendo da resposta a ser obtida, poderá ser adotado para os modelos de análise (a térmica, a estrutural e a termo-estrutural). Também serão realizados estudos adicionais, em que são consideram a eliminação da chapa de topo e o acoplamento dos nós do topo do pilar, na forma de simplificação dos modelos.

No entanto, determinadas simplificações não podem ser aplicadas em todos os casos, tendo em vista que o modelo simétrico só poderá ser utilizado quando o pilar misto for submetido ao incêndio (carga térmica) em todo o seu contorno. Quando o incêndio não for aplicado em todo o contorno, ou seja, apenas em parte do contorno da seção do pilar, o modelo a ser utilizado é o modelo completo, tendo em vista ser o mais adequado.

Com relação à consideração ou não da chapa de topo, vale destacar que, se considerada, possibilita a aplicação de carregamento axial centrado e excêntrico. Por outro lado, uma simplificação do modelo consiste na sua desconsideração, e implica na utilização de modelos submetidos apenas a carregamentos axiais centrados, tendo em vista que no modelo simplificado é realizado o acoplamentos dos nós do topo do pilar, impondo a todos os nós acoplados o mesmo deslocamento axial, de modo que, mesmo que uma força axial aplicada de forma excêntrica, o carregamento será centrado.

As simplificações a serem aqui adotadas poderão ser entendidas nos capítulos que se seguem. No Capítulo 5 serão apresentados os resultados das análises térmicas, para fins de validação do modelo adotado, enquanto que no Capítulo 6 serão apresentados os resultados das análises de pilares mistos curtos em temperatura ambiente e acopladas. 



\section{MODELOS NUMÉRICOS PARA ANÁLISE TÉRMICA - VALIDAÇÃO DA ESTRATÉGIA ADOTADA}

No presente capítulo serão apresentados resultados referentes à evolução da temperatura nos modelos tridimensionais de pilares mistos curtos, com perfil circular de aço preenchido com concreto, quando submetidos ao incêndio-padrão ISO 834. Os resultados aqui apresentados foram obtidos por simulações numéricas realizadas com a utilização do pacote computacional ANSYS ${ }^{\circledR}$ V9.0.

É importante destacar que o código computacional ANSYS é, dentro do contexto científico, reconhecido pelo seu grande potencial quando aplicado em análises de interesse por meio da aplicação do Método dos Elementos Finitos. Porém, se deve ressaltar que o mesmo código não foi construído especificamente com vistas à análise térmica, razão pela qual se faz necessária a validação dos seus resultados, em campo térmico, para uma adequada calibração e análise dos modelos de pilares a serem aqui analisados.

Para a validação do campo térmico, alguns modelos numéricos de pilares mistos curtos de aço e concreto foram analisados por meio do $\boldsymbol{A N S Y S}$ e do código computacional sueco SuperTempCalc (inserido dentro do TCD V5.5), em ambos os casos submetido ao incêndio-padrão e por meio das mesmas propriedades térmicas, coeficiente de transferência de calor por convecção e emissividade resultante.

Com vistas a uma compilação mais adequada dos modelos analisados e de seus respectivos resultados, nos capítulos que se seguem, serão convenientemente adotadas algumas notações referentes aos modelos em estudo. São as seguintes:

PMC: Pilar Misto de seção circular preenchido com concreto;

$\theta$ : Análise térmica;

E: Análise estrutural;

A: Análise acoplada $(\mathrm{E}+\theta)$

D e t: Diâmetro externo e espessura da seção transversal do tudo de aço, respectivamente;

L: Comprimento do pilar misto. 
Portanto, a designação a ser associada ao pilar analisado seguirá como procedimento, denominações do tipo PMC-19- $\theta$. Neste caso, por exemplo, a sigla PMC indica o tipo de pilar misto analisado, o número 19 indica a relação D/t, e o parâmetro $\theta$ indica o tipo de análise a ser considerada (no caso, térmica).

Na tabela 5.1 estão apresentados os dados da geometria dos pilares mistos que serão analisados neste capítulo e, portanto, apenas em contexto térmico. Os valores adotados para a realização da análise térmica estão apresentados na tabela 5.2.

Tabela 5.1- Geometria dos pilares mistos adotados

\begin{tabular}{|c|c|c|}
\hline Dados & PMC-19 & PMC-63 \\
\hline $\mathrm{D}(\mathrm{mm})$ & 114,3 & 355,6 \\
\hline $\mathrm{t}(\mathrm{mm})$ & 6 & 5,6 \\
\hline Relação D/t & 19 & 63,5 \\
\hline
\end{tabular}

Tabela 5.2- Valores adotados

\begin{tabular}{|c|c|}
\hline Parâmetros de Interesse & Adotado \\
\hline Curva de incêndio-padrão & ISO 834-1:1999 \\
\hline Emissividade resultante & 0,5 \\
\hline Coeficiente de transferência de calor por convecção & $25 \mathrm{~W} /\left(\mathrm{m}^{2} \cdot{ }^{\circ} \mathrm{C}\right)$ \\
\hline Massa específica do aço & $7.850 \mathrm{~kg} / \mathrm{m}^{3}$ \\
\hline Calor específico do aço & Eq. 3.24 \\
\hline Condutividade térmica do aço & Eq. 3.26 \\
\hline Massa específica do concreto & $2.400 \mathrm{~kg} / \mathrm{m}^{3}$ \\
\hline Calor específico do concreto & Eq. 3.25 \\
\hline Condutividade térmica do concreto & Eq. 3.28 \\
\hline Obs: Equações 3.24, 3.25, 3.26 e 3.28 estão definidas no capítulo 3 \\
\hline
\end{tabular}

Nos itens seguintes, para fins de validação dos resultados do ANSYS, serão apresentados os resultados de campos de temperatura para casos de pilares curtos, considerando variações na aplicação da carga térmica e, conseqüentemente, na consideração ou não de modelos completos (inteiros) ou em parte, considerando simétrica dos mesmos. Estes resultados serão diretamente comparados aos resultados do TCD. 


\subsection{MODELOS NUMÉRICOS - VALIDAÇÃO DO CAMPO TÉRMICO}

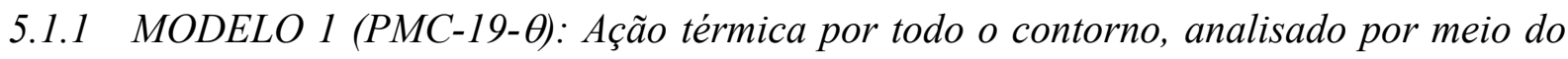 modelo inteiro.}

O primeiro modelo analisado, aqui denominado PMC-19- $\theta$, se refere a um pilar misto de seção circular preenchido com concreto, apenas com vistas à análise térmica cujas propriedades térmicas já estão definidas na tabela 5.2, submetido ao incêndio-padrão ISO 834 por todo o contorno da seção (todos os pontos da circunferência externa do tubo de aço) e sem variação ao longo do comprimento do mesmo.

As figuras 5.1a e 5.1b, extraídas do ANSYS e do TCD, respectivamente, representam a distribuição da temperatura na seção transversal do pilar misto, para um TRRF (Tempo Requerido de Resistência ao Fogo) igual a 60 minutos. Na mesma figura 5.1b também pode ser visualizada a malha gerada pelo TCD para fins de análise térmica.

Para comparação dos resultados obtidos entre ambos os códigos, foram construídos dois gráficos referentes ao modelo numérico PMC-19- $\theta$, apresentados nas figuras 5.3 e 5.4. A figura 5.3 representa a elevação da temperatura na seção transversal para TRRF iguais a 15 minutos, 30 minutos, 45 minutos e 60 minutos. A figura 5.4, por sua vez, representa a elevação da temperatura em função do tempo, relacionando alguns pontos de interesse da seção transversal.

As coordenadas dos pontos da seção transversal escolhidos estão apresentadas na tabela 5.3 e na figura 5.2, sendo adotadas as coordenadas $\mathrm{X}=0$ e $\mathrm{Y}=0$ para o centro do núcleo de concreto, conforme figura 5.1, que também corresponde ao centro do pilar misto.

Tabela 5.3- Coordenadas dos pontos analisados: modelo PMC-19

\begin{tabular}{|c|c|c|}
\hline Coordenadas & X (mm) & Y (mm) \\
\hline Ponto 1 & 0,0 & 0,0 \\
\hline Ponto 2 & 35,67 & 0,0 \\
\hline Ponto 3 & 57,00 & 0,0 \\
\hline
\end{tabular}

Observando as figuras 5.1a e 5.1b, se nota uma proximidade satisfatória na distribuição do campo térmico, comparando ANSYS e TCD, e representada de forma mais clara quando analisamos o gráfico da figura 5.3, em que pode ser observada a variação da temperatura ao longo da seção transversal do pilar misto. 
NODAL SOLUTION

$\mathrm{STEP}=1$

SUB $=108$

$\mathrm{T} I \mathrm{ME}=3600$

TEMP

(AVG)

RSYS $=0$

$\mathrm{SMNN}=576.267$

$\operatorname{SMX}=905.856$

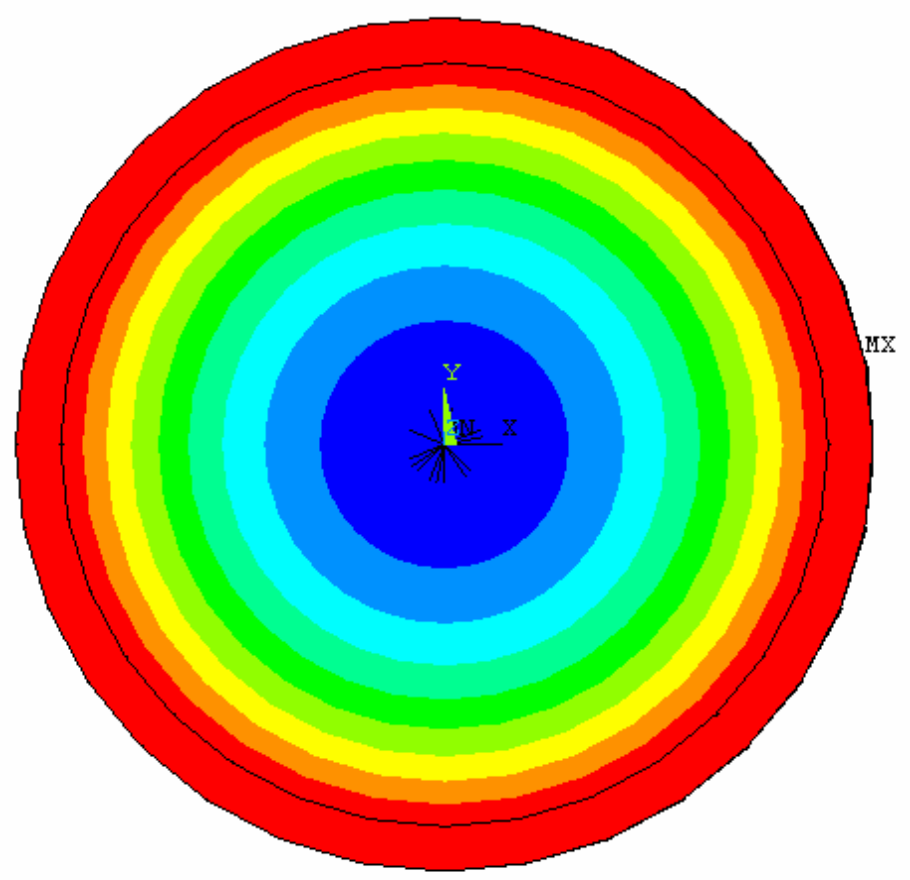

$\mathbf{N}$

FEB 252008

$16: 11: 10$

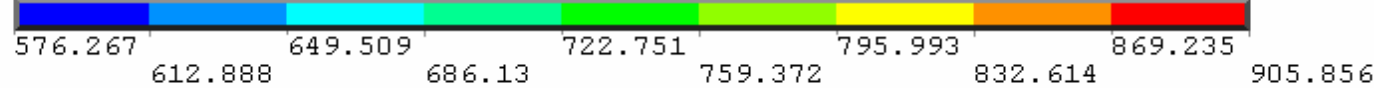

(a) ANALISE TERMICA
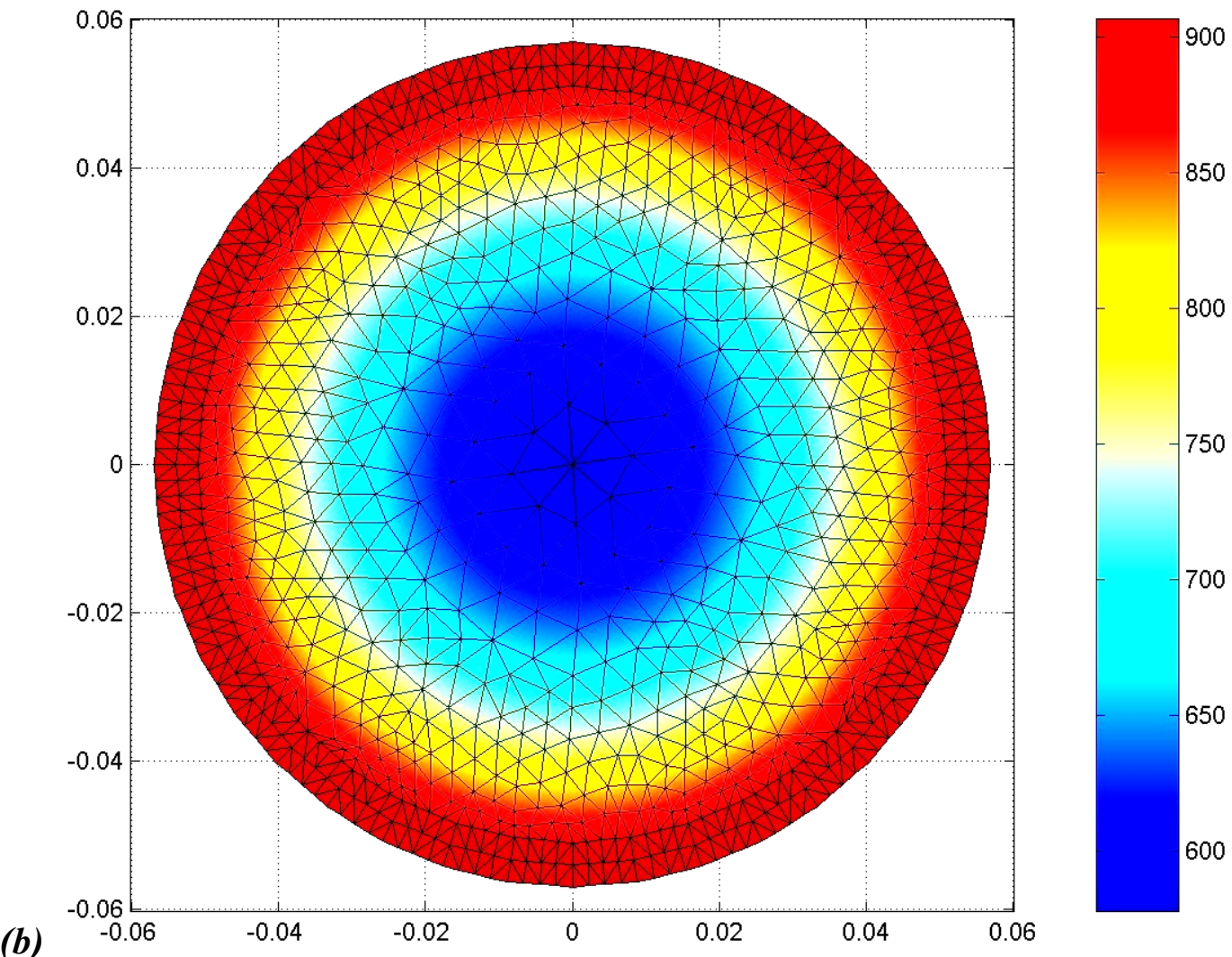

$-800$

750

700

650

600

(b)

Figura 5.1 - Campo de temperaturas referentes para TRRF igual a 60 minutos para o modelo PMC-19: (a) Resultado do ANSYS e (b) Resultado do TCD. 


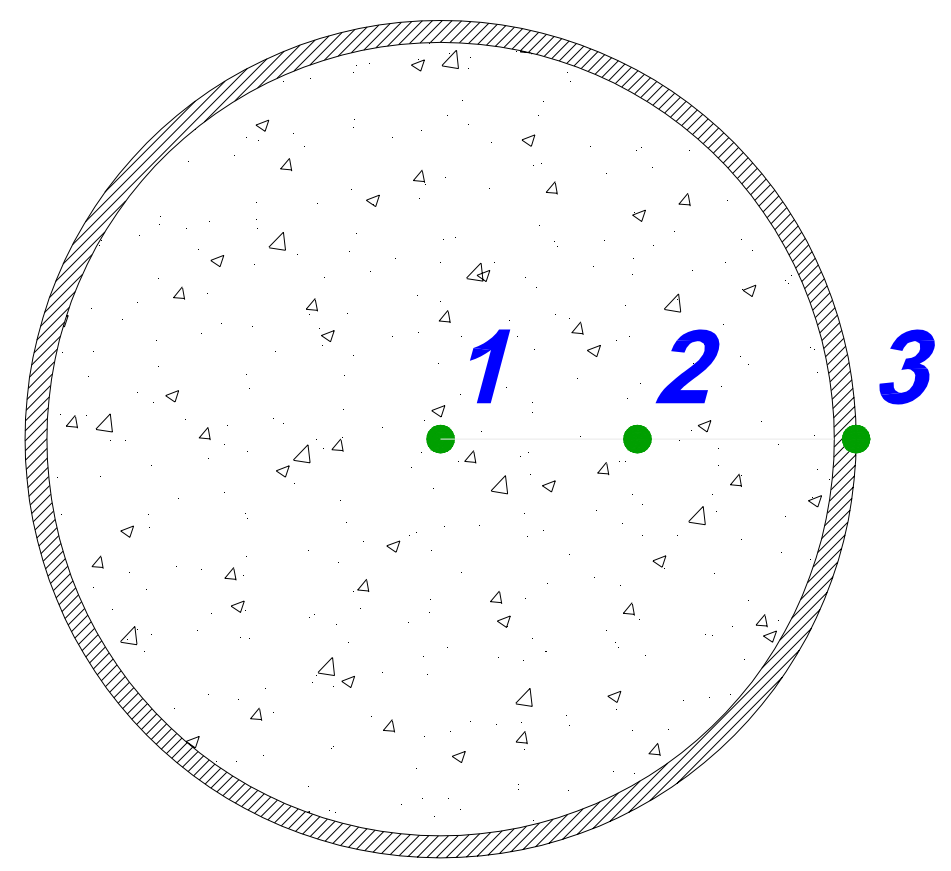

Figura 5.2 - Localização dos pontos 1, 2 e 3 para o modelo PMC-19.

Os pontos escolhidos para apresentar a evolução da temperatura em função do tempo são: Ponto 1 localizado no centro do núcleo de concreto, Ponto 2 localizado no núcleo de concreto entre o centro do núcleo e o tubo de aço, e Ponto 3 localizado na face externa do tubo de aço, conforme figura 5.2.

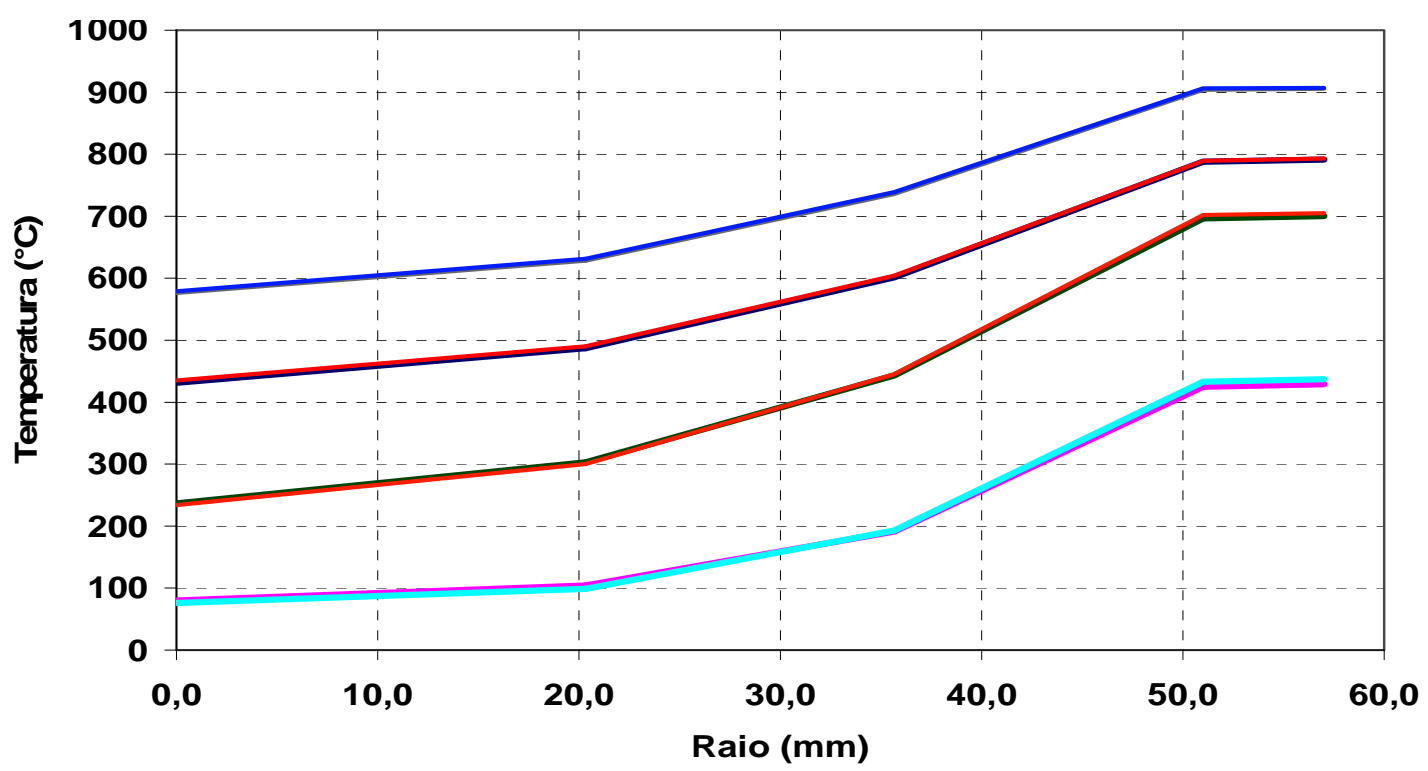

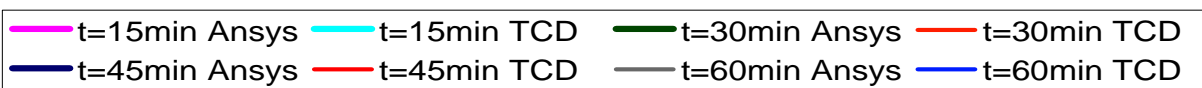

Figura 5.3 - Campo de temperaturas referentes a valores de TRRF's iguais a 15, 30, 45 e 60 minutos para o modelo PMC-19. 


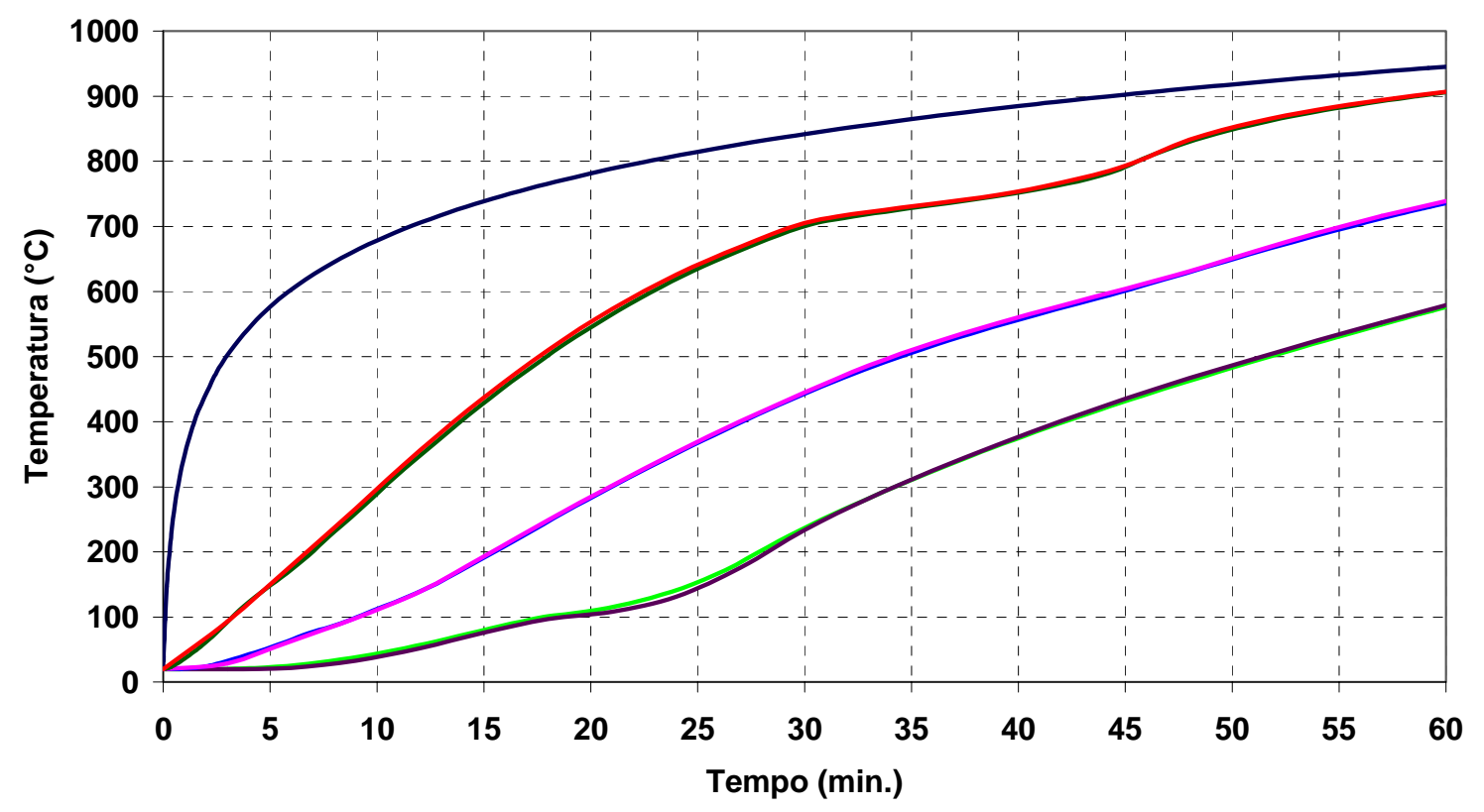

\begin{tabular}{lll}
\hline - ISO 834 & - Ponto-1 Ansys - Ponto-1 TCD - Ponto-2 Ansys \\
- Ponto-2 TCD & - Ponto-3 Ansys - Ponto-3 TCD
\end{tabular}

Figura 5.4 - Elevação da temperatura em função do tempo para pontos da seção transversal para o modelo PMC-19.

Observando a figura 5.4, é possível notar (e destacar) que a temperatura na face externa do tubo de aço é praticamente coincidente com aquela identificada na face interna do mesmo tubo, fato que sinaliza confiabilidade dos resultados de elevação de temperatura.

\subsubsection{MODELO 2 (PMC-63- $\theta$ ): Ação térmica por todo o contorno, analisado por meio de} modelo inteiro.

O segundo modelo analisado, aqui denominado PMC-63- $\theta$, se refere a um pilar misto de seção circular preenchido com concreto, cujas propriedades térmicas estão definidas na tabela 5.2, submetido ao incêndio-padrão ISO 834 por todo o contorno e em todo o seu comprimento.

As figuras 5.6a e 5.6b, extraídas de uma das telas de resultados do código ANSYS e do código térmico TCD, respectivamente, representam a distribuição da temperatura na seção transversal do pilar misto (modelo 2), para um TRRF igual a 60 minutos. Na mesma figura 5.6b também pode ser visualizada a malha gerada pelo TCD para fins de análise térmica.

Para comparação dos resultados obtidos entre ambos os programas, foram construídos dois gráficos referentes ao modelo numérico PMC-63- $\theta$, apresentados nas figuras 5.7 e 5.8. A figura 5.7 representa a elevação da temperatura na seção transversal para TRRF iguais a 15 minutos, 30 minutos, 45 minutos e 60 minutos. A figura 5.8, por sua vez, 
representa a elevação da temperatura em função do tempo relacionado a alguns pontos da seção transversal.

As coordenadas dos pontos da seção transversal, adotados para avaliação dos resultados, estão apresentadas na tabela 5.4 e na figura 5.5 , sendo adotados $X=0$ e $Y=0$ como coordenadas do centro no núcleo de concreto e centro do pilar.

Tabela 5.4- Coordenadas dos pontos - PMC-63

\begin{tabular}{|c|c|c|}
\hline Coordenadas & X (mm) & Y (mm) \\
\hline Ponto 1 & 0,0 & 0,0 \\
\hline Ponto 2 & 48,67 & 0,0 \\
\hline Ponto 3 & 103,58 & 0,0 \\
\hline Ponto 4 & 144,75 & 0,0 \\
\hline Ponto 5 & 177,80 & 0,0 \\
\hline
\end{tabular}

Observando as figuras 5.6a e 5.6b, nota-se uma boa proximidade na distribuição do campo térmico apresentado nas figuras extraídas dos códigos ANSYS e TCD, a qual se torna mais clara quando da análise do gráfico da figura 5.7, em que pode ser observada a variação da temperatura ao longo da seção transversal do pilar misto.

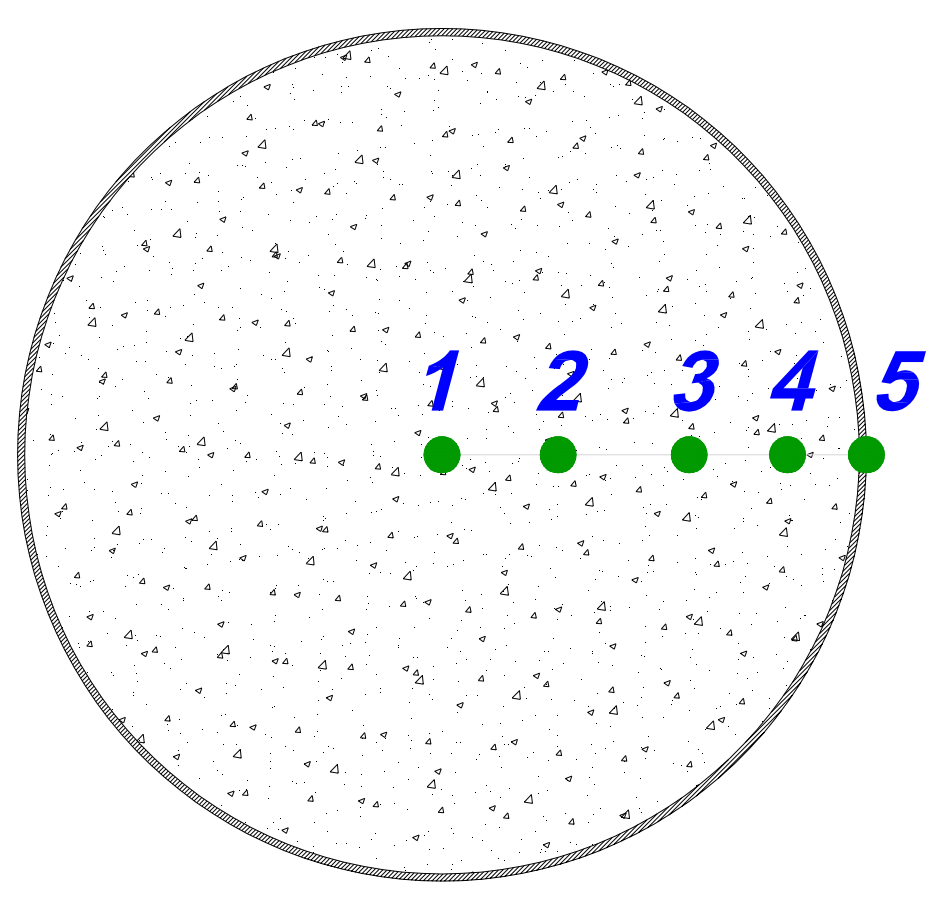

Figura 5.5 - Localização dos pontos 1, 2, 3, 4 e 5 para o modelo PMC-63. 
NODAL SOLUTION STEP $=1$

SUB $=117$

$\mathrm{TIME}=3600$

TEMP

RSYS $=0$

$\operatorname{SNN}=33.915$

$5 \mathrm{MX}=863.737$

(a)

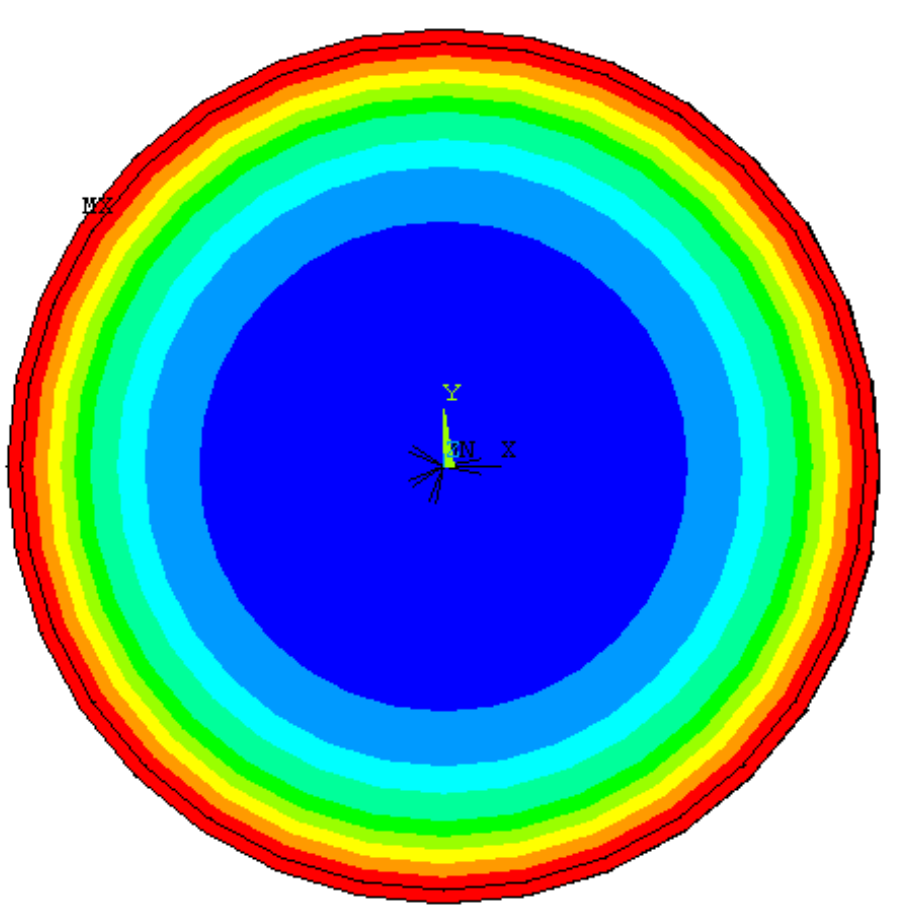

$\mathbf{N}$

FEB 252008

$16: 05: 02$

$33.915 \quad 126.118^{218.32} 310.522^{402.725} 494.927^{587.13} 679.332^{771.534} 863.737$

(b)
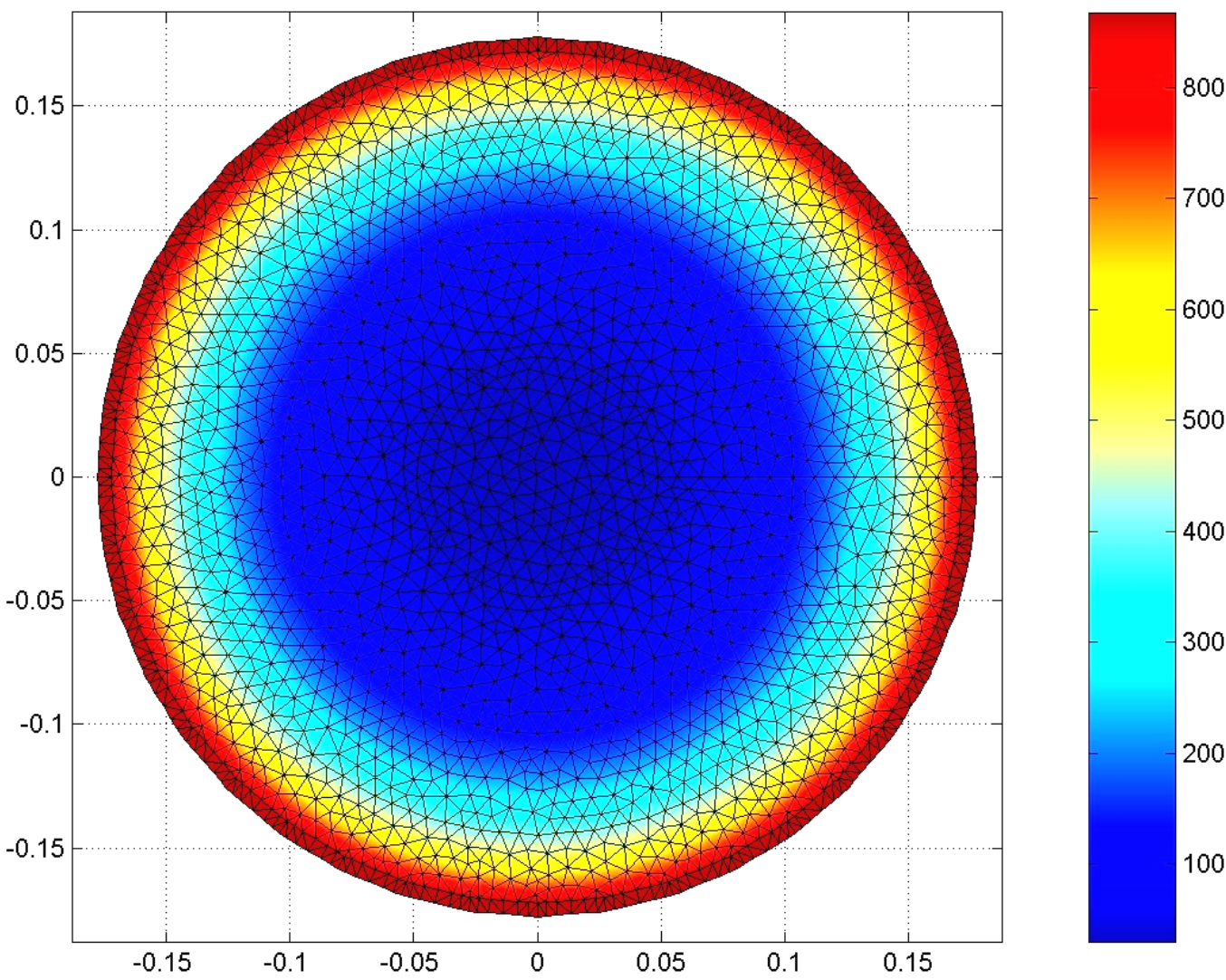

Figura 5.6 - Campo de temperaturas referentes a um tempo (TRRF) de 60 minutos para o modelo PMC-63: (a) Resultado do ANSYS e (b) Resultado do TCD. 


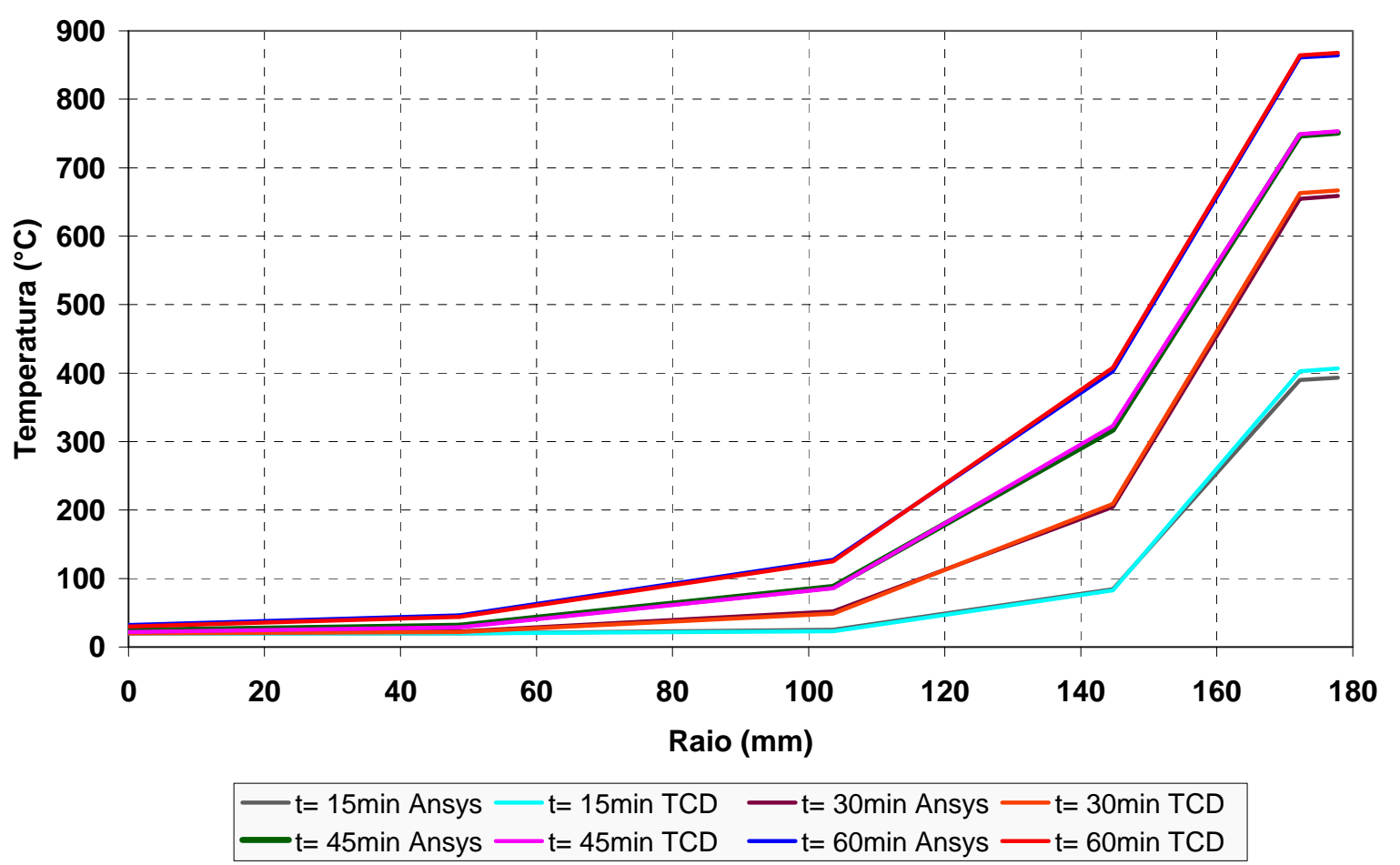

Figura 5.7 - Campo de temperaturas referentes a valores de TRRF iguais a 15, 30, 45 e 60 minutos para o modelo PMC-63.

Observando a figura 5.7, é possível notar que a temperatura apresentada na face externa do tubo de aço é praticamente coincidente com aquela apresentada na face interna, de modo análogo ao modelo anterior (item 5.11).

Comparando os gráficos das figuras 5.3 e 5.7 pode-se notar a influência do concreto na elevação da temperatura do tubo de aço, tendo em vista o fato de o modelo PMC-63 apresentar um diâmetro de, aproximadamente, três vezes o diâmetro do modelo PMC-19, apesar de as espessuras dos tubos resultarem bastante próximas.

Essa constatação se deve ao fato de o Modelo 2 possuir maior massa de concreto se comparado ao Modelo 1 , conseqüentemente resultam, temperaturas na face externa do aço da ordem de $40^{\circ} \mathrm{C}$ menor para os TRRF's iguais a $15,30,45$ e 60 min. A temperatura no centro do núcleo de concreto do modelo 2 praticamente não varia, enquanto que a temperatura no centro do modelo 1, após 60 minutos, é da ordem de $575^{\circ} \mathrm{C}$.

$\mathrm{Na}$ figura 5.8, os pontos escolhidos para apresentar a evolução da temperatura em função do tempo são:

a-) Ponto 1: localizado no centro do núcleo de concreto;

b-) Pontos 2, 3 e 4: localizados no núcleo de concreto;

c-) Ponto 5: localizado na face externa do tubo de aço. 
O gráfico apresentado na figura 5.8 também indica uma aproximação bastante satisfatória dos resultados extraídos do ANSYS e comparados àqueles do TCD.

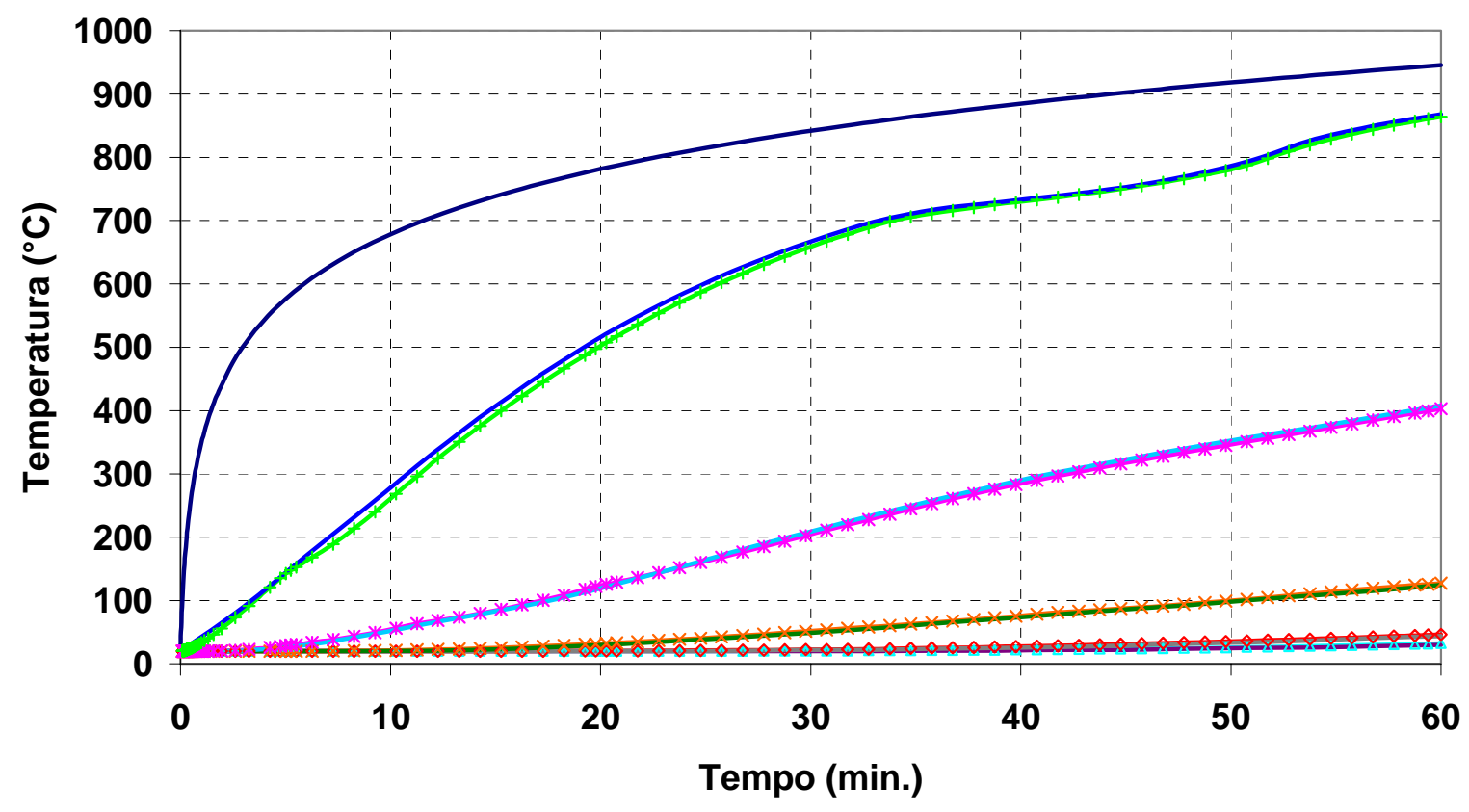

\begin{tabular}{|c|c|}
\hline - ISO 834 & $\longrightarrow$ Ponto 1 Anys - Ponto 1 TCD $\multimap$ Ponto 2 Anys $\longrightarrow$ Ponto 2 TCD $\approx$ Ponto 3 Anys \\
\hline - Ponto 3 TCD & *-Ponto 4 Anys —Ponto 4 TCD $\longrightarrow$ Ponto 5 Anys $\longrightarrow$ Ponto 5 TCD \\
\hline
\end{tabular}

Figura 5.8 - Elevação da temperatura em função do tempo para pontos da seção transversal para o modelo PMC-63.

Analisando os resultados apresentados pelos modelos 1 e 2, é possível concluir que o ANSYS representa muito bem o campo térmico para os pilares mistos preenchidos com concreto submetidos à carga térmica por todo o contorno.

\subsubsection{MODELO 3 (PMC-63- $\theta$ ): Ação térmica na metade do contorno, analisado por meio de modelo inteiro.}

O modelo 3 tem como objetivo avaliar a distribuição do campo térmico para um pilar misto preenchido com concreto submetido à elevação de temperatura apenas por um lado (metade da seção transversal do pilar) e constante ao longo de seu comprimento. Trata-se de uma forma de inserir a influência de uma possível compartimentação existente em um dado ambiente em chamas.

O pilar misto adotado foi aquele já denominado PMC-63- $\theta$, cujas propriedades térmicas são as mesmas definidas na tabela 5.2, com curva de aquecimento adotada também com base na curva de incêndio-padrão, proposto pela ISO 834. 
As figuras 5.9a e 5.9b foram extraídas do ANSYS e do TCD, respectivamente, e representam a distribuição da temperatura na seção transversal do pilar misto, para um TRRF igual a 60 minutos.

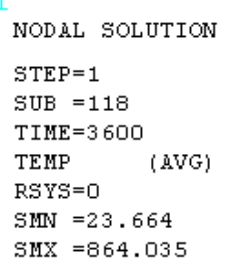

$\mathbf{N}$

NOV 52008 $13: 46: 26$

(a)

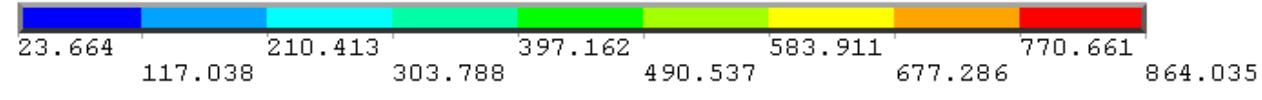

(b)

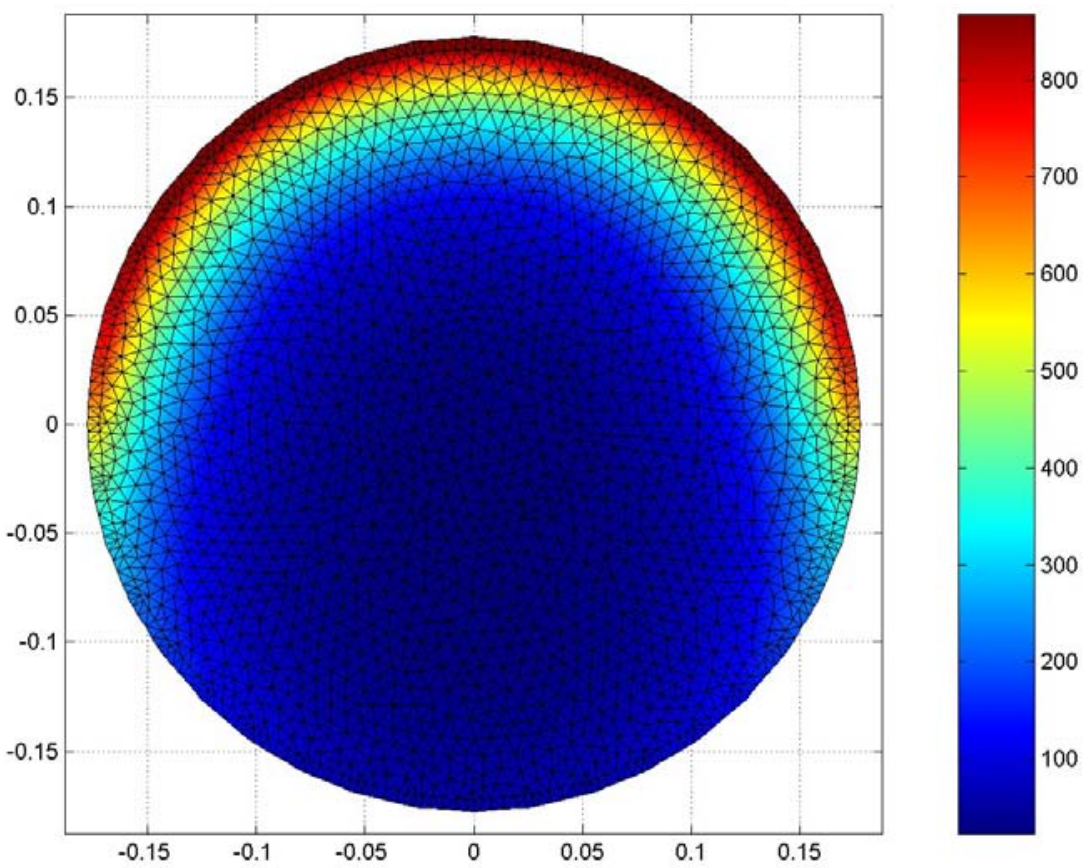

Figura 5.9 - Campo de temperaturas referentes a um TRRF igual a 60 minutos, com temperatura aplicada por um lado: (a) Resultado do ANSYS e (b) Resultado do TCD. 
Para melhor compreensão dos resultados obtidos, optou-se por representar esses resultados na forma gráfica, conforme figura 5.10, na qual são apresentadas a elevação da temperatura nos eixos $\mathrm{X}$ e $\mathrm{Y}$ da seção transversal (eixos X e $\mathrm{Y}$ indicados na figura 5.9a), para tempos (TRRF) iguais a 15 minutos, 30 minutos, 45 minutos e 60 minutos.

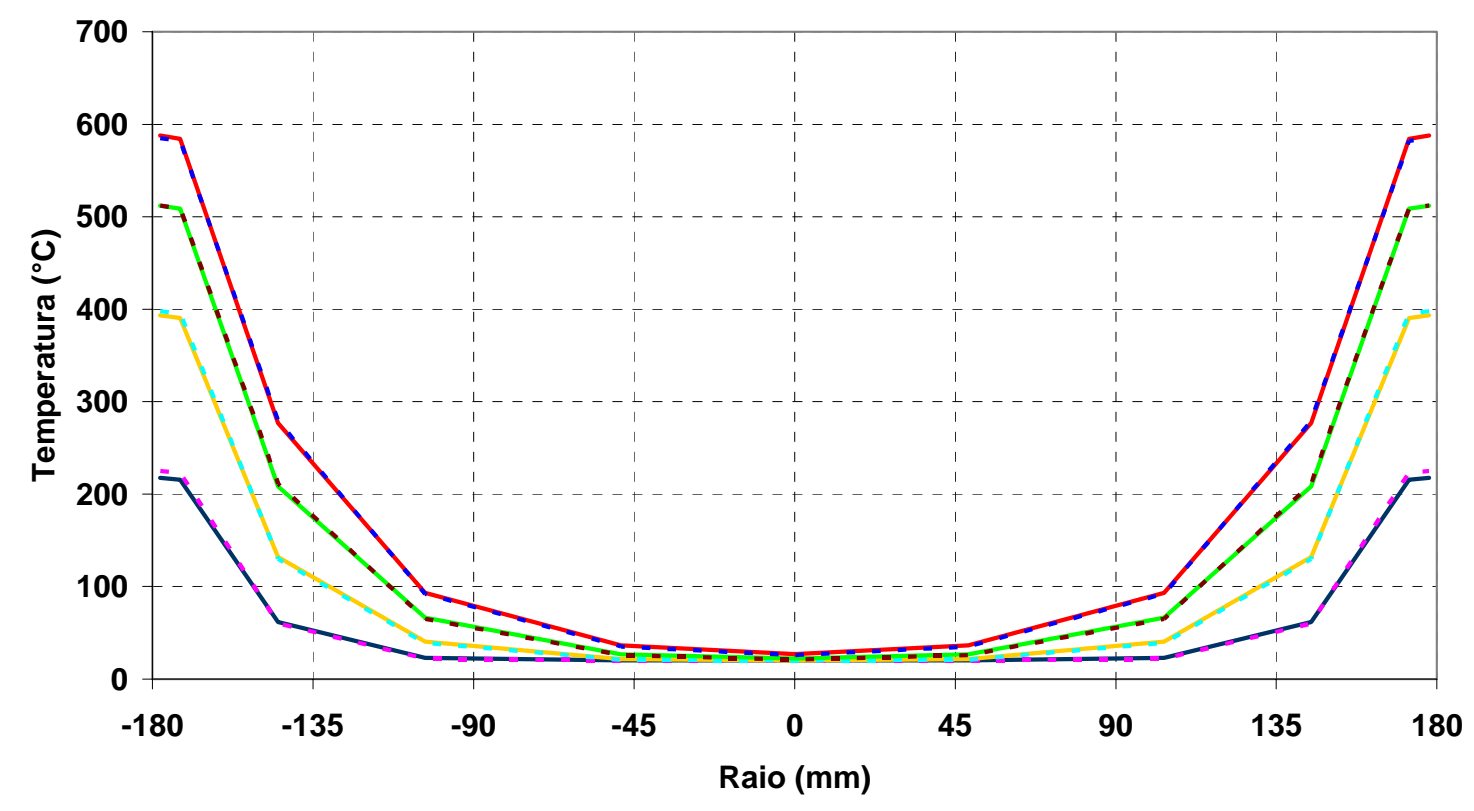

(a)

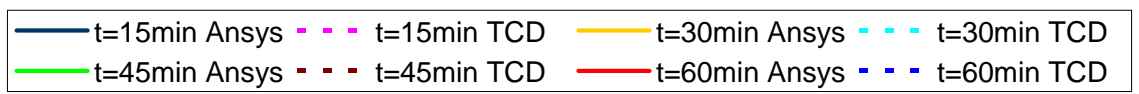

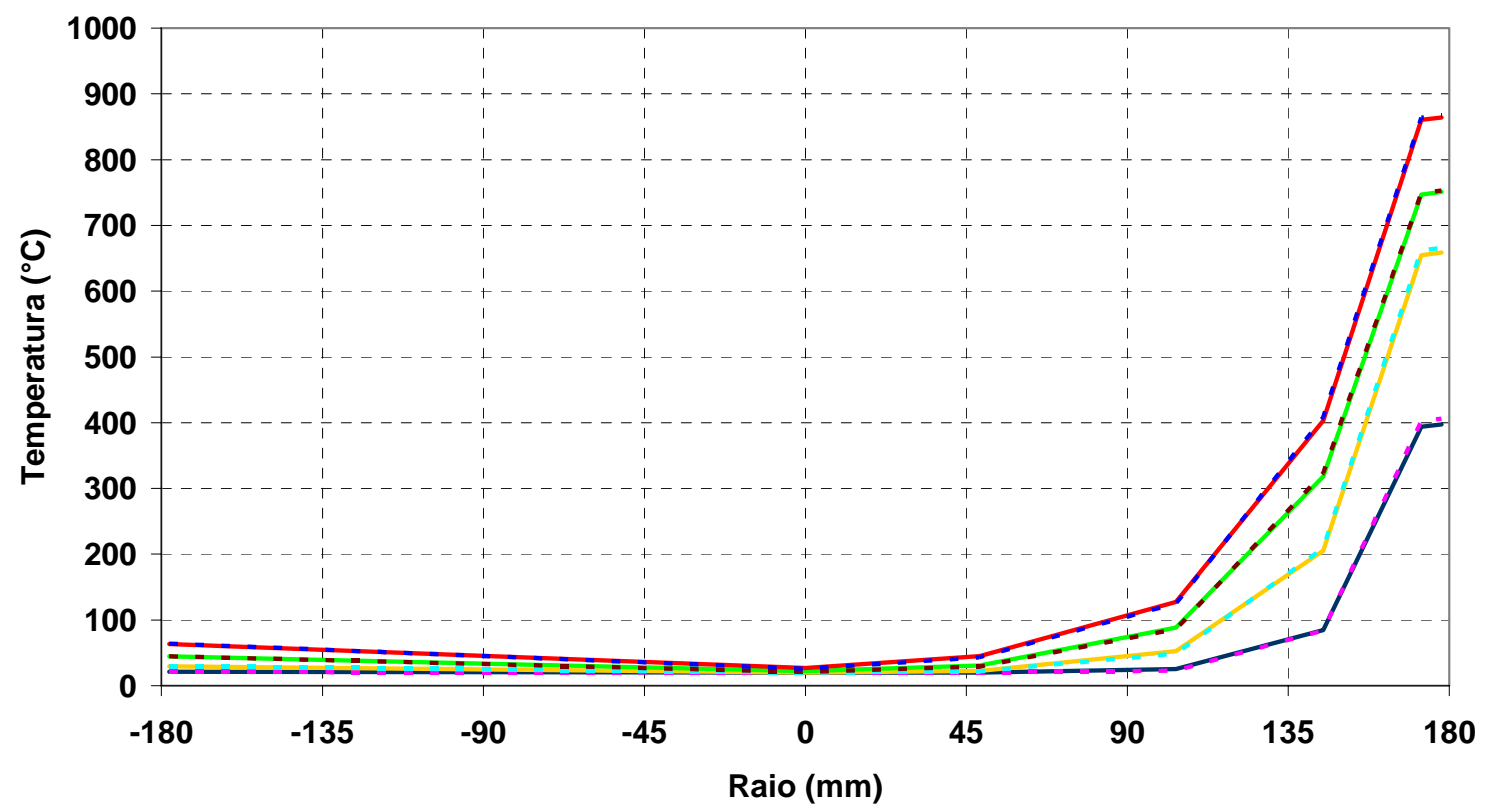

(b)

\begin{tabular}{|c|c|}
\hline$-\mathrm{t}=15 \mathrm{~min}$ Ansys $=-\mathrm{t}=15 \mathrm{~min}$ TCD & $\mathrm{t}=30 \mathrm{~min}$ Ansys $=-\mathrm{t}=30 \mathrm{~min}$ TCD \\
\hline
\end{tabular}

Figura 5.10 - Variação de temperaturas, para TRRF's iguais a 15, 30, 45 e 60 minutos, para o modelo PMC-63: (a) Eixo X e (b) Eixo Y 
Assim como nos casos anteriores (itens 5.1.1 e 5.1.2), os gráficos apresentados na figura 5.10 mostram uma boa aproximação dos resultados obtidos via ANSYS quando comparados àqueles obtidos por meio do TCD.

5.1.4 MODELO 4 (PMC-19- $\theta$ ): Ação térmica por todo o contorno, analisado por meio de modelo simétrico.

O modelo aqui analisado se refere a um pilar misto de seção circular preenchido com concreto, idêntico ao Modelo 1 (item 5.2.1), porém, diferente do primeiro por ser considerada a simetria da seção transversal, com vistas a considerar apenas metade do pilar misto e, conseqüentemente, reduzir do esforço computacional na realização futura de análise acoplada do tipo termo-estrutural.

O pilar misto, conforme figura 5.11, foi submetido ao incêndio-padrão ISO 834 por todo o contorno da seção transversal, levando-se em consideração o carregamento térmico aplicado somente na face externa do perfil metálico, e constante ao longo de todo o comprimento. A figura 5.11, extraída do ANSYS, representa a distribuição da temperatura na seção transversal do pilar misto, para um TRRF igual a 60 minutos.
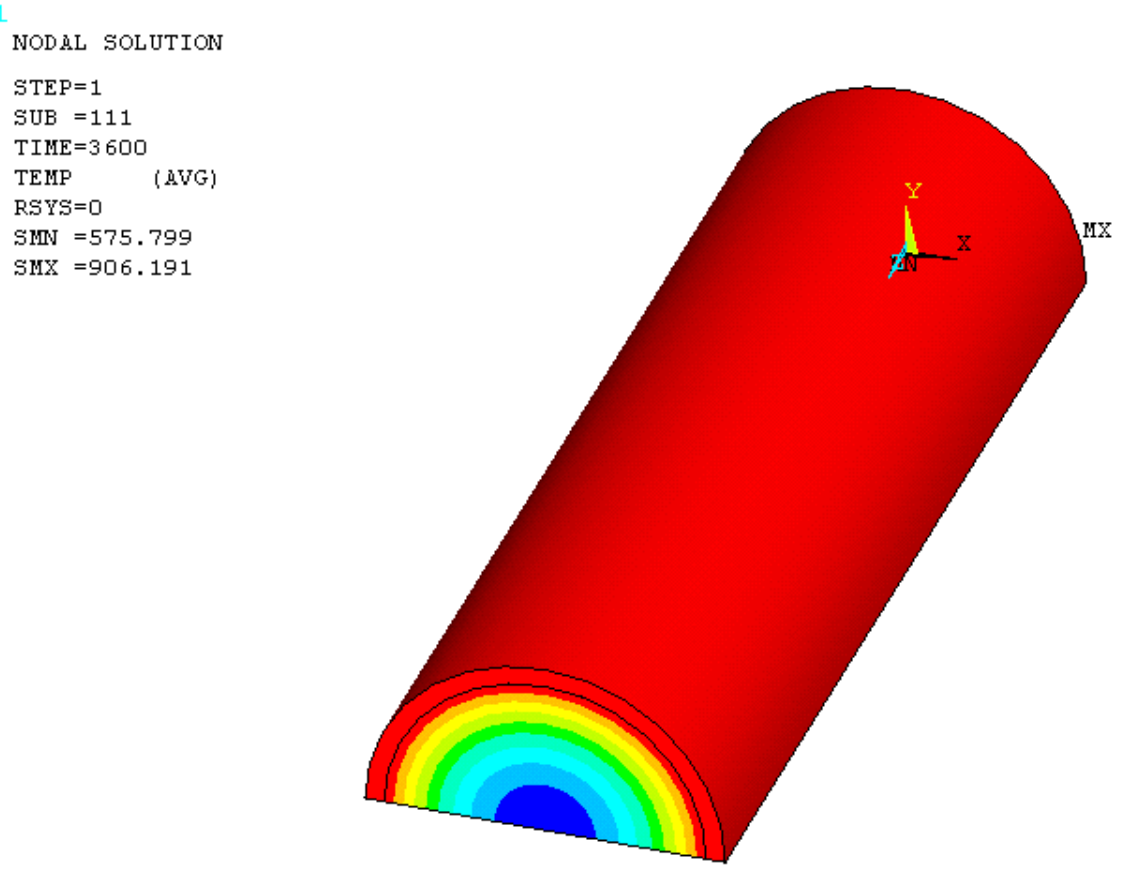

$\mathbf{N}$

NoV 112008 $17: 16: 42$

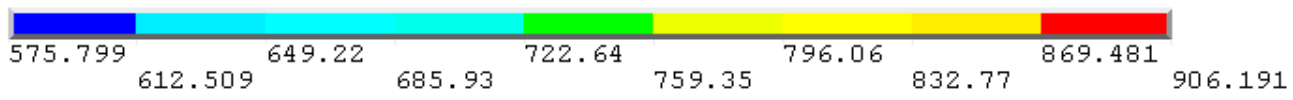
ANALISE TERMICA

Figura 5.11 - Campo de temperaturas referentes a um TRRF igual a 60 minutos para metade do modelo PMC-19. 
Para a constatação de que apenas metade do modelo completo, aqui denominado “modelo simétrico", possa ser utilizado para reduzir o esforço computacional, foi construído o gráfico da figura 5.12, em que foi comparada à elevação da temperatura, via ANSYS, entre pontos coincidentes nos Modelos 1 e 4. Os pontos escolhidos foram: o Ponto 1 (localizado no centro do núcleo de concreto com raio igual a zero) e o Ponto 3 (localizado na face externa do tubo de aço).

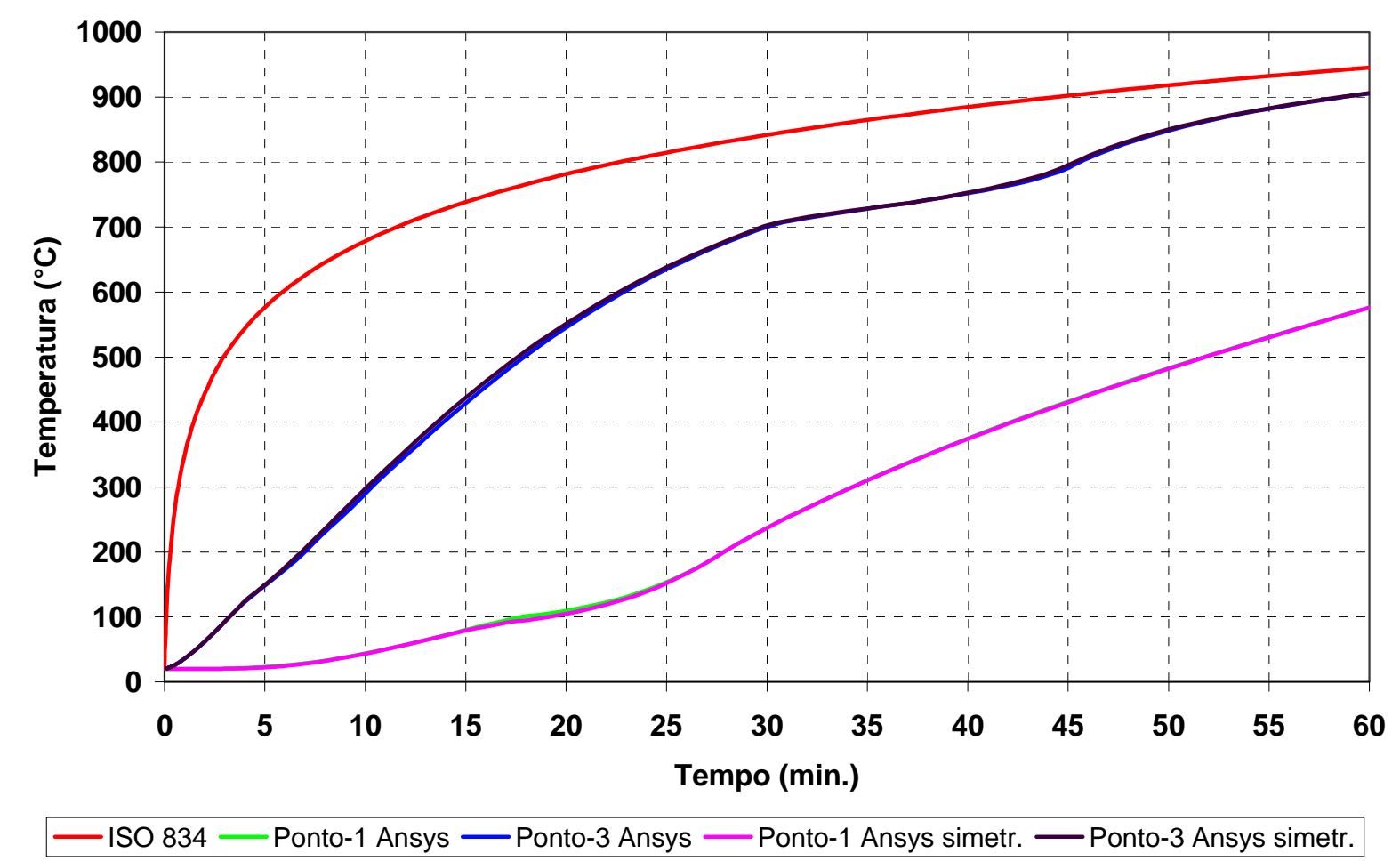

Figura 5.12 - Elevação da temperatura em função do tempo para pontos da seção transversal para os Modelos 1 e 4.

Visualizando os gráficos da figura 5.12, é possível notar que os valores de temperatura nos pontos coincidentes dos modelos 1 e 4 (modelo inteiro e modelo simétrico) são praticamente iguais e, com isso, concluir que o Modelo 4, em que foi levada em consideração a simetria, pode ser utilizado em substituição ao modelo inteiro, com vistas a reduzir o esforço computacional. Sendo importante ressaltar que o Modelo 4 poderá ser utilizado apenas para a situação de carregamento térmico por todo o contorno da seção transversal, para diferentes condições de carregamento térmico, deverá ser aplicado o modelo inteiro (sem a consideração da simetria).

Após a constatação de que os resultados obtidos pelas análises com o ANSYS estão bem próximos dos resultados do TCD e tendo em vista ser este último um código específico 
para análise térmica, é possível admitir que o código computacional ANSYS é adequado para fins de obtenção de campos de temperatura nos modelos aqui de interesse e, portanto, viabiliza a realização da etapa final do presente trabalho, no caso, análises do tipo termoestrutural (acoplada), conforme será demonstrado no capítulo seguinte. 



\section{ANÁLISE DE PILARES MISTOS CURTOS DE AÇO E CONCRETO: TEMPERATURA AMBIENTE E INCÊNDIO}

\subsection{CONSIDERAÇÕES PRELIMINARES}

No presente capítulo são apresentados os resultados referentes à análise acoplada, do tipo termo-estrutural, para modelos tridimensionais de pilares mistos curtos com perfil de aço preenchido com concreto. Os resultados aqui apresentados foram obtidos por simulações numéricas realizadas com a utilização do código ANSYS ${ }^{\circledR}$ V9.0.

A análise acoplada considera os efeitos da elevação de temperatura na resposta de estruturas em situação de incêndio, considerando campos de temperatura previamente obtidos por meio de análise térmica, em que se determinam os conseqüentes efeitos, seja de um elemento isolado ou de um sistema estrutural.

Em uma "primeira etapa”, a análise acoplada aqui proposta consiste na aplicação de uma porcentagem da carga última do pilar misto em temperatura ambiente, para posterior aplicação do carregamento térmico em situação de incêndio, com vistas à determinação do tempo crítico (ou temperatura crítica) do pilar misto em estudo, inclusive de seu comportamento mecânico durante a elevação de temperatura. Em uma "segunda etapa", se faz a análise inversa, considerando o carregamento sempre crescente para um dado campo térmico correspondente a um determinado tempo de incêndio.

Portanto, das considerações anteriores e, tendo em vista que no capítulo anterior já se fez uma validação dos campos térmicos para duas seções transversais diferentes de pilares mistos preenchidos, se faz ainda necessária uma validação do modelo estrutural em temperatura ambiente antes da análise acoplada.

Na tabela 6.1 estão apresentados os dados da geometria dos pilares mistos que serão analisados em temperatura ambiente para, posteriormente, serem analisados sob elevadas temperaturas. Os comprimentos dos pilares serão aqui adotados iguais a três vezes o diâmetro dos mesmos, para assegurar a análise de pilares mistos do tipo "curto", bem como a 
consideração apenas do colapso desses no referente à plastificação da seção transversal, sem a preocupação de se considerar efeitos dos tipos instabilidade global ou imperfeições iniciais.

Tabela 6.1- Geometria dos pilares mistos analisados

\begin{tabular}{|c|c|c|c|}
\hline DIMENSÕES & $P M C-19$ & $P M C-26$ & $P M C-46$ \\
\hline $\mathrm{D}(\mathrm{mm})$ & 114,3 & 168,3 & 219,1 \\
\hline $\mathrm{t}(\mathrm{mm})$ & 6,0 & 6,4 & 4,8 \\
\hline $\mathrm{L}(\mathrm{mm})$ & 342,9 & 504,9 & 657,3 \\
\hline Relação D/t & 19 & 26 & 45,7 \\
\hline
\end{tabular}

Os valores das propriedades mecânicas dos materiais aço e concreto em temperatura ambiente estão apresentados na tabela 6.2.

Tabela 6.2- Propriedades mecânicas adotadas para os materiais: aço e concreto

\begin{tabular}{|c|c|c|c|}
\hline PROPRIEDADES & $\boldsymbol{P M C}-19$ & $\boldsymbol{P M C}-\mathbf{2 6}$ & $\boldsymbol{P M C}-\mathbf{4 6}$ \\
\hline $\mathrm{f}_{\mathrm{ck}}(\mathrm{MPa})$ & 32,68 & 32,68 & 32,68 \\
\hline $\mathrm{E}_{\mathrm{c}}(\mathrm{MPa})$ & 27.220 & 27.220 & 27.220 \\
\hline $\mathrm{f}_{\mathrm{v}}(\mathrm{MPa})$ & 342,95 & 342,95 & 342,95 \\
\hline $\mathrm{E}_{\mathrm{s}}(\mathrm{MPa})$ & 205.000 & 205.000 & 205.000 \\
\hline
\end{tabular}

\subsection{PILARES MISTOS CURTOS-Análise em temperatura ambiente}

Faz-se aqui a determinação da carga de colapso de pilares mistos curtos em temperatura ambiente, uma vez que o valor da carga de colapso obtida é de fundamental importância para a análise acoplada, visto que a determinação do "tempo crítico" na análise termo-estrutural é obtida em função da relação do carregamento aplicado na análise acoplada (temperaturas elevadas) com a carga de colapso em temperatura ambiente. Portanto, a análise acoplada só será representativa e com resultados confiáveis se os resultados das análises térmicas e estruturais em temperatura ambiente estiverem consistentes e corretos.

Nos itens que se seguem serão apresentados os resultados das análises numéricas em temperatura ambiente para os três modelos cujas características geométricas e mecânicas foram descritas nas tabelas 6.1 e 6.2: modelo 1 (PMC-19), modelo 2 (PMC-26) e modelo 3 (PMC-46). É importante ressaltar que apenas o Modelo 1, utilizado na validação da estratégia adotada, terá seus resultados comparados com valores experimentais, apresentados em OLIVEIRA (2008), trabalho de doutorado realizado no Departamento de Engenharia de 
Estruturas da Escola de Engenharia de São Carlos, trabalho este, que teve como objetivo avaliar de forma teórica e experimental a influência de fatores como: a resistência a compressão do concreto, a esbeltez do pilar, a espessura do tubo de aço e a forma de introdução do carregamento, no comportamento dos pilares mistos preenchidos de seção circular. Os resultados experimentais foram comparados com resultados normativos (EUROCODE 4, NBR 8800:2008, ANSI/AISC:2005 e CAN/CSA:2001) e alguns pilares foram modelados numericamente via o código computacional DIANA.

Ainda que o foco do presente trabalho se direcione aos pilares mistos curtos, apenas para fins de validação da modelagem adotada será também realizada uma variação deste modelo com relação ao comprimento do mesmo, nesse caso, $\mathrm{L}=10 \mathrm{D}$, cujos resultados numéricos também serão comparados com resultados experimentais obtidos na última referência.

Ao final do presente item, uma tabela será apresentada comparando os resultados dos Modelos 1, 2 e 3 com os valores obtidos por meio de documentos normativos.

\subsubsection{MODELO 1 (PMC-19-E) - Análise estrutural em temperatura ambiente}

Para a validação do modelo, os resultados obtidos com o ANSYS foram comparados com os resultados extraídos de OLIVEIRA (2008), tendo em vista a disponibilidade de todos os dados e resultados obtidos, apresentados na última referência. Na construção do aqui denominado Modelo 1, com comprimento considerando a relação $L=3 . D$, foram feitas quatro variações do mesmo:

- M1.1 = Modelo completo (inteiro) e com chapa de topo, conforme figura 6.1 (a);

- M1.2 = Modelo completo (inteiro) e sem chapa de topo, conforme figura 6.1 (b);

- M1.3 = Modelo com meia simetria e com chapa de topo, conforme figura 6.2 (a);

- M1.4 = Modelo com meia simetria e sem chapa de topo, conforme figura 6.2 (b).

As figuras 6.1 e 6.2 apresentam as variações do Modelo 1, assim como a malha de elementos finitos adotada: o perfil de aço (cor verde), o núcleo de concreto (cor roxa) e a chapa de topo (em vermelho). 
(a)

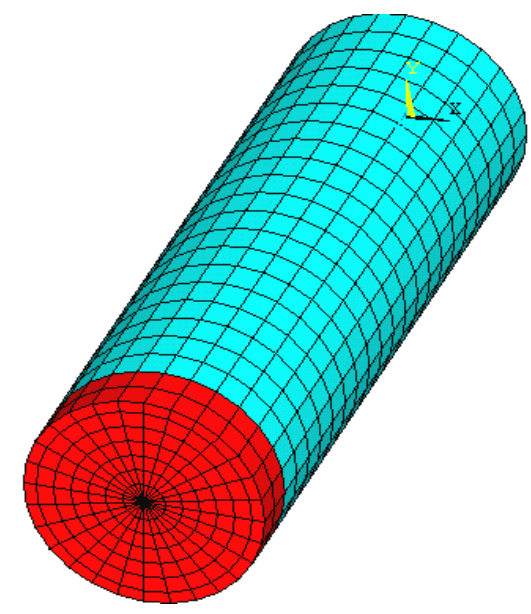

(b)

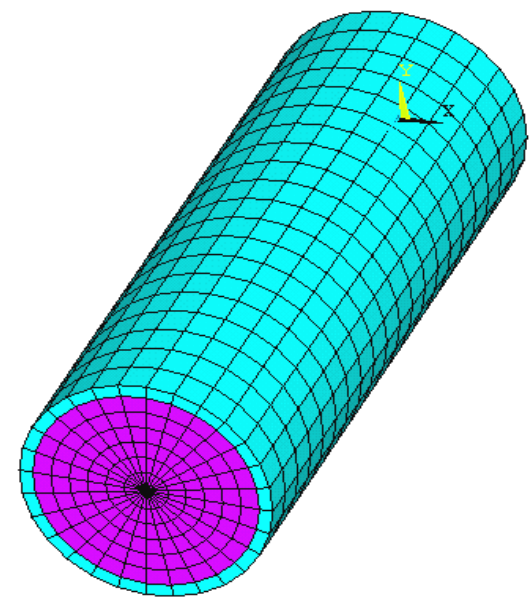

Figura 6.1 -Geometria e malha do modelo PMC-19, completo (seção total): (a) Com chapa de topo e (b) Sem chapa de topo.

(a)

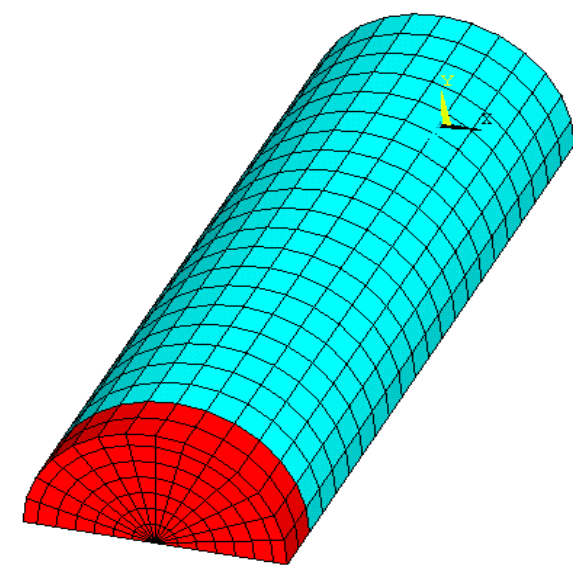

(b)

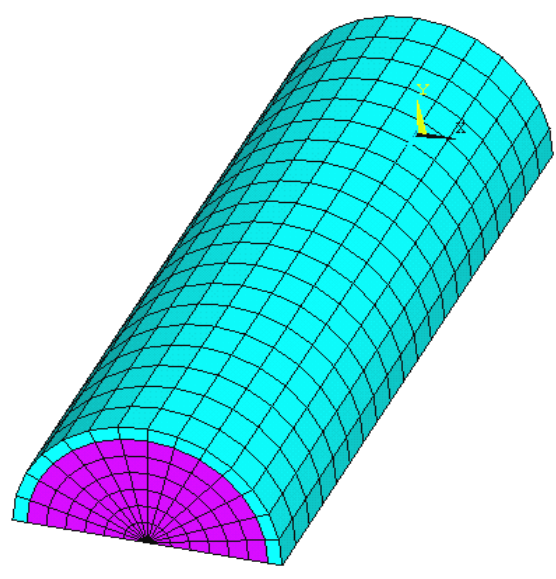

Figura 6.2 - Geometria e malha do modelo PMC-19, com simetria (1/2 seção): (a) Com chapa de topo e (b) Sem chapa de topo.

A avaliação dos quatro modelos em questão se faz com o intuito de adotar aquele de melhor relação benefício/custo na análise em temperatura ambiente e, conseqüentemente, em situação de incêndio, objetivando diminuir o tempo de processamento. Os resultados desses modelos serão apresentados para análise em temperatura ambiente, bem como na análise acoplada para a qual o tipo de compartimentação considerado será determinante quando da escolha dos modelos completo ou simétrico. Na figura 6.3 estão apresentadas configurações deformadas das variações do Modelo 1 (PMC-19), em que se considera a relação L = 3.D.

Os resultados dos tipos experimental e numérico, obtidos da análise estrutural em “temperatura ambiente” com relação ao Modelo 1 (PMC-19-E, L = 3.D), estão apresentados no gráfico da figura 6.4. O gráfico Força $(\mathrm{kN})$ x Deformação (\%o) compara resultados experimentais, extraídos de OLIVEIRA (2008), com os resultados numéricos obtidos via ANSYS, para as variações M1.1, M1.2, M1.3 e M1.4, em concordância com a figura 6.3. 
(a)

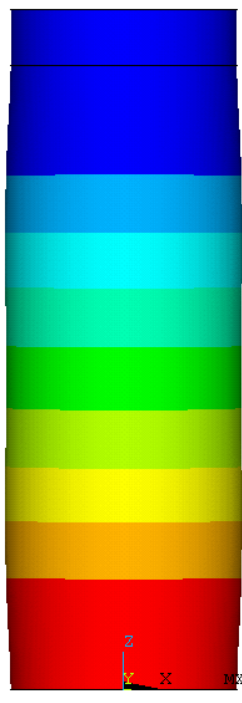

(b)

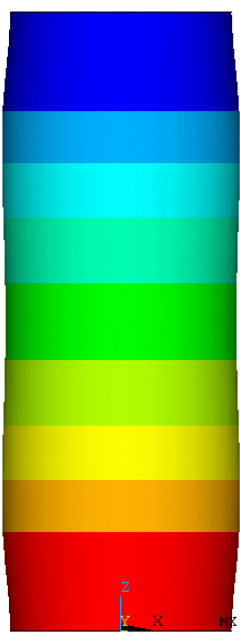

(c)

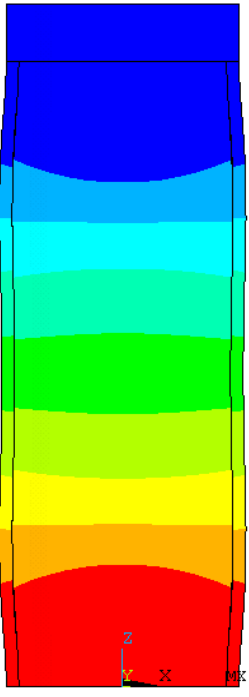

(d)

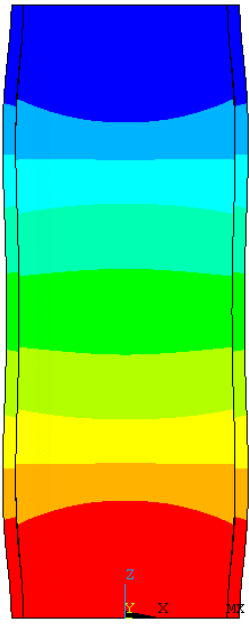

Figura 6.3 - Configuração deformada do PMC-19: (a) Inteiro e com chapa de topo, (b) Inteiro e sem chapa de topo, (c) Com simetria e com chapa de topo e (d) Com simetria sem chapa de topo.

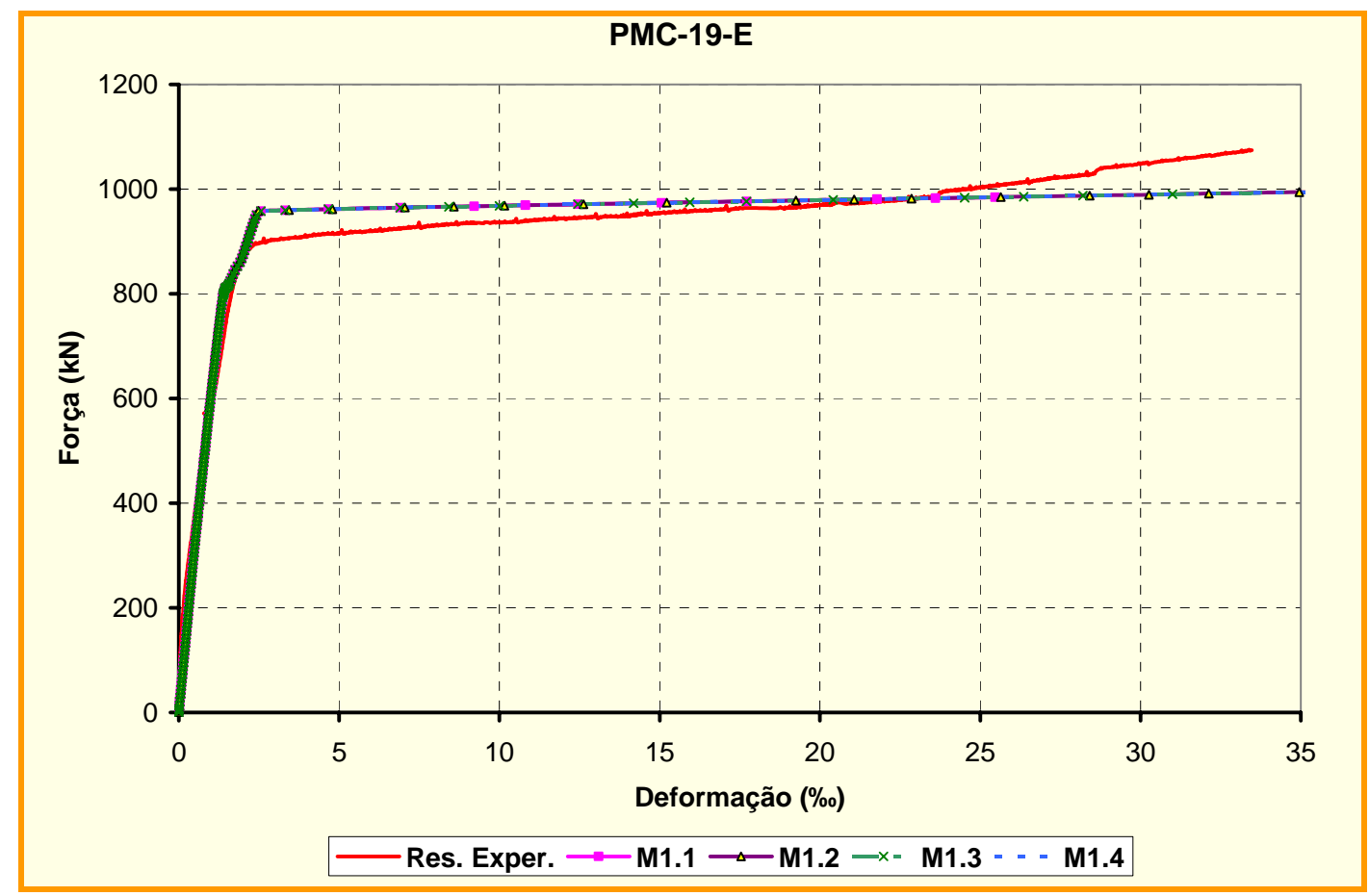

Figura 6.4 - Diagrama Força vs. Deformação axial: valores experimental e numéricos.

Por meio de análise com relação à figura 6.4, se nota pouca (ou mesmo nenhuma) variação nos resultados dos modelos numéricos, indicando inclusive que o modelo numérico mais otimizado, ou seja, com simetria e sem chapa de topo (M1.4), apresenta resultado idêntico ao modelo mais completo, no caso, inteiro e com chapa de topo (M1.1). Fica evidente no gráfico a boa aproximação dos resultados numéricos com o resultado experimental e com isso, a validação da estratégia adotada. Para pilares curtos com carregamento centrado, o modelo simplificado é aqui adotado, diminuindo o tempo de processamento. 
Nas figuras que se seguem, serão apresentados resultados complementares para o Modelo 1 (PMC-19), em que se considera comprimento com relação L = 10D. Neste caso, a idéia é apenas a de comparação entre resultados e, portanto, validação da estratégia adotada, não se objetivando análise acoplada uma vez que essa relação não é de interesse dentro do escopo do presente trabalho.

A figura 6.5 apresenta a malha de elementos finitos e a geometria, adotadas para o Modelo 1, com comprimento de dez vezes o diâmetro, se tornando necessária a utilização de chapa de topo devido à consideração de uma excentricidade, e $=4 \mathrm{~mm}$, quando da aplicação do carregamento.

$\mathrm{Na}$ figura 6.6a está apresentada a configuração deformada, extraída de OLIVEIRA (2008), cuja modelagem numérica foi realizada utilizando o código computacional DIANA V9.2, enquanto que na figura $6.6 \mathrm{~b}$ se faz referência aos resultados do ANSYS V9.0, utilizando aquela mesma estratégia considerada para os modelos de pilares mistos curtos.

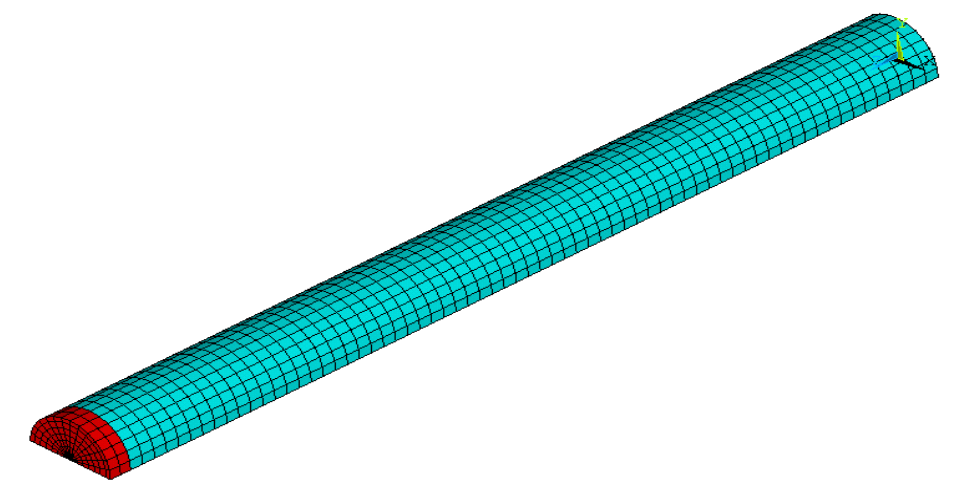

Figura 6.5 - Geometria e malha de elementos finitos: Modelo 1, com comprimento L = 10.D.

(a)

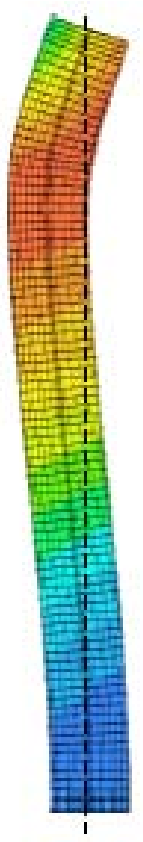

(b)

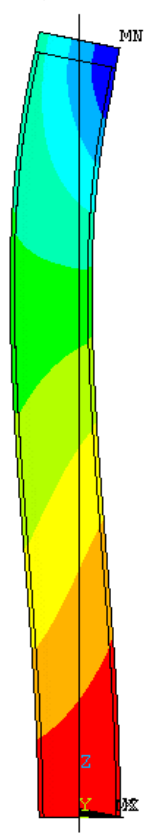

Figura 6.6 - Configurações deformadas: (a) código DIANA e (b) código ANSYS. 
No gráfico da figura 6.7 estão apresentados os valores dos resultados numéricos e resultados experimentais extraídos de OLIVEIRA (2008), denominados na mesma figura como Res. DIANA e Res. Experimental, respectivamente, bem como os resultados do presente trabalho, aqui denominados Res. ANSYS.

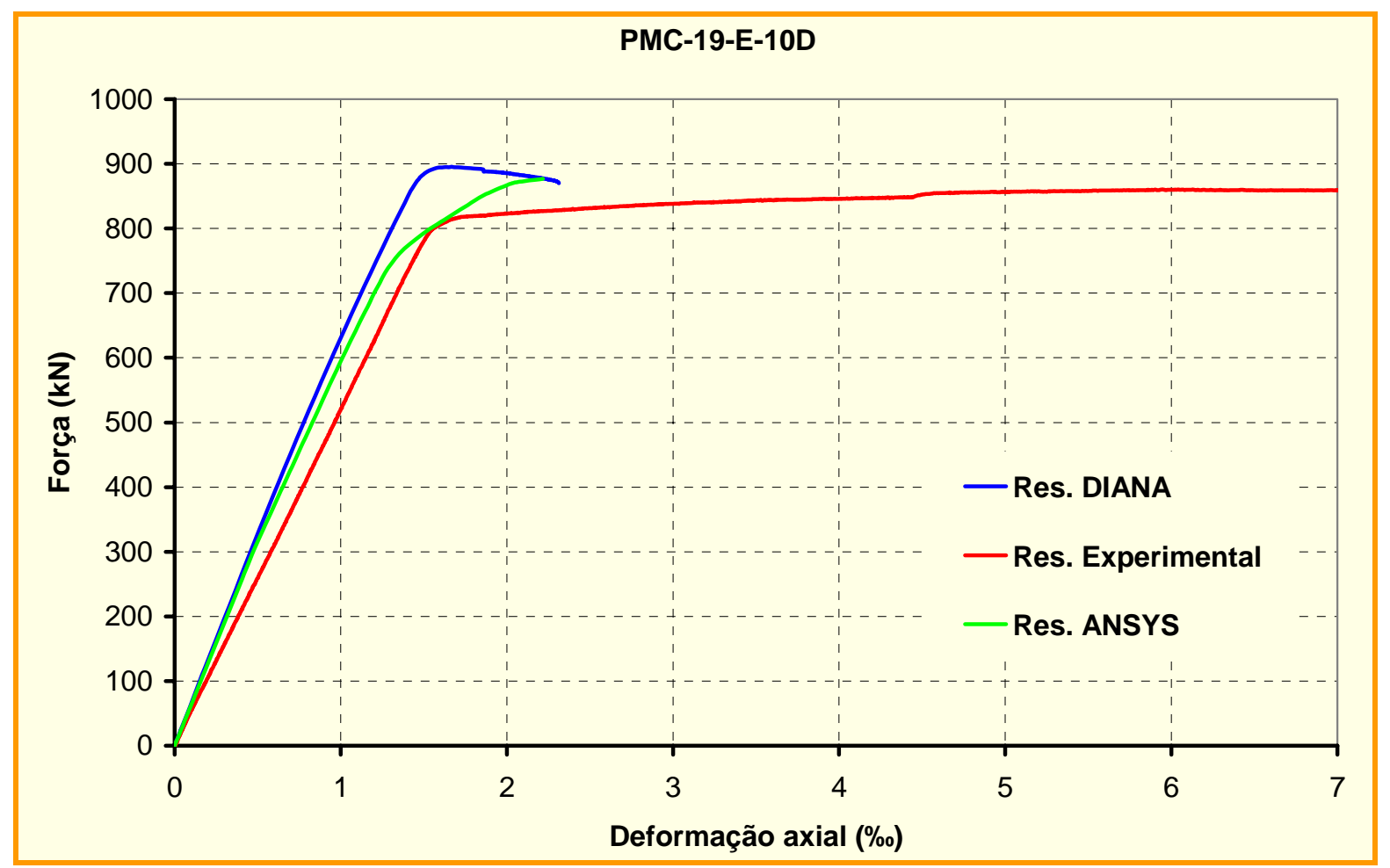

Figura 6.7 - Diagrama Força vs. Deformação axial: valores experimental e numéricos.

Por meio de análise com relação à figura 6.7, se pode observar uma boa aproximação do resultado extraído do ANSYS V9.0 com o resultado experimental, se destacando o fato de que esses mesmos resultados apresentam uma melhor aproximação e concordância se comparados com os resultados obtidos por meio do DIANA V9.2.

Portanto, mesmo quando da análise de pilares longos com comprimento (L) igual a dez vezes o diâmetro (D), ainda que essa relação não seja objeto de estudo do presente trabalho, é importante ressaltar que a estratégia aqui adotada atende não somente à análise de pilares curtos, em temperatura ambiente, mas também "possivelmente" à análise de pilares de maior comprimento, ficando como sugestão que outros testes sejam realizados de modo a confirmar essa tendência.

Tomando como validada a estratégia adotada, nos itens que se seguem serão apresentados outros resultados de análises numéricas em temperatura ambiente, obtidos com o ANSYS V9.0, agora para os modelos de pilares denominados PMC-26 e PMC-46. 


\subsubsection{MODELO 2 (PMC-26-E) - Análise estrutural em temperatura ambiente}

Tendo em vista as poucas variações na estratégia de modelagem quanto à utilização do pilar inteiro ou considerando sua meia simetria, bem como com relação à utilização ou não da chapa de topo, conforme esquematizado na figura 6.4, nos estudos de pilares mistos preenchidos submetidos ao carregamento axial centrado, para determinação da carga de colapso do Modelo 2, aqui em análise, será adotada a modelagem considerada mais otimizada, em que se utiliza simetria e inexistência de chapa de topo.

O resultado da análise numérica do Modelo 2 (PMC-26) está apresentada na figura 6.8 na forma de Força $(\mathrm{kN})$ x Deformação (\%o), possibilitando a determinação da carga de colapso do pilar misto em temperatura ambiente para utilização desse resultado na análise acoplada. Na mesma figura se apresenta apenas o resultado numérico, tendo em vista a não realização de ensaios para esse caso e, portanto, a inexistência de resultados experimentais para esse mesmo modelo.

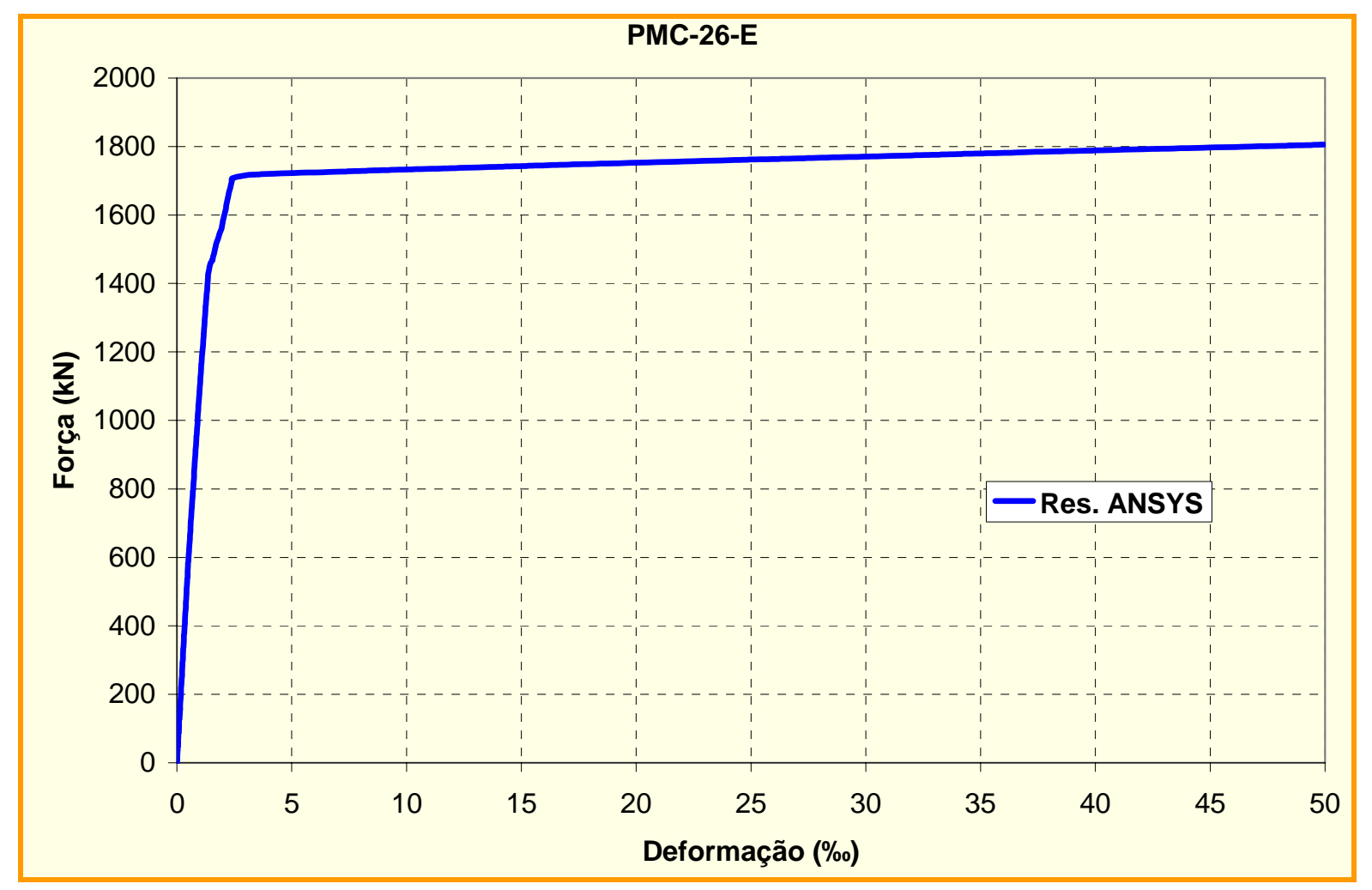

Figura 6.8 - Diagrama Força vs. Deformação axial para o modelo 2.

Os resultados obtidos pelo processamento do Modelo 2, apesar de não comparado com outros resultados numéricos ou experimentais (inexistência dos mesmos), servirá como valor de referência a ser comparado com valores normativos apresentados na tabela 6.3. 


\subsubsection{MODELO 3 (PMC-46-E) - Análise estrutural em temperatura ambiente}

Pelo mesmo motivo exposto no item 6.2.2, a análise do Modelo 3 aqui apresentada foi realizada considerando simetria do pilar (1/2 simetria) e sem a consideração da chapa de topo, cujos resultados estão apresentados na forma gráfica conforme figura 6.9.

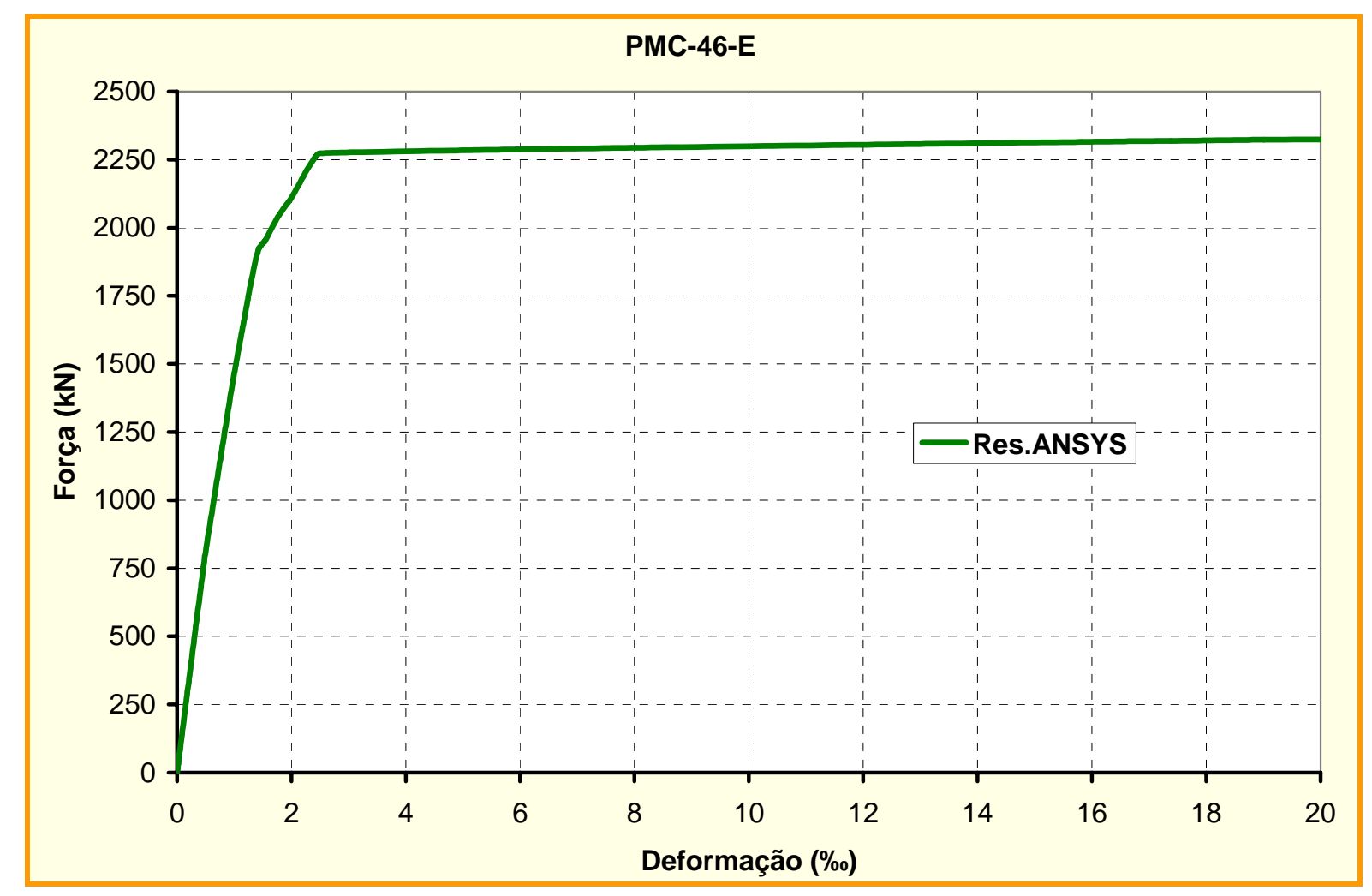

Figura 6.9 - Diagrama Força vs. Deformação axial para o modelo 3.

Assim como ocorrido com o Modelo 2, o resultado numérico obtido com o Modelo 3 também não é aqui comparado com outros resultados, numéricos ou experimentais, devido à inexistência dos mesmos, porém, também servirão como valores de referência a serem comparados com valores normativos apresentados na tabela 6.3 .

\subsubsection{MODELOS 1, 2 E 3 (PMC-46-E) - Análises comparativas}

Na tabela 6.3 são comparados os valores das cargas de colapso resultantes de ensaio experimental (quando realizado) e de modelagens numéricas para os Modelos 1, 2 e 3, assim como valores resistentes calculados por procedimentos normativos.

O resultado experimental apresentado na tabela 6.3 foi extraído de OLIVEIRA (2008), os resultados numéricos são os obtidos via ANSYS, e os procedimentos normativos 
adotados para o cálculo da norma de plastificação foram descritos no Capítulo 2 do presente trabalho, no caso, NBR 8800:2008 e EUROCODE 4:2004 (EC4). É importante ressaltar que como não se trata de dimensionamento, mas sim de investigação de estratégia numérica, os valores dos coeficientes de segurança foram adotados iguais a 1.

Assim como em OLIVEIRA (2008), para efeito de verificação da parcela de acréscimo de resistência do concreto $\left(\eta_{\mathrm{c}}\right)$ e penalização na resistência do aço $\left(\eta_{\mathrm{a}}\right)$ devido ao efeito do confinamento, conforme apresentado na formulação do EC4, foram consideradas duas possibilidades apresentadas na tabela 6.3: (a) consideração das parcelas $\eta_{\mathrm{c}}$ e $\eta_{\mathrm{a}}$ atribuídas ao confinamento e (b) sem o efeito do confinamento, adotando $\eta_{\mathrm{c}}=0$ e $\eta_{\mathrm{a}}=1$.

Tabela 6.3- Resultados de cargas de colapso: experimental, numérica e normativa.

\begin{tabular}{|c|c|c|c|}
\hline CARGAS DE COLAPSO $(\boldsymbol{K N})$ & PMC-19 & PMC-26 & PMC-46 \\
\hline Experimental & $1.075,4$ & - & - \\
\hline Numérico & $1.005,3$ & $1.805,3$ & $2.323,1$ \\
\hline NBR 8800:2008 $^{\text {(a) }}$ & 951,2 & $1.690,8$ & $2.168,1$ \\
\hline EC4 $^{(\text {b) }}$ & $1.302,3$ & $2.292,0$ & $2.827,5$ \\
\hline EC4 $^{(b)}$ & 968,7 & $1.729,4$ & $2.234,8$ \\
\hline
\end{tabular}

A comparação dos resultados apresentados na tabela 6.3 mostra que os valores calculados pela NBR 8800:2008 e pelo $\mathrm{EC}^{(\boldsymbol{b})}$, em que não se leva em consideração o efeito do confinamento, resultaram inferiores quando comparados com os resultados experimentais, mas bastante próximos dos resultados numéricos obtidos com o ANSYS e, em ambos os casos se mostram a favor da segurança. Por outro lado, é possível observar que os resultados obtidos pelo $\mathrm{EC}^{(a)}$ resultam maiores se comparado aos demais, aspecto esse que sugere atenção na utilização deste procedimento normativo tendo em vista que os resultados apresentados resultam superiores se comparados com resultados numéricos e experimentais.

Comparando os resultados do modelo PMC-19, fica evidente a boa aproximação dos resultados numérico (ANSYS) e experimental. Quando comparado o resultado obtido pela NBR 8800:2008 com o resultado experimental, fica constatado que o último resulta da ordem de $13 \%$ maior, provavelmente, em resposta ao efeito do confinamento.

Vale destacar novamente que os valores de carga de colapso dos modelos apresentados e analisados no presente item, não só foram importantes como parâmetros de comparação com valores normativos, mas também servirão como referência para estudos apresentados no item seguinte, voltado aos modelos numéricos para análise acoplada. 


\subsection{PILARES MISTOS CURTOS - Análise em situação de incêndio}

Conforme exposto nos capítulos 2 e 3, o aumento da temperatura provoca alterações nas propriedades mecânicas dos materiais, impondo reduções de resistência e de rigidez, podendo levar a estrutura ao colapso prematuro, razão pela qual se faz aqui a consideração dos pilares estudados no item 6.2, agora voltada para análise em temperaturas elevadas. Nos itens que se seguem, serão apresentados resultados obtidos por meio da modelagem numérica, em campo tridimensional, de pilares mistos curtos com seções tubulares circulares de aço preenchidos com concreto submetidos ao incêndio-padrão, considerando apenas a condição de “carregamento térmico com aquecimento igual ao longo do perímetro da seção".

Inicialmente, se faz a determinação do "tempo crítico" (ou temperatura crítica) referente ao tempo de colapso do pilar misto em situação de incêndio, por meio de análises acopladas termo-estruturais, para uma determinado nível de carga aplicada, sempre proporcional àquele que provoca o colapso do pilar misto em temperatura ambiente.

A modelagem numérica acoplada aqui proposta consiste na aplicação de uma carga axial centrada proporcional à carga última (conforme parágrafo anterior) com subseqüente aplicação do campo térmico com temperatura sempre crescente, que ocorre até que a perda de resistência e rigidez dos materiais seja tal que o pilar misto não resista mais ao carregamento proporcional imposto, caracterizando o colapso estrutural do elemento.

Conforme descrito no Capítulo 2 do presente trabalho, durante os estágios iniciais de exposição ao fogo, o aço resiste à maior parcela da carga aplicada, tendo em vista o fato de a seção de aço inicialmente se expandir mais rapidamente que a do núcleo de concreto. Com o aumento da temperatura, a seção de aço começa a se deformar mais, em resposta à redução da resistência ao escoamento e do módulo de elasticidade longitudinal, quando então o pilar subitamente se contrai, freqüentemente acompanhado por flambagem local da seção de aço. Após esse instante o concreto começa a receber cada vez mais carga.

Para a verificação do comportamento do modelo aqui proposto quanto à expansão dos materiais aço e concreto, inicialmente foi realizado um estudo de um pilar misto sem chapa de topo e sem aplicação de carregamento axial, aplicando-se apenas o campo térmico. Para tanto, como suporte serão paralelamente utilizados resultados de análises térmicas e de fatores de redução de resistência, obtidos por meio do código computacional $\boldsymbol{T C D}$ Temperature Calculation and Design V5.0, código esse específico para tal finalidade, gentilmente cedidos por Valdir Pignatta e Silva, atualmente professor Doutor da Escola Politécnica da USP. 
A idéia é verificar se os materiais sofrem expansões coerentes se comparadas àquelas relatadas em trabalhos desenvolvidos por outros pesquisados, item 2.6 do Capítulo 2, bem como constatar se o modelo numérico se comporta de modo coerente como relatado, pois a expansão do aço nos instantes iniciais do incêndio é maior que aquela ocorrida no núcleo de concreto.

A figura 6.10 apresenta a expansão dos materiais aço e concreto do pilar misto com a elevação da temperatura para diferentes tempos de exposição ao fogo.

(a)

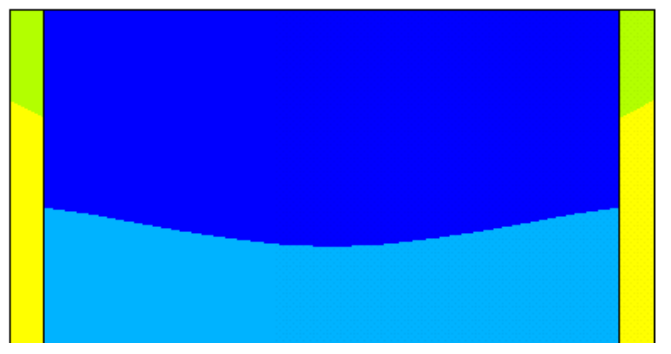

(c)

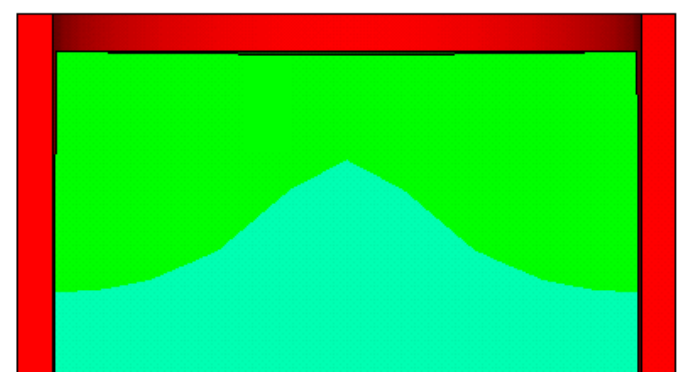

(e)

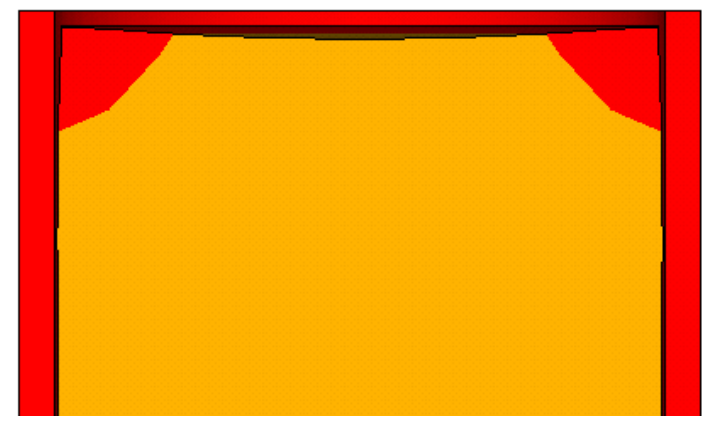

g)

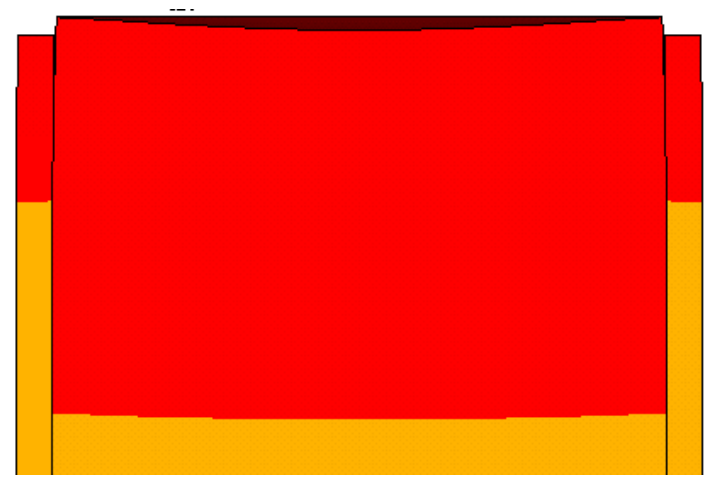

(b)

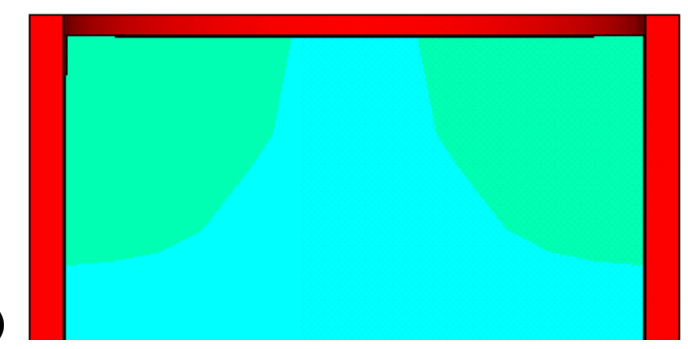

(d)

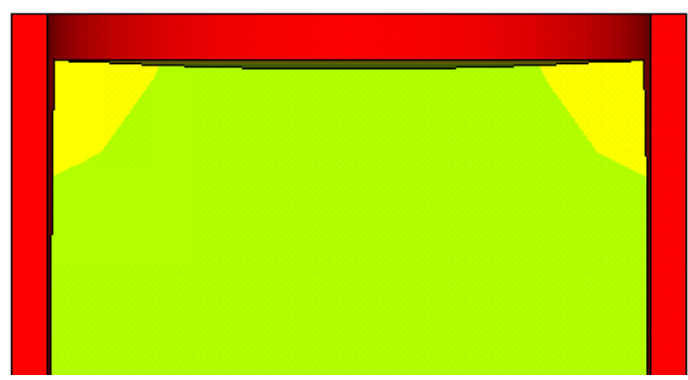

(f)

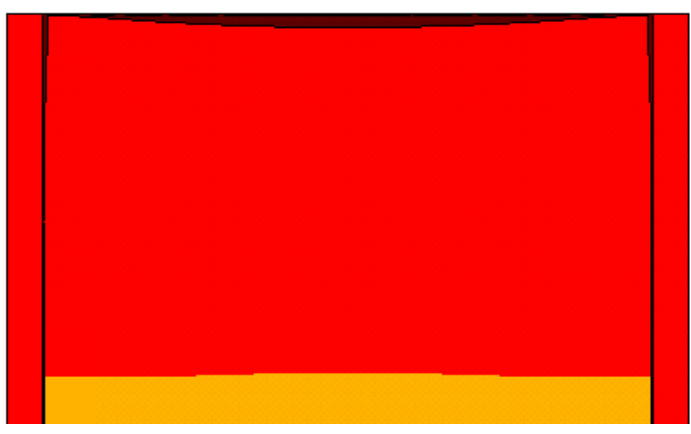

(h)

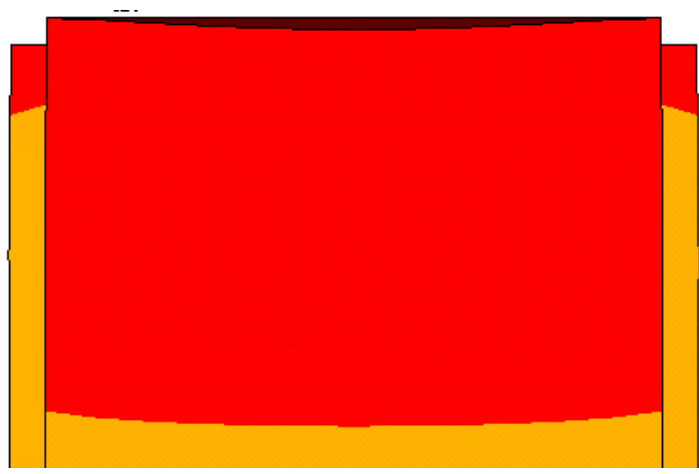

Figura 6.10 - Expansão do tubo de aço e do núcleo de concreto devida à ação térmica, para tempos de exposição ao fogo iguais a: (a) 0 minuto, (b) 5 minutos, (c) 10 minutos, (d) 20 minutos, (e) 30 minutos, (f) 33minutos, (g) 40 minutos e (h) 50 minutos. 
Como pode ser visualizado na figura 6.10, já esperado e relatado em trabalhos apresentados por outros pesquisadores, ocorrem expansões diferenciadas nos elementos de aço (tubo) e de concreto (núcleo), razão pela qual o tudo de aço se descola do núcleo de concreto, em sua interface, tendo uma expansão maior nos instantes iniciais de incêndio por estar mais aquecido que o núcleo de concreto e, é claro, por possuir condutividade térmica mais elevada se comparada à do concreto.

Porém, com o passar do tempo, o concreto vai aquecendo e pode até mesmo expandir, axialmente, mais que o aço. A expansão do concreto pode eventualmente resultar maior que aquela apresentada pelo tubo de aço devido ao fato de o coeficiente de expansão do concreto ser superior se comparado ao do aço, como indicado no Capítulo 3. No entanto, cabe ressaltar que tal aspecto também depende do diâmetro do pilar misto, uma vez que quanto maior o diâmetro do mesmo, menor será a temperatura no núcleo de concreto.

Portanto, fica como destaque o fato do comportamento mecânico dos modelos submetidos a elevadas temperaturas ter correspondido, de forma coerente e em concordância com o esperado e descrito em outros trabalhos. No entanto, apesar de ser importante verificar a coerência do modelo em campo térmico, é importante salientar que para pilares mistos de comprimentos reduzidos, como aqui em análise, essa expansão diferenciada não provoca grandes alterações nos resultados, como poderá ser constatado nos itens que se seguem, razão pela qual esse mesmo fenômeno será desconsiderado para fins de análise termo-estrutural, na forma de simplificação da estratégia numérica adotada.

No entanto, no caso de pilares de comprimentos maiores daqueles aqui analisados, fica como sugestão, dos autores do presente trabalho, a realização de verificação de possível perda ou não de precisão. No item seguinte, serão apresentados estudos referentes à análise acoplada para o Modelo 1 (PMC-19-A), Modelo 2 (PMC-26-A) e Modelo 3 (PMC-46-A).

\subsubsection{MODELO 1 (PMC-19-A) - Com carga térmica em todo contorno do pilar}

O modelo numérico aqui em análise, denominado Modelo 1 (PMC-19), se refere a um pilar misto de seção circular preenchido com concreto, cujas características geométricas estão indicadas na tabela 6.1 apresentada anteriormente.

As características mecânicas dos materiais aço e concreto, a serem utilizadas na análise acoplada, estão de acordo com as equações já apresentadas no capítulo 3 (item 3.5.2) do presente trabalho, as quais estão baseadas no EC3 e EC2. A figura 6.11 apresenta a relação constitutiva adotada para o aço. 


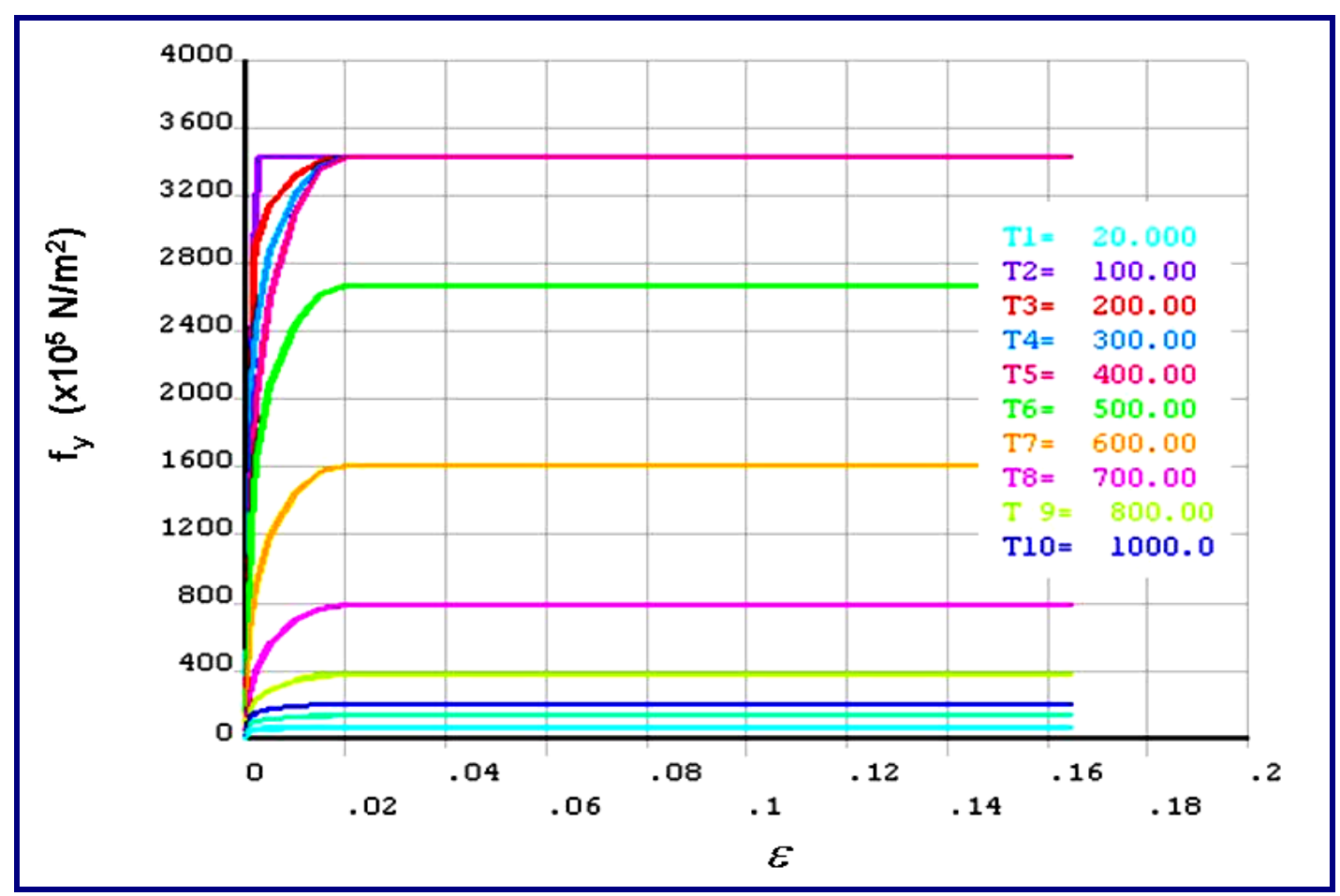

Figura 6.11 - Relações “Tensão x Deformação” para aço, em função da temperatura.

A figura 6.12 e figura 6.13 apresentam as relações constitutivas adotadas para o concreto, quando solicitado por esforços de tração e de compressão, respectivamente.

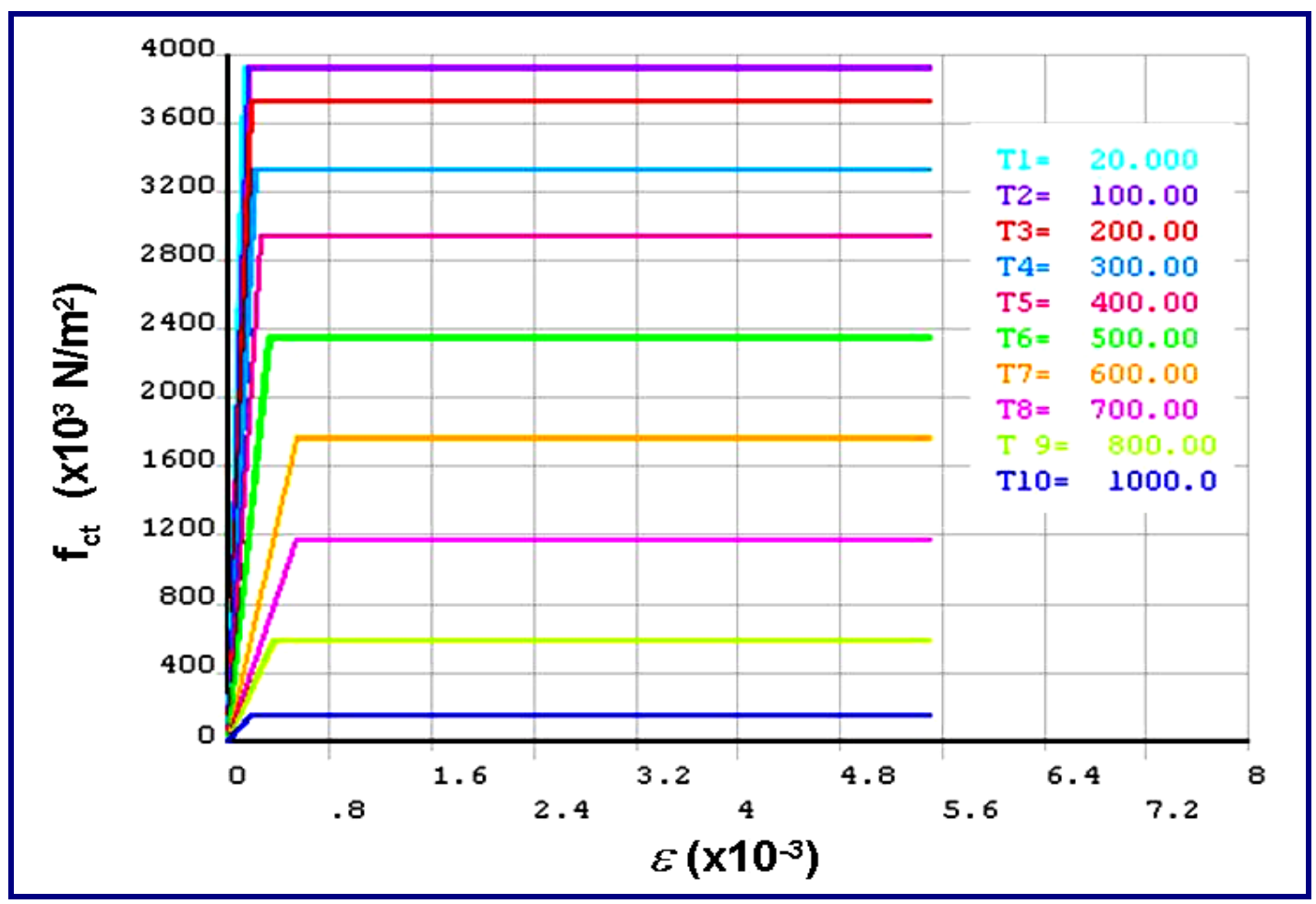

Figura 6.12 - Relação "Tensão x Deformação" para o concreto tracionado em função da temperatura. 


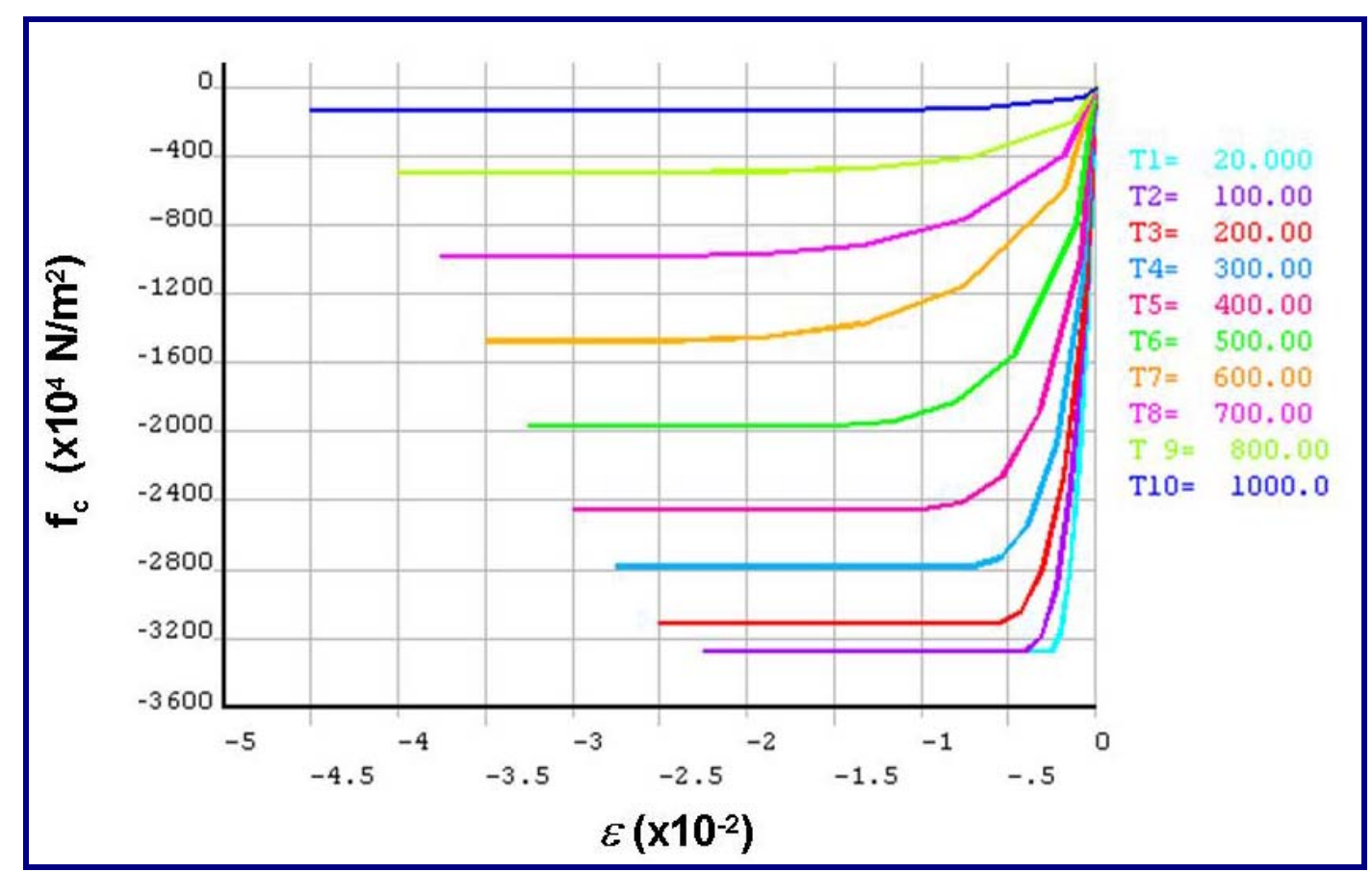

Figura 6.13 - Relação "Tensão x Deformação" para o concreto comprimido, em função da temperatura.

A análise acoplada que será realizada permite a determinação do "tempo crítico" (ou temperatura crítica) para cada nível de carregamento aplicado e, com isso, permiti apresentar uma dada curva referente ao fator de redução da força resistente do pilar misto curto, aqui definido pelo parâmetro $\mathbf{K}_{\mathbf{P M}}$, obtido em função do tempo de incêndio.

De início, serão apresentados dois gráficos do tipo "Deslocamento axial x Tempo", com deslocamento apresentado em milímetros e o tempo em minutos, tempo este que representa o Tempo Requerido da Resistência ao Fogo (TRRF). Os gráficos apresentados são referentes a níveis de carregamento distintos: um primeiro, conforme figura 6.14, correspondente a um carregamento igual a 15\% daquele que provoca o colapso em temperatura ambiente $\left(\mathrm{K}_{\mathrm{PM}}=\mathrm{F}_{\mathrm{c}, \mathrm{t}} / \mathrm{F}_{\mathrm{c}, \mathrm{ta}}=0,15\right)$, e o segundo, conforme figura 6.15, correspondente a um carregamento igual a $\mathbf{3 0 \%}$ daquele que provoca o colapso em temperatura ambiente $\left(\mathrm{K}_{\mathrm{PM}}=\mathrm{F}_{\mathrm{c}, \mathrm{ti}} / \mathrm{F}_{\mathrm{c}, \mathrm{ta}}=0,30\right)$, ressaltando que $\mathrm{F}_{\mathrm{c}, \mathrm{ti}}$ é a força crítica em incêndio e $\mathrm{F}_{\mathrm{c}, \text { ta }}$ a força crítica em temperatura ambiente.

Os gráficos estão apresentados separadamente, por se tratarem de uma validação da simplificação adotada para os modelos em análise. Assim como no item 6.1.1, a comparação dos resultados se dá entre os modelos: Modelo M1.1 - Modelo inteiro e com chapa de topo, conforme figura 6.1a e Modelo M1.4 - Modelo com simetria sem chapa de topo, conforme figura $6.2 \mathrm{~b}$. 


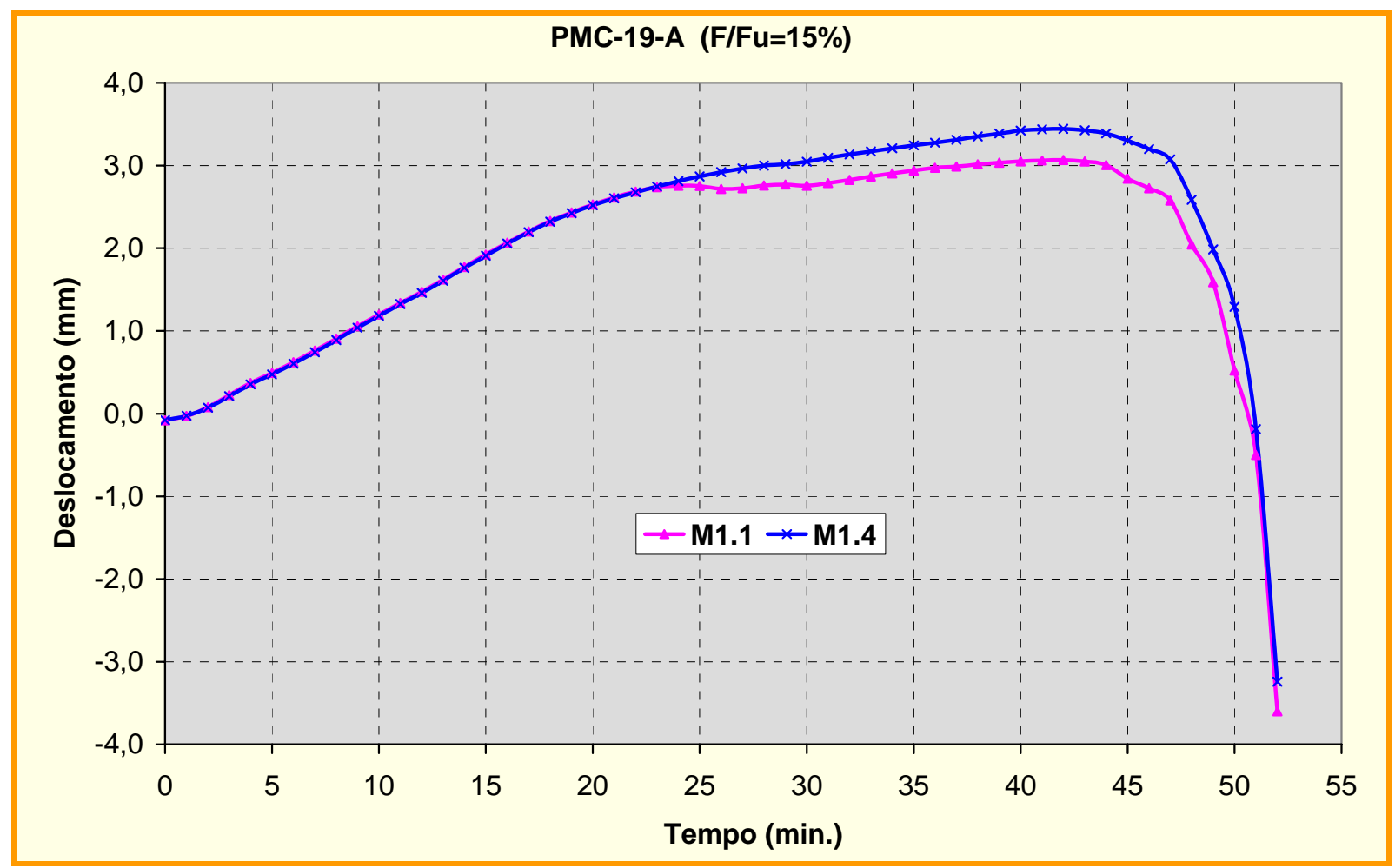

Figura 6.14 - Deslocamento $x$ Tempo: para o Modelo 1, com $\mathrm{K}_{\mathrm{PM}}=\mathrm{F}_{\mathrm{c}, \mathrm{ti}} / \mathrm{F}_{\mathrm{c}, \mathrm{ta}}=15 \%$.

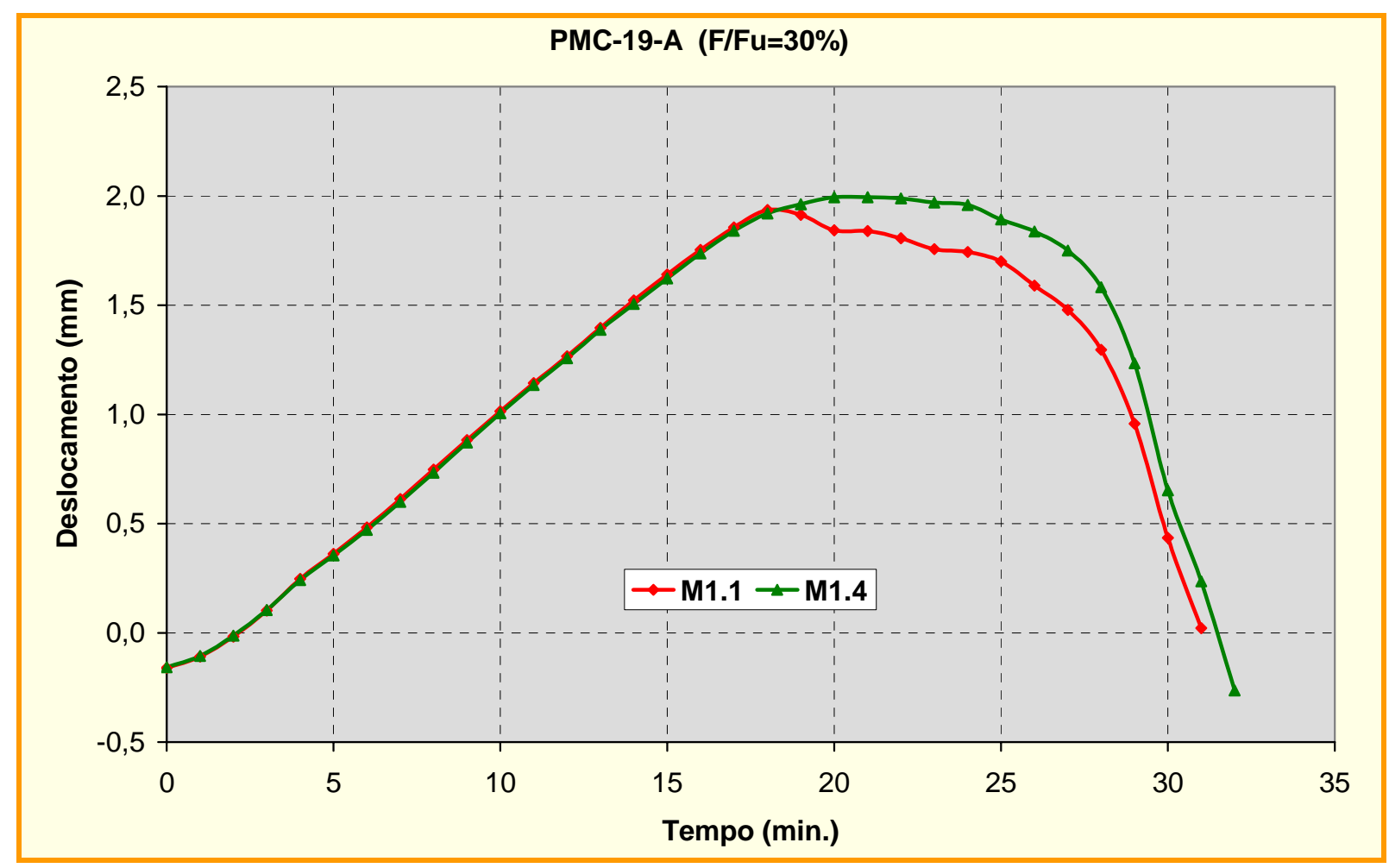

Figura 6.15 - Deslocamento x Tempo: para o Modelo 1, com $\mathrm{K}_{\mathrm{PM}}=\mathrm{F}_{\mathrm{c}, \mathrm{ti}} / \mathrm{F}_{\mathrm{c}, \mathrm{ta}}=30 \%$. 
Os modelos M1.1 e M1.4 foram escolhidos para essa validação por se tratarem de modelos dos tipos completo e simplificado, respectivamente. Se constatado que os resultados são próximos o suficiente, a idéia é de apenas utilizar o modelo M1.4 para a aplicação de outros fatores de carregamento. A escolha dos níveis de carga de $15 \%$ e $30 \%$ deve-se ao fato de que o aço só expandirá mais que o concreto na direção axial para baixos fatores de carregamento, pois para fatores mais elevados isso não ocorrerá e a expansão do aço só será maior na direção radial.

Os resultados apresentados nos gráficos das figuras 6.14 e 6.15 indicam que, apesar da pequena diferença de deslocamento axial entre os modelos M1.1 e M1.4, o comportamento geral das curvas resulta semelhante e, com aspecto de maior importância, os tempos de colapso também, fato que sugere a utilização do modelo M1.4 e substituição ao modelo M1.1.

Também é importante observar que as maiores diferenças no deslocamento dos modelos M1.1 e M1.4 diminuem com o aumento do fator de carregamento, uma vez que para $\mathrm{K}_{\mathrm{PM}}=0,15$ a máxima diferença resulta da ordem de $0,5 \mathrm{~mm}$, enquanto que para $\mathrm{K}_{\mathrm{PM}}=0,30 \mathrm{a}$ máxima diferença de deslocamento resulta da ordem de $0,25 \mathrm{~mm}$.

Nos instantes iniciais em que praticamente só o aço trabalha, devido à sua expansão mais pronunciada, as curvas dos modelos M1.1 e M1.4 resultam com comportamento coincidente, e a diferença entre as curvas começa a ocorrer após o instante em que o aço perde resistência e rigidez e, conseqüentemente, começa a sofrer uma contração.

Este comportamento se mostra mais evidente na curva M1.1 da figura 6.15, aproximadamente entre os tempos de 18 e 20 minutos, sendo que após o tempo de 20 min., o concreto também passa a receber parcela do carregamento aplicado. É importante ressaltar que tal comportamento é evidente neste modelo, apesar do pequeno diâmetro, e se mostrará mais pronunciado no gráfico do comportamento do modelo de maior diâmetro.

$\mathrm{Na}$ figura 6.16 está apresentado o gráfico de Deslocamento Axial x Tempo para vários níveis de carregamento aplicados ao modelo M1.4 (adotado para a análise em substituição ao modelo M1.1), para o qual passa a ser possível determinar o tempo de ruptura do pilar misto para cada nível de carregamento e, com isso, construir o gráfico da curva de redução de resistência $\left(\mathrm{K}_{\mathrm{PM}}\right)$ para o Modelo 1 - PMC-19.

O tempo crítico (máximo) de exposição ao incêndio de cada modelo, a ser utilizado na construção futura do gráfico ' $\mathrm{K}_{\mathrm{PM}} \mathrm{x}$ Tempo', foi adotado como sendo aquele correspondente ao último passo de carga alcançado quando do processamento do modelo numérico em análise. Vale ressaltar que para os últimos passos de carga, os valores de tempo são praticamente assintóticos, como é possível observar nos gráficos da figura 6.16. 


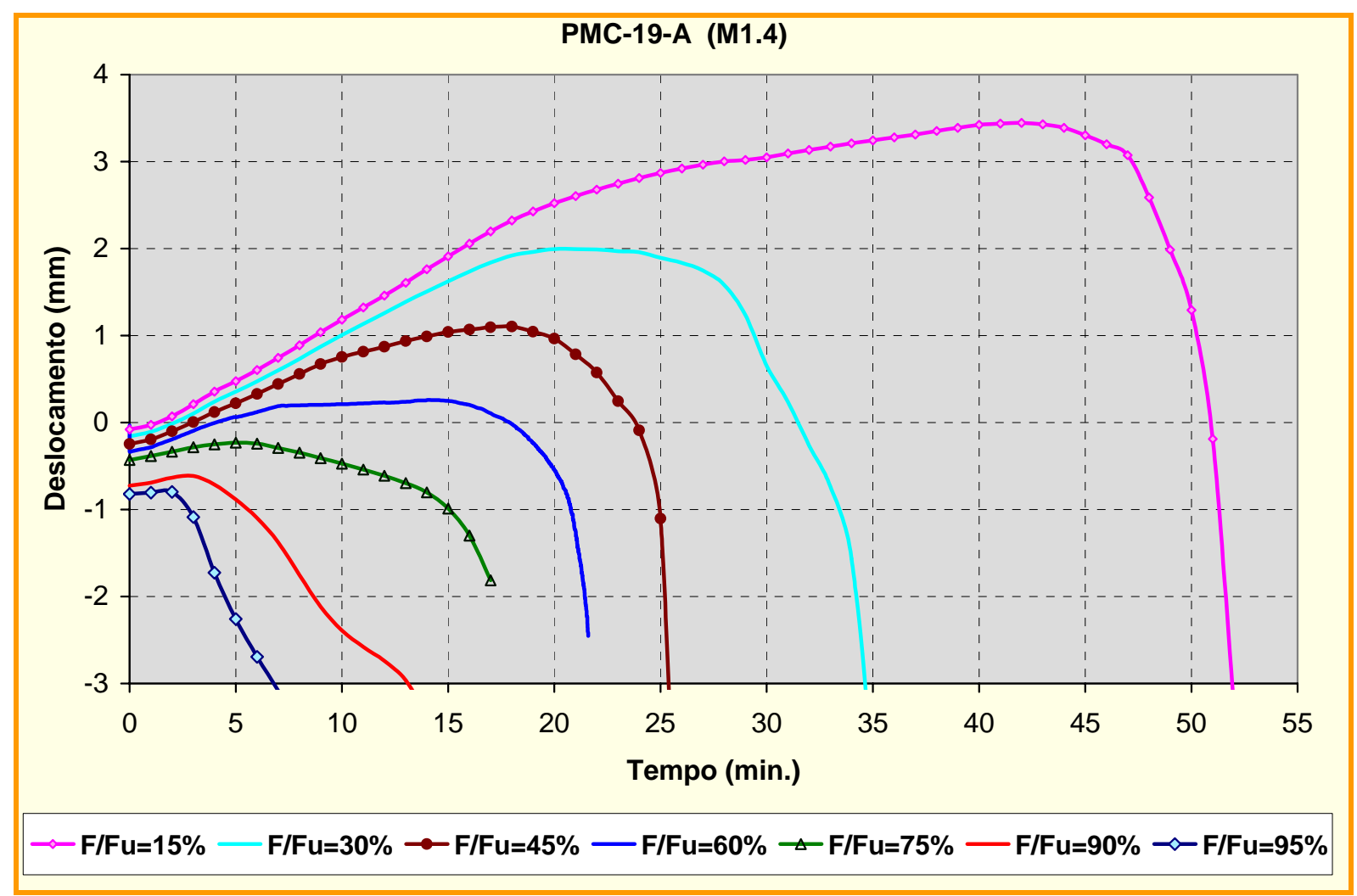

Figura 6.16 - Deslocamento x Tempo para vários níveis de carregamento aplicados no modelo M1.4 (representativo do Modelo 1: PMC -19)

É importante salientar que foi utilizada a curva de “incêndio-padrão” para descrever a elevação da temperatura dos gases do ambiente em chamas. Portanto, o tempo obtido deve ser interpretado como um "tempo fictício", e não tempo físico real. A variação de redução de força resistente, $\mathrm{K}_{\mathrm{PM}}$, com o tempo para o Modelo 1 está apresentada na figura 6.17, na qual se faz a comparação dos resultados obtidos com o ANSYS e com o TCD.

Por meio de análise da figura 6.17, é possível determinar o tempo de colapso para o pilar PMC-19 em função do nível de carregamento aplicado. É importante lembrar que esta curva é válida para um pilar curto e com carregamento centrado, lembrando que variações no índice de esbeltez e na forma de aplicação do carregamento (centrado ou excêntrico) podem interferir na determinação do tempo de colapso dos pilares.

Vale ainda ressaltar que o código TCD V5.0 obtém o fator de redução com base na análise plástica da seção, por meio de procedimento simplificado do EUROCODE 4, para a determinação da normal resistente de plastificação da seção do pilar misto à temperatura ambiente e em situação de incêndio. Nota-se, pela figura 6.17, que os gráficos apresentados são praticamente coincidentes e que, para valores de $K_{P M}$ maiores que 0,7 , os resultados do ANSYS se mostram mais conservadores se comparados ao TCD, tendo em vista o fato de o 
ANSYS, diferentemente do TCD, ser capaz de identificar eventuais instabilidades locais no perfil de aço, normalmente mais pronunciadas para elevados níveis de carregamento.

A figura 6.18 apresenta a configuração deformada final para o Modelo 1: PMC-19 obtida via ANSYS, para $\mathrm{K}_{\mathrm{PM}}=0,75$ e tempo de 17 minutos.

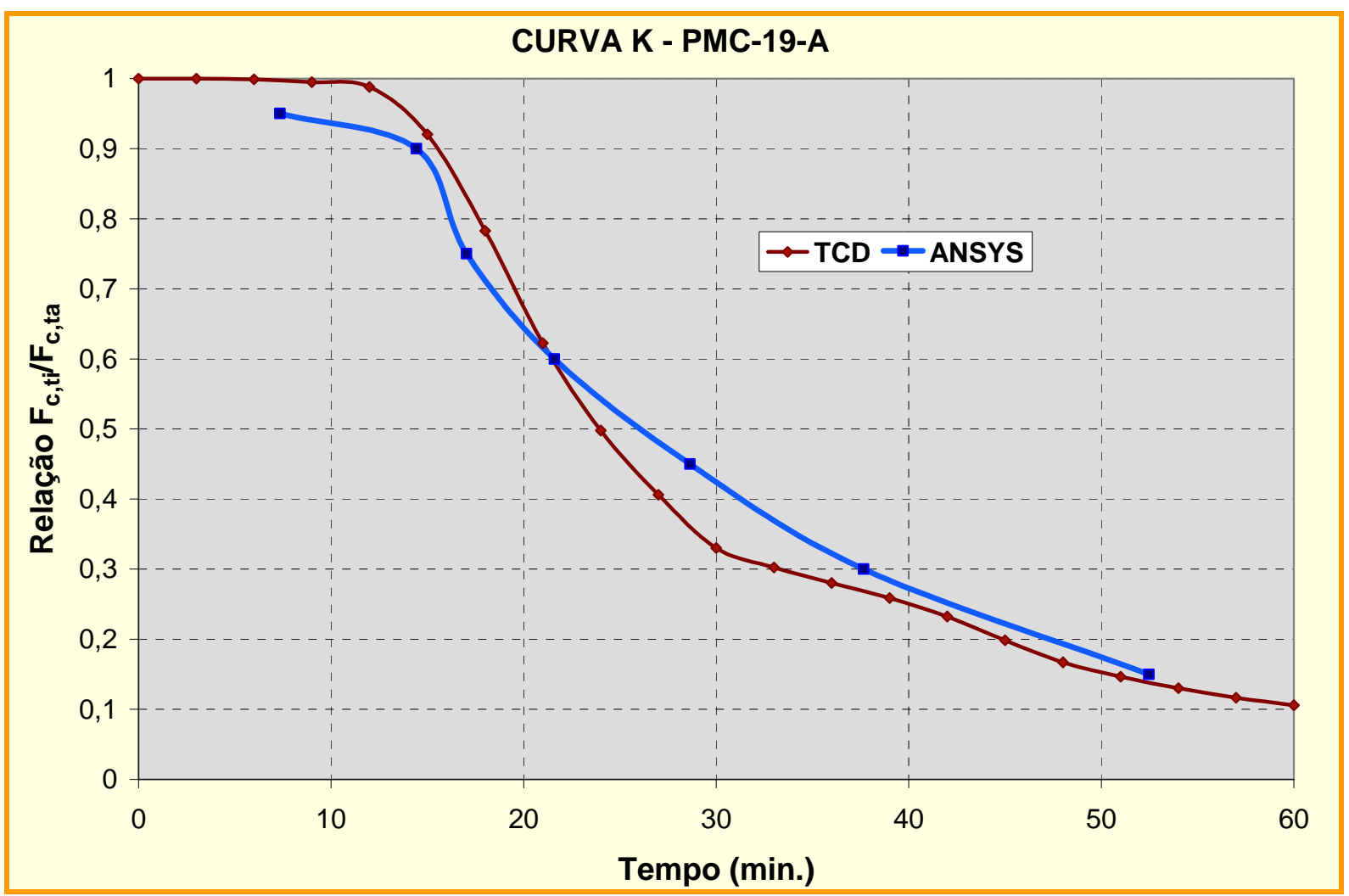

Figura 6.17 - Curva de redução de força resistente, para o Modelo 1: PMC-19.

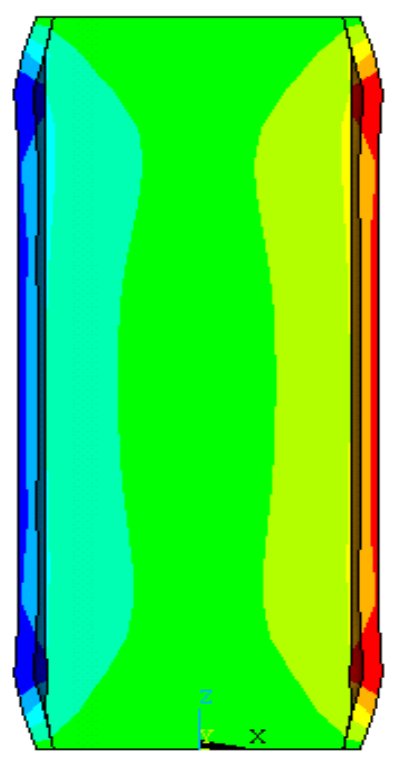

Figura 6.18 - Configuração deformada para níveis de deformação do modelo PMC-19, para $\mathrm{K}_{\mathrm{PM}}$ igual a 0,75 e tempo de exposição ao fogo igual a 17 minutos. 
Com base nos resultados obtidos e apresentados, se constata uma concordância bastante satisfatória dos resultados obtidos por meio do ANSYS, quando comparados àqueles obtidos por meio do programa TCD.

\subsubsection{MODELO 2 (PMC-26-A) - Com carga térmica em todo contorno do pilar}

O modelo aqui analisado, denominado Modelo 2: PMC-26, assim como para o Modelo 1, tem suas características geométricas indicadas na Tabela 6.1 e suas características mecânicas indicadas nas figuras 6.11, 6.12 e 6.13 anteriormente apresentadas. A análise acoplada, a ser agora realizada com o Modelo 2, permite a determinação do "tempo crítico" para cada nível de carregamento aplicado e, com isso, a obtenção da curva $K_{P M}$ (referente ao fator de redução da força resistente) do pilar misto curto em função do tempo de incêndio.

Como foi comprovada a validade do modelo mais simples, sem chapa de topo e utilizando a simetria para o Modelo 1: PMC-19, a mesma simplificação será aqui adotada para o Modelo 2: PMC-26 e será referenciada como M2.4.

Na figura 6.19 está apresentado um gráfico “Deslocamento Axial x Tempo” para vários níveis de carregamento aplicados ao Modelo M2.4.

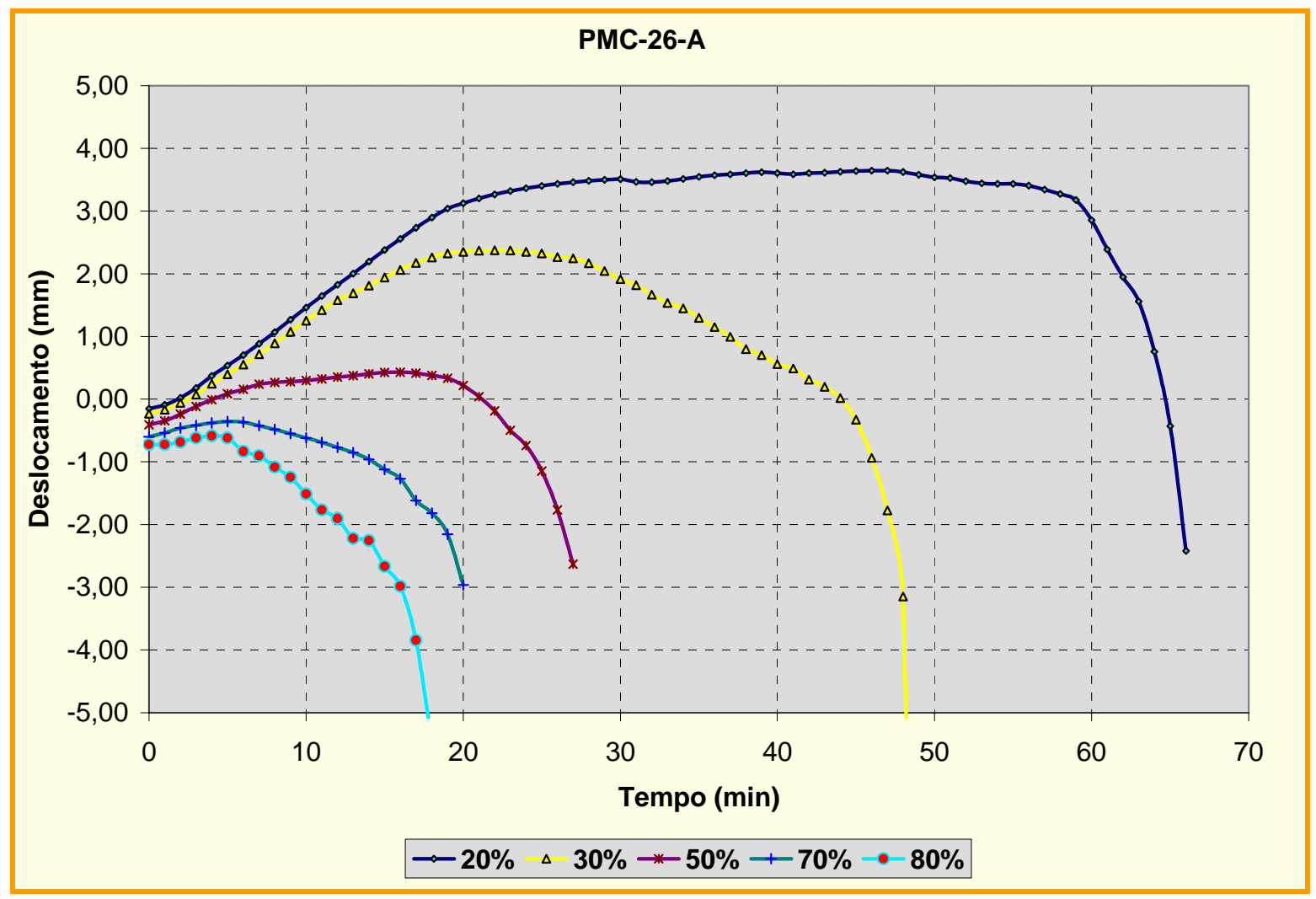

Figura 6.19 - Deslocamento x Tempo para vários níveis de carregamento aplicados no modelo M2.4 (representativo do Modelo 2: PMC -26) 
Por meio da mesma figura, se pode determinar o tempo de colapso do pilar para cada nível de carregamento aplicado e, assim construir o gráfico da curva de redução $K_{P M}$ para o Modelo 2: PMC-26. O gráfico contendo as curvas de fatores de redução da força resistente $\left(\mathrm{K}_{\mathrm{PM}}\right)$, obtidas via ANSYS e TCD para o Modelo 2, é apresentado na figura 6.20. Com o auxílio do gráfico, é possível determinar o tempo de colapso para o Modelo 2: PMC-26, em função do nível de carregamento aplicado.

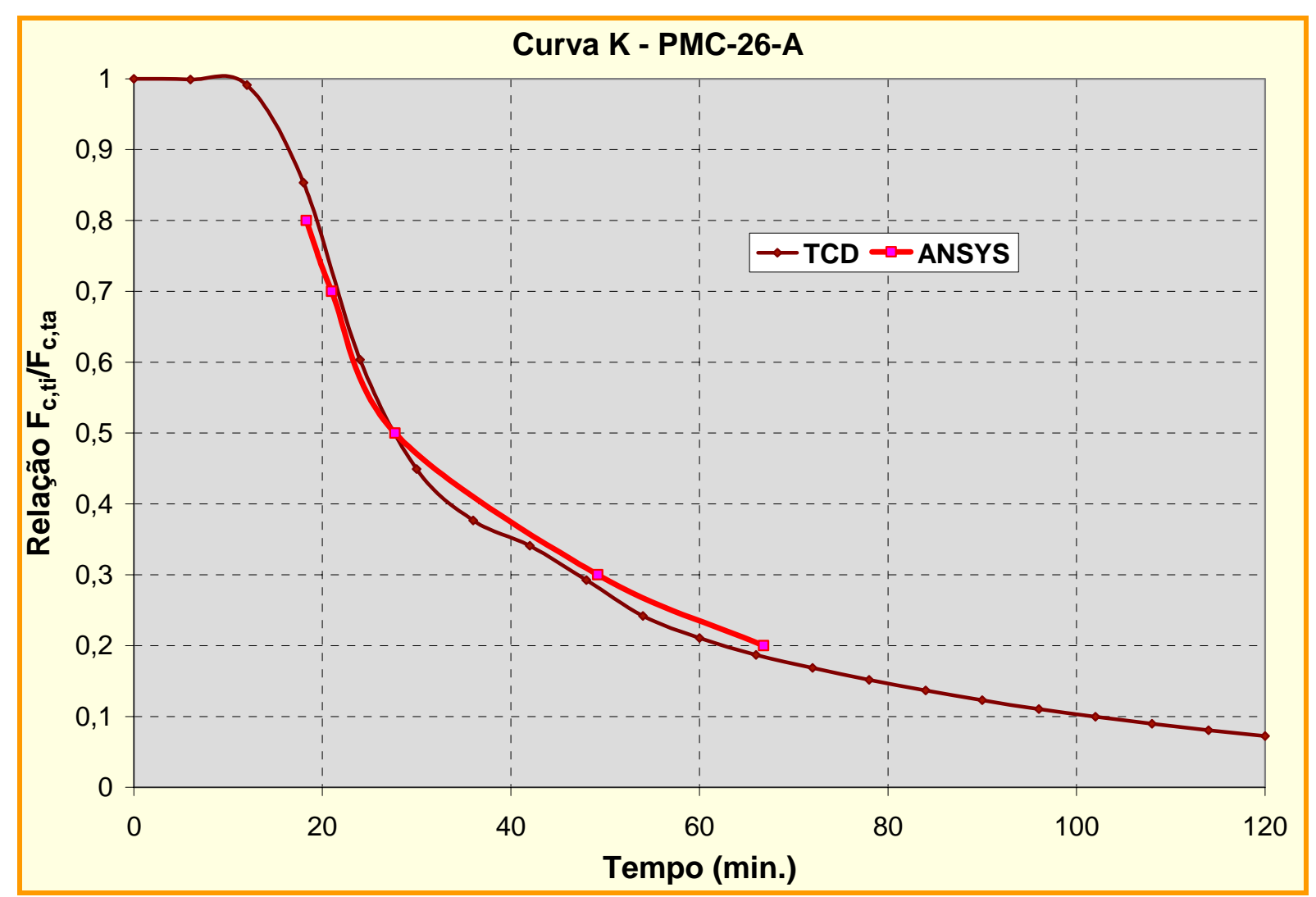

Figura 6.20 - Curvas de redução de força resistente para o Modelo 2: PMC-26.

Por meio de análise da figura 6.19, é possível determinar o tempo de colapso para o Modelo 2: PMC-19 em função do nível de carregamento aplicado. É importante lembrar novamente que esta curva é válida para um pilar curto e com carregamento centrado, lembrando variações no índice de esbeltez e na forma de aplicação do carregamento (centrado ou excêntrico) podem interferir na determinação do tempo de colapso dos pilares.

Nota-se, pela figura 6.20, que os gráficos apresentados são praticamente coincidentes e que, para valores de $K_{P M}$ maiores que 0,5, os resultados do ANSYS se mostram mais conservadores se comparados ao TCD, tendo em vista o fato de o ANSYS ser capaz de identificar eventuais instabilidades locais no perfil de aço, normalmente mais pronunciadas para elevados níveis de carregamento. 
A figura 6.21 apresenta a configuração deformada final para o Modelo 2: PMC-26 obtida via ANSYS, para $\mathrm{K}_{\mathrm{PM}}=0,5$ e para o tempo de 27 minutos. Com base nos resultados obtidos constata-se uma concordância bastante satisfatória dos resultados obtidos por meio do ANSYS, quando comparados àqueles obtidos por meio do programa TCD.

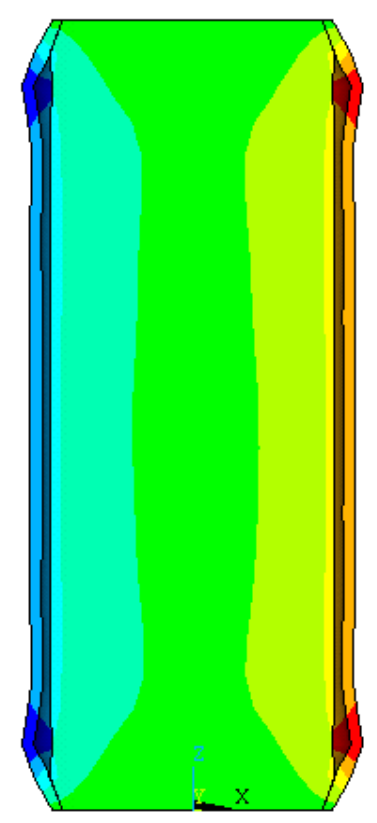

Figura 6.21 - Configuração deformada para níveis de deformação do Modelo 2: PMC-26, para $K_{P M}$ igual a 0,5 e tempo de exposição ao fogo igual a 27 minutos.

\subsubsection{MODELO 3 (PMC-46) - Com carga térmica em todo contorno do pilar}

O modelo aqui analisado, denominado Modelo 3 (PMC-46), assim como os Modelos 1 e 2, tem suas características geométricas e mecânicas indicadas na Tabela 6.1 e nas figuras 6.11, 6.12 e 6.13 anteriormente apresentadas. A análise acoplada, a ser agora realizada com o Modelo 3, permite a determinação do “tempo crítico" para cada nível de carregamento aplicado e a obtenção da curva $K_{P M}$ (fator de redução da força resistente) do pilar misto curto em função do tempo de incêndio.

Diferentemente daquelas considerações de simplificações adotadas para os Modelos 1 e 2, quanto à simetria e consideração da chapa de topo, tendo em vista o fato de o Modelo 3 representar um pilar misto curto de maior diâmetro a ser analisado neste trabalho, se optou por comprovar a eficiência do modelo simplificado em correspondência ao modelo completo. Assim, serão apresentados os resultados de deslocamentos axial em função do tempo para os modelos numéricos aqui denominados M3.1 (modelo inteiro e com chapa de topo) e M3.4 (1/2 simetria e sem chapa de topo). 
Os resultados de deslocamento em função do tempo para os modelos M3.1 e M3.4 estão apresentados nos gráficos das figuras 6.22 e 6.23, respectivamente, para níveis de carregamentos aplicados em situação de incêndio iguais a 30\% e 40\% daquele que identifica o colapso em temperatura ambiente.

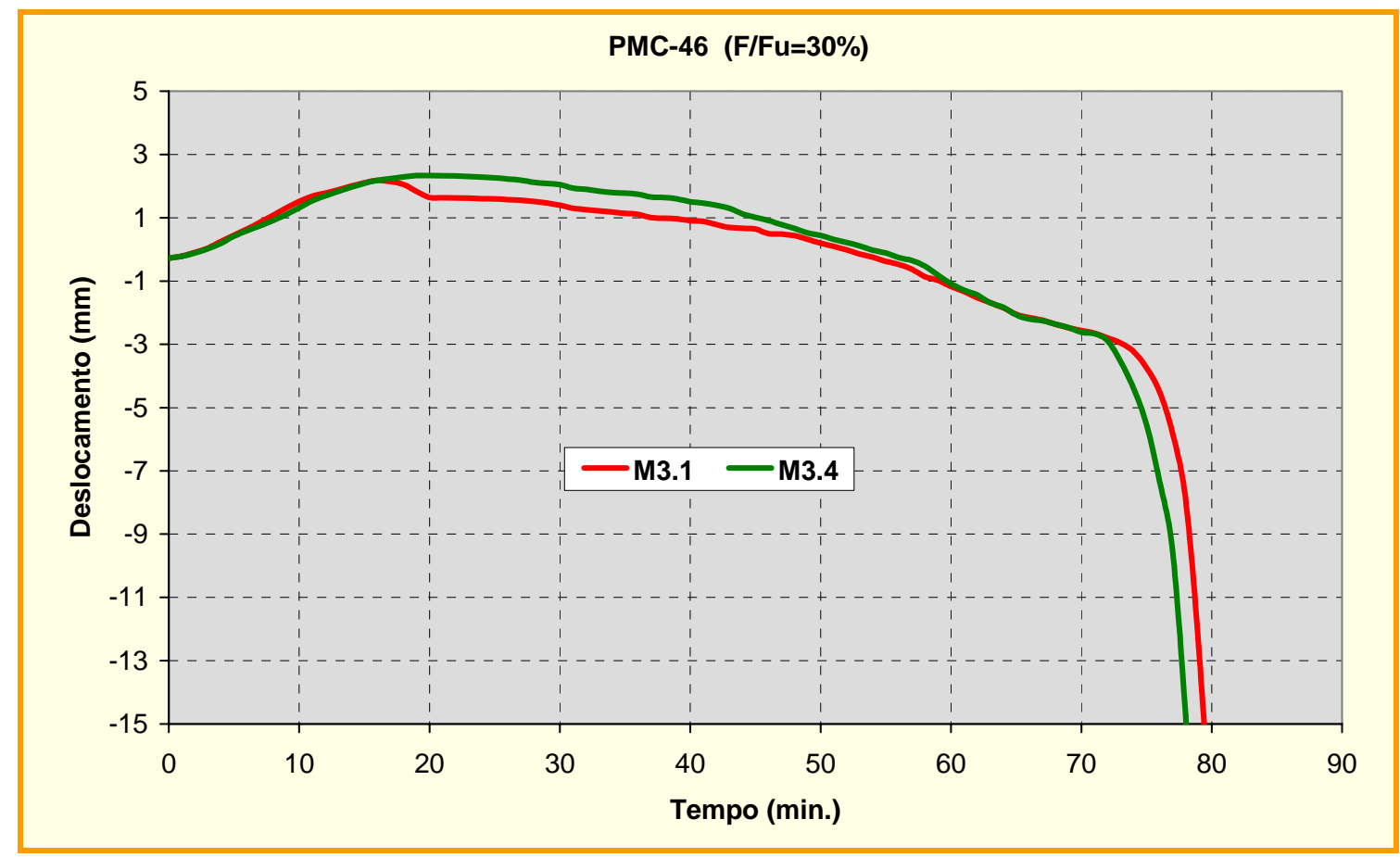

Figura 6.22 - Deslocamento $x$ Tempo: para o modelo 3 com $\mathrm{F}_{\mathrm{c}, \mathrm{t} i} / \mathrm{F}_{\mathrm{c}, \mathrm{ta}}=30 \%$.

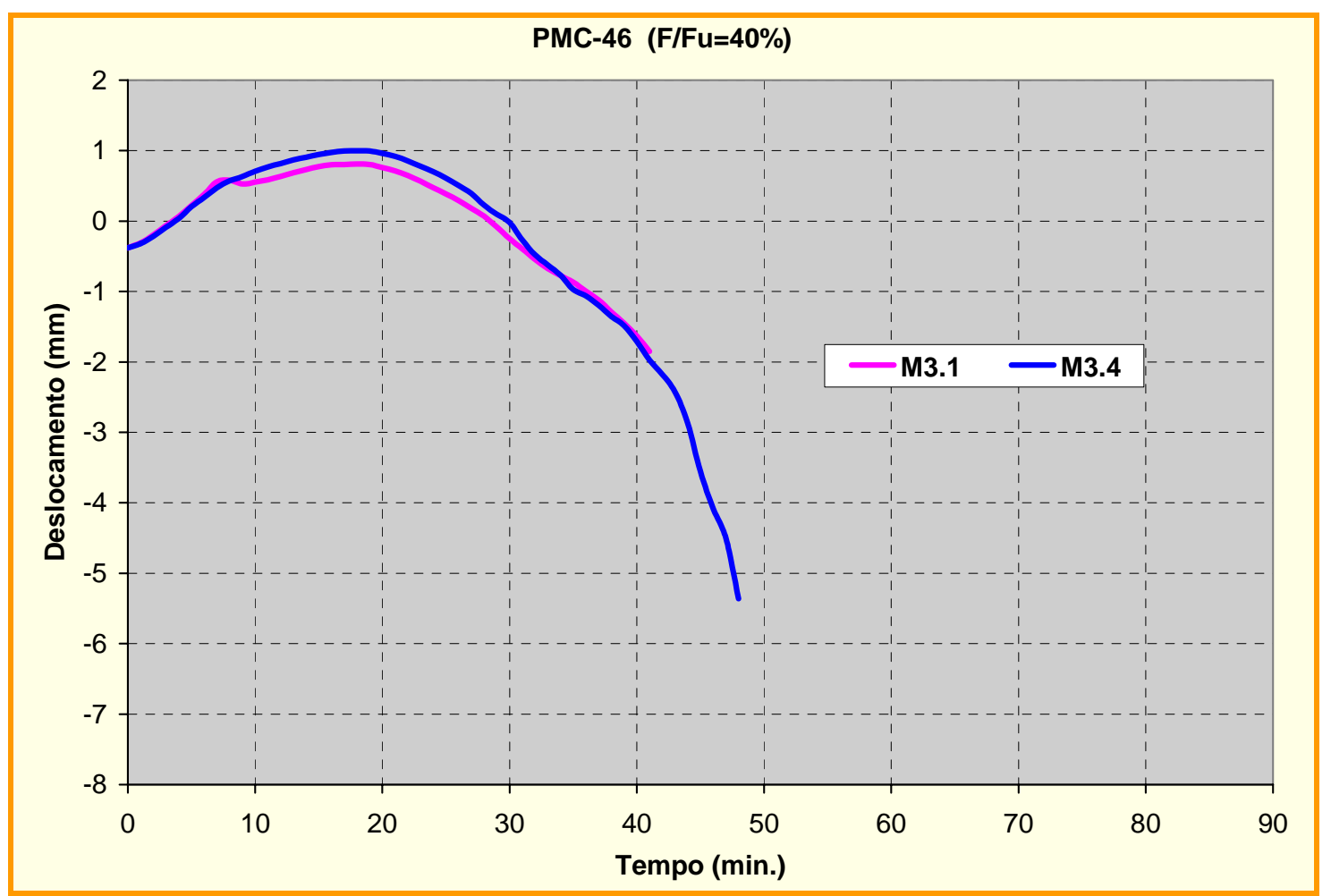

Figura 6.23 - Deslocamento $x$ Tempo: para o Modelo 3 com $\mathrm{K}_{\mathrm{PM}}=\mathrm{F}_{\mathrm{c}, \mathrm{t}} / \mathrm{F}_{\mathrm{c}, \mathrm{ta}}=40 \%$. 
As curvas de deslocamento em função do tempo para o M3.1 (modelo completo) e M3.4 (modelo simplificado) apresentaram resultados bastante próximos. Tendo em vista o fato de os resultados obtidos para o pilar de maior diâmetro apresentaram boa concordância e mesma tendência do tempo de ruptura, fica evidente a potencialidade do modelo simplificado, comprovado que esta estratégia pode, de fato, ser adotada para os estudos de pilares mistos curtos submetidos ao carregamento axial centrado.

Apesar da eficiência verificada do modelo simplificado, em caráter adicional, será apresentado o comportamento do modelo M3.1, sob incêndio-padrão e submetido a um carregamento igual a $600 \mathrm{kN}$ (aproximadamente $25 \%$ da carga de colapso em temperatura ambiente). Os resultados obtidos estão organizados na forma gráfica, conforme figura 6.24, e estão em concordância com o gráfico da figura 2.18, apresentada no Capítulo 2 do presente trabalho, no qual se constata que o aço resiste ao carregamento aplicado no início do incêndio e, posteriormente, o concreto passa a receber o carregamento.

Para auxiliar no entendimento do gráfico da figura 6.24, foi observada a evolução da configuração deformada do pilar misto, Modelo M3.1 para diferentes tempos de exposição ao fogo, cujas imagens, extraídas do ANSYS, estão ilustradas nas figuras 6.25 e 6.26.

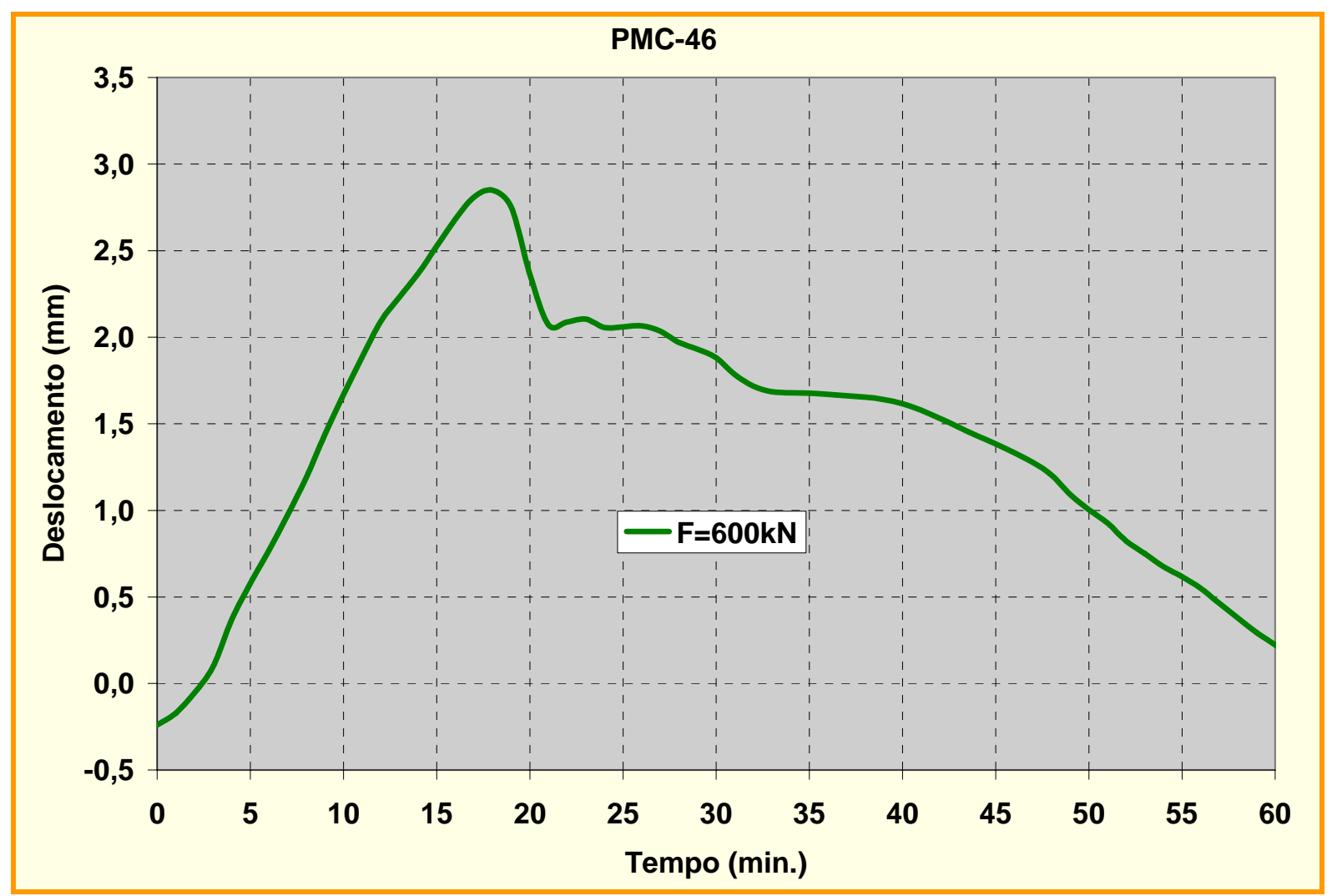

Figura 6.24 - Deslocamento x Tempo: para o modelo M3.1 com F $=600 \mathrm{kN}$. 
MN

(a)

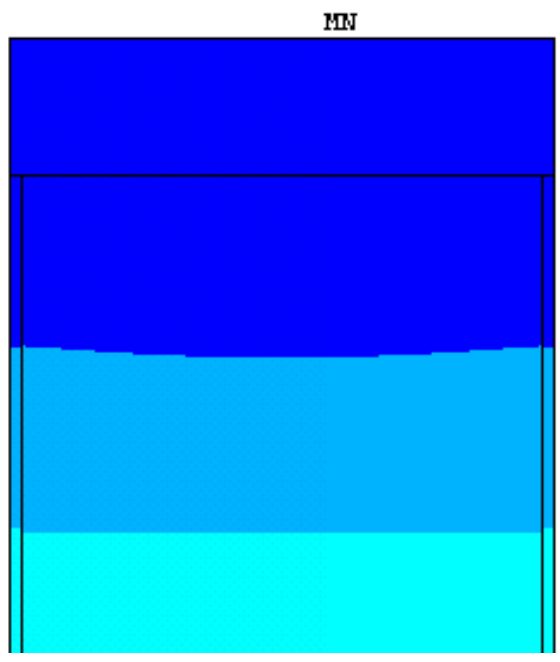

(c)

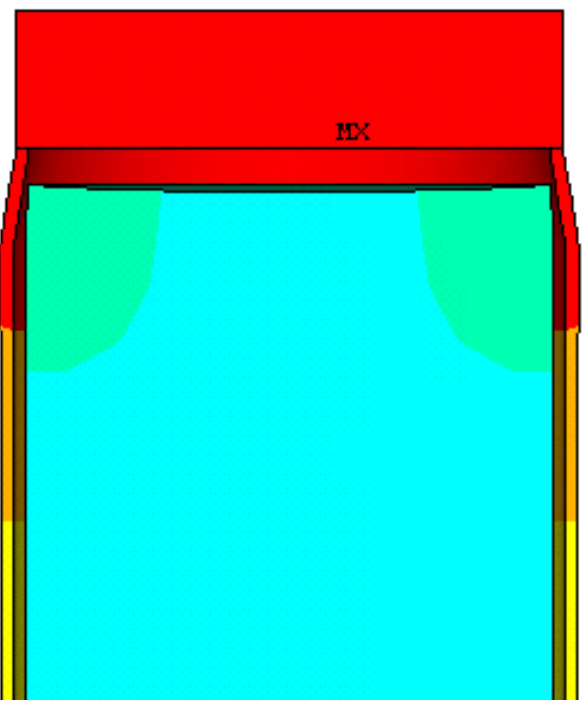

(e)

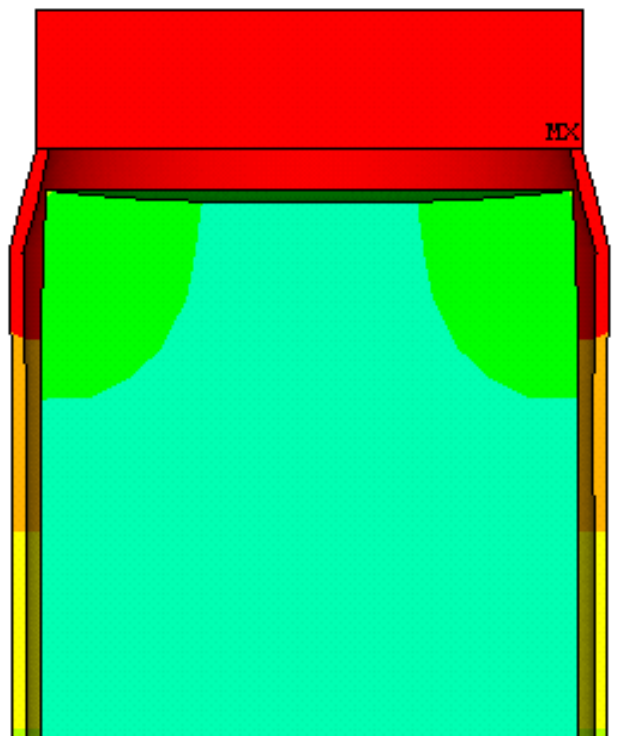

(b)

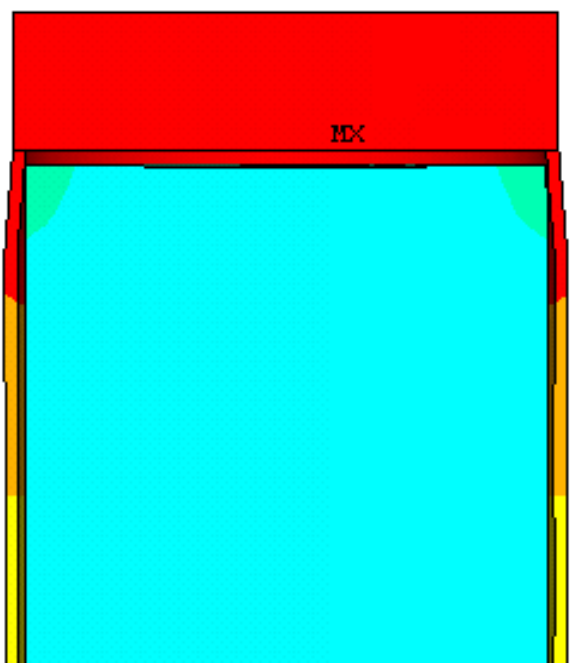

(d)
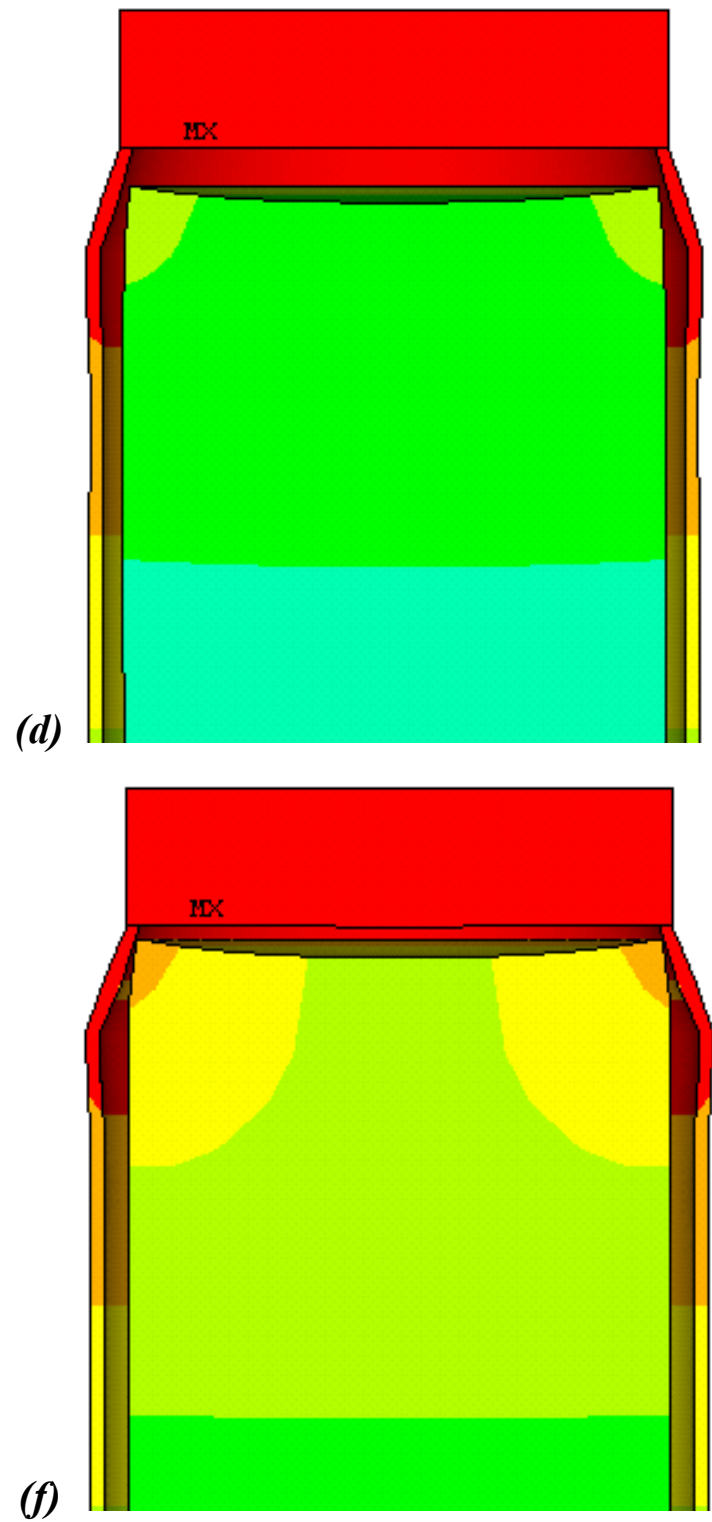

Figura 6.25 - Configuração deformada do Modelo M3.1, sob incêndio e com F $=600 \mathrm{kN}$, para os tempos de exposição iguais a: (a) 0 minuto, (b) 5 minutos, (c) 10 minutos, (d) 15 minutos, $(e) 18$ minutos e $(f) 20$ minutos. 


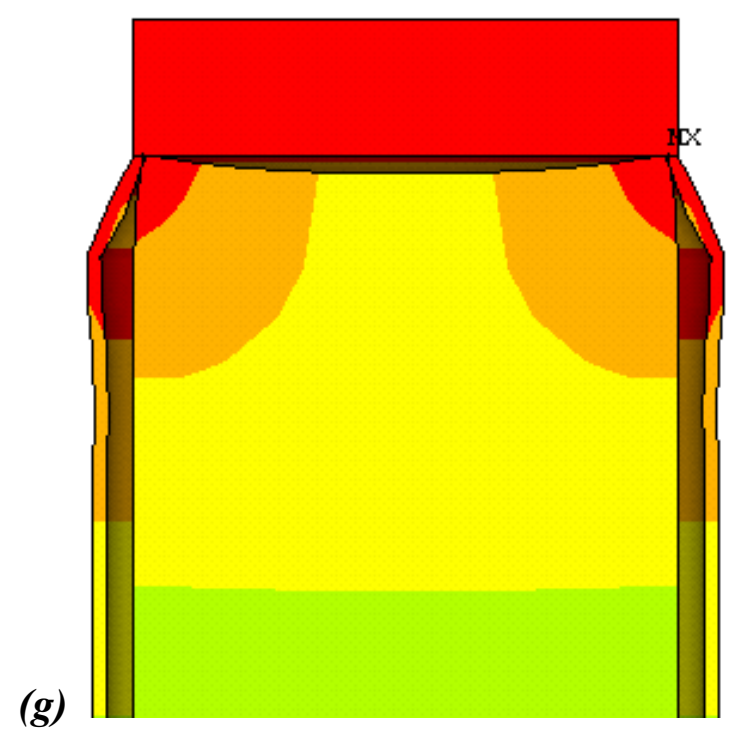

(h)
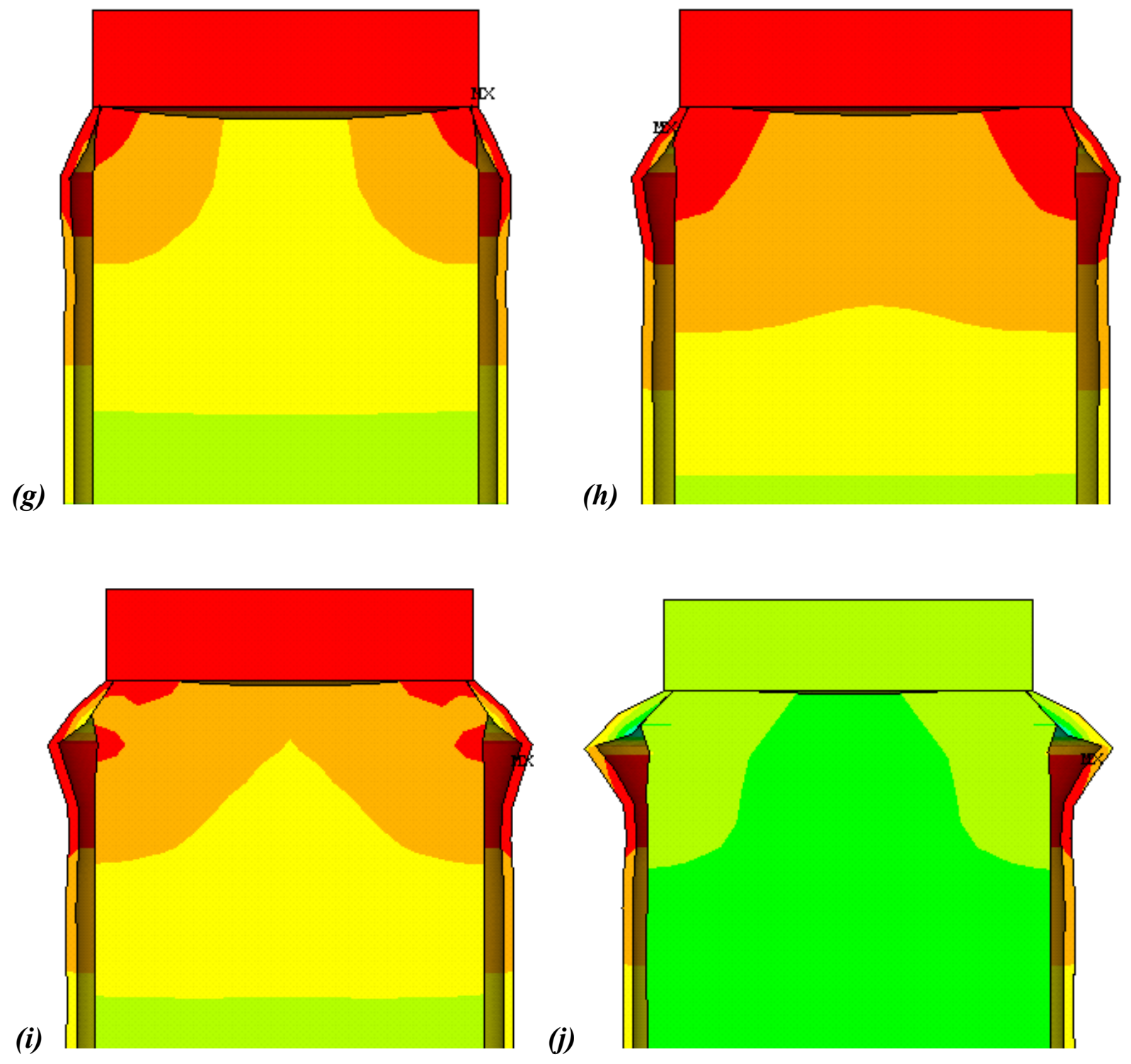

(k)

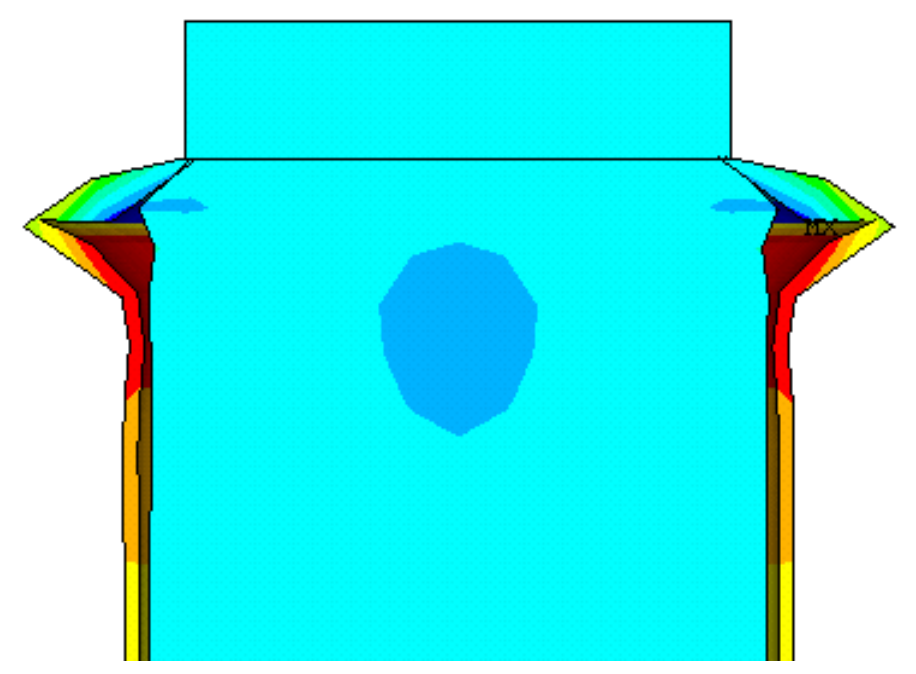

Figura 6.26 - Configuração deformada do Modelo M3.1, sob incêndio e com F $=600 \mathrm{kN}$, para os tempos de exposição iguais a: (g) 22 minutos, (h) 30 minutos, (i) 40 minutos, (j) 50 minutos e (k) 60 minutos 
As imagens, disponibilizadas em tempo crescente, sinalizam que do instante de tempo igual a 0 minutos até o instante de tempo igual a 18 minutos, o tubo de aço se expande axialmente mais que o núcleo de concreto e, nesta fase, apenas o aço deve resistir ao carregamento aplicado. A partir deste instante de tempo (18 minutos) o aço passa a sofrer uma degradação em suas propriedades mecânicas e, consequentemente, a não resistir mais por si só ao carregamento imposto ao modelo.

A sua taxa de expansão se torna menor se comparada à retração causada pelo carregamento imposto, até que no instante de tempo igual a 22 minutos a chapa de topo faz contato com a face externa do concreto. No entanto, vale lembrar que a região do núcleo de concreto próxima à interface com o tubo de aço sofre uma maior expansão quando comparada ao centro do núcleo de concreto devido à configuração do campo térmico aplicado, em que a face externa do concreto está mais aquecida que a região central. A partir deste instante, o carregamento começa a ser transferido para o concreto até o instante de tempo igual a 60 minutos, em que toda a face superior do núcleo de concreto se encontra em contato com a chapa de topo, e apenas o concreto resiste ao carregamento imposto.

Após a análise da figura 6.24, é possível constatar uma boa representação do modelo M3.1 com o comportamento real de um pilar misto em situação de incêndio, inclusive no referente ao processo evolutivo da expansão térmica e correspondentes configurações deformadas, conforme figuras 6.25 e 6.26 , as quais se mostram em concordância com aspectos citados em trabalhos desenvolvidos por outros pesquisadores.

No entanto, tendo em vista a grande economia em tempo de processamento e os bons resultados apresentados pelo modelo simplificado, os resultados que se seguem foram obtidos com base na proposta de modelagem M3.4, conforme ilustra a figura 6.27, em que se apresentam gráficos de "Deslocamento Axial x Tempo" para vários níveis de carregamento aplicados ao modelo M3.4, permitindo determinar o tempo de colapso para cada nível de carregamento e a construção da curva de redução de força resistente $\left(K_{P M}\right)$ em função do tempo para o modelo PMC-46.

O gráfico contendo a comparação das curvas de fatores de redução da força resistente $\left(\mathrm{K}_{\mathrm{PM}}\right)$, obtidas via ANSYS e TCD para o Modelo 3, estão apresentados na figura 6.28. Com o auxílio do gráfico é possível determinar o tempo de colapso para o Modelo 3: PMC-46 em função do nível de carregamento aplicado. É importante lembrar que esta curva é válida para um pilar curto e com carregamento centrado, sendo que a esbeltez e a forma de carregamento (centrado ou excêntrico), podem interferir na determinação do tempo de colapso para uma determinada carga aplicada. 


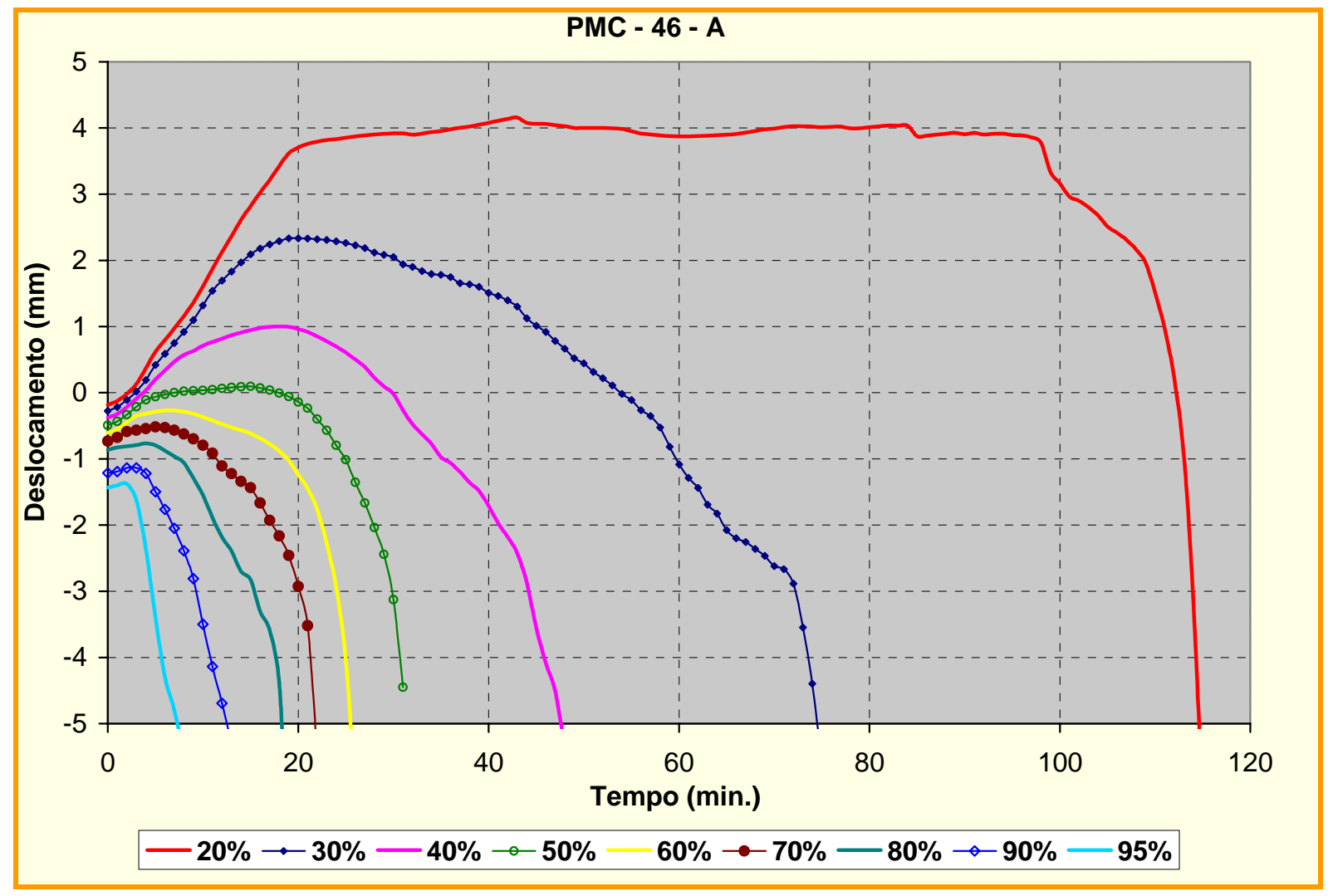

Figura 6.27 - Deslocamento x Tempo para vários níveis de carregamento - Modelo M3.4.

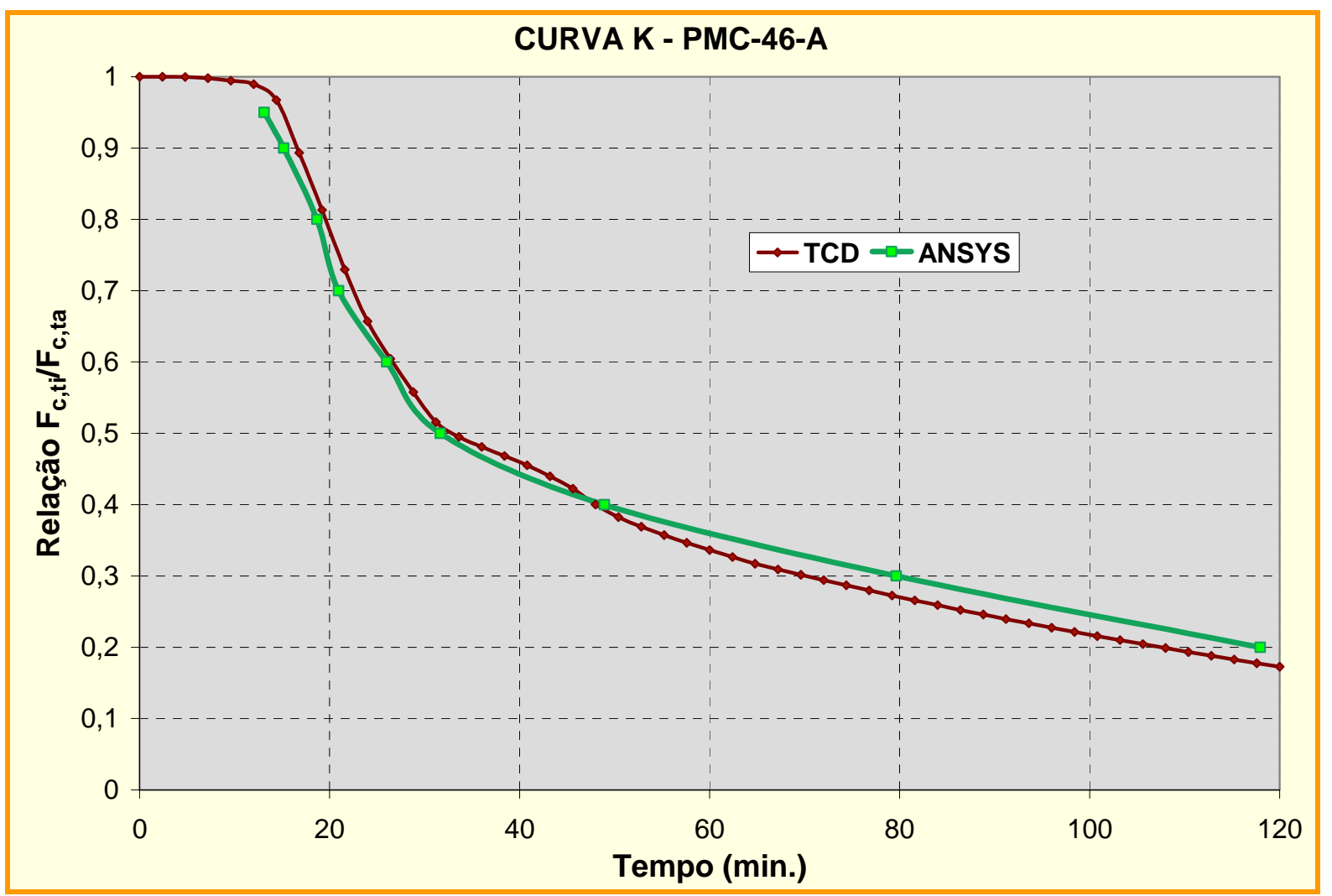

Figura 6.28 - Gráfico da curva de redução de resistência para o modelo PMC-46. 
A figura 6.29 apresenta a configuração deformada final para o modelo M3.4: PMC46, obtida por meio do código computacional ANSYS.

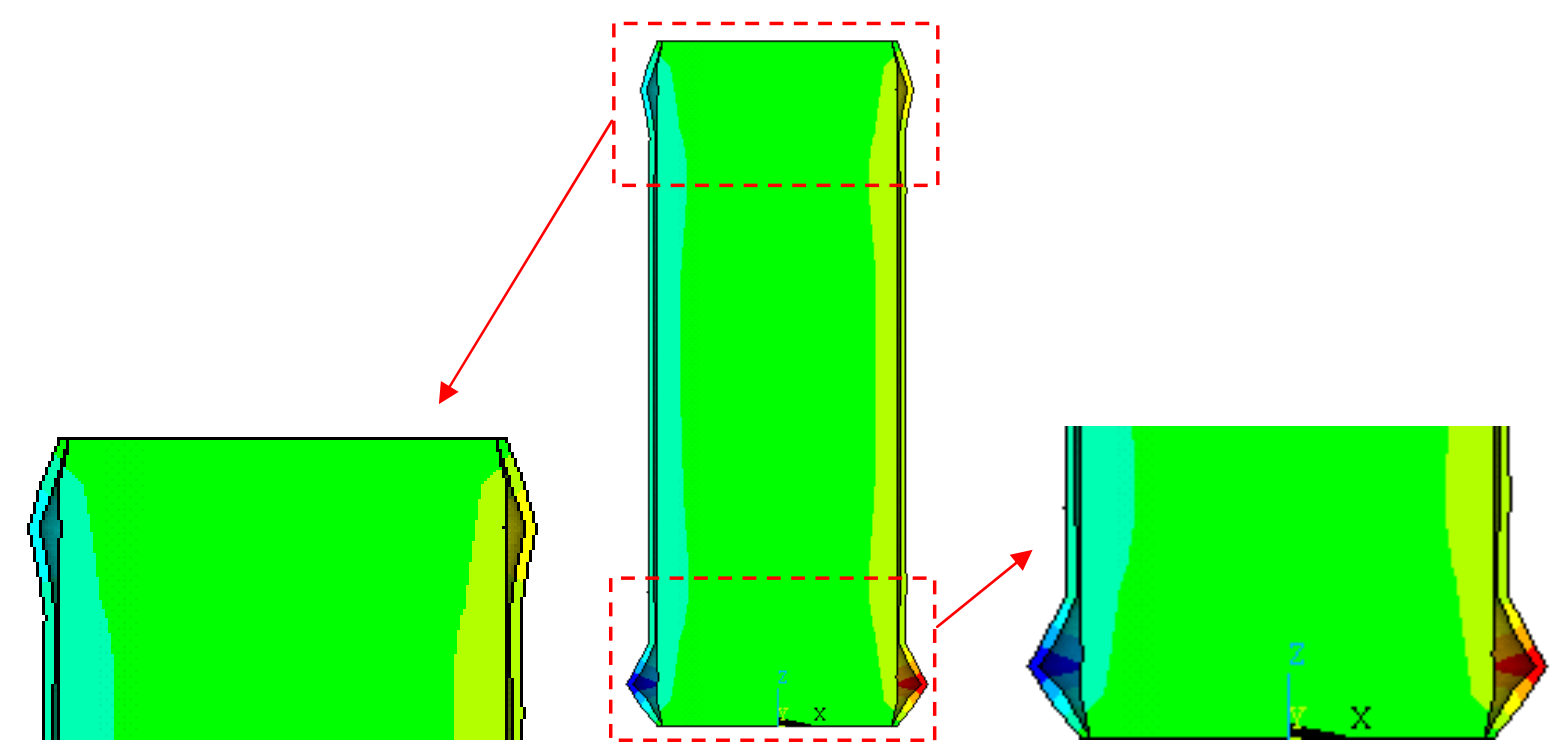

Figura 6.29 - Configuração deformada para níveis de deformação do modelo PMC-46, para $K_{P M}$ igual a 0,6 e tempo de exposição ao fogo igual a 26 minutos.

Comparando os resultados obtidos nos itens 6.3.1, 6.3.2 e 6.3.3, referentes à análise acoplada de pilares mistos para os Modelos 1, 2 e 3 respectivamente, com o Método Tabular apresentado pela NBR 14323:1999, conforme tabela 3.6 apresentada no capítulo 3 do presente trabalho, vale destacar, apenas para fins comparativos, os seguintes aspectos:

- Para $K_{\mathbf{P M}}=$ 0,3: com o Modelo 1 (diâmetro igual a $114 \mathrm{~mm}$ ) se obtém TRRF igual a 38 minutos, e com o Modelo 2 (diâmetro igual a $168 \mathrm{~mm}$ ) se obtém TRRF igual a 49 minutos, enquanto que a NBR 14323:1999 prescreve diâmetro de $160 \mathrm{~mm}$ para TRRF igual a 30 minutos. Com o Modelo 3 (diâmetro igual a $219 \mathrm{~mm}$ ) se obtém TRRF igual a 80 minutos, enquanto que a NBR 14323 prescreve diâmetro de $260 \mathrm{~mm}$ para TRRF igual a 60 minutos

- Para $\mathbf{K}_{\mathbf{P M}}=\mathbf{0 , 5}$ : com o Modelo 2 (diâmetro igual a $168 \mathrm{~mm}$ ) se obtém TRRF igual a 28 minutos, e com o Modelo 3 (diâmetro igual a $219 \mathrm{~mm}$ ) se obtém TRRF igual a 32 minutos, enquanto que a NBR 14323:1999 prescreve diâmetro de 260 mm para TRRF de 30 minutos;

- Para $\mathbf{K}_{\mathbf{P M}}=$ 0,7: com o Modelo 3 (diâmetro igual a $219 \mathrm{~mm}$ ) se obtém TRRF igual a 21 minutos, enquanto que NBR 14323:1999 prescreve diâmetro igual a $260 \mathrm{~mm}$ para TRRF igual a 30 minutos. 
Com base nos aspectos citados, nota-se, aparentemente, que para baixos níveis de carregamento, por exemplo, $\mathrm{K}_{\mathrm{PM}}=0,3$, a NBR 14323:1999 apresenta valores a favor da segurança. Para $K_{P M}=0,5$, os valores apresentados pela NBR 14323:1999 resultam mais próximos dos resultados dos modelos numéricos, porém, ainda a favor da segurança. E ainda, para $\mathrm{K}_{\mathrm{PM}}=0,7$ pouco pode ser considerado, tendo em vista que o maior diâmetro analisado no presente trabalho, foi de $219 \mathrm{~mm}$, enquanto que o menor diâmetro considerado pela norma para esse $\mathrm{K}_{\mathrm{PM}}$ resulta igual a $260 \mathrm{~mm}$.

Apesar do fato de os valores prescritos pela NBR 14323:1999 resultarem superiores aos resultados dos modelos numéricos, aspecto já esperado uma vez que esses se referem aos pilares mistos curtos enquanto que a NBR 14323 apresenta valores para pilares mistos com comprimentos de edifícios correntes, é possível perceber que os resultados demonstram boa concordância entre valores numéricos e valores normativos e, portanto, a eficiência numérica da estratégia aqui adotada.

\subsubsection{MODELO 4 (PMC-26-A) - Carga térmica apenas em metade do contorno do pilar}

A análise a ser aqui realizada com base em um outro modelo numérico, denominado Modelo 4, o qual possui as mesmas características geométricas e mecânicas do Modelo 2, apresenta uma diferente forma de consideração e aplicação do campo térmico. A presente análise consiste na aplicação de um nível de força e, em seguida, a consideração de carregamento térmico em apenas metade do contorno da seção transversal do pilar misto, em concordância com o apresentado no item 5.1.3 do Capítulo 5.

Os resultados obtidos para o Modelo 4 serão comparados com os resultados do Modelo 2 (carga térmica em todo o contorno), com o objetivo de avaliar a influência do campo térmico na determinação da força de colapso do pilar e, consequentemente, seu tempo crítico e seus fatores de redução.

A figura 6.30 apresenta os resultados das curvas de redução da força resistente $\left(\mathrm{K}_{\mathrm{PM}}\right)$ para o Modelo 2 (M2) e para o Modelo 4 (M4), apenas para níveis de carregamento estático iguais a $30 \%, 50 \%$ e $70 \%$, uma vez que a idéia é apenas a de reconhecer se as condições de compartimentação do ambiente em chamas, responsável por diferentes maneiras de se considerar o campo térmico, pode exercer influência significativa na força resistente do elemento de interesse. 


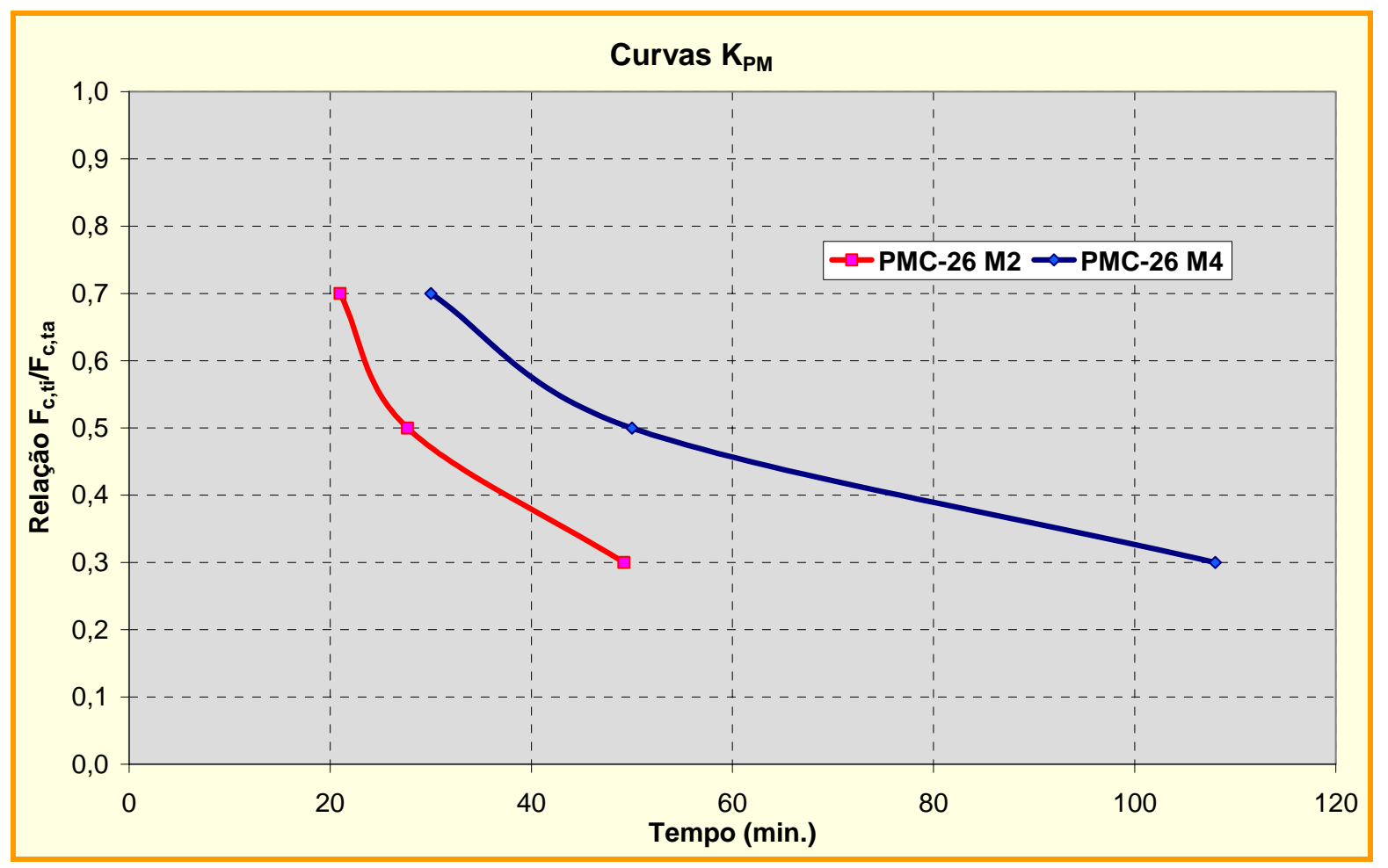

Figura 6.30 - Curva de redução de resistência para os Modelos 2 e 4 (PMC-26).

Por meio de análise com relação à figura 6.30, é possível notar que os valores de tempos de colapso referentes ao Modelo 4, para os três diferentes níveis de carregamento estático considerados, resultam consideravelmente superiores àqueles apresentados para 0 Modelo 2, indicando que para os pilares curtos, em que não se leva em consideração efeitos de instabilidade global, a aplicação de carga térmica em todo o contorno resulta em tempos inferiores de resistência ao incêndio e, portanto, a favor da segurança.

No entanto, se para pilares curtos a forma de carregamento térmico mais crítica é aquela que se faz em todo seu contorno, tal fato não implica que esta também seja a forma de carregamento térmico mais crítica para os pilares mais longos, pois o campo térmico não simétrico na seção do pilar pode gerar esforços de segunda ordem e, eventualmente, resultar em colapso do pilar misto em tempo reduzido se comparado ao carregamento térmico por todo o contorno.

Apenas para fins de ilustração, a figura 6.31 apresenta os níveis de temperatura para o Modelo 4: PMC-26 obtidos via ANSYS, para $\mathrm{K}_{\mathrm{PM}}=0,3$ e para o tempo igual a 108 minutos. $\mathrm{Na}$ mesma figura também é possível observar a configuração deformada final referente ao mesmo campo térmico. 

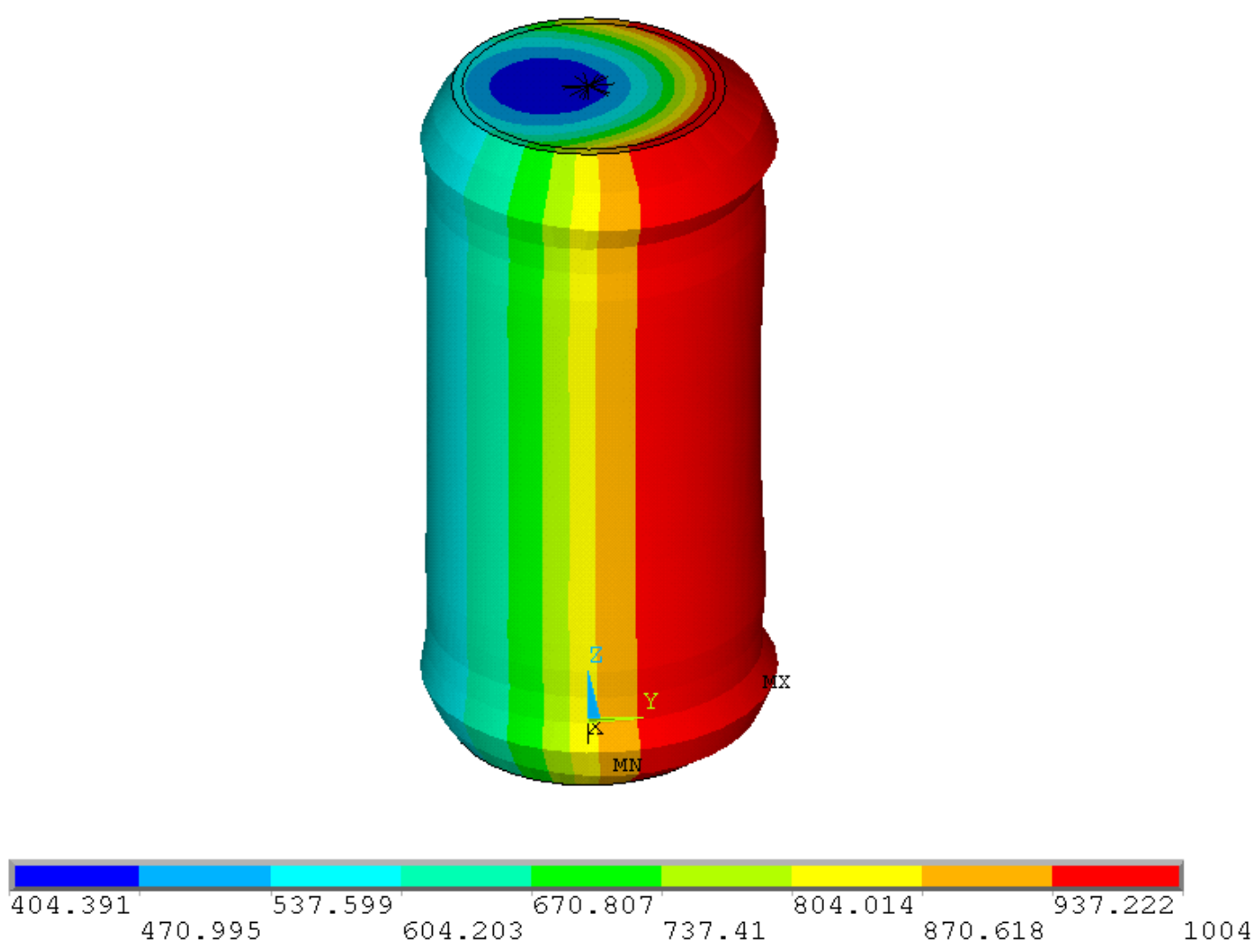

Figura 6.31 - Configuração deformada paras níveis de temperatura do Modelo 4 PMC-46. para $K_{P M}$ igual a 0,3 e tempo de exposição ao fogo igual a 108 min.

\subsubsection{ANÁLISE PARAMÉTRICA - Diâmetro e resistência à compressão}

Neste item serão apresentadas duas análises paramétricas referentes ao pilares mistos curtos estudados nos itens anteriores, dentro do presente capítulo, lembrando que tudo se faz agora considerando carga térmica em todo o contorno do pilar em razão dos aspectos comparativos citados ao final do item 6.3.4.

Inicialmente, se faz uma avaliação da interferência na variação do diâmetro nos pilares mistos curtos de seção circular na resposta do tempo de resistência ao incêndio, com base nos resultados das curvas de fatores de redução de força resistente $\left(K_{P M}\right)$ obtidas via ANSYS e apresentadas nos itens anteriores, conforme ilustra a figura 6.32.

Aqui, vale ressaltar que os resultados na forma gráfica apresentados na figura 6.32 estão em concordância com descrições citadas em referências apresentadas no Capítulo 2, em que é comentado que a variação do diâmetro da seção transversal para pilares mistos curtos de aço preenchidos com concreto apresenta grande influência na resistência em temperaturas elevadas, uma vez que o tempo requerido aumenta em resposta ao aumento do diâmetro da seção transversal. 


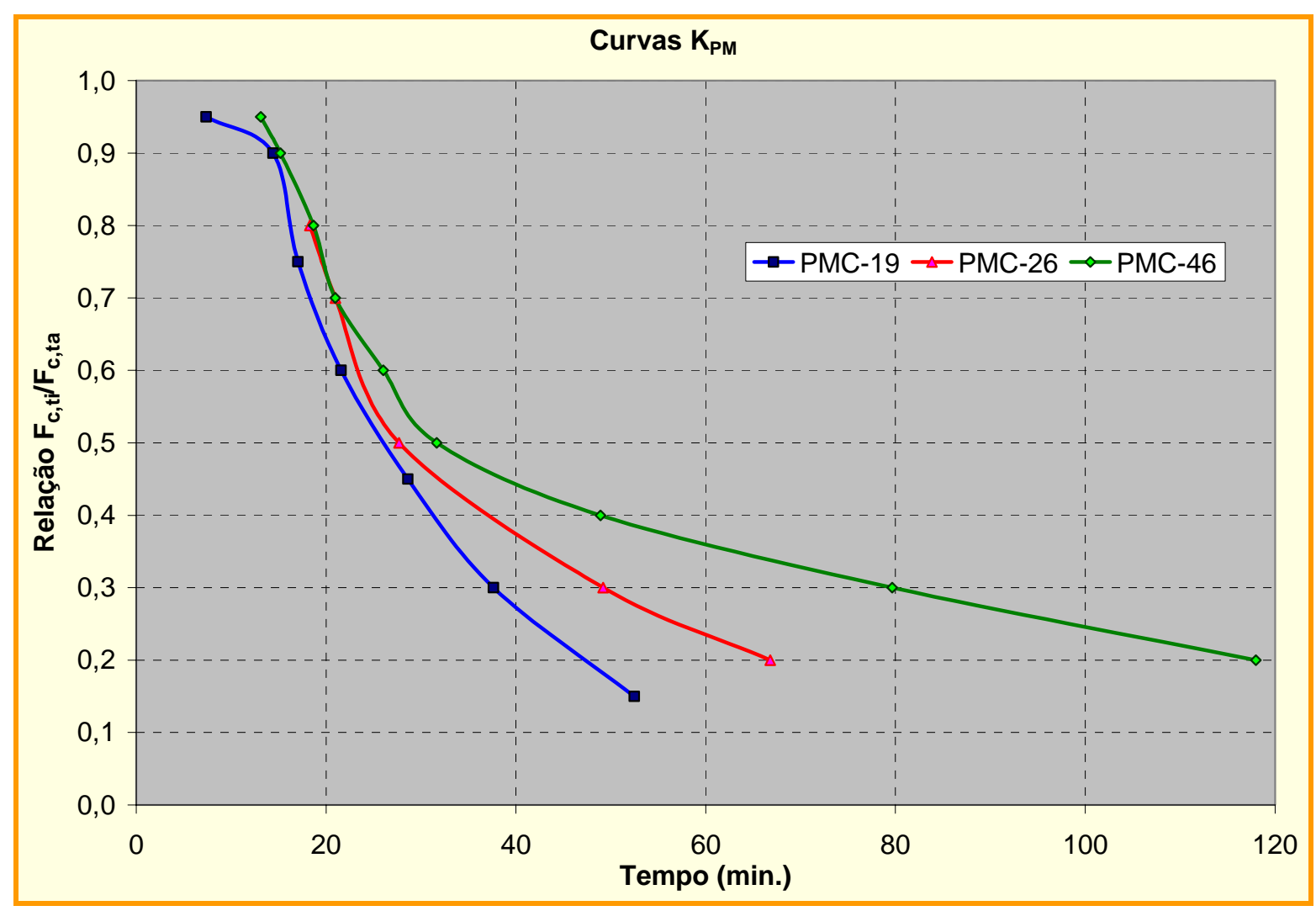

Figura 6.32 - Curvas de redução de força resistente para os Modelos 1, 2 e 3.

Em seguida, são consideradas variações na resistência à compressão do concreto $\left(f_{\mathrm{ck}}\right)$ para o Modelo 1 apresentado no item 6.2.1, comparando-se as curvas de fator de redução da força resistente, $K_{P M}$ para valores de resistência à compressão $\left(f_{c k}\right)$ iguais a $25 \mathrm{MPa}$ e 32,68 $\mathrm{MPa}$. Os gráficos considerando a variação do $\mathrm{f}_{\mathrm{ck}}$ estão apresentados na figura 6.33 .

Os resultados apresentados nos gráficos da figura 6.33 também estão em concordância com aspectos citados nas referências pesquisadas, em que se descreve que a variação da resistência à compressão do concreto apresenta influência moderada na resistência dos pilares mistos preenchidos ao incêndio. De fato, as curvas da figura 6.33 sinalizam que o aumento na resistência do $f_{c k}$ proporciona um pequeno aumento no tempo de resistência ao fogo.

Portanto, as considerações aqui adotadas indicam coerência da estratégia adotada quando da construção dos modelos de pilares, em que se fez a aplicação de uma porcentagem da carga última obtida para o pilar misto em temperatura ambiente, para posterior aplicação do carregamento térmico em situação de incêndio. Tendo em vista os resultados satisfatórios aqui obtidos, no item 6.4 se faz uma análise complementar, aqui denominada "análise inversa", em que se considera o carregamento sempre crescente para um dado campo térmico correspondente a um determinado tempo de incêndio. 


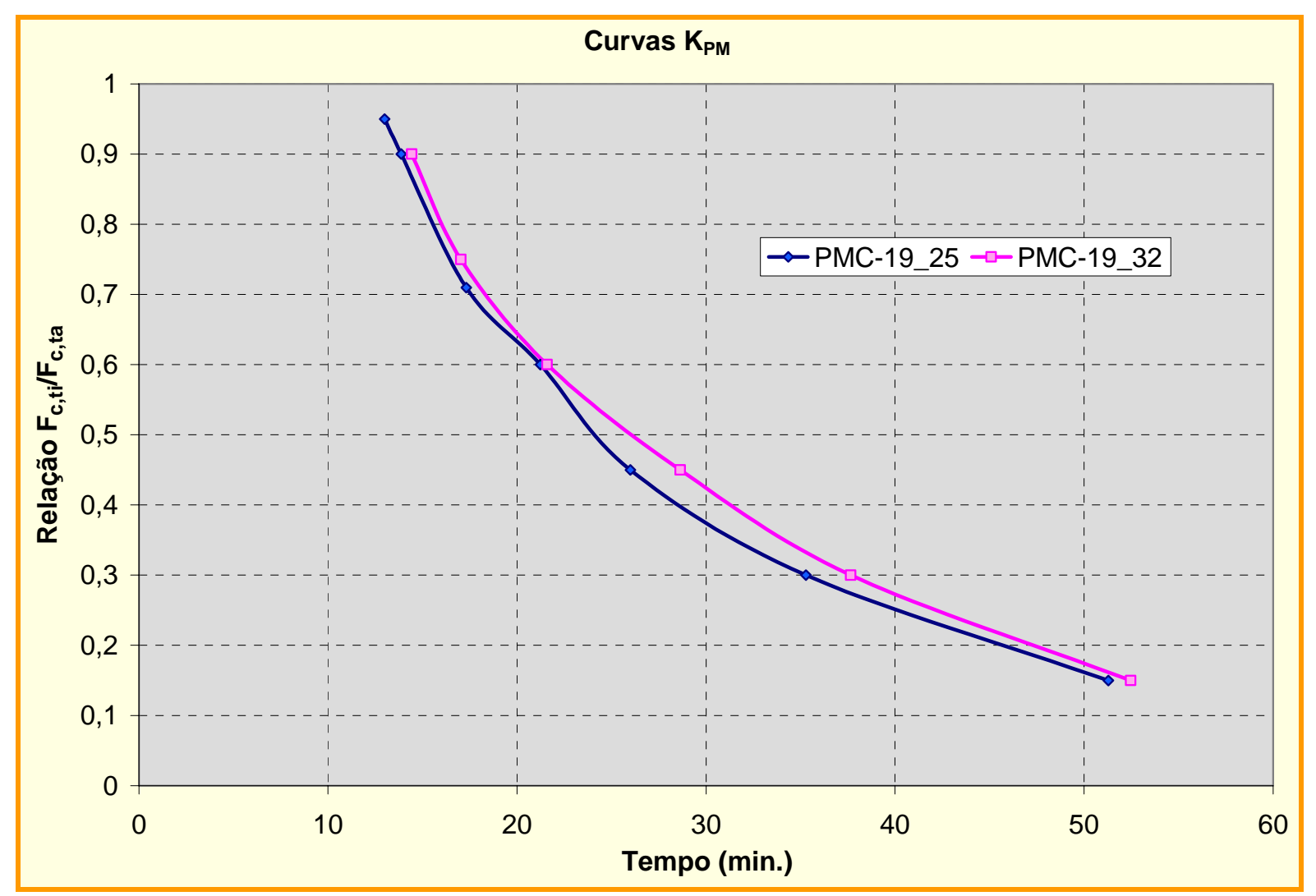

Figura 6.33 - Curvas de fatores de redução de força resistente em função do $\mathrm{f}_{\mathrm{ck}}$, para o Modelo 3 PMC-19.

\subsection{PILARES MISTOS CURTOS - Análise complementar em situação de incêndio}

No item 6.3 foram realizadas análises acopladas do tipo termo-estrutural em que foram consideradas porcentagens da carga última obtida para pilares mistos curtos de aço e concreto em temperatura ambiente, para posterior aplicação do carregamento térmico em situação de incêndio, com vistas à determinação do tempo crítico (ou temperatura crítica), inclusive de seu comportamento mecânico durante a elevação de temperatura.

A análise a ser aqui realizada, denominada “análise inversa”, também dentro do contexto de acoplamento termo-estrutural, consiste de modelagens numéricas dos mesmos pilares mistos curtos de aço e concreto considerados no item 6.3, porém, admitindo um nível de aquecimento previamente estabelecido com posterior carregamento crescente, até que seja atingido o colapso do elemento misto.

Em outras palavras, os pilares mistos em análise são, inicialmente, considerados inseridos dentro de um contexto de aquecimento com carregamento térmico fixo, em que a temperatura é mantida constante em um dado nível pré-estabelecido em resposta à curva de 
aquecimento referente ao incêndio-padrão para, em seguida, serem submetidos a um carregamento axial centrado e crescente.

Nesse caso, dadas as penalizações de resistência e rigidez para cada material em razão do aquecimento (fixo) considerado, os elementos mistos atingirão seus correspondentes valores de carregamento axial máximo a ser suportado, o qual será identificado quando do colapso estrutural do mesmo associado a deslocamentos assintóticos.

Vale ressaltar que a análise inversa se faz com vistas a "sinalizar" (e apenas sinalizar) em qual nível de temperatura o "efeito do confinamento", presente nesse tipo de elemento, deixa de ser pronunciado e, consequentemente, pouco influencia na forma de ganho de capacidade resistente e no comportamento estrutural.

Os modelos numéricos analisados dentro do contexto da análise inversa são aqueles mesmos apresentados no item 6.3, denominados Modelo 1: PMC-19, Modelo 2: PMC-26 e Modelo 3: PMC-46, para os quais ainda permanecem válidas as condições de $1 / 2$ simetria e não utilização da chapa de topo. Os resultados das análises dos modelos numéricos mencionados estão apresentados em gráficos nas figuras 6.31, 6.32 e 6.33. Para cada modelo, são analisadas e apresentadas curvas referentes à "Força de colapso ( $k N)$ x Deformação axial (\%o)" para um determinado campo térmico aplicado.

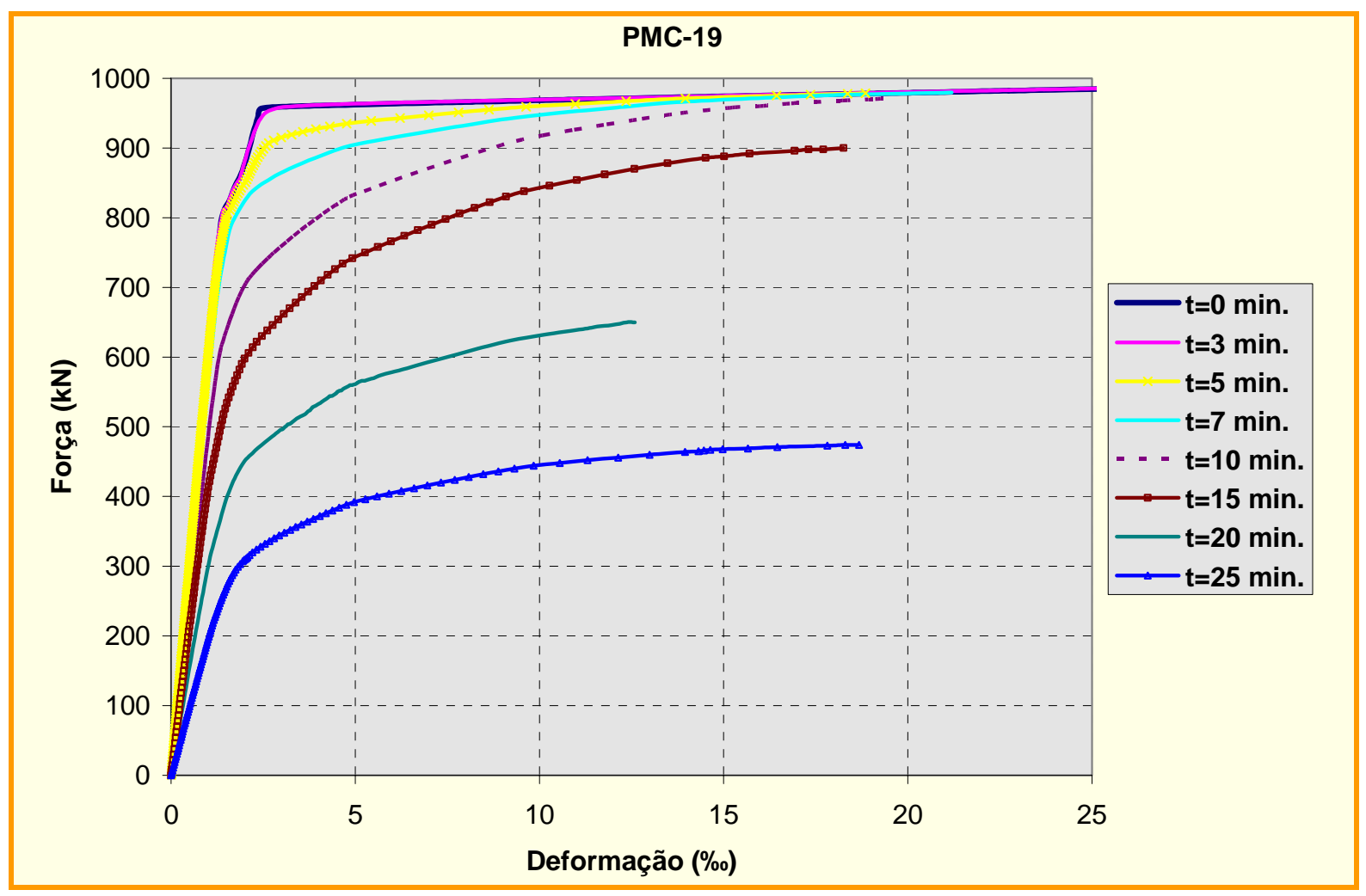

Figura 6.34 - Diagramas Força de Colapso x Deformação axial, para diferentes tempos de exposição ao incêndio-padrão: Modelo 1: PMC-19. 


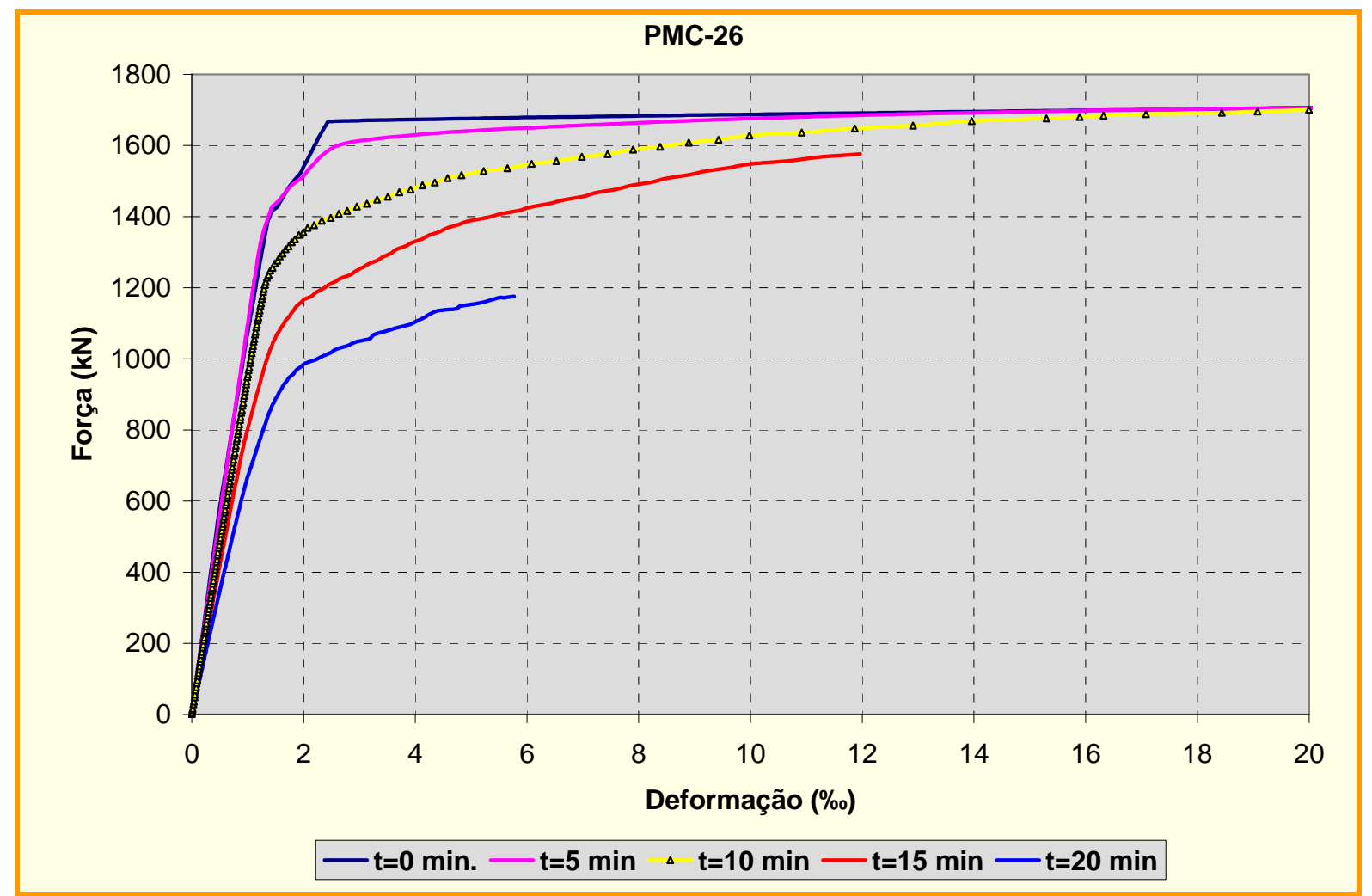

Figura 6.35 - Diagramas Força de Colapso x Deformação axial, para diferentes tempos de exposição ao incêndio-padrão: Modelo2: PMC-26.

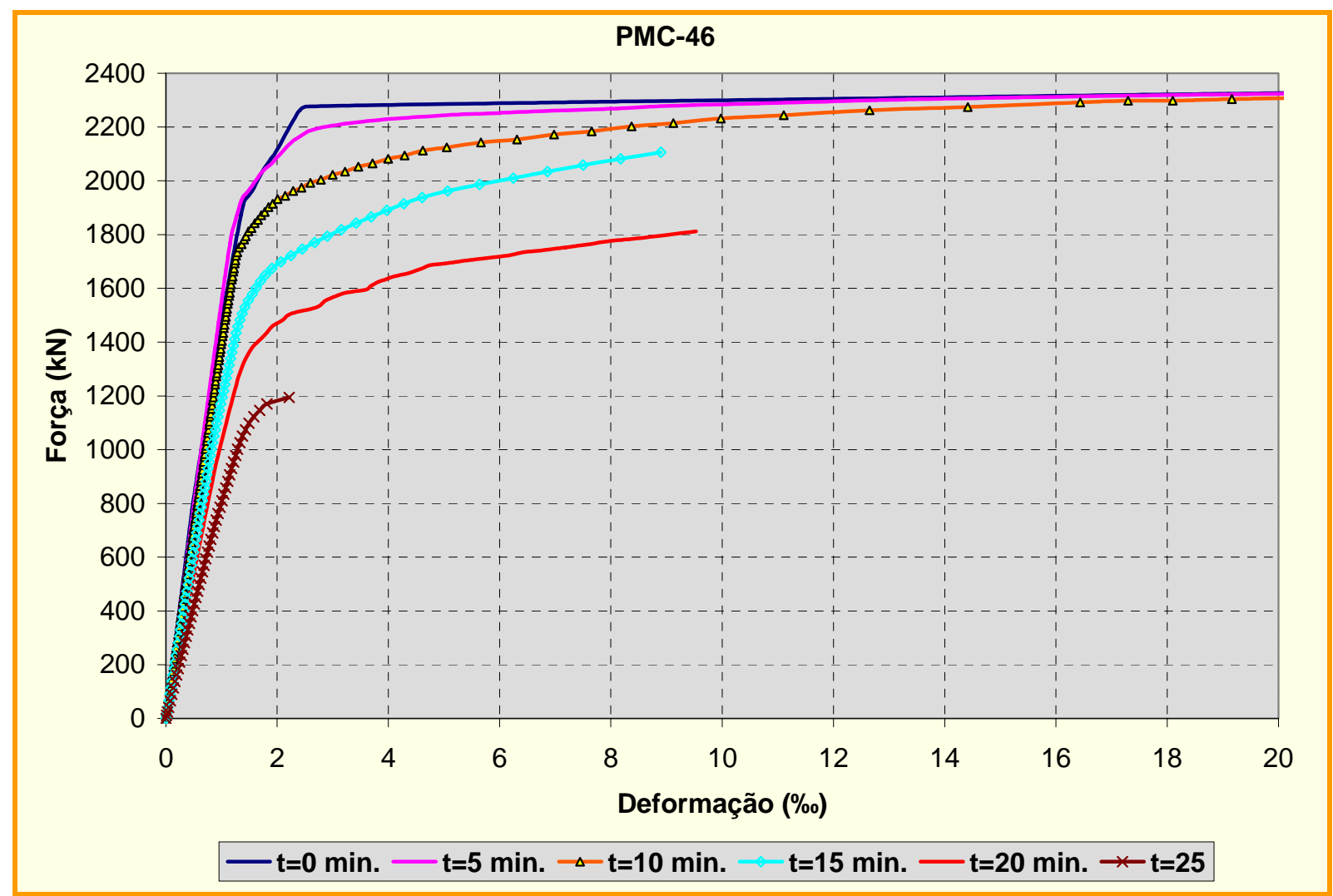

Figura 6.36 - Diagramas Força de Colapso x Deformação axial, para diferentes tempos de exposição ao incêndio-padrão: Modelo 3: PMC-46. 
Inicialmente, é importante ressaltar o fato, de acordo com referências bibliográficas coletadas e consultadas ao longo do desenvolvimento do presente trabalho, de o "efeito do confinamento", presente em pilares mistos de aço e concreto, garantir um ganho de capacidade resistente entre $10 \%$ e $15 \%$ (considerado como valores médios de referência) daquela que seria obtida pelo mesmo elemento sem levar em conta a contenção lateral imposta pelo tubo de aço ao núcleo de concreto.

Com base nos aspectos expostos no último parágrafo, por meio de análise dos gráficos apresentados nas figuras 6.30, 6.31 e 6.32, é possível observar, como aspecto evidente, que para os instantes iniciais de aquecimento do elemento misto, da ordem de 15 minutos de exposição, os modelos analisados apresentam força de colapso reduzidas em cerca de $10 \%$ daquela identificada em temperatura ambiente $(\mathrm{t}=0$ minuto), sinalizando, aparentemente, que o efeito do confinamento deixa de colaborar no comportamento estrutural para níveis de temperatura não muito baixos (da ordem de $700^{\circ} \mathrm{C}$ ), porém, para tempos de exposição ao fogo reduzidos, se comparados a TRRF's iguais a 30, 60, 90 e 120 minutos.

Vale destacar que, para 15 minutos e 20 minutos de exposição ao fogo, a força resistente está em concordância com os gráficos das curvas de redução $\left(\mathrm{K}_{\mathrm{PM}}\right)$.

Com relação ao processamento dos modelos, foi utilizado um computador com as seguintes características: Intel (R) Core (TM) 2 Quad CPU, 2.40 GHz, 4.00 GB of RAM.

O tempo de processamento dos modelos varia em função da malha de elementos finitos e do incremento de carga. Quanto maior o pilar misto estudado maior o número de elementos finitos utilizados e menor o incremento de carga, resultando em menores tempos de processamento para os modelos PMC-19 e maiores para os modelos PMC-46. A utilização da chapa de topo também interfere, aumentando o tempo de processamento.

Alguns tempos de processamento referentes à análise termo-estrutural apresentada no item 6.3, para um nível de carregamento de 30\%:

- PMC-19 com simetria e sem chapa de topo, tempo de 45 minutos;

- PMC-19 com simetria e com chapa de topo, tempo de 120 minutos

- PMC-46 com simetria e sem chapa de topo, tempo de 790 minutos;

- PMC-46 com simetria e com chapa de topo, tempo de 4710 minutos. 
O nível de carregamento também interfere no tempo de processamento, quanto menor o nível de carregamento maior é o tempo de processamento.

Tendo em vista que a quantidade de elementos finitos e a utilização da chapa de topo tornam maior o tempo de processamento, a utilização de modelos simplificados, utilizando-se da condição de simetria e a não utilização da chapa de topo, pode reduzir significativamente o tempo de processamento. 


\section{CONCLUSÕES E SUGESTÕES PARA TRABALHOS FUTUROS}

\subsection{CONSIDERAÇÕES FINAIS}

A presente pesquisa, cujos procedimentos adotados e resultados foram apresentados ao longo dos capítulos anteriores, se fez dentro do contexto das estruturas em situação de incêndio, tendo em vista a necessidade de se avaliar o desempenho dessas quando submetidas à ação térmica, uma vez se sabe que a elevação da temperatura provoca alterações nas propriedades mecânicas dos materiais, fazendo com que ocorra redução de resistência e rigidez, podendo levar a estrutura ao colapso prematuro, mesmo em elementos como os pilares mistos curtos, cujos resultados servem de base para o dimensionamento dos mesmos quando possuem comprimentos aplicados à prática das construções.

Em caráter mais específico, o estudo aqui realizado teve como objetivo principal iniciar pesquisas referentes a pilares em situação de incêndio no Departamento de Engenharia de Estruturas da Escola de Engenharia de São Carlos, particularmente com vistas a modelar em contexto numérico e em campo tridimensional, pilares mistos curtos com seções tubulares circulares de aço preenchidas com concreto, sob carregado centrado.

Esses mesmos pilares mistos curtos foram analisados inicialmente em temperatura ambiente para, em seguida, serem submetidos a elevadas temperaturas, via incêndio-padrão, para a determinação do tempo (ou temperatura) de colapso, aqui denominado "tempo crítico", em resposta a uma determinada carga aplicada. A razão da análise em temperatura ambiente se justifica pelo fato de os mesmos resultados servirem para fins de comparação (referencial) com os correspondentes valores sob temperaturas elevadas.

Vale lembrar que o estudo aqui desenvolvido se deu com base nos capítulos 1, 2 e 3, nos quais são apresentados aspectos relacionados a elementos mistos e, em particular, os pilares mistos em temperatura ambiente e em situação de incêndio, inclusive procedimentos normativos. No capítulo 4 se faz a apresentação da estratégia de modelagem numérica adotada para simulação dos pilares mistos curtos, desenvolvida por meio do pacote 
computacional ANSYS, por possibilitar as análises estruturais em temperatura ambiente e em situação de incêndio, denominada análise “acoplada”.

A análise "puramente térmica", fundamental para viabilizar a análise acoplada, foi apresentada no capítulo 5 e realizada por meio do código computacional ANSYS, cuja validação do campo térmico se fez por meio do código TCD, programa específico para análise térmica, cujos resultados foram gentilmente cedidos pelo Professor Valdir Pignatta e Silva, da Escola Politécnica da USP. No Capítulo 6, por sua vez, foram realizadas análises estruturais em temperatura ambiente e em situação de incêndio.

\subsection{CONCLUSÕES DO TRABALHO}

\subsubsection{ANÁLISES EM TEMPERATURA AMBIENTE}

Para as etapas iniciais, dentro do contexto da análise estrutural, foram adotados 3 pilares mistos com diâmetros diferentes e denominados Modelos 1, 2 e 3 (M1, M2 e M3), os quais possuem diferenças em termos de geometria. Inicialmente, foi realizada a análise estrutural em temperatura ambiente para os três modelos, cujos resultados numéricos foram comparados com valores normativos, lembrando que apenas para o M1, em particular, foi possível a comparação com resultado experimental.

Os resultados de variações consideradas para o Modelo 1, identificadas por M1.1, M1.2, M1.3 e M1.4, resultaram bastante próximos entre si e, ao mesmo tempo, bastante próximos do resultado experimental. Os resultados dos Modelos 2 e 3, analogamente ao Modelo 1, também resultaram próximos dos valores calculados pelas prescrições da norma brasileira ABNT NBR 8800:2008, bem como pelas prescrições do EUROCODE 4, no caso, os resultados do $\mathrm{EC}^{(\mathrm{b})}$ (ver tabela 6.3, página 118 do capítulo 6).

A proximidade entre resultados numérico, experimental e normativo sinaliza que a utilização de possíveis relações constitutivas que levam em consideração o confinamento pode ser eventualmente desconsiderada, tendo em vista que o procedimento aqui adotado quando da construção de modelos numéricos para avaliação de pilares mistos curtos de aço e concreto utiliza elementos de contato entre os materiais aço e concreto, com a finalidade de considerar a imediata contenção lateral do núcleo de concreto imposta pelo tubo de aço.

Por outro lado, é importante mencionar que, apesar da utilização elementos de contato entre os materiais aço e concreto, fenômenos particulares relacionados à aderência e 
ao atrito entre concreto e aço não foram considerados na estratégia aqui adotada, podendo eventualmente influenciar de algum modo nos resultados, razão pela qual deverão ser melhor investigados em oportunidade futura.

Por meio dos resultados obtidos nas análises numéricas em temperatura ambiente foi possível identificar a potencialidade da estratégia adotada, bem como a confiabilidade dos modelos para análises em situação de incêndio, denominada análise acoplada.

\subsubsection{ANÁLISES EM SITUAÇÃO DE INCÊNDIO}

Para as análises acopladas do tipo termo-estrutural, se considerou inicialmente a aplicação de uma porcentagem da carga última obtida para o pilar misto em temperatura ambiente, para posterior aplicação do carregamento térmico, em situação de incêndio, com vistas à determinação do tempo crítico. Primeiramente, foi realizado um estudo do comportamento dos modelos numéricos de pilares mistos sob temperaturas elevadas, analisando a coerência dos mesmos em termos de expansão térmica.

Por meio dos resultados, ficou constatada a coerência do modelo em termos de expansão térmica, tendo em vista o fato de os modelos recuperarem um dado comportamento em situação de incêndio em conformidade com os aspectos mencionado nas referências citadas no Capítulo 2, no qual se constata que no início do incêndio o aço, por apresentar uma maior expansão nos instantes iniciais de aquecimento, recebe inicialmente todo o carregamento aplicado. Em fases posteriores, a expansão apresentada pelo núcleo de concreto se iguala àquela apresentada pelo aço, que também passa a receber o carregamento, juntamente com o tubo de aço.

No entanto, vale destacar que os aspectos citados no parágrafo anterior foram constatados experimentalmente para pilares longos (da ordem de 2,5 metros) e, portanto, resultam pouco pronunciados para pilares curtos, razão pela qual a diferença de expansão térmica, nesse caso, pode ser desconsiderada, por simplificação, pois aparentemente exerce pouca ou mesmo nenhuma influência nos resultados de força resistente, tendo em vista a proximidade dos resultados obtidos para os modelos completo e otimizado, conforme informações relatadas nos parágrafos seguintes.

$\mathrm{Na}$ análise acoplada foram comparados os resultados dos modelos aqui denominados completo e otimizado, evidenciando que o modelo numérico “completo” (com chapa de topo), quando comparado ao modelo numérico “otimizado" (em que é considerada a simetria da seção transversal e desconsiderada a chapa de topo) apresenta tempos de colapso bastante 
próximos apesar de os respectivos comportamentos mecânicos diferirem um pouco, ficando evidente a eficiência do modelo otimizado para as análises de carregamento centrado e carga térmica por todo o contorno.

A identificação do tempo crítico para os vários níveis de carregamento considerados possibilitou a construção de Curvas de Redução de Força Resistente para os Modelos 1, 2 e 3, denominada curva $\mathrm{K}_{\mathrm{PM}}$ (determina o tempo de colapso do pilar misto em função do nível de carregamento aplicado). Nesse caso, os resultados obtidos pelas análises acopladas utilizando o ANSYS foram comparados com resultados obtidos via TCD, e resultaram praticamente coincidentes. Vale destacar que, nesta etapa, foi considerada carga térmica uniforme ao longo de todo o contorno da seção transversal dos pilares analisados.

Para a análise do Modelo 2, quando considerado carregamento térmico em apenas metade do contorno da seção transversal, utilizando o modelo inteiro e sem chapa de topo, foram obtidos resultados e, em seguida, comparados aqueles em que se considerou carregamento térmico por todo o contorno. Neste caso, foi possível constatar que o carregamento térmico por todo o contorno é, de fato, a situação de interesse para os pilares mistos curtos de seção circular preenchidos com concreto, tendo em vista as diferenças obtidas entre valores de força resistente (ou de colapso).

Porém, vale ressaltar que o carregamento térmico em apenas parte do contorno, se não resulta crítico para pilares curtos, pode ser situação crítica para pilares longos, lembrando que para esses últimos o fenômeno das instabilidades se faz mais evidente e pode exercer influência na capacidade resistente em função do gradiente térmico e, consequentemente, no tempo de colapso do elemento misto.

Análises paramétricas com relação ao diâmetro e à resistência à compressão também foram realizadas. Os resultados obtidos indicam concordância com as referências pesquisadas, mostrando que a variação do diâmetro da seção transversal para pilares mistos de aço preenchidos com concreto apresenta grande influência na resistência em temperaturas elevadas. Por outro lado, o mesmo não ocorre quando da consideração da variação da resistência à compressão do concreto, que nesse caso apresenta influência moderada, ou mesmo pouco expressiva nos resultados obtidos.

As análises realizadas com relação às Curvas de Redução de Força Resistente para os Modelos 1, 2 e 3, para os vários níveis de carregamento considerados, possibilitou identificar uma considerável redução na capacidade resistente do pilar curto, indicando que para tempos reduzidos de exposição ao fogo sua capacidade resistente é fortemente penalizada e, consequentemente, exerce influência no efeito do confinamento. 
Tendo em vista o aspecto exposto no último parágrafo, para fins de "sinalização" da redução do efeito do confinamento, se optou por realizar análise complementar, aqui denominada "análise inversa", em que a modelagem numérica dos pilares mistos curtos considerou um dado nível de aquecimento previamente estabelecido com posterior carregamento crescente, até ser atingido o colapso do elemento misto.

De maneira geral os resultados apresentados pelos modelos analisados mostraram-se coerentes e satisfatórios, indicando o potencial da estratégia de modelagem aqui adotada para análise de pilares mistos curtos de aço e concreto, o que permite considerar a mesma estratégia para modelar pilares mistos de aço e concreto com comprimentos compatíveis com a prática da construção.

\subsection{SUGESTÕES DE CONTINUIDADE}

A partir dos resultados das simulações numéricas, ficam como sugestões para trabalhos futuros:

- Modelagem numérica de pilares mistos preenchidos com concreto e de comprimento usual na construção civil;

- Consideração de restrição axial no topo do pilar para simular o efeito de pórtico;

- Desenvolvimento de um modelo numérico específico para o concreto. 



\section{REFERENCIAS BIBLIOGRÁFICAS}

ANDERBERG, Y. (1997). TCD 5.0 edition - User's Manual. Fire Safety Design. Lund.

ANSYS INC. (2004). Ansys Release 9.0 - Documentation.

ASSOCIAÇÃO BRASILEIRA DE NORMAS TÉCNICAS (2004). ABNT-NBR 15200: Projeto de estruturas de concreto em situação de incêndio. Rio de Janeiro.

ASSOCIAÇÃO BRASILEIRA DE NORMAS TÉCNICAS (1999). ABNT-NBR 14323: Dimensionamento de estruturas de aço de edifícios em situação de incêndio - Procedimento. Rio de Janeiro.

ASSOCIAÇÃO BRASILEIRA DE NORMAS TÉCNICAS (2000). ABNT-NBR 14432: Exigências de resistência ao fogo de elementos construtivos de edificações - Procedimento. Rio de Janeiro.

ASSOCIAÇÃO BRASILEIRA DE NORMAS TÉCNICAS (2008). ABNT-NBR 8800: Projeto e execução de estruturas de aço de edifícios. Rio de Janeiro.

AZEVEDO, M. S. (2005). Determinação da temperatura em elementos estruturais de aço externos a edificações em situação de incêndio. Vitória. Dissertação (Mestrado) Universidade Federal do Espírito Santo.

BUCHANAN A. H. (2002). Structural design for FIRE safety. John Wiley \& Sons; Chichester

CLARET, A.M. (2000). Resistência ao fogo de vigas mistas aço-concreto modeladas pelo método dos elementos finitos. In: Jornadas Sudamericanas de Ingenieria Estructural, Punta Del Este 2000. Anais.

CUNHA, P. G. (2006). Influência da resistência à compressão do concreto no efeito de confinamento de pilares mistos preenchidos. São Carlos. Relatório (Iniciação Cientifica) Escola de Engenharia de São Carlos, Universidade de São Paulo. 
DE NARDIN, S. (1999). Estudo teórico-experimental de pilares mistos compostos por tubos de aço preenchidos com concreto de alta resistência. São Carlos. 148p. Dissertação (Mestrado) - Escola de Engenharia de São Carlos, Universidade de São Paulo.

DE NARDIN, S. et al. (2006). Pilares mistos aço-concreto: novos procedimentos e recomendações normativas no Brasil. In: Jornadas Sulamericanas de Engenharia Estrutural, Campinas, São Paulo, Brasil.

DING, J., WANG, Y. C. (2008). Realistic modelling of thermal and structural behaviour of unprotected concrete filled tubular columns in fire. Journal of Constructional Steel Research, Received 25 May 2007; accepted 15 September 2007.

EUROPEAN COMMITTEE FOR STANDARDIZATION (2002). prEN 1992-1-2:2002 Eurocode 2 - Design of Concrete Structures. Part 1-2: General rules - Structural Fire Design. Brussels.

EUROPEAN COMMITTEE FOR STANDARDIZATION (2005). BS EN 1993-1-2:2005 Eurocode 3 - Design of Steel Structures. Part 1-2: General rules - Structural Fire Design. Brussels.

EUROPEAN COMMITTEE FOR STANDARDIZATION (2004). BS EN 1994-1-1:2004 Eurocode 4 - Design of composite steel and concrete structures. Part 1-1: General rules and rules for buildings. Brussels.

EUROPEAN COMMITTEE FOR STANDARDIZATION (2005). BS EN 1994-1-2:2005 Eurocode 4 - Design of composite steel and concrete structures. Part 1-2: General rules Structural Fire Design. Brussels.

FERNANDES, M. A. S. (2006). Determinação de esforços resistentes em barras de aço sob incêndio natural compartimentado "one zone". São Paulo. Dissertação (Mestrado) - Escola Politécnica da Universidade de São Paulo. Departamento de Engenharia de Estruturas e Fundações.

HAN, L. H. (2001). Fire performance of concrete filled steel tubular beam-columns. Journal of Constructional Steel Research, vol. 57, p. 695-709.

HAN, L. H., ZHAO, X. L., YANG, Y. F., \& FENG, J. B., (2003). Experimental Study and Calculation of Fire Resistance of Concrete-Filled Hollow Steel Columns. Journal of Structural Engineering (C) ASCE, vol. 129, No. 3, p. 346-356.

HAN, L. H., HUO, J. S., WANG, Y. C. (2005). Compressive and flexural behaviour of concrete filled steel tubes after exposure to standard fire. Journal of Constructional Steel Research, vol. 61, p. 882-901. 
INTERNATIONAL STANDARD (1999). Fire-resistance tests - Elements of building construction - Part 1: General requirements. ISO 834-1:1999.

JOHANSSON, M. (2002). Composite Action and Confinement Effects in Tubular Steel Concrete Columns. Thesis for the degree of doctor of philosophy. Chalmers University of Technology, Göteborg, Sweden 2002.

KODUR, V. K. R. (1998). Performance of high strength concrete-filled steel columns exposed to fire. Canadian Journal of Civil Engineering. vol.25, p. 975-981.

MALITE, M. (1990). Sobre o cálculo de vigas mistas aço-concreto: ênfase em edifícios. São Carlos. 144p. Dissertação (Mestrado) - Universidade de São Paulo. Escola de Engenharia de São Carlos. São Paulo.

LAMONT., S. (2001). The Behaviour of Multi-storey Composite Steel Framed Structures in Response to Compartment Fires. Disponível em: http://www.civ.ed.ac.uk/research/fire/project/thesis/masterSL2.pdf $>$ Acesso em:janeiro/2007.

OLIVEIRA, W. L. A. (2008). Análise teórico-experimental de pilares mistos preenchidos de seção circular.. São Carlos. Tese (Doutorado) - Universidade de São Paulo. Escola de Engenharia de São Carlos. São Paulo.

REGOBELLO, R. (2007). Análise numérica de seções transversais e de elementos estruturais de aço e mistos de aço e concreto em situação de incêndio. São Carlos. Dissertação (Mestrado) - Escola de Engenharia de São Carlos - Universidade de São Paulo. 2007.

RIGAZZO, A. O. et al. (2006). Dimensionamento de pilares tubulares de aço preenchidos com concreto em situação de incêndio. In: Jornadas Sul-Americanas de Engenharia Estrutural. Campinas, São Paulo, Brasil.

SILVA, V.P. (2001). Estruturas de Aço em Situação de Incêndio. Zigurate. São Paulo.

WANG, Y. C. (2002). Steel and Composite Structures - Behaviour and Design for Fire Safety. Spon Press. London.

YIN, J.; ZHA, X.; LI, L. (2006). Fire resistance of axially loaded concrete filled steel tube columns. Journal of Constructional Steel Research. vol.62, n.7, p.723-729. July.

ZHA, X. X. (2003). FE analysis of fire resistance of concrete filled CHS columns. Journal of Constructional Steel Research. vol. 59, p. 769-779. 